University of South Florida

DIGITAL COMMONS

Digital Commons @ University of

@ UNIVERSITY OF SOUTH FLORIDA

South Florida

Integrative Biology Books

Integrative Biology

1879

\title{
Comparative Anatomy of The Skeleton of Stellerides
}

Camille Viguier

John M. Lawrence

University of South Florida, lawr@usf.edu

Follow this and additional works at: https://digitalcommons.usf.edu/bin_books

\section{Recommended Citation}

Viguier, C. Comparative Anatomy of The Skeleton of Stellerides (J. M. Lawrence, Trans.).

This Book is brought to you for free and open access by the Integrative Biology at Digital Commons @ University of South Florida. It has been accepted for inclusion in Integrative Biology Books by an authorized administrator of Digital Commons @ University of South Florida. For more information, please contact digitalcommons@usf.edu. 


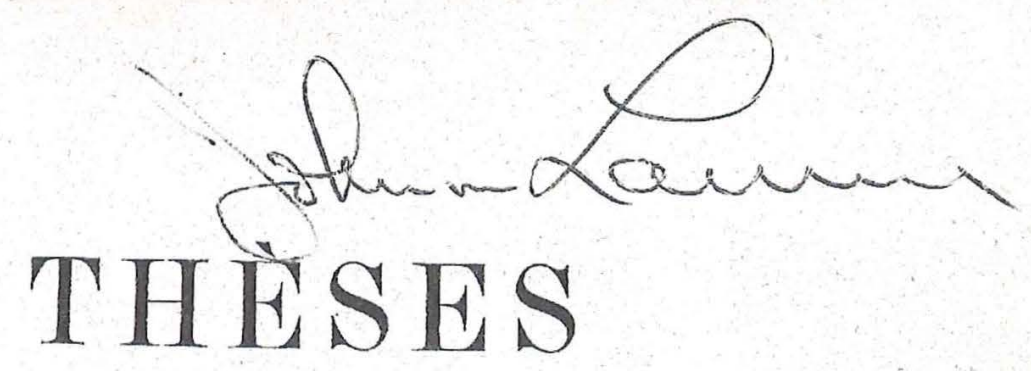

PHLSENTÉES

\section{A PACULTLE DES SGIENCLS IDE PARIS}

POUR OBTENIR

E GRADE DE DOGTEUR ÈS SGIENGES NATURELLES

PAR

\section{CAMILLE VIGUIER}

DOCTEUก FN MÉDECINE

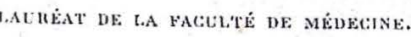

THESE: - ANATOME COMPAREE DU SQUELETTE DES STELLÉHULS.

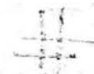

(1, the

THESE. - Propositions DONNEES PAR LA FACULTE.

los le fonvier 1870 devant la Gommission d'examen

MM. HÉBER'1, président.

DUCHARTRE,

DE JAACAZE-DUTHIERS, \}E:aminateurs.

\section{PARIS}

TYPOGRAPHIE A. HENNUYER

RUE D'ARGET', T 


\section{THESIS}

PRESENTED

\section{TO THE FACULTY OF SCIENCES OF PARIS}

to the Faculty of Sciences of Paris

for

the degree of Doctor in Natural Sciences

BY

CAMILLE VIGUIER

DOCTOR OF MEDICINE

LAUREATE OF THE FACULTY OF MEDICINE

COMPARATIVE ANATOMY OF THE SKELETON OF STELLERIDES

Submitted 10 January 1879 before the examining committee

MM. HEBERT, President

DUCHARTRE

DE LACAZE-DUTHIERS, Examiners

Translated by John Lawrence

Department of Biology

University of South Florida

Tampa, Florida 33620 


\section{Translator's note}

Viguer made a notable contribution to the understanding and taxonomy of asteroids through his observations on their skeletal parts and organization. Viguier also made insightful interpretations on the consequences of skeletal structure on the functioning of the organisms although he gave no indication he ever observed living individuals. His commentary gives insight into the nature of museum collections in the latter half of the nineteenth century and the interaction of scientists concerned with their care and use.

I know nothing of Camille Viguier except he became Directeur de la Station Zoologique d'Alger and Professeur à l'Ecole Superieur des Sciences.

This translation was made in 1983 on the beautiful Isles de Kerguelen, Southern Ocean. 


\section{TO EDMOND PERRIER}

Professor Administrator

of the Museum of Natural History 
COMPARATIVE ANATOMY

OF THE

\section{SKELETON OF THE STELLERIDES}

by Doctor Viguier

\section{INTRODUCTION}

Until now it has scarcely been possible to use, in the different classifications of the Stellerides, the characters furnished by the various accessory productions that cover the skin of these animals and that one can see without preparation of their external skeleton.

The anatomical study, strictly speaking, of the skeleton from the exterior to the interior still has not been attempted in the past two years. At least nothing has been published on the subject save brief notes in the more general works that I shall mention in the historical account of the question.

It is easy to understand why this work still has not been done. The complete study of the skeleton involves the destruction of the specimen as, in order to render an exact account of the form and the situation of the calcareous pieces that constitute it, it is absolutely necessary to attack with potash the often very dense skin in which these pieces are more or less enclosed.

This procedure should be done in the cold as it is very difficult to control otherwise. The concentration of the alkaline solution should vary with the strength of the skin. When it is seen that the action is too rapid, it is necessary to wash the piece first with water, then with strong alcohol in order to remove the potash and harden the tissue a little. One then dries with cautiously, but without using heat.

It is necessary to proceed with a certain prudence to be able to draw the ossicles as soon as they are exposed, and before the skin is very altered so that they lose their relationships. That sometimes happens abruptly. A tissue that at first seems very resistnt can in effect me1t in some manner with great rapidity under the action of alkali. One or two small gaps in the collection of my plates are due to accidents of this nature with animals of which I could not obtain another specimen.

Considering the often very great difficulty experienced in procuring certain species, and reflecting on the incontestable fact that a study of this kind will be conclusive only if the condition of a11, or at least most of the types of a whole group is addressed, it is understandable that a work requiring material so difficult to assemble has not yet been done.

The necessity of seeing whether or not it is possible to extract from this study characters that are new and that more precisely can serve to establish anatomically the classification of the group of Stellerides is still felt. Also, my wise friend and master, Professor Perrier, investigated new elements of classification in 1869. He examined, in an important 
memoir (1), all of the works that had appeared on this question and knew better than anyone of studies undertaken to this general point of view. He proposed to me first of all to make it the subject of my thesis for the doctorate of science.

The present work has thus been done in his laboratory at the Museum since May 1876. I spent more than a month in August and September at the Laboratory of Experimental Zoology of Professor Lacaze-Duthiers at Roscoff where I could study the species that live on that coast. I had already obtained interesting results when I had to leave abruptiy in the month of November in order to spend the winter on the Isthmus of Darien as the physician of an international commission of engineers who seek the most favorable point for a route of an interoceanic canal. This excursion, which I undertook not only for the love of travels, but from which I hoped to give an account, visiting a relatively new country for naturalists, of some interesting information unfortunately has not produced all that I had hoped due to the difficult conditions where I was located. The small collections that gave me pleasure to offer to various departments of the Museum on my return were little compared to the good will with which they were made or even to the sacrifices that they cost me. Could I hope that the intention would be considered? Be that as it may, the present work was interrupted for an entire year, from November 1876 to November 1877. During this time, Alexander Agassiz published an important memoir. The author stated in his preface that the plates that he gives are lithographs produced over a period of more than twelve years, and that, as time for him to finish the work following the initial plan was lacking, he made haste to publish them from fear that the work of European naturalists, who he knew now to work on the subject, would make them lose their present interest.

I shall often have to return to this memoir of $A$. Agassiz, most frequently to confirm his views, but sometimes however to dispute them.

This work has for the principal goal, as indicated by its title, the description of American species. For the moment I shall remark only that it is rarely possible, even after a careful examination of the figures, which most frequently preserves the soft parts and spines, gives an exact idea of the skeleton of the animals represented. If my plates, which always show the skeleton completely denuded, are compared with those of Agassiz, the importance of this observation will be understood.

In addition, it is nearly impossible to compare the figures he gave of one type with those of another. Instead, I undertook from the beginning of my work to represent always the same view, the same section, and the same pieces so that the comparison could be made immediately. It is necessary not to forget, however, the conditions in which the memoir of A. Agassiz appeared, and I would be ungreatful to complain that something remained for me to glean where had passed one of the masters of science.

It is certainly with this work that my study has the most analogy. Several of the species represented by Agassiz were already studied and figured by me at the time of the publication of his memoir, but I did not believe that they should be suppressed. First of al1, it is easy to be convinced that a very small number of my figures duplicate his, and the exact disposition of the various pieces of the skeleton is always easier to see in

(1) Révision de la collection de Stellérides du Museum de Paris (Arch. de zoologie expérimenta7e, 1875. 
mine. Finally, it is good to present a11 of my research simultaneously.

I tried first of all to represent, as one sees in the memoir of the American author, the interbrachial systems which he called interbrachial arch

at some times and interbrachial partition at others. However I renounced, well before the publication of his work, his system of illustration. It suffices, in fact, to look at the plates he included in order to see how difficult it is to compare figures of this sort. I do not believe any longer that longitudinal sections of the arms of an asteroid are very useful to consider. If one excepts the first pieces from the side of the mouth, all of the rest are only a series of articles repeated exactly, diminishing gradualiy to the end of the arms.

I have nearly always given a lateral view of the teeth and the first pieces of the ambulacral system. To continue to represent this series up to the end of the arm seemed uninteresting to me.

I so much prefer the transverse section of an arm that I am astonished at seeing none in the plates of Agassiz. They have the advantage of showing exactly the form of the arms that cannot be done with a longitudinal section. Many other authors, notably Gaudry, have already published some sections of this kind which are represented only by two small figures in the works of the scholarly professor of Cambridge. I myself have adopted this transverse section which, along with an exactly interbrachial section that bisects the angle formed by two adjacent rays, seems to me perfectly sufficient to give an exact idea of the form of the animal. These sections, which I have represented in a diagramatic fashion for more clarity, have none the less been drawn with a camera lucida, as are all of my figures without exception. In such cases as Mithrodia clavigera and Porania pulvillus, where the state of the subject did not permit me to do this, I preferred to abstain from composing a figure, as would have been easy for me to do, from the pieces I had in hand.

The exactly interbrachial section has the advantage of showing the exact form of the interbrachial system, when it exists, and the position of the odontophore that Agassiz mentioned several times but to which he evidently had not attached a very great importance. I shall have to return to what he said about it. However for the moment I shall state that, although he did not judge it useful to give the figure of that which he named the basal plate of the interbrachial partition, I was struck by the special form of this piece from the beginning of my studies. I took care to draw it in three positions for the ambulacral asteroids, in four for the adambulacral asteroids. These positions correspond exactly, being done on the same plates, are very easy to compare, and give a very just idea of this piece to which I am the first to attach a great importance in classification.

The interior view, which shows especially the system of ligaments, has seemed useless to me in most cases, and I have employed it only to show the two types of musculature of the mouth in the two very distinct divisions of ambulacral and adambulacral asteroids. As for tube feet in which I found rosettes of spicules, hardly mentioned lately by Teuscher after I had already studied them myself, I limited myself to drawing two very different types of these crowned spicules. Their variability scarcely permits, I believe, their

(1) North American Starfishes (Memoirs of the Museum of comparative Zoology, Cambridge, March 1877). 
use in classification as those of urchins, seeing that they exist in only a small number of genera. I did not want at al1 to complicate a work undertaken to this special point of view.

Permit me, in terminating this short statement, and before sketching the history of the question, to thank Prof. Lacaze-Duthiers for the benevolent welcome I received from him at his laboratory at Roscoff, and especially my excellent friend Perrier, for the liberality with which he placed at my disposal all of the duplicates available from the beautiful collection of the Museum where he succeeded, by dint of work, to establish order without which all of these riches would be essentially inaccesible to workers.

\section{HISTORICAL REVIEW}

I do not want to give a 1 ist of all of the works that are related to the question I treat. The bibliography of Stellerides was done with much care by Perrier in the memoir I cited above. The few omissions that can still be noted will be filled easily by a supplement that will include also an indication of all the new works that have appeared on the subject.

Besides, onty a very few memoirs that pertain to the skeleton are found in this long list. The other points of anatomy, embryology, and especially the description of species form the subject of the greatest number of these works.

I shall thus restrict myself, referring all those who desire to study the complete bibliography to the memoir of Perrier, to a consideration of those works that I shall have to cite in the course of my work.

It was Aristotle who first raised the first idea that we have of the integument of asteroids. It is only a simple reference, and in comparing this envelope to a test, the Greek naturalist did not give a very exact idea of it. Pliny, who without doubt observed Astropecten which is so common in the Mediterranean Sea, considered the upper part of the body as a hardened skin. This observation is not inappropriate, as the cutaneous envelope in this type is very much more important than the paxillae that cover it. These are the only references to the integument made by the ancient authors. It is necessary to come up to Réaumur to have some new information. One finds, in fact, in the Histoire de 7'Académie des sciences de Paris for 1710, a note of his titled Observatio de Stellis marinis where, after having recalled the two authors above, he added: "The lower part is composed of an infinity of smal1 pieces, regular and white as pearls (without doubt the adambulacral pieces). These pieces form in each ray a veritable trellis, in the middle of which are placed two rows of vertebrae (the ambulacral pieces)." It is still, as can be seen, only a very superficial notion. However in 1733 , Linck produced an important work that gives numerous figures, of which some are very recognizable. This work was especially undertaken from the point of view of classification. Unfortunately, Linck attached a very great importance to the number of arms, which he considered fixed in each species. His classification is, as a result of this, artificial in large part. Dispersed in this memoir are some references to the solid pieces, but the comparison of the skeleton to a trellis does not teach us much and he considered as teeth the spines that arm the buccal pieces. The few pieces he illustrated are

(1) De Stellis marinis liber singularis. Leipzig, 1733. 
only the marginal plates, the spines, or the madreporic plates. The integuments were never removed for a view of the ensemble and he did not show sections.

In a note titled Anatomia Stellae marinae Holsaticae, and joined to the work of Linck, David Kade made a study of the pieces composing asteroids. He employed for them names borrowed for the osteology of vertebrate animals, e.g., the word, vertebrae. It is there that we find the first mention of "os quadrangulare which surround the mouth and form a solid ring around it." He also distinguished the ambulacral system from the rest of the skeleton and mentioned the madreporic plate.

Linnaeus, whose Systema naturae appeared a little after the work of Linck, did not employ new notions on the skeleton and limited himself to classification.

Ellis and Solander (1) gave only three plates, all of which refer to Asterias echinites (Acanthaster): aboral surface, oral surface, and a large arm. It is easy to recognize the animal there, and to see likewise there, very well indicated, the articulation of the spines on the elevated pieces. However, they did not illustrate denuded plates.

Like Linnaeus, Cuvier scarcely occupied himself in his Règne animal, dated 1816, with the classification of sea stars. Lamarck himself (2) only secondarily occupied himself with the anatomy of these animals. He gave however some new notions: "There are in the mouth of the Stellerides, sometimes only granular and angular columns and sometimes only five small osseous forks particularly appropriate to squeeze circulariy the body and the food that the animal eats" (3). This latter observation refers without doubt to the mouth of ophiuroids. We find again (4), "The mouth, always situated at the center of the oral surface of the asteroid, communicates almost immediately with the stomach which is very short. This mouth is armed with five osseous forks which appear to act by contracting as a unit on the center of the opening. Beyond these direct and essential functions, the mouth also serves as an anus. The intestinal canal is only an excessively short cul-desac, with a very vast stomach, augmented laterally by five pairs of elongated and feather-like caeca, which increase the means of digestion, etc... In order to give more firmness to each ray and maintain the internal organs, nature, by a secretion of stony material, has produced in the length of each ray a longitudinal assemblage of small stony pieces, joined together, that form by their disposition a column with a groove on one side. By a false analogy the name vertebral column is given to this assemblage of stony bones. This is not however an organ of movement, i.e., destined to furnish points of support to the muscles. It never produces ribs and gives no sheath to a spiny marrow. Thus this series of stony pieces, quite analogous to those of the articulated axis of the Encrines, has nothing comparable to the vertebral column of the animals with vertebrae." I have cited this passage of Lamarck in its entirety, the importance of which will not escape the reader. Note only this notion of the digestive tube with a single opening, observed without doubt in Astropecten, and falsely generalized to the entire group of Stellerides, and also this clearly little founded assertion that the ambulacral system is not at a 11 an organ of movement, i.e., destined to furnish points of support to the muscles.

(1) The Natural History of Zoophytes. London, 1788. (2) Histoire naturelles des animaux sans vertébres. Paris, 1816. (3) T. III, p. 2. (4) T. II, p. 549. 
This same year of 1876, Tiedemann (1) published in Germany a work often cited since then. The type chosen was Astropecten aurantiacus, and it is especially the anatomy of the internal organs that makes this work valuable. The name of vertebrae, given wrongly by Kade to the ambulacral plates, is conserved by Tiedemann. Finally, it was he who gave an opinion, which I shall discuss later, on the functions of that which he called the sand canal.

In 1825 Delle Chiaje (2) gave a good partial section of an arm of Astropecten aurantiacus. The piece of the ambulacral support is very well figured. There are also the muscles that insert into the fossettes of the ambulacral pieces and that are inserted on the aboral apophyses of the same pieces. He did not 1 imit himself to the study of Astropecten, and he remarked that in Asterias echinophora, where the vertebrae are smaller, the tentacular pores are alternatively disposed in two ranges, in order for the ampullae to have more space. Finally, he described summarily the pedicellariae, but without giving the name to them.

Konrad (3), in the midst of some notions with summaries on the skeleton of asteroids, introduced a new idea. After distinguishing a central portion and more or less developed appendices, he stressed the symmetry of the oral surface and established the distinction between this surface and the aboral surface. He gave a nomenclature of pieces which compose Astropecten (this nomenclature is fairly closely repeated in Meckel). Konrad finished by saying that these diverse pieces join around the mouth to form a circular bone that should be compared to the cranium of higher animals, formed like it by the confluence of several bones. It is true, in fact, that this bony ring encircles the mouth, but it is not at all, as Konrad believed, composed of fused pieces with what could be called the nervous center of the asteroid, at least as far as the present studies indicate. The very strange comparison of this bony ring to a vertebrate cranium seems to me to enter into the domain of extreme assimilation and views of a murky science for which exact observations are so often neglected.

In recent years, Niles (4) made a very singular communication to the Boston Society of Natural History on what he called cephalization, or the relation of the head to the posterior part of the body. For him, one should arrange all the animals according to their degree of cephalization, even those that do not have a head, as the echinoderms. I would have to believe that the ideas of Konrad had seduced Niles, and I shall limit myself to regretting that the Comptes rendus de la Sociéte' de Boston has not developed further his theory which, thus formulated, is very bizarre.

With Mecke1 (5), we return to the serious study of the facts. The type chosen was always Astropecten aurantiacus. I shall discuss later the ideas of this scholarly author on the constitution of the mouth and the general musculature. For the moment, I shall mention only his nomenclature of the pieces. He named the principal piece, or body, the ambulacral piece; the transverse intermedial piece, the supporting ambulacral; the lateral inferior piece, the inferior marginal; the lateral superior piece, the superior marginal; and the inferior piece, the adambulacral piece. For him, two

(1) Anatomie der Rohrenholothurie der Pomeranzenfarbigen Seesternes und Steinseeigels. Landshut, 1816. (2) Memorie sulla storia degli animali senza vertebre. Napoli, 2 e volume. (3) De Asteriarum fabrica, etc., dissert. inaug. Halae. (4) Proc. of the Boston Soc. of Natural History, vol. XI, p. 288. (5) MECKEL, System der Vergleichende Anatomie, 1828. 
ambulacral pairs correspond to a marginal pair. This relation is not constant, as he supposed. Finally, he compared the paxillae of the back to the spines of the marginal plate.

We find a note of Desmoulins (1) in the Actes de la Societe Tinneene de Bordeaux where, in regard to fossit ossicles found in Tertiary and Cretaceous deposits, he added: "Possessing very few living asteroids, I can investigate onty a single species, Asterias rubens, from which part of the body provides similar osselets. I have found analogues, but much smaller, towards the angle which two rays from at their base. It is possible these bony pieces, more solid and stronger than the other articulations of the rays, replace in some fashion the jaws, which the large mouth of asteroids lacks. Whatever it is, keeping the same proportion, the fossil osselets we found must belong to enormous species." If one considers the small size of the teeth in Asterias, proportionally to those in the goniasterids for example, it will be seen that this conclusion is not at all necessary. In addition, all of the fossil pieces drawn by the author are marginal plates, without doubt of Astropecten. Was Desmoulins deceived by the quadrangular form of the tooth of Asterias?

De Blainville (2) expressed himself thus: "The characteristic of the order of asteroids can scarcely be based 1) on the nature of the skin, which is always more or less flexible although solidified by very diversified forms of calcareous pieces, and which has on the buccal surface a kind of vertebral disposition serving in effect for locomotion; 2) on the absence of an anus for the intestinal canal, which is no more than a stomach, more or less lobed at the circumference; 3 ) on the constant termination of ovaries disposed in rays at the circumference of the mouth." We already know what to think of these ideas. Further on (p. 237) he added, "The best character that we can still find to distinguish the asteroids is the form of the madreporite tubercle on the back. The tubercle is certainly involved in reproduction, but we are still ignorant of the special function." I shall treat this question further. None of the figures he gave are recognizable and have no sections.

Louis Agassiz, (3) in his Prodrome d'une Monographie des Radiaires, said the asteroids correspond to the limits that Lamarck had assigned to the genera of this name established by Linnaeus in a much broader sense. According to him, they are still distinguished by having a single orifice from the intestinal canal, surrounded by suckers, but lacking teeth. The views of this scientist on the growth of the body by the interradial angle and on the merging of the asteroids with the urchins will be recalled in treating these questions.

In 1835, Sars made interesting observations on the development of Asterias sanguinolenta from the coasts of Norway and, this same year, MilneEdwards and Deshayes began the publication of the second edition of Lamarck.

W. Sharpey (4) gave in 1839 very good information on the skeleton. Some of his views are nevertheless subject to criticism: such as, for example, the constitution of the buccal ring. I shall speak about it again in describing the mouth of ASTERIADAE (the type chosen by Sharpey was Asterias rubens), and the structure of the ossicles that I shall treat further. However, his description of the skeleton of an Asterias is very good, and he was the first to suspect the true use of the hydropore canal.

(1) T.V, 1832. (2) Manuel d'actinologie, Paris, 1834, p. 233. (3) Mémoires de la Societé des sciences naturelles de Neufchâtel, t. I, p. 190. (4) Article Echinodermata. Todd's Cyclopedia. 
Gray (1), in his Synopsis of the General and Species of the Class Hypostoma (Asterias Linnaeus), and Edw. Forbes (2) have always occupied themselves with the classification of asteroids and have scarcely added to the knowledge of the skeleton. In the latter work, Forbes supported the idea that the hydropore is only the representation of the crinoid stem.

The next year, J. Müller and Troschel (3), who had already inserted a memoir in the Archiv für Naturgeschichte for 1840, published their important system der Asteriden. These works still had for their goal almost exclusively the classification of the various groups of Stellerides. Nevertheless, useful notions on the solid pieces are found dispersed here and there. Finally, one must give them the credit for discovering the important fact that, except for the genera Astropecten, Luidia, and Ctenodiscus, all asteroids possess two openings to their alimentary cana?.

R. Owen (4) gave a description of the skeleton of an Asterias and stated that the mouth is without teeth. As to the hydroporic canal, he has the air of sharing the ideas of Coldstream and Forbes, but cited always the opinions of Sars and W. Sharpey.

Koren and Danielsen (5) concerned themselves a little with the skin of the skeleton, but their several remarks scarcely pertain to the skeleton, and none to the arrangement of the pieces.

In 1848 Duvernoy (6) produced a great memoir sur 7'analogie de composition et quelques points de 7'organization des Echinodermes. This work, which contains mainly the exposition of the theoretical views of this great scientist, has few new anatomical ideas. I shall recall these views, already expressed before by him (7) in speaking of the theory of the polyzoicity of echinoderms, a theory of which Duvernoy is in reality the author.

The translation of Siebold, published in 1849 in the series of Manuels Roret, by Spring and Lacordaire, summarizes the works appearing before that date, and contains considerations on the madreporite that I shall have to examine further.

The memoir of Forbes on the Asteriadae Found Fossil in the British Strata contains a very large number of descriptions of isolated pieces. Most of these descriptions correspond to the marginal plates. Nevertheless, there is very useful information. He tried to demonstrate that in the same genera the plates can be smooth, granular, tubercular, spiny even, or yet pitted with alveoli for pedicellariae. We shall often have the occasion to ascertain how often this observation is justified.

The Zoologie générale of Milne-Edwards (1851) and the Elements de paléntologie of Alcide d'Orbigny (1852) still remain to be cited. Then we reach the thesis of Gaudry (8), which was defended this same year.

In this work, done very scientifically, and beginning with a nearly

(1) Annals and Magazine of Natural History, vol. VI, 1841. (2) British Starfishes, London, 1841. (3) Uber die Gattungen der Asteriden (Arch. für Naturg., t. I, p. 138-328 and 367-8). (4) Lectures on the comparative Anatomy and Physiology of the Invertebrate Animals, London, 1843. Observations sur le Bipinnaria asterigera (Annales des sciences naturelles, 3e series, Zool., t. VII, 1847, p. 347-352). (6) Comptes rendus de 7'Academie des sciences, 1848. (7) Comptes rendus, 15 February 1837. (8) Mémoire sur les pieces solides des stellérides (Ann. des sciences nat., $3 \mathrm{e}$ series, Zoo7. t. XVI. 
complete bibliography, Gaudry studied asteroids, ophiuroids, and euryalids. He ended by a comparison of these various animals with an echinoid. The plan of the work was too vast to include very minute details. Nevertheless very interesting observations were made. For this memoir, as for all the subsequent works, a rapid analysis is no longer adequate. It is in treating each particular point that I shall have to recall the views of each of my predecessors. Their ideas, placed thus in the presence of current knowledge, will be grasped more easily and the whole of this study will gain in clarity.

We first describe the consitution of the skeleton in general. We then study them more particularly: the ocular plate, the hydropore system (plate and canal), the pedicellariae, the tube feet, the interbrachial system, and finally the constitution of the mouth and its musculature.

\section{COMPOSITION AND STRUCTURE OF THE OSSICLES}

The body of asteroids contains a multitude of solid pieces of all sizes, from the fine spicules visible only with the microscope up to very thick plates. This is only a difference in size, however, and the mode of aggregation is nearly the same in all cases. These solid pieces are of calcareous nature. The analyses of Hatchett, cited by Sharpey (Todd's cyclopedia), and of Gaudry (memoir cited) agree to the recognition of a small amount of calcium phosphate, combined with a large amount of calcium carbonate. Magnesium, reported by Valentin in the test of urchins, does not exist here according to Gaudry. Finally, the pieces colored red contain a small proportion of iron oxide.

There are no elements of bony tissue, strictly speaking, and microscopic examination shows that these pieces should no longer be considered as bone. But I cannot see why Duvernoy wanted to make them cartilage. There are really no more elements of cartilage than those of bone. They are calcareous depots of a special nature and to which it is convenient to conserve the name of ossicles under which they are generally known.

W. Sharpey said these calcareous pieces are of homogeneous structure without cells or fibers. The English author indeed did not take the trouble to verify this assertion, which has long been recognized as entirely erroneous. The miscroscope shows in fact that all of the ossicles are formed of calcareous trbeculae connected in an anastomosing network, and forming a porous mass of very close mesh in the hard pieces, looser in contrast in those that have less need of resistance. A very great regularity in the mesh of this often very elegant network occurs in sections of the large pieces. There is not, nevertheless, the admirable structure of the spines of the cidarids. The spines of the Stellerides are composed of calcareous branches disposed verticalty and connected by transverse trabeculae as seen in the figures of Gaudry (1).

The calcareous matrix is thus very divided. It explains very well why Pentaceros, a very massive animal collected in abundance in the Red Sea, was employed with success by the Egyptians for the improvement of their land. It functions evidently as a calcareous additive in a soil that does not possess this element in substantive quantities. It is moreover the sole economic use to which the animals of this class have thus far been used.

(1) Loc. cit., p1. XII, fig. 1-4. 
According to the observations of Desor (1), the ossicles of the skeleton begin to appear at the same time as the tube feet, and have at first the aspect of calcareous stars that grow gradually and form a network by uniting at a larger size. A kind of articulation composed only of two or three small rods in the network is always apparent in the newly formed calcareous stars. Next to these stars are still many isolated smal1 rods enveloped by a membrane. It seems thus that they are formed at the expense of the nuclei of cells and are grouped then in a network as a property of a particular attraction.

I share the point of view of Desor that one recognizes in the adult animal a11 of these intermediate formations. The peritoneal membrane, the wall of the tube feet, etc. have isolated spicules. These spicules have various forms, from the simple rod to aureolar plates where sometimes the traces of articulation are still visible, as one verifies easily in the spicules of Anthenea for example.

The mesh of the calcareous network is filled by the living organic matter that works incessantly for the growth of the pieces or their repair.

The analogy of structure is too great, I believe, for one to be able to use usefully microscopic examination of the ossicles in the classification of types.

The spicules, arranged in some genera at the base of the ambulacral groove for the length of the nerve, are of a very remarkable form: they are kinds of quadrangular prisms elongated and pierced with very fine holes. However, in the various types where I have shown their presence, their appearance was nearly alike. This structure is besides nearly the same as those of the calcareous arches that give the hydropore canal its appearance of a trachea, and that also differ very little in the various genera. The spicules found in the peritoneal membrane are, in contrast, sometimes of a very simple form: small rods, branched pieces, or finally plates with a very large mesh. In a work undertaken from the special point of view of the study of new means of classification it seems to me useless to illustrate the various formations that fail so often. I shall speak again, in treating the tube feet, of spicules one finds in the GONIASTERIDAE and some LINCKIDAE. I give two examples of them (plate XVI).

We pass now to the arrangement of the ossicles, to the general form of the skeleton.

\section{AMBULACRAL SYSTEM}

In all asteroids, whether with two or four rows of tube feet, a system of pieces is very clearly distinguished on the oral surface juxtaposed the entire length of the arm (2). These pieces, arranged transversally and of an elongated form, always correspond very exactly on each side of the median line, and decrease gradually in size from the origin of the arms towards their ends. As the ambulacral tube-feet exit between these plates, they have naturally been named ambulacral pieces. They are the principal pieces of Meckel. In all our figures, they are indicated by the letter $a$.

Directly in communication with their inferior-exterior ends, as seen in al1 of the sections of arms, are other pieces always in strictly equal

(1) Ueber die Entwickelung der Asteriden (Müller's Archiv fur Anatomie, 1849, p. 79-83). (2) See for example p1. XI, fig. 2 and 5. 
numbers that evidently make part of the same system. These plates appear most often in a fashion alternating with the ambulacral pieces, so that each ossicle of one of the series is connected with two of the others. These small plates, uniformly designated in my figures by the letters ad were named by Meckel inferior pieces and are generally called interambulacral pieces by authors. I believe that the name should be changed to adambulacral pieces, employed already by $\mathrm{J}$. Müller in the same sense (1). In fact, all of the plates, oral or tergale, can with as much reason have the same name. In reality, these interambulacral plates have a variable number of series of the various types. It is not until the supporting ambulacrals (designated by the letter $s$ in the sections of the arms in plates VI, VII, and XI), which have not been placed in this category of plates, and apparently with more reason since their number is strictly equal to those of the ambulacral pieces except near the mouth. Note that these pieces, which Gaudry called internal ambulacrals, exist only in a small number of genera. This is not at all the characteristic of an essential organ. The reason some have given the supporting ambulacrals a slightly exaggerated importance is, I believe, because Astropecten aurantiacus, so common on the coasts of Europe and almost always used as the subject of studies by the first anatomists because of its relative simplicity, shows these supports (intermediary transversal pieces of Meckel) in their state of greatest development (2).

For Gaudry, these pieces form the second interambulacral series, the first being constituted by the ambulacral pieces and the third by the marginal inferior plates ( $m i$ ) in the types Astropecten and Luidia he studied. I have found these supports, not only in Ctenodiscus, whose affinity to these two preceding genera was pointed out for this genus of study and where $J$. Müller had already seen them, but in a very different family, that of LINCKIADAE, where they had not been reported before. In one part of this family, in Scytaster and ophidiaster, for example, they no longer extend from the ambulacral piece to the second, but to the third row beyond the ambulacral series (3). This third row has larger ossicles and the role of support I attribute to the supports can thus be efficiently filled. In the ASTROPECTINIDAE, where the solid skin of the back makes their presence still more necessary, they are found in the inferior marginal plates. The inferior marginal plates are large and solidly connected to the superior marginal plates, the point of support necessary to maintain the form of the arms. Sctytaster furnishes an argument more in favor of the opinion I defend. In this type, in fact, the supports are no longer constituted by a single piece. Sometimes one finds two or even three of them, intimately united it is true, al1 serving as efficiently for support (4). But it is no longer a matter of a series perfectly defined in position and number, while we never observe the duplication of the pieces of the ambulacral system. Thus only one series of pieces is in constant proportion of numbers and position with the ambulacral series, and that is the one just considered. It is this series, because of its location and in order to distinguish it from all of the others, I shall call henceforth the adambulacral series. We see further, in the formation of the mouth, the modification of these pieces are always in connection with the modifications of the ambulacral pieces. In the same way, the middle of the

(1) Ueber den Bau der Echinodermen (Mémoires de 7 'Académie des sciences de Berlin, 1853). (2) See pl. XV, fig. 4. (3) See pl. IX, fig. 4 and 11. (4) See pT. IX, fig. 11, s. 
oral surface of the arms always has four parallel series of pieces that correspond exactiy. Here is, contrary to the opinion of Lamarck and as Meckel demonstrated, the true organ of movement. I am going to return to it shortly, but it is necessary first of 211 to examine how the rest of the skeleton is constituted.

Nothing is constant outside the ambulacral series, and likewise most often nothing is regular. It is convenient for description to conserve the terms of ventral, marginal, and dorsal plates, but to attempt to assign numbers to all these series is a very unprofitable work. Marginal plates do not exist in most types. In the ASTERIADAE a ventral surface is not present, strictly speaking. Finally, the often very complicated systems that form the frame of the back in most types do not mean any assimilation. Here juxtaposed, there imbricated, most often reticulated, these pieces do not permit a general description and each type should be studied separately.

As for their form, a glance at the plates that accompany this work says more than a long description, but I should from the beginning insist on the fact that no form is characteristic of a group in an absolute fashion. It is for not having perceived this idea that, until now, authors have combined in one family all animals whose dorsal ossicles have the particular form known as paxillae. The family ASTROPECTINIDAE, thus constituted, was completely artificial. J. Muller has already, in the work cited above, spoken of some characteristics that distinguish Archaster from Astropecten. The detailed description of types will show the profound differences that make me separate the ASTROPECTINIDAE from Archaster and Chaetaster.

Return now to the ambulacral series.

In all asteroids with two rows of tube feet, the form of the ambulacral ossicle is nearly the same. Whatever differences occur are very slight, and pertain especially to the thickness and the length as is apparent by glancing at the numerous figures that represent the oral extremities of the ambulacral series in the different types. (In all of these figures, $d$ represents the tooth, ad the adambulacral series, and a the ambulacral series). This piece is elongated, slightly boxlike on top. The ambulacral face has a smooth and flat surface, nearly quadrangular, on top. The junction of all of these surfaces forms the base of the ambulacral groove. on top is a little irregular space united to the middle of a ligament at the corresponding face of the opposite piece. It is this that constitutes the articulation of a groove, and permits it to more or less open or close. The angle that the two pieces of one pair ordinarily form together is very variable, although it is generally more open in asteroids with four rows of tube feet as is shown in the numerous transverse sections of the arms contained in the plates. However, they never are sufficiently covered so that the tube feet, which they protect, become incapable of serving as organs for crawling, as Gaudry (1) said.

A little apophys is elevated above the articulating surface has three principal faces: one smooth that extends from the dorsal face of the ambulacral face, and two that serve for muscle attachments. Figure $A$, page 70 , shows the disposition of these two muscles, the one transverse 8), the other longitudinal 9), inserting into the apophysis 7). Above the articulation and the little free space mentioned above (2), is a triangular

(1) Loc cit., p. 28. (2) See for example p1. VIII, fig. 6 (supposing the figure to be reversed in the ordinary situation of the animal). 
fosette with curved sides and an inferior summit. The muscle that closes the groove and that is the most powerful of the system is inserted there. Above this fosette, the piece that is in direct connection with its neighbors by nearly flat faces is compressed laterally. A sharp ridge, which leaves from the top of the triangle and extends to the lower edge, divides its very restricted ambulacral face in two. These pieces thus leave between them at this level a series of paired holes through which pass the tube feet.

At the point where it reaches the corresponding adambulacral pieces, the thin end of the ambulacral piece dilates a 1 ittle, then narrows abruptly into a sharp edge directed transversely in the direction of the arms. Two small fosettes, which one can see in the different sections, are left on each side. The vertical muscles that lift up the corresponding pieces of the two series insert into the fosettes (1). The dorsal or visceral face is rounded and smooth and extended above by the little apophysis spoken of above. This face is in connection with the ampullae of the tube feet.

As for the adambulacral piece, it is very simple, sometimes cuboidal, other times much less thick in the longitudinal direction of the arms. It is ordinarily indented, but in a very variable fashion, at its inferior-proximal ridge, which carries more or less developed spines. Sometimes it is pitted with alveoli for pedicellariae. The ambulacral pieces never support any. outside the vertical muscles, which I have already mentioned and which connect to the corresponding ambulacral plates, each adambulacral piece is united to its neighbor of the series by a longitudinal muscle that inserts on the entire corresponding face. The bunch of pearly white fibers connect them al so to the general skeleton, as they unite the various pieces that compose the skeleton, allowing only passages for the pores.

This membrane, fibrous and tough, contains nevertheless some muscular elements. It is irritable and contracts slowly when pricked with the point of a scapel, as Sharpey has already seen and as I have verified myself for Astrias glacialis at Roscoff.

These movements nevertheless are of very little importance, and this membrane is scarcely involved in changing form other than by its elasticity. The active movements are due to the muscles of the ambulacral groove already seen by Meckel, who however had not noted the superior longitudinal muscle (2).

This omission is explained by the fact that, in the type he studied, Astropecten aurantiacus, this system of muscles is not very apparent. The ambulacral apophysis, becoming vertical, is a little developed as a wing, and no longer can slide on the neighboring piece to which it is connected by a very short muscle that inserts on the edge of the wing. This disposition and the intimate liaison of their marginal plates are the reasons why Astropecten and Luidia have nearly rigid arms, and are encountered nearly always absolutely flat in the collections. I note that one does not see these longitudinal muscles in the plates and diagrams of Agassiz, where the superior transverse muscle are in contrast well represented.

In this way we come to see that the number of muscles for each article of the ambulacral system are not eight as Meckel believed, but ten: 1) four vertical muscles, two from each side that connect the ambulacral pieces to the corresponding adambulacral pieces; 2) four longitudinal muscles, two from

(1) See pl. VIII, fig. 1, v, and in all sections of the corresponding plate. (2) See 9, Fig. A, p. 25. 
each side; a superior between the apophysis of the ambutacral pieces, the other, inferior between the adambulacral pieces; 3 ) finally, two transversal muscles, superior and inferior, both of which connect the two ambutacral pieces of a single pair, the one above and the other below their articulation.

Little has been said of the play of these various muscles, and it seems to me useful to examine here their mode of action.

The vertical muscles are small and scarcely serve to hold together the pieces to which they insert.

The superior longitudinal muscles insert, as we have seen, on small apophyses that surmount the ambulacral pieces. These apophyses are not at all exactly vertical, but laid one on the other in the manner of tiles of a roof. They can thus execute sliding movements under the action of thesemuscles. The result of this action is the raising of the arm in a curve with the concavity uppermost, the animal being positioned in the normal position. In this movement, it is evident that the ambulacral pieces of one single series are brought together more at their upper than to their lower extremity, and that the adambulacral pieces of the same series separate from each other.

The inferior longitudinal muscles are thus the antagonists of those of the preceding system. However, their mode of insertion most often is perpendicular to the broad surfaces they connect. At the same time that it assures the solidity of the system, it does not permit very extensive movements. Here, besides, these movements are not very necessary. The downward bending of the arm, i.e., in a curve with the concavity below that is really one of the most useful movements as it permits the animal to fix itself on its prey, is principally determined by the tube feet that, in attaching to external objects, shape the form of the arms in some manner. The principal function of the inferior longitudinal muscles is thus to connect the pieces of the adambulacral series, and additionally to inflect the arm below when the two series of an arm contract simultaneously. If one of these series contracts alone, there will be torsion of the arm in the horizontal plane. The superior longitudinal muscle of the same half of the ray contributes a little to this movement without doubt, but it will be able to have, because of its nearness to the median line, only a very much weaker action.

The inferior transversal muscles insert into the triangular pits of which I spoke above. Their much larger size and especially the distance to the point of articulation of the pieces they move make them much the strongest of the system.

Moreover it has to be this way as they have to overcome the elasticity of the fibrous membrane of the back in order to close the ambulacral groove. As it is in closing this groove and in interweaving thus the spines that border the adambulacral pieces that the animal simultaneously covers and retracts the tube feet, one sees this movement is the most important and that it must be done with force and quickness.

The amplitude of the movement that determines all of these movements depends on the length and, subsequently, on the spacing and dimensions of the ambulacral and adambulacral pieces. It is also subordinated to the more or less great rigidity of the general skeleton. Also we see relatively 
we11-developed ambulacral systems in the ECHINASTERIDAE (1), where the skeleton is formed of very slightly reticulated pieces and where marginal plates do not exist. We see (2) that the adambulacral pieces of the same series leave relatively very large spaces between them for the inferior longitudinal muscles. In contrast, adambulacral ossicles are very tightiy pressed against each other in the ASTROPECTINIDAE (3), where the arm owes a nearly absolute rigidity to its marginal plates. As for the transverse muscles, superior and inferior, they have very few variations, which is very understandable since the opening and closing the ambulacral groove are important movements, whatever is the type considered.

The muscles, such as we have just described, are completely alike the length of the arm. The only difference noted is the greater strength of the muscles of the first ambulacral pair, power in relation to the greater dimensions of the ossicles of movement. As for the very remarkable musculature of the mouth, which has not been described, we shall see later that it forms an absolutely distinct system.

If we examine now the asteroids with four rows of tube feet, we are going to demonstrate that the difference of form of the pieces has not changed with the disposition of the ensemble.

Here the ambulacral pieces (4) are very narrow. They are sort of thin plates, folded back on themselves and leaving between them not one, but two series of pairs of holes. These ambulacral pores alternate between themselves not only in each section of the groove, but again from one side to the other of the median line the entire length of the arm except near the mouth where this arrangement becomes very irregular (5). The form of the pieces is such that the edge of these openings flares like a funnel.

The pieces of a single pair form between them a very broad angle and the inner surface of the arm is often made up nearly entirely by the ambulacral groove. As for the superior apophysis, it is very thin and very elongated in the transverse direction (6).

The adambulacral plates are also excessively thin. However, nothing is changed in the plan as a whole, and the musculature is overall absolutely a) $i k e$. Naturally the muscles are very much smaller, but their larger number compensates for this deficiency and the effect remains the same.

The only remark to make is that the holes for the insertion of the transverse inferior muscle are very small here, nearly vertical, but at the same time closer to the median line. Two conditions compete, one to decrease and the other to increase the relative strength of the muscle so that the effects nearly counterbalance. The muscles thus have the same disposition and the same mode of action as in the asteroids with two rows of tube feet, at least along the length of the arm. We shall see further on that very notable changes are produced in the muscles of the mouth (7).

After having read the description I have just made, it is easy to understand that the pieces so similar in each of the two great divisions of the Stellerides cannot furnish us with the characteristics of families or genera. We shall thus be obliged to search elsewhere for other means of classification. It is with this point of view that I am going to examine the differences that occur in the various types: first of al1, the ocular plate;

(1) See p1. VII, fig. 4. (2) See p1. VII, fig. 2. (3) See p1. XV, fig. 2 and 8. (4) See p1. V, fig. 2 and 10. (5) See p1. V, fig. 10. (6) See 7, figure E, p. 76. (7) See fig. E, p. 76. 
then, the madreporite plate that has sometimes been used in diagnosis; finally, the pedicellariae, the tube feet, and the calcareous skelet on that occurs in some genera, and the interbrachial systems.

I shall finish this general study by examining in depth the buccal apparatus and its musculature in the two types of asteroid ambulacra and interambulacra that differ so, and by comparing this mouth with those in various types of echinoderms.

We shall pass then to a description of the genera.

\section{OCULAR PLATE.}

A17 asteroids have an unpaired plate at the end of the arms, located in the same axis as the arm. It has a rounded upper surface, and is creased underneath with a groove continuous with the ambulacral groove. It is at the end of this plate, or in the inferior groove, according to different authors, that is found the organ of vision connected to the arm nerve. This was reported by various authors and described with details by Haecke1 (1), Mettenheimer (2), and S. Jourdain (3). These various scientists have not agreed much in their descriptions of this organ. The figure that G.-0. Sars (4) gave of the sensory organ of Brisinga differs from them greatly. Finally R. Greef (5), who studied Asterias rubens, Solaster papposus, and Astropecten aurantiacus, had seen in these animals the arm nerve leave the ambulacral groove before reaching its end, its inferior branch alone extending up to the eye.

It is therefore possible that different types have different arrangements. I have not, moreover, occupied myself with this question in the present work, and shall speak only of the plate which is usually called the ocular.

This plate, designated in all of my figures by the letters oc, attains a considerable development in the family ASTROPECTINIDAE (6). Generaliy, its dimensions are much smaller, and sometimes are very small (7), comparatively, to the dimensions of the animal. The form in addition has very great variations: globulose, in general, in Asterias (8), narrow and elongated in SOLASTERINAE (9), enlarged in the ASTROPECTINIDAE, etc. Finally, in the very curious genus Brisinga, it has, according to the work cited of Sars ( 1 . II, fig. 5 and 6 ), a quite remarkabie appearance.

In some cases, the characteristics of this piece therefore will be useful to consult, particularly since they are very easy to see on the intact animal. But, very often, one finds an absolute resemblance between the ocular plates of very different types or, to the contrary, very remarkable differences in closely related species. I believe therefore that the characters furnished by this plate should aiways by subordinated to those of the buccal apparatus.

(1) Zeit. Zoo7.,X. (2) Abhand7ung d. Senkenb. Gesellschaft, III (Arch. anat. phys., 1862). (3) Comptes rendus de 7'Ac. des sciences, 1865, p. 104. (4) Researches on the structure and affinity of the genus Brisinga. Christiania, 1875. (5) Ueber den Bau der Echinodermen (S.B. Gese77. Marb., Nov. 1871). (6) See p1. XV, fig. 1, 9, and 14. (7) See p1. XI, fig. 4. (8) See p1. V, fig. 1. (9) See pl. VIII, fig. 1 and 8. 
It is generally acknowledged today that the new ossicles that are incessantly added to the arm during growth are produced behind this terminal plate. This opinion seems more rational than that proposed by L. Agassiz at the beginning of his works on echinoderms. He proposed growth is produced by the formation of new ossicles in the interradial angles. Yet, as I have not been able up to now to make observations myself on this subject, I shall not permit myself to settle the question in an absolute fashion. I shall return to the remarks that I make regarding this question in the description of Anthenea.

\section{MADREPORITE PLATE AND HYDROPORE CANAL.}

On the back of a11 asteroids is a calcareous plate of a special nature, always situated excentrically on the line separating two rays. The distance from it to the center of the disc varies within a very narrow limit. Sometimes there are several of them, but there is always at least one. The previous authors who had given a contrary opinion had been misled by the fact that, in Astropecten and especially in Luidia, it is hidden by the spines spread out from the pieces of the back. In certain species it can itself have variously disposed spines that sometimes conceal it almost entirely. This is without doubt why it has sometimes escaped very exact observations.

This plate, which is called madreporite because of the folds that furrow the surface, is characteristic of the asteroids as de Blainville (1) said very well. Its analogue is found in the ophiuroids on the oral surface, always near the mouth in the angle formed by two jaws, and in the urchins near the apical pole.

From the internal part of this plate leaves a slightly flexible canal with the appearance of a trachea. It follows the oral border of the interbrachial system when this exists (this border is even sometimes creased by it into a sort of groove). In all cases it is maintained in a fold of the interbrachial membrane, which forms a sort of mesentary. This canal grows narrower at its inferior end and opens into the circumbuccal vascular ring between the two teeth of the corresponding pair of the interbrachial area where the madreporite plate is situated.

This relation is absolutely constant, whatever is the type examined.

According to Tiedemann, who was the first to speak of it (2), this canal, which he named the sand canal, is destined to furnish the calcareous substance necessary for the skeleton of asteroids. This explanation is not satisfactory, especially now that we have seen the calcareous material appear in the very nuclei of cells. Also, the opinion of Tiedemann was not slow to be opposed. However, by a singular fortune, the name of sand canal, which everyone recognizes is false, still remains thanks to the uncertainty that remains on the true function of the organ. Ehrenberg (3) observed that this canal did not contain amorphous calcareous material, but that it is organized and pierced with holes, having the appearance of mail. He even compared the structure of this organ with the cavernous tissue with irregular mail of the penis. This observation is very applicable to the superior part of the canal in Ophidiaster pyramidatus.
(1) Manuel d'actinologie, p.237.
Loc. cit., p. 54.
(3) Müiler's Archiv,

1834, p. 580 . 
For de Blainville, the madreporite plate was certainly involved with reproduction. L. Agassiz, Müller, and Troschel were of this opinion that Gaudry also seems to have taken. Moreover, this latter author believed still that the existence of the plate was not absolutely constant at al1. Sharpey (1) suspected the true function of the sand canal, but Forbes (2) opposed the opinion that the madreporite plate was part of the water system and wanted to see in the sand canal only the crinoid stem. Doctor Coldstream, cited by Owen (3), was of the same opinion. But, as Owen remarked, the observations of Sars showed, and subsequent studies confirmed, the asteroids are never attached at any stage of their Tife.

Jourdain (4) tried to demonstrate the plate and canal were the only way by which exterior water enters the water system. However, Milne-Edwards, in his scholarly Lecons sur la physiologie et 7'anatomie comparée (5), still declared their uses unknown. But the works of Greff and Hoffmann (6) have onty confirmed those of Jourdain.

One finds, moreover, in the Manuel d'anatomie comparee of Gegenbaum (7), a figure that represents the water system of an asteroid. I can only reject the description he gave of it.

I shall hereafter call, with Jourdain, the sand canal by the more rational name of hydropore tube or canal.

The walls of the tube are kept separate by a series of calcareous arcs that give it the appearance of a trachea These arches are pierced by very fine mail. On the inner side of the wall is a lamina that runs its entire length. The lamina divides into two sheets that diverge and coil around themselves as described by Loven (8). It is this that gives the hydropore canal the aspect of a double-barreled gun (9). The lower end of the tube opens, as we have said, into the buccal vascular ring. As for the upper end adjoining the madreporite plate, the tube is pierced by several openings leading into the radiating and ramified canals dug horizontally into the external face of this plate and corresponding exactly to the grooves of the surface. The roof of these canals is pierced through and through by a large number of canalicules directed perpendicularly to the plate. Their openings are visible at the base of the grooves (10). This arrangement is clearly seen in figure 270 of Loven's work that represents the plate of Asterias glacialis. In the Asteriadae, the plate is formed of a large, hollow piece whose upper part only is furrowed. In the other types of asteroids, it is generally only a simple lamella of variable thickness, resting on the pieces of the dorsal skeleton that often forms sort of a frame for it. However, we find in Palmipes a fuurrowed plate as in Asterias. In Heliaster, the plate is always composed of a very large number of juxtaposed furrowed pieces (11) that communicate directly with the hydropore canal. Whatever be the number of pieces, the canal is always single (12). I was thus very surprised to read in the Comptes rendus (13) a note of Giard declaring that he had encountered in Asterias rubens two sand canals ending at a single madreporite plate, but

(1) Art. Echinodermata (Todd's Cyclopedia). (2) British Starfishes. (3) Loc. cit. (4) Comptes rendus de 7'Acad. des sciences, 1867, p. 1003. (5) T.X, 1872, p. 132. (6) C.-K. HOFFMAN, Zur Anatomie der Asteriden (Nieder7. Arch. für Zoologie, t. IX. (7) Traduction Vogt, 1874, p. 313. (8) Etudes sur les Echinoides, p1. LIII, fig. 272. (9) See pl. VI, fig. 9 ch. (10) S. JOURDAIN, loc. cit.(11) See p1. VI, fig. 4, m. (12) Id. fig. 9, ch. (13) 19 November 1877 . 
formed by the fusion of two plates.

I would very much like to know what was the connection of these two canals, and I am sorry that the author, occupied with inferring from this fact some scientific deductions, did not believe it necessary to go into some detail into this question. As for me, I have never encountered two sand canals going to the same plate, whatever be the number of pieces that constitute it. In addition, I have always seen the single plate in the genus Asterias. I have nevertheless examined examples of six-armed Asterias rubens, A. glacialis, A. tenuispinus, A. borealis, A. gracilis, A. gelatinosa, and even ten specimens of Asterias calamaria having ten to twelve arms. This latter species possesses sometimes, as does Asterina polyplax, a variable number of plates, more or less irregularly disposed, but these plates are single. The only appearance of divided plates that Perrier described in an Asterias calamaria resulted without doubt from some accident, as everywhere else I have ascertained that the plates are simple as in Asterias. In Heliaster, where they are composed of variable numbers of pieces, there is only one plate whatever be the number of arms, and the canat is single.

I am persuaded that in these Asterias with many plates, as I have confirmed in Acanthaster echinites and in Linckia diplax, a single hydropore canal corresponds to each plate and always has the same relation.

In ophidiaster pyramidatus, where the development of the madreporite plate is enormous (1), the hydropore canal is still single, only it entarges to a funnel at its upper part in order to apply itself to the entire inner surface of the madreporite plate. At the point where the canal dilates, it loses its appearance of a trachea, and its cavity is filled by interlacedbranches that take a vertical position and justify very well the comparison of Ehrenberg.

I would have to regard the fact cited by Giard only as exceptional, and to reserve some doubts about it.

Thus as I have already said above, the microscopic examination of the arcs of the hydropore canal does not appear to me to furnish useful characters for classification. The madreporite plates can certainly render some service. But, if the mode of striation of the plate appears at first to conform in the same family, we see it take different dispositions in the same genus. It is thus that in Astropecten subinermis (M.T.) the plate is round and the folds nearly straight rays from the center. In Astropecten indicus (2) (sp.n., E.P.), the plate is circular, slightly depressed, and the folds, instead of being rays, are nearly parallel as one sees in ctenodiscus (3). In an unnamed Astropecten species from the Sandwich Islands, the plate is nearly granular and the contour is irregular. Finally (4), it can have very marked digitations. So much for the form and striation. As to dimensions, if one compares the petite plate of ophidiaster ophidians with the very developed plate of ophidiaster pyramidatus, one will see that they do not furnish more certainty.

The examination of the madreporite plate can thus give only signs of a very secondary importance.

(1) See p1.IX, fig. 1, m. (2) See p1. IX, fig. 7, ch. (3) See p1. XV, fig. $14, m$. (4) Id., fig. 1 , m. 


\section{PEDICELLARIAE AND TUBE FEET}

In his thesis titled Recherches sur 7es pédicellaires et les ambulacres des Asterides et des oursins (Paris 1869), Perrier showed the importance that the former can have in the classification of asteroids, and how they differentiate very clearly the two groups of asteroids with two and four rows of tube feet. All that I shall say on these organs in the description of the genera will be taken from his work. But the very fact that the pedicellariae very frequently are 1 acking proves that one should subordinate the characters that they furnish to those whose form varies with the various types but that are always present, as we shall show for the mouth pieces.

Perrier, who dwelt extensively in this work on the tube feet of urchins, and especially on the calcareous pieces that they enclose, said little about the tube feet of asteroids.

These organs, whose form and even the musculature have been well known for a long time, can show three or four different types. However, at first glance there seem to be two.

The tube feet are composed of two parts: an exterior, tubed portion, properly called the tube foot that exits by ambulacral pores; the interior portion in form of a pouch most often deeply divided into two parts, called the ampulla. These ampullae, situated in the visceral face of the ambulacral pieces, are connected as we have seen to the hydropore system.

The tube foot contains two systems of muscular fibers, one circular, the other longitudinal, situated inside the tough membrane that constitutes the framework and ordinarily ends in a sucker that has radiating muscular fibers.

The existence of this sucker is not constant. It has long been known that the tube feet are conical in ASTROPECTINIDAE. However it seems that the terminal extremity of the cone can be turned inward and thus make the base of a sort of sucker that forms at this moment and serves for movement as in the other asteroids. I have not been able to verify this. Be that as it may, these pointed tube feet seem to be special to the family ASTROPECTENIDAE, and suffice already to separate Archaster and Chaetaster.

In all the other asteroids, whether they have two or four rows of tube feet, the organs have suckers. However no previous reports of calcareous spicules have been made.

Nevertheless, a figure of Teuscher (1) shows these spicules in ophidiaster ophidianus in a vertical section of the tube foot. The author did not speak of it in the text.

J. Müller (2) said that he found scarcely a trace of calcareous skeleton in the tube feet and in particular in their extremities. The types he studied were Asteracanthion rubens, Astropecten, Solaster papposus and endeca, Asteriscus verruculatus, Luidia savignii, and Astrogonium cuspidatum. I can confirm only the correctness of his results, and without doubt had it appeared sufficiently demonstrated the spicules were always missing, they would no longer be of concern.

Nevertheless, if we examine an Ophidiaster or a Linckia we see on the edge of the sucker a circle of flat, areolar spicules disposed in a single

(1) Beiträge zur Anatomie der Echinodermen (Jenaisch Zeitschrift, t.: X, pl. XII, fig. 8. (2) Bemerkungen uber die Metamorphose der Seeigel (Müller's Archiv, 1848, p.119). 
line (1). The tube does not contain spicules. This is a third type of tube foot.

We find the fourth type in Pentacerous or Culcita for example. Here the sucker is garnished with a wide, thick crown composed of a large number of tabular and areolar spicules, always disposed flat (2).

other spicules, simpler, branched, or in the form of little batons, are scattered on this crown, and some also are inside and outside. The tube contains simple spicules, straight or slightly branched, disposed transversely, and which become very rare towards the sucker. These spicules are rather irregularly arranged. They nevertheless limit on one side a rather wide avenue that narrows a little from the base of the tube to the sucker. They are closer together on the sides than in the rest of the tube. This disposition is seen very well in Pentaceros muricatus for example. We have thus here a fourth type of tube foot.

The comparison of this type with the tube feet of urchins is of great interest. Unfortunately characters of classification cannot be drawn from the study of calcareous deposits in these animals. Thus, one sees them in ophidiaster, but I have never found them in Scytaster that is so close to them. They exist in Linckia, but not in Chaetaster. Finally, in the only tribe where their presence is constant, the GONIASTERINAE, the crowns can be either simple as those of Linckia in Goniodiscus, or extremely complicated as in Culcita, and yet the form of the spicules and even their dimensions change 1ittle. Finally, spicules may found in the tube or be completely lacking.

Thus one can conclude only very accessory characters from this examination. Also I confine myself to giving two examples of the spicule crowns: one very simple and the other very complicated, at a uniform size of 120X (3). It seems to me without interest to draw the spicules of the tube, or those that are found sometimes very clearly in the wall of the ampullae.

\section{INTERBRACHIAL SYSTEMS}

In the adambulacral asteroids the division of the arms, however accentuated it is, never goes up to the mouth. There thus exists an interbrachial space or interbrachial area. This space is rather frequently divided by a veritable wall of ossicles, disposed vertically between the aboral and oral surface, and sometimes projecting to their surface (4).

This wall generally continues to the odontophore, but often it is far from complete and sometimes is limited to the angle between the two surfaces. In a large number of cases, it is reduced to a single line of ossicles going from the aboral surface to the odontophore. Finally, it can be completely missing. I shall designate by the general name interbrachial systems this variable series of ossicles. The system is uniformly designated by the letter $i$ on the numerous interbrachial sections that fill my plates. They are in fact special systems. The arrangement of the plates of the top and bottom most often undergo no modification at their level, and one would scarcely know to consider them, in fact, as an extension of the covering of the arms, at least in the adambulacral asteroids. I thus would not share the opinion of Gaudry, who, moreoever, scarcely mentioned them and seems to have hardly seen them.

(1) See p1. XVI, figs. 8 and 10. (2) Id., figs. 9 and 11. (3) See p1. XVI, figs. 10 and 11. (4) See p1. XI, figs. 1 and 2, and p1. XII, fig. 2 . 
A1. Agassiz, who called them now interbrachial arcs, now interbrachial partitions, illustrated them in various types in his last memoir (1). But the perspectives he gave of this system, still covered by their soft parts, do not permit an easy comparison among them.

When the interbrachial system forms a complete wall, the form of the body will be able to vary within very narrow limits. But when only a vertical line of ossicles exists, they can fold back on themselves in a manner to permit very considerable changes in thickness, as in culcita. We are going to see that the special muscles are then charged with bringing back together the two sides of the body when they have been extended.

The interbrachial systems furnish by their presence or absence, and in this case by their various forms, good characters of classification. One will see however that some reservations are necessary. In addition, their absence in very different families does not permit absolute reliance on them.

The ambulacral asteroids do not have an interbrachial area strictly speaking. The arms are divided up to the mouth, and the pieces that occur exactly between two arms in the interior of the disc can be considered as the continuation of the walls of the arms (2).

It is especially apparent in Heliaster, where the arms are fused for a great length (3). However, in Pycnopodia, where the skeleton is so rarefied, the interbrachial partition is constituted primarily by the skin. This partition has only some ossicles that form a range on the oral surface and come to rest on the odontophore.

After having spoken successively on the various parts of the skeleton that can furnish accessory characters, I am going to explain the plan of the mouth and describe the different parts that comprise it and furnish the principal characters for the determination of the families.

Mouth

The mouth of asteroids has not been described in an extensive fashion since Meckel (4). The type he chose was Astropecten aurantiacus. Also he complicated his description of all that related to the marginal pieces and the supporting ambulacrals that he regarded without doubt as very important. I do not want to concern myself with them here becauses they are pieces that do not occur in all types.

Replacing the terms he used with current ones, here is his description: "Near the mouth, the ambulacral pieces become shorter from the axis towards the lateral border, longer from top to bottom, and narrower from the outside to the inside. The apophyses with which they are garnished in front and back are more imperfect. They draw nearer each other. The innermost piece thickens abruptly from the outside to the inside, and is at least three times that of the preceding pieces in the direction of this dimension." And further on: "The four innermost supporting pieces seem to be replaced by a large single piece located before and a little on the side of the first ambulacral piece. In fact, entirely below the base of two rays, between the innermost vertebrae, is a large mobile piece in the form of a $Y$ that can be considered without contradiction as the junction of the four innermost

(1) North American Starfishes. (2) See PI. V, fig. 3. (3) See pl. VI, figs. 6, 7, and 8. (4) Loc.cit. 
supporting pieces. It could actually be considered analogous to the innermost inferior marginal pieces. But the first opinion seems better as the supporting ambulacrals are completely missing, and as this $Y$-shaped piece does not reach the surface or have a mobile spine. The adambulacral pieces become very narrow from the fifth article. They change their direction, until then obliquely transverse, so that they form from the outside to the inside a very oblique angle with the ray. The entire length of the last piece is applied against the same piece of the adjacent ray (1).

The end of this description is good, as can be ascertained by looking at the type of Meckel (2). One notes only that as the appearance of the tooth in Astropecten is very like that of an ordinary ambulacral piece, Meckel did not notice that it really represents two. With other types, Pentaceros for example, he made this error without doubt. As for the odontophore which one recognizes in his $Y$-shaped piece, although its form is in reality rather different (3), if it is admitted it is formed by the coalescence of four supporting ambulacrals, which still would not make its size, how could its presence be explained in numerous types where the supports do not exist?

Is it thus necessary to admit that an important and permanent organ was produced by the coalescence of pieces that are encountered only very rarely?

For the ambulacrals of the mouth of asteroids, there is only the description in W. Sharpey (4) I have already cited above, which gave a not very exact idea of the mouth of Asterias. "The calcareous pieces form inferiorally a ring round the mouth and a series of transverse segments placed in succession along the floor of each ray. The first of these segments is connected with the ring; they decrease in size as they approach the point or distal end of the ray, in approaching the end of the arm, and leave between them openings for the passage of the feet. In Asterias rubens, which has five rays, the central ring consists of ten larger and five smaller pieces, the former disposed in pairs opposite the commencement of the rays, the latter corresponding to the angles between the rays." It is evident that here Sharpey had taken for a single piece the joining of two teeth, and nothing in his description can be made to suggest the presence of the odontophore.

Gaudry dwelt 1ittle on this subject: "Each part of the segment (of ray) is formed of fragments. These fragments are obviously the same from the mouth up to the ends of the arms; only, against the mouth, the first two or three are fused to form a firm base. The following fragments differ from them only in size, which decreases progressively from the mouth to the ends (5)."

A. Agssiz was much more explicit:

"In the pentagonal Starfishes the plates forming the so-called jaws are huge interambulacral plates extending far towards the centre of the mouth, where they nearly meet, to form, with the papillae, the so-called jaws and teeth of Starfishes (6)."

"In 211 the pentagonal Starfishes the fact that the jaw ossicles are simply the modified interambulacral plates of the last segment is very apparent, as well as that the interbrachial plates forming the base of the interbrachial are are also only a modified part of the interambulacral plates

(1) Translation Riester et Sanson, v. II, p. 26. (2) See pl. XV, fig. 2. (3) See p1. XV, fig. 5. (4) Art. Echinodermata, loc. cit. (5) Loc. cit., p. 17. (6) North American Starfishes, p 110. (7) Id, p. 109. 
formed by the soldering together of the inner lateral spaces of the opposite interambulacral plates of the joint of the jaw (7)."

"In no other genera of Starfishes do we find so great a simplicity in the structure of the plates of the actinal ring as in Astropecten and Luidia. Usually the ambulacral and interambulacral plates of the arms differ in no essential way except at the actinal ring formed in most Starfishes by such a modification of the last joint as to make it somewhat difficult to trace the homology of al1 the parts. This last joint is extremely simple in Astropecten, being but slightly modified and differing from the others mainly in length. Thus the homology I have attempted to trace between the jaws can there be seen in its simplest form (1)."

Agassiz admitted thus, as Meckel, that the tooth of Astropecten, so Tike an adambulacral piece, is only a slightly modified one, and he generalized from there to the entire group. We shall see that in reality, no more in Astropecten than in others, the tooth does not represent a single piece, but always at least two pieces.

As for the mouth of ASTERIADAE, Agassiz said nothing special about it, but the very fact that he derived Solaster papposus from Pycnopodia proves he had not made as profound a study of it as of Pentaceros.

In the work of Sars on Brisinga, one finds a homology of the mouth of this animal with that of Solaster endeca. According to the illustrations of Sars, despite its two rows of tube feet, the mouth of Brisinga is constructed on the plan of that of ASTERIADAE. The homology, possible with Solaster as we are going to see, would thus have been more direct with Asterias. But one sees by the description that Sars had not recognized the existence of two clear and distinct types of mouths in asteroids.

In reality, the mouths of all of these animals not only can be related to one of the two types, but the differences they show concern only the relative dimensions of the pieces and not their disposition. Thus nothing is more constant, despite the diverse appearance, than the structure of the mouth in each of these two divisions. We are going to see that the se two types allow perfect homologies between them.

In figures $A-G$, which show the skeletal pieces, I have also drawn to scale the muscles I shall describe, and whose disposition is not indicated by the authors.

We commence with the mouth, a little more complicated, of a type with two rows of tube feet. Figure $A$ represents the mouth of Pentaceros turritus seen from above, with the aboral body wall removed. On one pair of teeth, the soft parts are removed and the odontophore retained in order to show better its position. On another pair of teeth, I have removed also the odontophore in order to show better the form of the teeth. In order to have a more perfect idea of the form of the odontophore, one can refer to figure 11 (PI. XII) which represents that of Pentaceros muricatus, a very related species, in four different positions. Figure D represents three adjacent teeth in their normal situation, seen from the side of the mouth. Finally, in order to better show their relation, figures $B$ and $C$ represent, respectively, two teeth of the same pair and two teeth of adjacent pairs imagined as seen from the very center of the mouth, i.e. exactly opposite. In all these figures, the same numbers designate the same thing in order to make the description easier.

(3) Id., p. 118. 


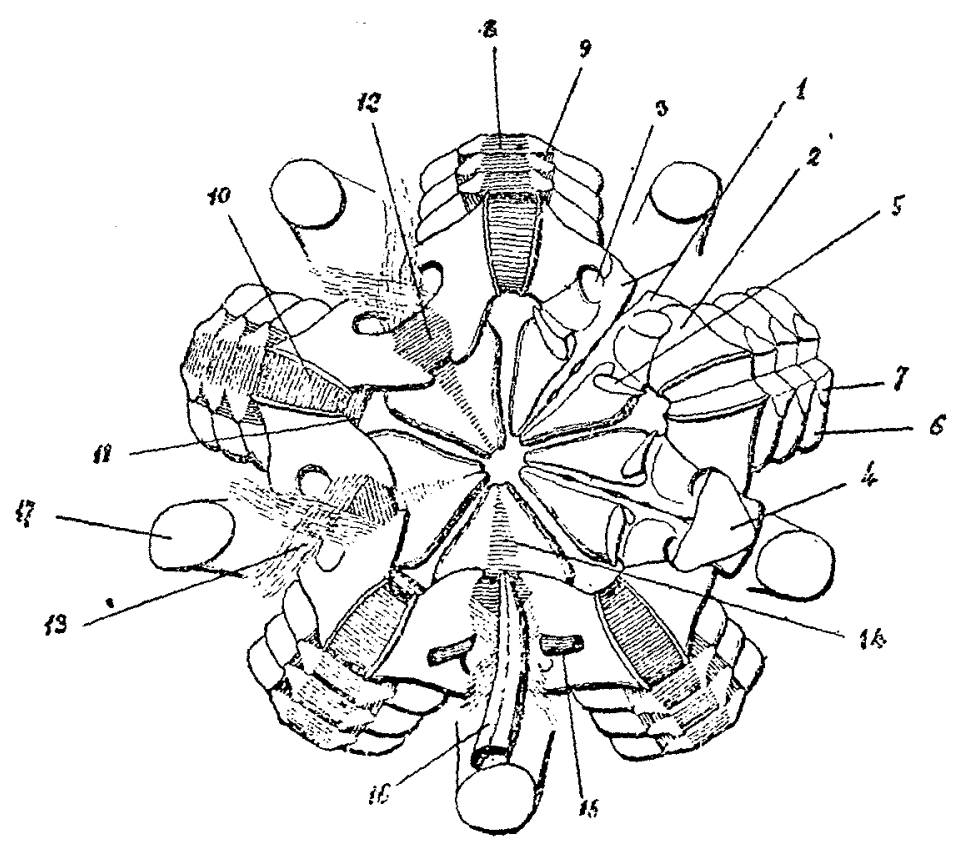

Fig. A. - Mouth of Pentacerous turritus, view from above, the body wall removed. The soft parts have been removed from two pairs of teeth, and the odontophore between them, to be able to see their relations better.

1. The teeth formed by the first two adambulacral ossicles, and bordering:

2. The first ambulacral ossicle, continuing with the coalescence of two pieces, the first ambulacral orifice, 3 , which engages the corresponding apophysis of the odontophore, 4 .

5. Wing of the apophysis where the adductor and abductor muscles insert.

6. Normal ambulacral ossicle.

7. Its superior apophysis.

8. Superior transverse muscle, opening the ambulacral groove.

9. Superior longitudinal muscle.

10. Muscle from series I, but having here a greater development.

11. Abductor muscle of the tooth.

12. Adductor muscle of the tooth.

13. Crossed ligaments that cover it, and which have been cut in 12 to allow the ligaments to be seen.

14. Interdentary muscle.

15. Dorsal-ventral muscle spread to allow the oral side of the interbrachial system to be seen. 


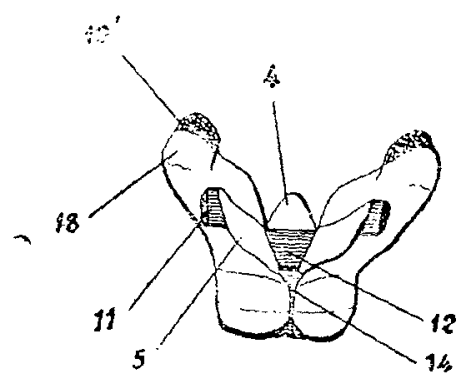

Fig. B. - A pair of teeth, seen from the center of the mouth (the numbers are the same as those above).

18. Surface by which the first ambulacral piece connects with the corresponding piece of the other side of the groove.

10'. Surface where muscle 10 inserts.

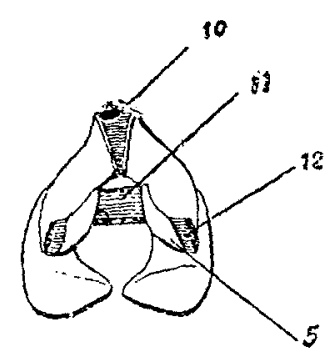

Fig. C. - Teeth of two adjacent pairs, seen from the center of the mouth. The numbers are always the same).

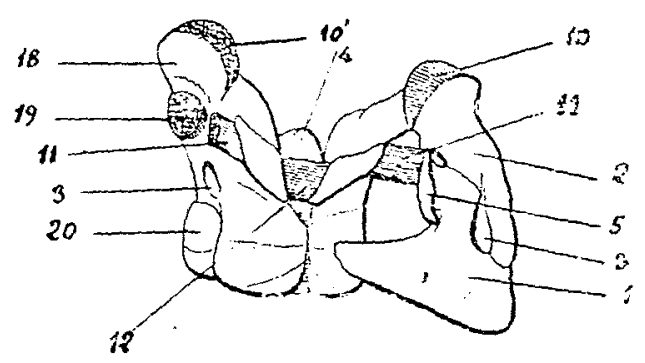

Fig. D. - Three adjacent teeth in their normal relationship (same numbers as those above).

19. First inferior transverse muscle, closing the groove.

20. First normal adambulacral piece. 
The composition of the arms, such as we have seen, does not vary untit the mouth. But there we find a circle formed of ten large pieces called the jaws that have an entirely special appearance. Their homologies are still rather easy to establish. Each of these ten pieces is in fact pierced by a hole (3), through which often passes a tube foot. By prolonged maceration in potash, it separates in two along a line that passes across this ambulacral hole. One has thus two distinct pieces. One is the tooth (1) and the other can be called the tooth support (2). The latter, very wide and thick in height, is bifurcated inferiorally. The branch of the oral side, which is thicker, is very short while the other, which is a little more slender, descends to the same level as the ambulacral pieces of the arm. The superior part, very thick as we have seen, unites with its homologue on the other side of the ambulacral groove in the same manner as two ambulacral pieces of the same pair. Only the pieces being higher, this articulation is a little more elevated than the line of homologous articulations of the same arm. It is quite evident also that the muscle (10), which is really only a muscle of series (8), should be much stronger in order to move pieces of a considerable size.

The tooth that forms the inferior wall of the ambulacral hole is composed of two parts that are easy to distinguish. One is the tooth proper, which advances into the interior of the mouth as a wedge. Its form is very easy to see in the various figures and in the plates. The other, which can be called the climbing branch, combines with the oral branch in support of the tooth. This branch carries on its oral side a form of wing (5) that projects more or less far into the interior of the mouth. With this apophysis, two faces are recognizable, the ambulacral turned towards its homologue on the other side of the ambulacral groove of the same arm, and the interambulacral turned towards its homologue in the same pair of teeth. On each of these two faces is inserted a special muscle. But these insertions do not occur at the same level. At the superior adambulacral part of the apophysis is inserted the muscle I shall call abductor (11) as it spreads apart the teeth of the same pair. It is the opposite with the inferior part of the interambulacral face that attaches muscle (12). This muscle brings together the teeth of the same pair. I shall call it the adductor muscle for this reason. The power of these abductor and adductor muscles is obviously the same. They form a complete ring all around the mouth, interrupted only by the apophyses of insertion. It is necessary to note that pieces (1) and (2) are closely united in an absolutely rigid fashion so that the movements take place as though they constituted in reality only a single piece. The movements determined by muscle (10) occur almost entirely around the longitudinal articulation that it covers. Its antagonist is muscle (19). As for the movements the abductor (11) and adductor (12) muscles determine, they consist of rocking movements of the entire jaw with the odontophore as center. The odontophore (4) is an unpaired piece situated exactly on the Tine that separates two contiguous arms. It is divided into two symmetrical halves by a vertical plane passing through this line. This piece is always single and is never missing. It cannot be compared with any of the pieces of the interbrachial system. The interbrachial system is often entirely missing. When present, there is only a similarity in the disposition of the ensemble, and it varies in form and size not only in two individuals of the same species but in two interbrachial areas of the same animal. The odontophore itself is absolutely similar in form and size in the five buccal 
angles as the jaws themselves. It is thus a special piece that can be distinguished with ease. I shall return now to its homologies.

The odontophore is generally armed with two more or less protruding apophyses as can be seen in the various figures. These apophyses are engaged in the ambulacral holes (3), and the two teeth of a single pair can therefore oscillate in more or less extensive limits according to the relative dimensions of the body and the apophyses and odontophore. They are fastened to this piece by ligaments that are attached on one hand to the apophyses of the odontophore and on the other to the periphery of the corresponding hole. The movements are, as we have said, principally determined by the abductor muscle (11) and the adductor muscle (12) that insert on the winged apophyses. A crossed ligament (13), which attaches directly below the insertion of this latter muscle and loses itself on the superior face of the ventral side and on the sides of the interbrachial system, fastens the odontophore and prevents it from being displaced during the jaw movements. This ligament has been cut (12) in order to permit all of the muscle to be seen. Another auxiliary muscle exists. It attaches to the two surfaces to connect the teeth of a single pair (14). This muscle is covered by a rather resistant ligament. I shall call it the interdentary muscle because of this. The adduction movements would have to be stronger than those of abduction if there did not exist also a muscle auxiliary to the abductor muscle (11). The auxiliary muscle (19) is only another of those of the series of inferior transversals that have developed in relation to the volume of the movable pieces.

In order to finish the study of musculature, there remain only the dorsal-ventral muscles (15). These muscles, which have been retained only with a pair of teeth, are also ten in number. They are very slender and slightly cylindrical bundles. They insert inferiorally on the jaws before the ambulacral holes and move vertically upward to the inferior face of the aboral body wall. They have no well-determined point of attachment there and lose themselves in the interlaced fibers of the wall. According to their insertions, these muscles can only bring together the two sides of the body when they have been distended passively by ingested food. Without doubt the purpose of this movement is to permit the animal to remove non-useful food substances, e.g. shells of molluscs that are most usually their prey. During their contraction, the interbrachial arc folds on itself. Yet, when the interbrachial system forms a complete wall, these movements would have to have only a very limited extension.

In figure $A$, the dorsal-ventral muscles have been separated a little in order to see the connections of the hydropore canal. The canal always follows the oral side of the interbrachial system when it exists, and has a corresponding position in all cases. It opens, as we have said, into the buccal ring in passing on the oral side of the adductor muscle (12). The vascular ring lies in the circular gutter formed all around the mouth by the inferior border of the winged apophyses and the superior face of the teeth. It is also at the border of this gutter that is attached the fibrous membrane that horizontally closes this large opening, and at the center of which is found the opening of the digestive apparatus.

If we examine now the mouth of an asteroid with four rows of tube feet, as Asterias glacialis (figure E), we are going to find some very important modifications in the form of the ossicles.

In order to facilitate the comparison with the preceding type, figure $E$ 


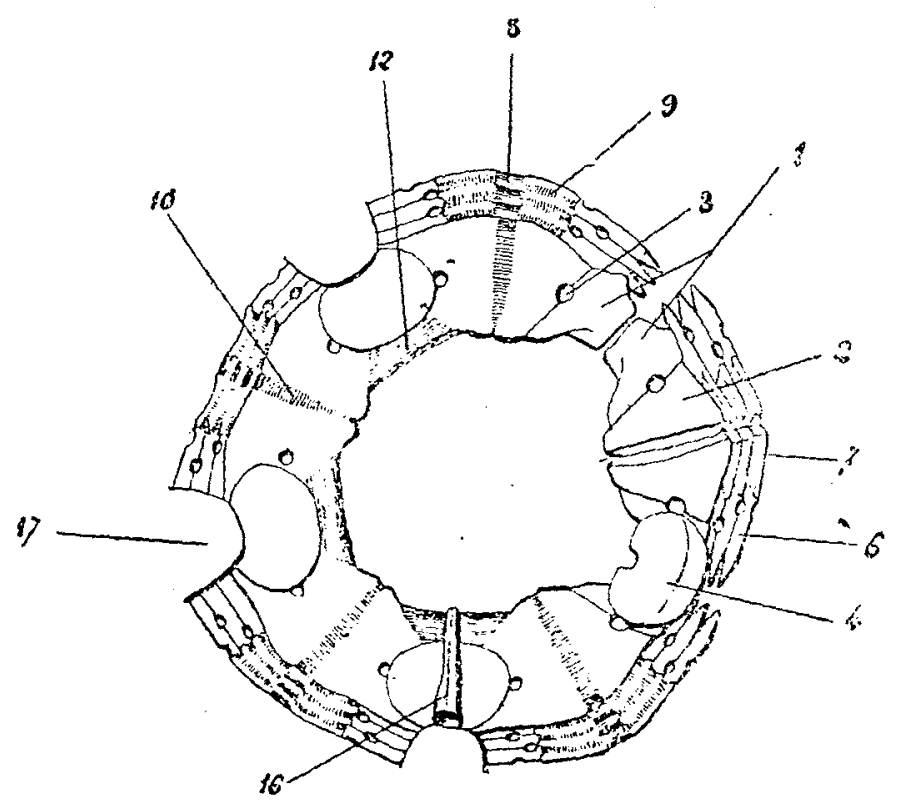

Fig. E. - Mouth of Asterias glacialis seen from above, the back removed (the numbers have the same designation as in the preceding figures).

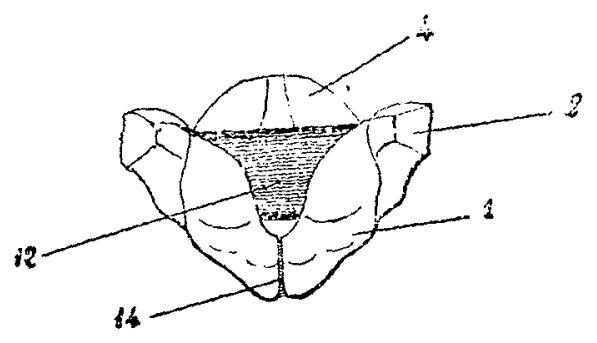

Fig. F. - A pair of teeth, seen from exactly the center of the mouth (same numbers as above).

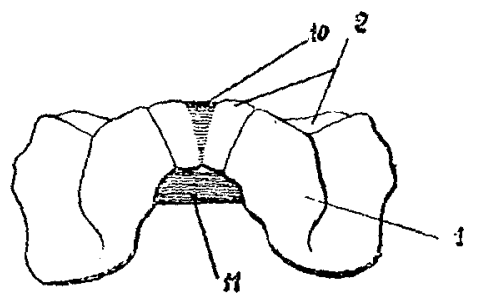

Fig. G. - Teeth of two adjacent pairs, seen from the center of the mouth (always the same numbers). 
corresponds to figure $A$, and figures $F$ and $G$ respectively to figures $B$ and $C$. In a11 of these figures, the same numbers designate the same ossicles.

In looking at the pair where the jaws are denuded and the odontophore elevated, the great difference of aspect of the two types of mouths is seen immediately. This is because the support of the tooth (2) in Asterias is developed considerably in the longitudinal direction of the arms and projects into the interior of the mouth. The tooth itself (1), which nearly closes the buccal orifice in Pentaceros, is very reduced, completely truncated from the oral side, and more separated from the center of the mouth than its supports themselves. In parallel conditions, it is evident that the movement of the jaws have become much less important. We also see that the odontophore (4), instead of being armed with two apophyses around which the jaws can oscillate as in the preceding type, is composed only of a large mass that is wedge-shaped at its inferior face and set between the two teeth that rest on the surface of the two oblique planes of this wedge. Two wide depressions, which occur on the inferior face of al1 odontophores of this type (1), serve for the insertion of a very strong ligament that unites each of these two halves of the corresponding tooth. It is necessary to see plate $V$, figure 5, 12, and 14 for the form of the odontophore, and Plate $V$, figure 6 for the relative position of the tooth and odontophore. It is still necessary to note that, in the latter figure, the odontophore is a little sunken between the teeth that are normally less spread. This relation is more exactly indicated in Figure 7 , where the soft parts maintain better the union of the pieces.

It is evident, from the form and relative position of the teeth and the odontophore in Asterias, that this functions scarcely more than to consolidate the circle formed by the jaws. Also, the winged apophyses to which the special muscles, the most powerful in the mouth, insert in the first type, have completely disappeared. However, it is not the same muscles that we find (see 11 and 12) inserting always on piece (1), but here simply on the nearly straight border of this piece. Also, the interdentary muscle (14) is extremely reduced. Finally, there as in the other type, the first inferior transversal muscle which is inserted on piece (2) and which is hidden in Figure $G$ by muscle (11) is attached to piece (1) and can be considered as the auxiliary of muscle (11). As for the dorsal-ventral muscle (15) (Figure A), it is henceforth without use, and no trace of it can be found in Asterias where the two sides of the animal are maintained at a nearly invariable distance by an interbrachial wall (2).

We have thus, as in Pentaceros, twenty muscles disposed in a circle around the mouth, or twenty-five counting muscles (10) that are indirect adductors of the teeth. But here the form of the mouth varies little, and all of this muscular apparatus has scarcely any other function than to maintain the connections of the calcareous pieces that constitute the oral circle. However, it is, as we have just seen, perfectly homologous as are these pieces themselves.

How must their constitution be understood now? If as Meckel and Agassiz, one sees in the jaws only pieces modified from the last segment, I really do not know how to explain the presence of the hole (3) through which, most often, passes a tube foot. This explanation is contradicted most easily if one admits with us that each jaw is constituted of four pieces fused two-
(1)
See PT. V and VI.
(2) See i, pl. V, fig. 3 . 
by-two: two ambulacrals and two adambulacrals, the first forming the support of the tooth and the second forming the tooth itself. An ambulacral pore is limited to these four, as is seen the entire length of the arm. In reality, nothing of the general plan is changed.

It is necessary to admit, however, that at the same time that they have this sort of coalescence, the pieces have undergone great modifications in their form. Especially in the type with two rows of tube feet where the pieces develop winged apophyses. Regarding this, it is necessary to note that the adambulacral pieces, which do not give attachment to any muscle the entire length of the arm, support here all of the special musculature of the mouth which takes precisely this transverse direction. It is the best proof that this muscular apparatus is a special apparatus, without homology in the rest of the body.

To return to the jaws, shall we conclude that they are formed, in the vast majority of cases, by four pieces: two ambulacrals and two adambulacrals, fused two by two? I still know only Ctenodiscus (1) where one can find five plates, two adambulacrals for the tooth and three ambulacrals for support as the presence of two ambulacral pores demonstrate. In all cases, those fused ambulacral pieces, which are the most elongated of the mouth, seem larger in size, and the triangular depression it has for the insertion of the inferior transverse muscle is 1arger, sometimes greatiy, than similar depressions on the other ambulacral pieces of the arm. For that of the fused ambulacral plates nearest the mouth, it seems very reduced and nearly lost. But it would have to be regarded as constituting the winged apophysis since it makes part of the tooth and belongs, in consequence, to the adambulacral series.

In the tooth itself, modification is so considerable that it cannot be determined which is formed by one or the other of the adambulacral ossicles that constitute it.

What now is the odontophore? According to Meckel, it would be the product of the fusion of the four supporting ambulacrals closest to the mouth. According to Agassiz, it would be in contrast, "a modified part of the interambulacral plate, formed by the fusion of the lateral internal parts of the opposed interambulacral plates that make part of the jaw segment."

As for me, I would not know how to take the part of either of these two hypotheses. What are these internal lateral parts of the interambulacral of which Agassiz speaks? I avow that I would be very embarrassed to respond to this question in view of the very simple adambulacral plates the entire length of the arms. Finally, one notes that the position of the odontophore is always superior to that of the adambulacral series. The hypothesis of Meckel answers a little better to this position, and, up to a point, to the function. But it is necessary to note that the odontophore has its principal connection with the adambulacral pieces and not with the ambulacral pieces, as one sees especially in the Asterias type.

I shall thus limit myself, without searching for another hypothesis for the explanation of the constitution of this particular piece, to point out its importance in classification.

As I shall have to refer to the odontophore very frequentiy in the course of this work, I have given it this name that has the dual advantage of indicating its role and of not prejudging its constitution.

(1) See p1. XV, fig. 19. 
In summary, the buccal armature of asteroids is composed of a number of pieces, equal in number to the arms multiplied by five. But the interbrachial pieces to which I have given the name odontophores do not contribute to the contour of the mouth, which is always limited by a number of pieces equal to the number of arms multiplied by four. These pieces are of two kinds, ambulacrals and adambulacrals, always disposed in alternate pairs.

Following what we regard as the one or other of our two types, we see sometimes that the ambulacral pairs project into the mouth while the adambulacrals stop far from the center of this opening. Sometimes, in contrast, the adambulacrals advance in their turn nearly to the center of the mouth while the ambulacrals, shortened and vertical, stay further back.

In order to mark clearly this difference in type, it seemed useful to me to employ expressions recalling this different disposition. I propose to name the mouth of Asterias the ambulacral type mouth or more simply ambulacral mouth, and the mouth of Pentacerous as the adambulacral mouth.

The asteroids of these two great divisions will be named, for more simplicity, ambulacral asteroids and adambulacral asteroids.

We have thus now perfectly established a great division in the asteroid group.

Up to now I have used terms, useful until now, of asteroids with two and with four rows of tube feet. There is, in fact, an agreement between these two characters in the vast majority of cases. However, the ambulacral asteroids do not always have four rows of tube feet and, likewise, the adambulacral asteroids can have more than two.

It suffices to examine the beautiful plates of the memoir of Sars on Brisinga, expecially Plate IV, in order to be assured that Brisinga, in spite of its two rows of tube feet, has a mouth constituted on the plan of that of Asterias and seems consequentiy an ambulacral type. It is the same in the genus Pedicellaster and the genus Labidiaster which Lutkin (1) cited as reversing the opinion of Perrier that the crossed pedicellariae characterize asteroids with four rows of tube feet. Here, in fact, there are only two rows of these organs although there are crossed pedicellariae.

In his Revision des Stellérides (2), Perrier correctly replied that he had not proposed these two characters as correlative, but as most usually superposable. Forced to choose which of them should determine the great division of the group, he settled for the crossed pedicellariae rather than the number of rows of tube feet. If we consider that Brisinga (3) has crossed pedicellariae and its mouth is of the ambulacral type, while its tube feet are in two rows, we can only fall in with the opinion of Perrier. Up to now, in fact, the crossed pedicellariae belonged exclusively to animals having an ambulacral type mouth.

I am sorry I was not able to examine Pedicellaster or Labidiaster. These species are not in the Museum. But the very fact that Lutken (4) declared Labidiaster is allied at the same time to Acanthaster (adambulacral type) and to Pycnopodia (ambulacral type) proves he had not examined the mouth of these animals. I am persuaded studies in this direction would confirm this proposition: the crossed pedicellariae are characteristic of the ambulacral type.

(1) Videnskabelige Meddelser, 1871, p. 289. (2) P. 13. (3) Loc. cit. , pl. IV. (4) Loc. cit. 
The first division of the stellerides would thus have as characteristics: mouth of the ambulacral type; straight or crossed pedunculate pedicellariae; and accessorily if desired, usually quadraserial tube feet.

In the second, or adambulacral type, the tube feet are nearly always in two rows. However, in Pteraster multipes, discovered by Sars, there are four rows of these organs.

I have not seen Pteraster multipes. However the genus Pteraster has an appearance so special that it is absolutely unthinkable that he made an error in classification. As I have demonstrated Pteraster caribaeus really belongs to the adambulacral type, I do not have the least doubt as to the place Pteraster multipes should occupy.

The characteristics of the second division of the Stellerides will hereafter be: mouth of adambulacral type; forcipulate or valvate sessile pedicellariae; and accessorily, usually biserial tube feet.

Thus, the study of the mouth has already given us the means to separate the class of stellerides into two great divisions. The more attentive examination of the modifications of the form of the teeth and the odontophore are now going to give us the means to distinguish the families that comprise these divisions. However, before entering into this study in detail, perhaps it would not be useless to compare the mouth of the Stellerides, which we recognize perfectly hencefore, with that of the echinoderms nearest to it.

In the first place, it is in the various types of ophiuroids: Astrophyton, ophioderma, and Ophiocoma, that one has the idea of seeking what has become of all of the pieces so perfectly determined in asteroids.

We shall see first, in few words, how one can understand the skeleton of ophiuroids.

Duvernoy, who has given much effort to homologize the skeleton of asteroids with that of urchins, neglected the ophiuroids and we are deprived of the light that his eminent scientific spirit would have thrown on the question.

For Gaudry, the ophiuroid discs would constitute an "internal system" perfectly distinct from the "intermediary system" that would exist only in the asteroids while the first would be without an analogue there. "Subject, in general, to the law of imitation, nature is however not at all invariably bound to it. The arms of ophiuroids and of euryalids having a length disproportionate to their width and likewise being more fragile, they have been provided special pieces that can be absolutely lacking in the asteroids (1)."

He thus did not accept the theory of Meckel, which would consider the discoid ossicles as analogues of the closely fused ambulacral pieces. It is, however, this opinion that is generally accepted at the present.

I shall be very prudent myself with all of these homologies. It is certainly a very worthwhile tendency that comparisons are made between related animals, and to generalize more and more in order to reach a knowledge of the general plan of nature. It is necessary to avoid, however, falling into this mania that certain authors have of wanting to find at any cost similar organs in animals of distant types. I am persuaded it is absolutely necessary to have a profound knowledge of the smallest details of the organization of the various animals being compared in order to be able to

(1) Loc.cit., p. 21. 
attempt usefully a synthetic work.

I would not be able to claim, at least for the moment, a perfect knowledge of all types of echinoderms. So I shall only recall the opinions of my predecessors, with the exception of the mouth, which I have studied with care. For the mouth, I shall indicate principally the homologies of position of the various pieces that constitute it, homologies that have not at a11, in my opinion, been sufficiently emphasized. I shall leave to others the care of deciding if one should consider these pieces as the same, more or less modified in the various types, or as different parts among them, even though they occupy a corresponding position.

It is, we have to say, rather generally accepted at present that the discs of ophiuroids correspond to the ambulacral system of asteroids. However, Lyman, who has recently made a thorough study of ophiuroids, agreed with Gaudry that it is difficult to indicate the homology of the disc. He noted correctly that the hydro-lymphatic system, which is above the ambulacral plates in asteroids, instead is below the discs and above only the ventra1, or ambulacral plates, in ophiuroids.

It would be rash for me to decide there where Lyman, who knows the question so well, hesitated. In any case, I cannot agree with Agassiz that Brisinga serves as a transition from one type to the other, to the point of "reduces the gap hitherto unfilled between Starfishes and Ophiurans to a comparatively unimportant method of development." I share on this point the ideas of Sars. Brisinga is clearly an asteroid, and has no more than any other animal of this group a resemblance to the ophiuroids, except perhaps for the external appearance. Its mouth is completely of the ambulacral type and no more resembles the mouth of ophiuroids than that of Asterias.

The skeleton of an ophiuroid, within the disc is formed by: 1) the line of ossicles united as vertebrae that extend into the arms; 2) the genital plates; 3 ) the radial shields; 4) certain irregular pieces arranged the length of the disc border; 5) finaliy, the strong forked pieces that form the five angles of the mouth and support the teeth (1).

one agrees the forked pieces are formed by the division of a disc on its median line, and the deviation of each of the two parts until they meet the corresponding part of the adjacent disc to which it fuses. Each angle of the mouth is supported by a skeleton in the form of a $V$, at the point of which is the jaw plate. As has already been said, each of the branches of this $V$ is formed (totally or in part) from half of one or several greatly modified discs. It generallily has been believed, continued Lyman, that only a modified disc was there. But evidently there must be two modified discs in each of these branches, as we find two tube-foot pores. However, in no ophiurid or or euryalid do we find more than one tube-foot from each side with each of the articulations.

These pores are visible in figures $H, I$, and $J$, each of which represent a fifth of the mouth, seen from above (the back removed), the first of Astrophyton, the second of Ophioderma, and the third of Ophiocoma.

If it is accepted that the discs of ophiuroids correspond to the ambulacral system of asteroids, there is a point of resemblance there as we have seen the jaws of asteroids formed by a fusion of the first two segments of these systems.

(1) TH. LYMAN, Ophiuridae and Astrophytidae new and o7d (Bulletin of the Museum of Comparative Zoology, Cambridge, vol. III, no 10, p. 254. 


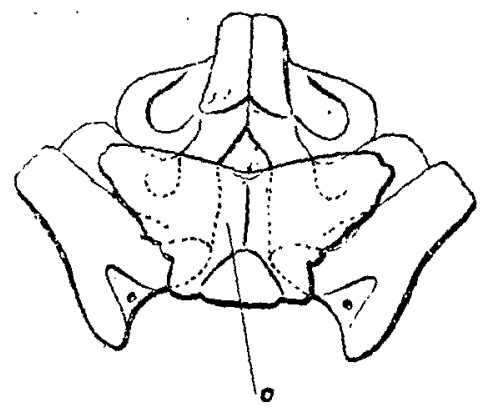

FIG. H. - Jaw of Astrophyton see from above. O. Peristomial bony plate of J. Mül Ter.

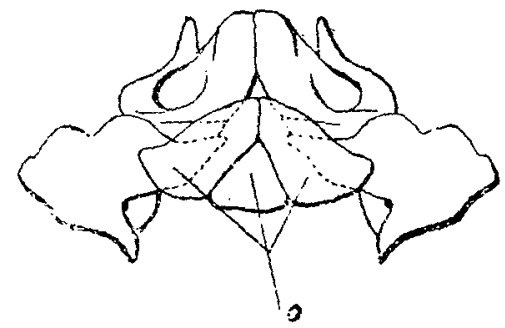

FIG. I. - Jaw of Ophioderma, seen from above. o. Peristomial bony plates.

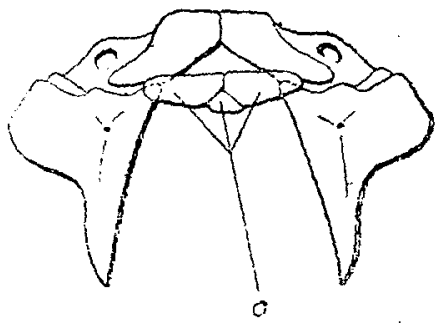

Fig. J. - Jaw of Ophiocoma, seen from above. 
By maceration in potash, these large $V$-shaped pieces can be separated from the innermost part which is, strictly speaking, the jaw. The latter does not carry a tube foot and is regarded by Müller as an interambulacral piece (or adambulacral, corresponding there to the teeth of asteroids), which is fused with its neighbor. In the angle thus formed is fixed the jaw plate which belongs to the cutaneous system and which in turn supports the teeth. This jaw plate, which Müller showed in all his figures of skeletons (1) and named "torus angularis", was completely demonstrated to belong to the cutaneous system by Lyman. I thus shall not concern myself with this point here, and I have not drawn it in Figures $H, I$, and $J$. It is, moreoever, without an analogue in the asteroids.

If we regard all of the figures that Lyman gave, we see that this piece will be the only one (understandably not counting the teeth that Miiller called "palae angularis") to occupy a position exactly interbrachial. It wi11 be necessary for us to give up finding anything here that corresponds to the odontophore. However, in the figures of Müller cited above, which are not very satisfying one must say, a plate or group of plates, which he simply called "peristomial bony plates", is seen at this location. He declared it "scarcely comparable" to the odontophore of asteroids as, he said, the odontophore would have to be counted as an interambulacral piece. The reason does not seem conclusive to me at all.

It is certain that if the three thin plates in Ophioderma (J) are considered as the shields o, which Müller called "peristomial plates", there would be some difficulty in recognizing an odontophore there. It is nearly the same in Ophioderma (I), where they have however developed considerably more. But, if we take Astrophyton $(H)$, we find in place of these three scales a single massive piece set as a wedge between the two jaws, having not only the form of certain odontophores, but exactly their interbrachial position.

One scarcely knows how to deny the identity of the plan between ophioderma, Ophiocoma, and Astrophyton in looking at the series of figures we give here that are drawn with the camera lucida with rather great magnification.

Thus it is not possible to refuse to accept the homology of this piece $o$ of Astrophyton with the systems o of Ophioderma and Ophiocoma.

Should one consider this piece as an odontophore? If figure $H$ is compared to the pairs of bare teeth of figures $A$ and $E$ above (pp. 25 and 29), it will be necessary to agree that they have nearly the form of an odontophore, unquestionably the interbrachial position that it occupies absolutely alone, and a function of consolidating the oral circle.

It can be accepted then that the odontophore is normaliy formed by a coalescence of three ossicles, distinct in ophiurids and ophiocomids, more or less closely united in adambulacral asteroids where one distinguishes in this piece a body and two apophyses, finally absolutely combined in ambulacral asteroids where the piece appears single.

One could object, however, to the identification of this piece 0 to an odontophore, that it is more distant from the center of the mouth relative to the jaws as in asteroids. It is no less true that it is the only piece in ophiuroids that canbe compared to the odontophore. I am surprised Lyman did not speak of it in his work.

(1) Ueber den Bau der Echinodermen (Abhand1. der König7. Ak. der Wissensch. zu Berlin, 1853, pl. VII, fig. 2-5. 
Perhaps these thin scales of the ophiurid and ophiocomid escaped him. But if he had examined an euryalid, his attention would have been strongly drawn to this point. As for Agassiz, who saw in the work of Lyman the proof that the parts constituting the mouth are strictly homologous in asteroids and ophiuroids (1), he did not go into greater detail and said nothing of the odontophore.

Is it necessary now, in spite of all the incertainty that prevails in making these homologies in the types that are the closest related in appearance, to try to establish comparisons with animals still more distant?

I have examined with the greatest care the buccal circle of holothuroids. I shall refrain from proposing the slightest theory on its constitution. As for echinoids, the difficulties are scarcely less. Agassiz avowed to be incapable of homologizing the echinoid tooth with any of the solid parts of ophiuroids or asteroids. I shall not be more affirmative than he. I shall limit myself to presenting some short remarks in order to prove that the only piece that can be compared, in position, to the echinoid tooth is specifically the asteroid odontophore.

If we take a clypeasteroid first, we find on the test, exactly between the ambulacrals, some kinds of small forks on which rests the dental apparatus. It seems thus that we have a piece exactly interambulacral. It is, however, only an appearance. In fact, in a regular echinoid, we no longer find these small forks, but developed arcs under which pass the nerves and radial canals. At first glance, it seems that they would be two very distinct systems. But if we suppose that each of the arcs of Echinus should be separated in the middle and that each of these halves are rejoined to the same part of the adjacent arc, we would have reproduced exactly the appearance of a clypeasteroid. Thus there is no more in the one than in the other a single piece exactly interambulacral, but two pieces situated on each side of the interambulacral line. These can be rejoined two by two either on this same line (clypesteroid) or on the ambulacral line (regular echinoid).

Examine now the jaws themselves. Understandably we shall leave aside the rotules of the clypeasteroids as well as the scythe of the regular echinoids that are situated in the ambulacral direction, and concern ourselves only with the jaws themselves that are situated between the interambulacral lines.

In the clypeasteroid (K), if the very small epiphyses $e$ are removed, there remain no more than two 7 arge pieces $m$, which are property called the jaws. They are joined by a suture exactly situated in the interambulacral ine. Embedded in this suture we find the tooth $d$ which is quite evidently the only interambulacral piece. It is the same in Echinus. If we look at a jaw in the corresponding position, we see only the two epiphyses e on which articulate the scythes that are joined by a suture directly on the median line. The tooth $d$ is within this suture. In looking at it by the external face, we still see the two epiphyses e joined at the median line. Below, the two jaws (exognathites of Milne-Edwards) also are fused to the epiphyses and rejoined by a suture situated exactly within the interambulacral line.

It has seemed good to draw attention to these facts. But it will be understandable that, in the presence of differences of all sorts that separate the armed echinoid tooth from the asteroid odontophore, the homology of position, so important stil1, does not permit me to conclude that the two

(1) Loc. cit., p. 110 . 


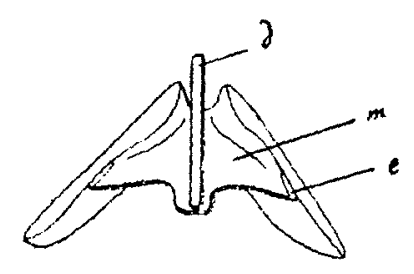

FIG. K. - Jaw of a clypeasteroid, seen from above. $m$, jaw; e, epiphysis; $d$, tooth.

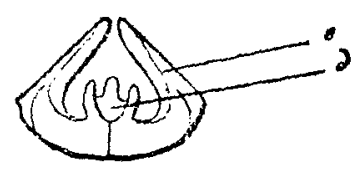

FIG. L. - Jaw of a regular urchin, seen from above. e, epiphysis; $d$, tooth.

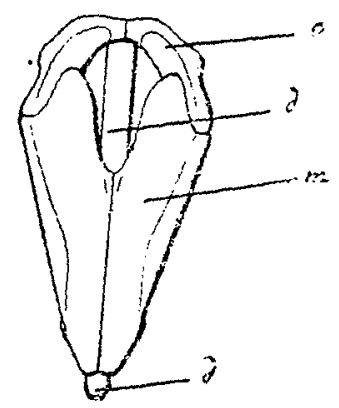

FIG. M. - The same, seen by the external face. (Same letters as above). $>$ ossicles are identical.

I do not have to consider at all the homologies of the complete skeleton in the various types of echinoderms, not having new information to give on a question that has already served as material or as the pretext for the most complicated scientific questions. One finds in the memoir of Agassiz ar exposition of the theories that are current in science today. I have madt above some reservations on this subject. I cannot however dispense wit presenting some remarks on a very controversial question, that of th polyzoicity of the echinoderms. It is in reality Duvernoy who was the firs author of what one generally calls the theory of Haeckel today. "For a lor time," he says in the note cited above, "one has recognized in asteroids $a$ internal skeleton. If it does not serve completely to protect the princip parts of the nervous system, as in the vertebrates, the skeleton doi preserve at least one of the principal usages of the latter, that of bei the passive organ for movement. In asteroids with five rays, there a appropriately five vertebral columns. These columns, for which the numt varies in the different species and the genera of this family with that the rays, are more or less free towards their caudal end and supported their buccal end. The asteroids are thus the serpents of the echinoder. 
but serpents with several bodies and a single mouth." These considerations mean that the echinoderms with pedicels, which are true rayed animals, can be seen as composed of symmetrical animals, especially in their organs of sensory perception and of reproduction, whose body would be united all along their length (echinoids and holothuroids) or free for a more or less great distance in the posterior part (asteroids) (1).

The theory of polyzoicity is very clearly indicated here. It is true that Duvernoy did not indicate that the animals composing the colony should be related to the annelids as done since Haeckel.

It is necessary to depend much on embryology to support these views. Huxley, using the studies of Müller, and drawing conclusions that the latter had not forseen, proposed combining the echinoderms with the articulates. The conclusions are unquestionably ingenious and original but not at all conclusive as AT. Agassiz said very well (2). Moreover, Huxley has not made studies himself.

Metschnikoff (3) has remarked that the fact of the origin of the buds that produce the arms of the asteroid proves nothing in favor of polyzoicity, and that this is a phenomenon of the same order as the budding of the tentacles of bryozoans. If each arm of an asteroid were a distinct animal, the digestive apparatus would be produced at the same time as the arms themselves and grow longer in the arm along with its formation. Instead, the arms are already formed while the digestive apparatus is still only a simple $\mathrm{sac}$ that extends later into the radial caeca. It is a fact analogous to the penetration of the extension of the digestive apparatus in the legs of pycnogonids, or in the dorsal appendages of nudibranchs.

Agassiz returned to this question in his last memoir (4): "As well might we compare", he said, "the simple chymiferous tube of an Acaleph with a single individual, and make a many rayed Zygodactyla a community of individuals with a single digestive cavity. The very fact that we can trace the passage between an Acaleph with a polymeral chymiferous system like Zygodactyla and a Siphonophore zoid in which we can trace but a single chymiferous tube, shows, at any rate, that the number of ambulacral tubes should not be taken as any proof whatever of a composite structure. When we come to the articulation of the arms, can we consider that as anything beyond the adaptation of the ambulacral system to the deposition of limestone plates, allowing certain limited movements?"

I do not want at all to dwell longer on this question that leaves the framework of my own research. I cannot leave the subject however without giving two reasons that do not seem to me to have been yet invoked to support the opinion that Agassiz defended and that I share for my part.

The first is that, whatever be the asteroid one takes, it is impossible to find a regular segmentation of the general skeleton corresponding to the ambulacral and interambulacral series.

Thus in ophidiaster where the skeleton, dorsal and ventral, forms a series of arcs with admirable regularity, there is never agreement between the number of these arcs and those of the ambulacral pairs. In Luidia, in contrast, where the inferior marginal plates, as well as the three or four

(1) Comptes rendus de l'Ac. des sciences, 15 February 1837. (2) The History of Balanoglossus and Tornaria, p. 423. (3) Studien über der Entwickelung der Medusen und Siphonophoren (Siebold und Köliker's Zeitsch., 1874). North American Starfishes. 
lateral rows of the aboral surface, correspond exactly to the ambulacral pieces, we see all regularity cease to exist towards the middle of the aboral surface. In other types, the differences are still much more striking, as one can easily convince himself by a simple glance at my plates. It would be possible to object, it is true, that segmentation is carried here only on the oral side, as one sees it at the beginning of development in the articulates. But it cannot be forgotten that if we deal with annelids here, they are certainly animals of an advanced type, and I do not know that there exists a single articulate of an advanced type where segmentation is incomplete.

The second reason is that the radial caeca do not have their divisions corresponding to the segments of the body as one always sees in the annelids.

Perhaps I shall be able, by further studies, to obtain new proofs for or against this interesting debate. For the moment, it seems to me that the theory of Haekel goes beyond the facts.

I shall stop this long discussion here and, taking up the explanation of my own studies, I am going to pass now to the description of the species. But first, I believe it useful to give a general table of the new classification that I propose and then to list the genera in the present work.

The names marked with an $\left(^{*}\right)$ are the genera that I have not been able to examine, and whose place should not be considered as fixed in a definitive manner. 


\title{
CLASS OF THE STELLERIDES.
}

\author{
FIRST SUB-CLASS. - AMBULACRAL ASTEROIDS.
}

AMBULACRAL TYPE OF MOUTH. - PEDUNCULATE PEDICELLARIAE, STRAIGHT OR CROSSED. AMBULACRA MOST USUALLY QUADRISERIAL.

I. Simple odontophore, quadriserial ambulacra............ I. ASTERIDAE.

A. Reticulated dorsal skeleton; ordinarily five, ten, or twelve arms at most; small disc when the arms are

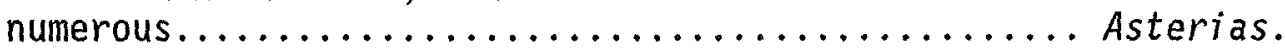

B. Almost no dorsal skeleton; five arms.............Anasterias.

C. Dorsal skeleton formed of pieces elongated transversally, imbricated and disposed in longitudinal series................................ Stichaster.

D. Skeleton formed of imbricated plates longer than wide; naked skin......................... Calvasterias.

E. Almost no dorsal skeleton; very numerous arms....... Pycnopodia.

II. Odontophore resulting from the fusion of two pieces:

A. Quadraserial ambulacra....................... II. HELIASTERIDAE.

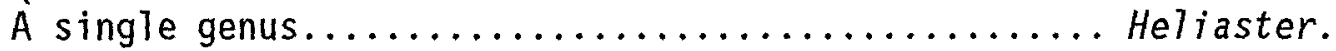

B. Biserial ambulacra...................... III. BRISINGIDAE.

a. Straight and crossed pedicellariae, numerous arms.*Labidiaster.

b. Only crossed pedicellariae:

1. Ten to twe ive arms................... Brisinga.

2. Five arms only...................... *Pedicellaster.

SECOND SUB-CLASS. - ADAMBULACRAL ASTEROIDS.

ADAMBULACRAL TYPE OF MOUTH. - SESSILE PEDICELLARIAE, FORCIPULATE OR VALVULAR. - AMBULACRA NEARLY ALWAYS BISERIAL.

I. Dorsal skeleton formed of reticulated thin, narrow, imbricated pieces, leaving between them a mail at least as large as the ossicles constituting the mesh; no supporting ambulacrals.....................IV. ECHINASTERIDAE.

A. Very small, truncated teeth; simple odontophore; interbrachial system reduced to some pieces near the angle of the two sides of the body; no spicules in the tube feet; usually five arms............... . ECHINASTERINAE. a. Ossicles with mamelons for the insertion of isolated spines.

$b$. Ossicles without distinct mamelons for the insertion of very small spines that cover them over

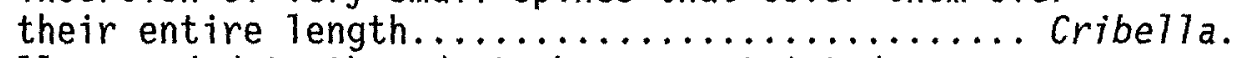

B. Sma11, rounded teeth; odontophore constricted Taterally; no interbrachial system; no spicules in the tube feet; five arms................. T.2. MITHRODINAE.

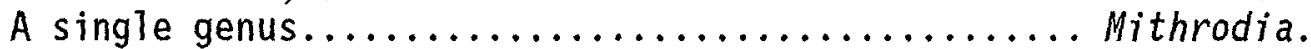

C. Small teeth, but massive and pointed; odontophore with very marked articulating apophyses; strong interbrachial systems; rosette of spicules in tube 
feet; large valvular pedicellariae on the border of

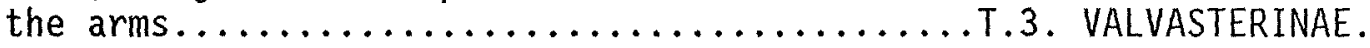
A single genus........................ Valvaster.

D. Very large, rounded teeth; odontophore with articulating apophyses and a dorsal apophysis; very thin, triangular interbrachial system, carrying the odontophore on top; no spicules in the tube feet; numerous arms.......................... $4 . .$. SOLASTERINAE.

a. Dorsal ossicles carrying radiating spines; a single

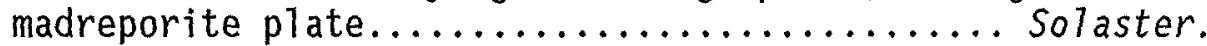

b. Dorsal ossicles carrying only a single, very long

spine; several madreporite plates............. Acanthaster.

II. Skeleton formed of round or quadrangular ossicles arranged in longitudinal series, at least on the ventral face; supporting ambulacrals......................V. LINCKIADAE.

A. Very small teeth; odontophores with slightly marked apophyses; wall of interbrachial system often incomplete; supporting ambulacrals upright on the first ventral row; ventral face of the arm flat, formed of at least three longitudinal rows of plates between which are not seen the tube-feet pores:

a. Dorsal skeleton never giving the arms an absolute regularity, at least in the adult animal, and not constituted of raised ossicles; spicules in the tube feet.............................. Linckia.

$b$. Dorsal skeleton of the arm very regular, constituted of raised ossicles and joined above by connective ossicles; no spicules in tube feet..... Chaetaster.

B. Average teeth; odontophore with very marked apophyses;

no interbrachial system; supporting ambulacrals upright on the second ventral row; ventral face poriferous:

a. Rounded teeth; dorsal skeleton very regular; rounded arms; spicules in tube feet................. Ophidiaster.

b. Pointed teeth; dorsal skeleton irregular; arms flattened below; no spicules in tube feet......... Scytaster.

III. Pointed teeth; mouth nearly closed; no supporting ambulacrals; skeleton formed, at least on the ventral face, of ossicles disposed in a manner to constitute a sort of pavement; marginal plates generally very distinct

A. Odontophore thin and without weil-deveioped apophyses; no interbrachial systems; no spicules in the tube

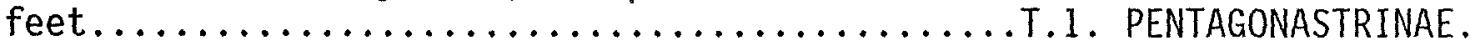

a. Tentacular pores on the ventral face............. Fromia.

Perhaps placed in this genus.................. Metrodira.

$b$. No pores on the ventral face:

1. Indistinct marginal plates............... Ferdina.

2. Very distinct marginal plates:

(a) Very thin teeth..................... Pentgonaster.

(b) Very strong teeth; large pedicellariae on both

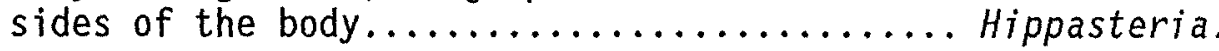


B. Massive odontophore with very developed apophyses; interbrachial system variable in form, but constant; rosettes of spicules in the tube feet.............. . GONIASTERINAE.

a. Each plate of ventral skeleton carrying a large valvular pedicellaria:

1. Dorsal skeleton reticulated or formed of round ossicles; interbrachial system closing the entire interbrachial area and making projections on both

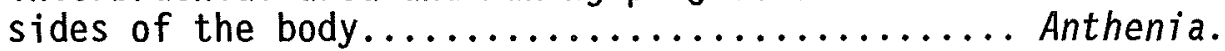

2. Dorsal skeleton reticulated; interbrachial system carrying the odontophores, and not apparent on the

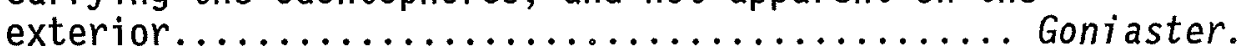

b. Dorsal skeletal plates star-shaped............... Goniodiscus. Place still undetermined.....................Nectria.

c. Dorsal skeleton reticulated or formed of elongated ossicles, ventral plates covered with granules, sometimes with small pedicellaria:

1. One pair of marginal plates at the end of each

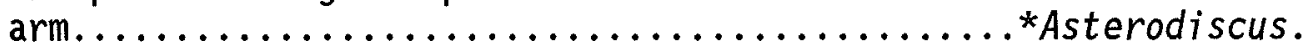

2. Thick pentagonal body without arms; marginal

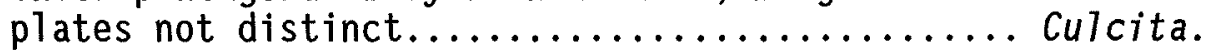

3. Five short large arms; marginal plates little apparent........................... ${ }^{*}$ Choriaster.

4. Pentagonal body; keeled interbrachials nearly absent.................................. Nidorellia.

5. Arms very distinct, nearly always keeled; dorsal marginal plates little apparent.............. Pentaceros.

6. Smooth skin entirely covering the skeletal ossicles that are very flat......................mnasteria.

IV. Large round teeth; mouth widely open; massive odontophore with little developed apophyses; interbrachial system variable in form; no supporting ambulacrals; no spicules in the ambulacrals; skeletal ossicles imbricated, round or disjointed................................... II ASTERINIDAE.

A. Marginal plates smaller than the others, or entirely equal:

a. Non-imbricated ossicles, covered with spines.....*Patiria.

b. Imbricated ossicles:

1. Body more or less convex; arms most often short

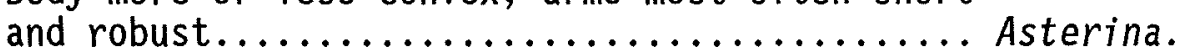

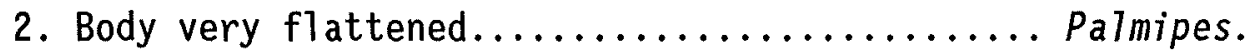

c. Disjointed ossicles, naked skin..............Diasterina.

B. Body bordered by a double row of marginal plates,

1 arger than all of the dorsal and ventral plates:

a. Dorsal ossicles star-shaped; ventral plates without space between them

1. Reticulation of the back nearly regular and

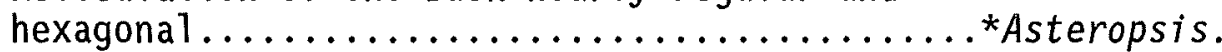

2. Irregular reticulation, arms very marked...... ${ }^{\star}$ Dermasterias.

b. Dorsal ossicles in form of rectangles with sloping

sides and rounded angles; ventral plates do not

touch each other al1 around their edge: 


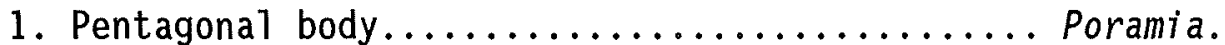

2. Arms very marked..................... *aneria.

V. Dermal covering supported by spines radiating around ossicles projecting from the skeleton.............VIII. PTERASTERIDAE.

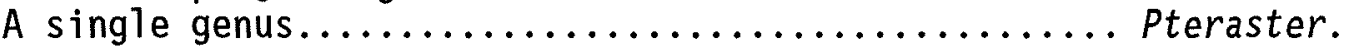
behind which it will undoubtedly be necessary to place several that I still have not been able to illustrate here.

VI. Teeth projecting at the ventral surface; mouth widely open; no interbrachial system; supporting ambulacrals; no anus; ocular plate very developed; conical tube-feet; dorsal skeleton formed of raised ossicles without completely regular disposition........................ IX. ASTROPECTINIDAE.

A. Wide teeth; marginal plates vertical, very thin, and with projecting ridge; ventral face imbricated; short arms; ossicles on top forming regular series........ Ctenodiscus.

B. Narrow, blade-like teeth; ventral face constituted only by inferior marginal plates; arms elongated:

1. Ventral marginal plates only; ossicles on top forming three or four regular series on the sides

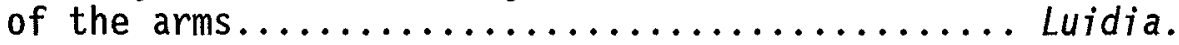

2. Dorsal and ventral marginal plates, ossicles on top not forming regular series................. Astropecten.

VII. Teeth triangular, pointed, not projecting at the ventral surface, and nearly closing the mouth completely; interbrachial system; no supporting ambulacrals; anus; small ocular plate; tube feet with suckers; dorsal skeleton formed of raised ossicles with a very regular disposition; dorsal and ventral marginal plates, the latter constituting the entire ventral

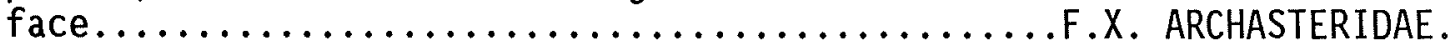

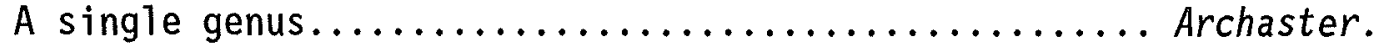




\title{
FIRST SUB-CLASS
}

\author{
AMBULACRAL ASTEROIDS
}

The general discussion of previous classifications was made with much care by Perrier in the work cited above (1), so I believe it useful to return to it here. I shall thus take his classification as a base. In explaining the reasons that justify it, or that have brought me to modify it on various points, I shall only recall the preceding system when it seems necessary in the course of the discussion.

I shall take from his work the synonymies of the genera, completing some on occasion. As for those of the species, it seemed useless to me to repeat them here, since my work does not have distinguishing them for a goal, and as the names that I give to my types are all the same as in Perrier's memoir.

His first family, ASTERIADAE, which he already perceived had to be separated from all the others, constituted alone his first division. Following me, the Asteriadae should be dismembered of the genera Labidiaster and Pedicellaster. These genera perhaps can be placed after Brisinga in one family of BRISINGIDAE, or must form the type of a new family that will be placed with the ASTERIADAE and the BRISINGIDAE in the first sub-class of the Stellerides.

It seems to me, in fact, that the disposition of the tube feet in two rows instead of four is a rather important character to separate Labidiaster and Pedicellaster from the fammily ASTERIDAE. I would not be able to say now if it is necessary or not to join them to Brisinga, but certainly they should be placed separate from the ASTERIADAE.

Although I have not been able to examine animals of this species, the very precise figures of Sars scarcely allow me doubt in this regard. The comparison of the mouth of Brisinga with that of my first type permits me to indicate the place of the family BRISINGIDAE, whose position has been still uncertain. The affinities of this family had in fact remained very doubtful. Wyville Thompson (2), after having spoken of Brisinga, said: "Solaster papposus, Forbes, apparent1y their nearest of kin though far removed,..." This idea is found again in A. Agassiz, who has believed it necessary to separate Solaster papposus, in restoring to it the name Crossaster (M. and T.), from Solaster endeca and who declared it very close to Pycnopodia and Brisinga. These two genera Pycnopodia and Crossaster, compared with Brisinga, proved to him in a conclusive fashion that the latter, far from having a special structure, is closely related to them by this same structure.

"We might readily", he said, "transform a Pycnopodia or a Crossaster into a Brisinga by reducing the actinal and abactinal interbrachial spaces into a minimum, which would give us a Starfish with a small disc, in which the ambulacral plates adjoing the actinosome assume a great development, and thus the numerous arms would appear quite disconnected (as in Brisinga). The connection of the arms in Starfishes does not depend so much on the greater or less development of the ambulacral and interambulacral systems, as upon the greater or less increase in the limestone network forming the

(1) Révision des Stellérides. (2) The Depths of the Seas, London, 1873, p. 118. 
interbrachial spaces, which, although a feature greatly affecting the physiognomy of the Starfish, yet influences but slightly its internal structure (1)."

One finds again there this tendency to join the species with numerous arms that made L. Agassiz say already in $1835(2)$ : The species of the genus Stellonia whose number of arms varies from five to seven, are the transition to the true solasterids", and who combined with Lütken, as I have already said, the genus Labidiaster at the same time to Acanthaster, to Pycnopodia, and to Pedicellaster.

Actually, each of these two sub-classes we recognize in the asteroids possess species with numerous arms. But it is quite necessary to keep from uniting them. Acanthaster no more resembles Pycnopodia than Echinaster resembles Asterias. The very clear separation of the two subclasses is one of the first services the study of the skeleton renders us.

I shall only very rarely, in the course of this work, place exactly the limits of a genus. For that it would be necessary to have examined all of the species. That would have been possible only by destroying a large number of specimens. I shall more often delimit a family. Finally, when a genus seems to me to present characters that clearly separate all of the other genera that belong to the same family, I shall propose to make it the type of a new family that takes its name.

This I propose now for the genus Heliaster. I shall give the reasons further on.

The first sub-class of Stellerides now will be composed of the following families: ASTERIADAE, HELIASTERIDAE, and BRISINGIDAE. This latter may or may not contain Labidiaster and Pedicellaster. In the latter case it would be necessary to form a new family.

\section{FAMILY 1. ASTERIADAE.}

I restrict the ASTERIADAE, which Perrier applied to all the asteroids with straight or crossed pedicellariae (the latter particularly characteristic) whether they had two or four rows of tube feet, to those animals that have four rows of tube feet and a simple odontophore.

The genera that comprise the family are:

Asterias (Linnaeus); Anasterias (Perrier); Stichaster (Müller and Troschel); Calvasterias (Perrier); Pycnopodia (Stimpson).

We are now going to examine them in detail.

\section{GENUS ASTERIAS (LINNAEUS)}

1735. Asterias, Linnaeus, Systema naturae.

1733. Stella coriacea, Sol, Pentadactylosaster (pars), Hexaktin, Heptaktin, Linck, De stellis marinis, p. 33 and 34.

1834. Stellonia, Nardo, Oken's Isis.

1834. Stellonia and Uraster, L. Agassiz, Prodrome. Mém. Soc. sc. de Neufchâte7, v. I.

1839. Uraster, Forbes. Mem. of Werner. Soc., VIII, p. 114.

1840. Asterias, Gray. Ann. and Mag. of Natural History, VI, p. 178.

(1) North American Starfishes, p. 102. (2) Prodrome d'une monographie des Radiaires, p. 192. 

p. 14 .

1842. Asteracanthion (pars), Müller and Trosche1, System der Asteriden,

1862. Asteracanthion (pars), Dujardin and Hupé. After Buffon, Echinodermes, p. 330.

1875. Asterias, Perrier, Révision des Stellérides, p. 38.

Forbes (1) gave these characteristics of his genus Uraster: "Body stellate, few-rayed; rays rounded, spinous; avenues bordered by three sets of spines; suckers quadriserial."

For Gray (2), the genus Asterias was determined by "Skeleton netted, with a single mobile spine at each anastomosis of the ossicula; body covered with more or less prominent elongated mobile spines." Finally, Perrier, by "a reticulated dorsal skeleton, usually five arms but up to ten, twelve, or more; small disc when the arms are very numerous."

There existed in the Museum in 1875, forty-nine species of the genus Asterias. Several others have since been added, of which a certain number are new.

The description of species is not in the framework of this work. Moreover, their distinction nearly always, if not always, takes place with the aid of various accessory appendages that cover the skeleton.

I do not know how to do other than give, wherever possible, a description of the skeleton of at least one species of each genus as the skeleton scarcely varies within a genus.

I shall take here for the type Asterias glacialis, the beautiful species common on the coast of Brittany, which attains sometimes 1 arge dimensions. I have been able to have numerous specimens of the animal at the laboratory at Roscoff, where I have studied all those that, in this work, are related not only to it but even to Echinaster sepositus, Cribella oculalta, Asterina gibbosa, and Palmipes membranaceus. All of these live on the coast in very great abundance except Palmipes, for which it is necessary to dredge far away.

I have represented (3) the skeleton of a juvenile Asterias glacialis, enlarged two times. Figure 2 shows a portion of the ventral surface of the same individual, seen a little obliquely to show how it connects to the dorsal surface.

In taking a young animal, one sees better the general plan that would be masked later by the ossicles that develop in the meshes of the original reticulation to strengthen the skeleton as it develops.

It is interesting to compare figure 1 with the excellent 117 ustrations given by Loven (4) representing the animal at $1.3,2$, and $4.5 \mathrm{~mm}$ in diameter. One finds in our figure its central disc or base become clearly pentagonal and carrying a spine at the center. The anus an opens on the most indented side. The genital plates or parabasals, with the 1 argest carrying the madreporite $m$, are equally visible. They limit what one can call the dorsal-central area, at the middle of which is only the central disc. The central disc is connected to the rest of the skeleton only by calcareous trabeculae leaving from each of the five angles. The radial piece or ocular oc is naturally found here at the end of the arm. Finally, from this plate to the parabasal plates extends a row, nearly rectilinear except towards the
(1) British Starfishes.
les Echinoïdes, pl. LIII.
(2) A Synopsis, etc.
(3) See pl. V, fig. 1 .
(4) Sur 
end of the arm, of imbricated ossicles that run from the periphery towards the center. The first piece of this row, called the peristomial or interradial system of Loven, rests on two parabasal plates and has two spines. Each of these pieces has only one spine. Some of them even lack them, but this is rare. These spines, which I have not illustrated at al1, are carried on small hemispherical mamelons. The mamelon has a depression in the center in which is inserted the ligament that fixes the spine (1). This arrangement is thus analogous to that seen in the spines of echinoids. There are cases however where the spine seems fused and is a unit with the piece that supports it.

Two equal rows of equally spined and imbricated pieces occur on each side of the arm. Each parabasal plate supports the first pieces of the two lateral series of two adjacent rays. Between these series are irregular rows that anastomose nearly equidistant from the regular rows. These pieces, in multiplying unceasingly, end by giving the skeleton of the arms an extremely complicated appearance.

The plates of the lateral rows are not at al1 connected directly to the adambulacral series. These cross-shaped plates, whose perpendicular arm is lacking in the the ambulacral seriesand whose form is seen so well in Figure 2 , are connected with them on $1 y$ by small pieces interposed between the two series very irregularly at long intervals. Gaudry (1) gave a theoretical figure that represents a part of the arm of Asterias. The adambulacral series is counted as the first interambulacral. The cross-shaped ossicles, the connectives, etc. have the same name and are numbered in the direction from the groove. A simple glance shows the difference between the general skeleton and the adambulacral series. The plates of series ad, rather wide but very thin the entire length of the arm, increase a little in thickness towards the mouth. The well-developed last one, as we have said, forms the tooth $d(3)$.

This tooth is seen from below and enlarged four times in figure 8. Figure 9 shows the opposite lateral view of the side of the ambulacral groove.

The ambulacral pieces a have the general appearance described above. I shall not repeat it, and restrict myself to return to the figures, particularly figure 10. This represents, enlarged two times, the mouth of an individual much larger than those given in figures 1 and 2 . That which we have already said can be seen, i.e. the irregular arrangement of the ambulacral pores that only a little further on are arranged in an absolutely regular and alternating series. The first ambulacral piece is here almost as long as wide. This distinguishes the two different arrangements of Pycnopodia and Stichaster (4) (figures 11 and 13).

Although I have said it in talking of the type in general, there does not exist here, strictly speaking, an interbrachial system. The pieces $i$, which are seen in the interbrachial section (5), can be considered as continuations of the walls of the arms.

The odontophore o (figure 3) is shown magnified four times (Figure 5). The views, which are the same for all of the odontophores of this type, show

(1) See pl. I, fig. 1. (2) Memoir cited, pl. XIII. (3) See p1. V, fig. 2 and $10, d$. (4) This piece is represented alone, enlarged four times, Fig. 7 , seen from below, that is to say in the same situation as in figure 10. (5) P1. V, fig. 3 . 
them in a seen from the side, in $b$ from the inferior face, and $c$ from the oral face.

The form of the piece is better represented by the figures than by a long description. I shall note only (in c) that the two laterally inclined planes form a much more open angle in Asterias than in Pycnopodia or Stichaster, and that they join on the medial line, and in a that the inclined plane does not fill the entire height of the piece.

These characteristics make recognizable immediately an odontophore of Asterias from those of Pycnopodia or Stichaster which however resemble it greatiy (1).

A. Agassiz has given in the work cited above two plates, one of Asterias berylinus or forbesi, the other of Asterias ochracea. These two plates, to which are applied the general remarks I have made at the beginning of this work, and represent chiefly the animals with their soft parts removed, permit nevertheless a rather clear idea of their skeleton that does not differ sensibly from the general plan of Asterias glacialis. However, Agassiz correctly insisted on the completely special appearance of the ventral face of Asterias ochracea. However, there is nothing new there as an element. It is a representation of the marginal row that can come to form three parallel rows with the corresponding adambulacral series. The pieces of the marginal row are disposed on lines exactly parallel to this series, thus reproducing an aspect rather similar to that of the ventral face of Linckia. I have nothing to correct in the description of Agassiz, who has besides chiefly insisted on the form and disposition of the spines. It is necessary to recognize however that he has mistaken the odontophore (which he has not, moreover, illustrated): "Seen from above (an interior view), the connecting plate between adjoing ambulacral systems is formed by the rising of the outer edge of the plate (the outer pore not being present) towards the 1 imestone network formed by the junction of the interambulacralimbricating pieces which constitute the framework of the abactinal system (2)".

In the genus Asterias, the madreporic plate occupies, as we have seen, the area of the superior face of one of the genital or parabasal pieces. This piece is a little larger than the four others and pitted. The striated portion is generally a little convex, but the degree varies great7y. I have even seen in an Asterias polaris (M. T.) donated by the Museum of Copenhagen, the striated portion slightly concave, while the smooth peripheral portion itself made a kind of pad. Another individual of the same species and origin had, in contrast, a regularly convex plate. One sees thus another occasion where it is necessary not to attach too much importance to the characters of the plate. The striations that it shows quite resemble the folds of a meadrine. While the folds radiate from the center as a general direction, there is not at all a single point of convergence. The width of the grooves and spacing are rather variable.

For most of the species of Asterias there is only a single madreporite plate whatever the number of arms. There are nevertheless some species that can have a variable number. These are Asterias tenuispina, A. calamaria, and A. polyplax. These numerous plates occur, as Perrier noted, in the species in which a large number of arms, often as many as half of the body, are obviously in the process of regeneration in most animals. They produce very complex arrangements that are described in his work.

(1) See fig. 5, 12, and 14, pl. V. (2) Loc. cit., p. 95. 
We have said above that these multiple plates are simple in Asterias and never show the aspect that one sees in Heliaster. I shall not come back to this.

Al1 species of the genus Asterias have rather fragile arms, and enjoy the property of being able to repair broken arms. They form on the surface of the rupture a sort of bud that elongates rather rapidly. The bud is single in most cases. However, some cases in which it is bifurcated have been noted (1).

If this bifurcation takes place on a broken arm at some distance from the center, there is the singular appearance of a simple arm at the base that divides into two branches like a $Y$. Unfortunately, it has not occurred to any who have reported these facts to look at the skeleton at the point of bifurcation. It would be curious to know the constitution of the spur that develops in the angle of bifurcation.

If a similar phenomenon of doubling is produced on an arm broken at the edge of the disc, it will be certain that it will appear to have two arms in place of one. I would not say however, with Giard, that one must explain by a similar division the numerous cases of hexametry where, apart from the increase in number of rays, one notes nothing abnormal in the makeup of the asteroid. I am persuaded that a similar accident should always be visible at the mouth, because for it to be otherwise would require a new pair of teeth and ambulacral ossicles, and a new odontophore as well, to be intercalated between the already-existing ambulacral ossicles. This hypothesis seems improbable to me. I believe that in the case, which must be rarer than Giard thinks, where a similar phenonenon of bifurcation is produced at the edge of the disc, the ambulacral grooves of each of the halves originating from this doubling must join into a single one at the point where the disc remains intact.

\section{GENUS ANASTERIAS (PERRIER).}

1875. Anasterias, Perrier, Révision des Stellérides du Museum, p. 81.

This genus, created by Perrier, contains only a single species, Anasterias minuta, of which a single specimen without indication of origin exists at the Museum of Paris. That is to say it has not been possible for ome to make a complete examination of the skeleton, which is particularly interesting in that the ossicles of the aboral surface seem to be missing. The animal seems completely soft to the touch. However, one is able to demonstrate rows of marginal plates on each side of the ambulacral system. The arms are short and obtuse. The animal is stout to the point of recalling Asterina gibbosa except, however, that the interbrachial angles are sharp and not rounded as in Asterina. The small circular madreporite plate is marked by a very small number of irregular, short, and wide grooves. It is located nearly halfway from the edge to the center of the disc.

(1) D. ROBERTSON, P.N.H. Soc. Glasgow, I, p. 41. See also the note, cited above, of Giard. 


\section{GENUS STICHASTER (MULLER AND TROSCHEL)}

1840. Stichaster, Müller and Troschel, Monatsberict der Berliner Wissenschaft 7 . Akademie.

1842. Asteracanthion (pars), Müller and Trosche1, System der Asteriden.

1861. Stephanasterias and Coelasterias (1872), Verri11.

1865. Tonia, Gray, Synopsis, p. 2.

1875. Stichaster, Perrier, Révision des Stellérides, p. 82.

This genus was first created by Müller and Troschel, who abandoned it Tater. Gray made it his genus Tonia, which several authors adopted. Perrier himself restored its first name, in emphasizing the arrangement of imbricated plates of the skeleton which separate it from the genus Asterias.

The Museum had only four species of Stichaster in 1875. The most common of all, Stichaster aurantiacus from the coasts of chile, served me as a subject.

The arrangement of the ambulacral system is the same as in the genus Asterias the entire length of the arms and the pores alternate very regularly (1). The rest of the ventral surface is constituted of two parallel rows of ossicles closely applied to each other to form a sort of pavement. The row that touches the adambulacral series has smaller pieces. Beyond the second are two series of elongated plates arranged vertically (2) which give the arm an elevated form. The dorsal portion of the skeleton is constituted by another series of regularly imbricated pieces. Each of them covers its neighbor of the series on the central side of the animal, and its neighbor on the external side in relation to the arms (3).

Finally, the middle is occupied by a line of equally imbricated plates from the end of the arm to its base and covering the pieces of the two neighboring series like tiles on the ridge of a roof.

This median line extends up to the end of the arm where it meets the two lateral lines of elevated pieces, all of the intermediates having successively disappeared.

We thus have here, as can be seen at first glance, an arrangement very different from that of Asterias. In place of the wide mesh that circumscribes very extensive poriferous areas, we find in Stichaster only narrow passages limited by the four neighboring pieces.

The regular series cease at the base of the arms. The first plates of the median series are enlarged and of irregular form. As for the lateral rows, they seem to lean against those of the adjacent rays in the interradial angles that are always narrow. The entire surface of the disc is formed of irregular pieces that keep only a vague imbrication of the edges towards the center. The center is occupied by a large, very irregular pentagonal plate in which the central disc of Loven is easily recognizable. We have seen its much more regular form in Asterias glacialis (4). The parabasal pieces, which are found also, are not very distinctive except the one with the madreporite plate that has many kinds of digitations. This piece is grooved as in Asterias and the madreporite plate has an appearance quite 7 ike that found in this genus.

A11 the pieces that constitute the dorsal skeleton are a little thick,

(1) See pl. VI, fig. 2. (2) See pl. VI, fig. 3. (3) Id., fig. 1 and 3. (4) See pl. V, fig. 1 . 
slightly convex, and rather clearly shaped at the edge.

The interbrachial partition is constituted as in Asterias. It has however a little less extensive development, corresponding to the dimensions of the interbrachial area (1).

Figures 1, 2, and 3 (p1. VI) are uniformly magnified by $3 / 2$. Figure 13 (p1. V) represents a pair of teeth with the ambulacral pieces of one side with a magnification of five times. The teeth, in the same way as $I$ have already said, do not furnish in ASTERIADAE information as important as in the adambulacral type. However we can note here that the tooth is proportionally a little more elongated, and especially that the first ambulacral piece is much shorter in the direction of the length of the arm than in the direction of its width. It is impossible to confuse it with a similar piece of Asterias or Pycnopodia.

As for the odontophore, which is represented (2) magnified five times and in the three positions indicated above, it can be noted that it has a form intermediate between those of figures 5 and 14. The two inclined planes form between them (in c) a sharper angle than that of Asterias, but more open than that of Pycnopodia. They do not unite on the median line. The oral surface does not have the deep indentations that one sees in Asterias, but a simple groove. Finally, the inclined planes do not occupy the entire height of the piece as in Pycnopodia.

In the specimen examined, and for which I have judged it not useful to represent the entire length of an arm, $R=60 \mathrm{~mm}, r=15 \mathrm{~mm}, \mathrm{R} / r=4$. There are ordinarily only five arms in the species of the genus stichaster. However, Stichaster australis can have up to eleven. Verrill (3) believed it necessary to make it the type of a new genus to which he gave the name Coelasterias. But, except for the number of arms, Perrier found it scarcely different from Stichaster aurantiacus. He noted correctly that the number of arms can hardly serve to distinguish genera, especially in a family where it is subject to great variation in the same genus.

\section{GENUS CALVASTERIAS (PERRIER).}

1875. Calvasterias, Perrier, Révision des Stellérides du Museum, p. 84.

This small genus that Perrier created for a single species, Calvasterias asterinoides, dates from the same time as the genus Anasterias.

Calvasterias al so has the form of Asterina. However, its four rows of tube feet and its non-rounded interbrachial angles distinguish it from them. The regular imbrication of the pieces of its skeleton is arranged like that of Stichaster. However, the pieces leave between them poriferal areas much wider than those that one finds in this last genus.

The small, round madreporite plate is marked with wide radiating grooves that are sinuous, few, and separated by thin ribs.

This animal has straight pedicellariae and not crossed ones.

One of the specimens is labeled Torres Straits. The others have no indication of origin.

It is necessary to see, for more details, the work of Perrier. As for me, I have not been able to study this curious species.

(1) P1. VI, fig. 2. (2) P1. V, fig. 14. (3) Trans. of Connecticut Acad. of Arts and Sciences, $\mathrm{V}$. I. 


\section{GENUS PYCNOPODIA (STIMPSON)}

1861. Pycnopodia, Stimpson, Proceed. of Boston Society of Natural History, v. VIII, p. 261.

1875. Pycnopodia, Perrier, Révision des Stellérides, p. 89.

This genus was created in 1861 by Stimpson for the Asterias helianthoides of Brandt. It contains only a single species that lives in great abundance on the coasts of California. It is represented in the Museum of Paris only by two dried specimens. I have thus not been able to make a complete separation of the skeleton and to give a general figure of it. I have however examined with care the two specimens, and took two pairs of teeth of one of them in order to assure myself of the exact place of this genus that has been given such diverse relations.

Stimpson said this species has up to six or eight irregular rows of tube feet near the base of the arms. If he wanted to say by that that the tube feet are no longer arranged in four regular 1 ines, he is incontestably right. But here, as in al1 ASTERIADAE, the rows of pores, instead of increasing in number, decrease by the disappearance of the two external rows of these orifices in approaching the mouth.

The skeleton of Pycnopodia can be easily conceived by imagining an Asterias with numerous and very confluent arms, with the solid reticulation of the back reduced to several pieces scattered here and there or circumscribing an irregular mesh, and with the irregular interbrachial partitions no longer formed by a simple membrane in which a line of ossicles leaves the inferior part to lie on the odontophore. Beside this adambulacral series is a double row of oval, imbricated spiny plates to which attaches the skin that forms the entire dorsal surface. As for the ambulacral systems, they show no obvious difference, save that the first ambulacral pieces of each arm form between them a narrower angle, and are shortened in the transverse direction, after the mouth, in order to a110w place for the numerous arms that converge to form this orifice.

The teeth shown in figure 11 (pl. V) magnified three times, do not differ, so to speak, from those of Asterias. But the first ambulacral piece is much larger in the longitudinal direction of the arm than in the transverse direction, and makes a very strong projection into the mouth. This figure shows that a single row of ambulacral pores no longer exists.

The odontophore, represented in fig. 12 enlarged three times and always in the position indicated above, has a general form that also very clearly shows the affinities of this genus. It is nevertheless easy to distinguish from an Asterias. The inclined lateral planes take up the entire height of the piece, making a narrow angle between them, and do not meet on the lateral line. The oral face of the piece is marked by a deep groove, as in the odontophore of Stichaster, but not a true notch as in Asterias.

The madreporite plate is single and simple, as can be seen well in the figure given by Agassiz (1). The confluence of the arms is rather variable, but scarcely extends beyond half their length.

Agassiz devoted one of the plates in his work as well as two diagrams in the text to Pycnopodia helianthoides.

Neither the figures, which one can reproach only for not indicating

(1) Loc. cit., pl. XIII. 
adequately the structure of the mouth, nor the description that is done with care, allow at all anticipating the conclusions the author drew from examining this species.

"In Pycnopodia the opening at the end of the large ambulacral plate near the actinosome is best seen in profile; it differs in no way from the structure of the corresponding plates in Asteracanthion, though apparently on first examination, the actinal* plates forming the actinal ring seem quite peculiar, owing to the disappearance near the mouth of the interbrachial membrane, and the isolation of the interbrachial partition; this connects the actinal and abactinal reticulated surfaces by a mere fiber only. "This is perfectly exact, but he added an error: "The large plate at the actinal ring, forming the base of the interbrachial partition, is entirely disconnected* from the interambulacral system, as can easily be seen by an examination of the actinal extremity of the arm from the inside of the actinal ring, showing the plate rising upon the side of the two large ambulacral plates of the actinal ring." In reality, here as in a11 the ASTERIADAE, the odontophore affects a connection only with the teeth, i.e., the adambulacral series, and never lies on the plates of the ambulacral system as Agassiz believed.

In summarizing the general characters of the family ASTERIADAE, we see that in the genera that compose it that the teeth are nearly as long as wide; the odontophore, a wide, massive piece, is single; and finally, the madreporite plate, or plates when several of them exist, are equally single. Wherever there exists a dorsal skeleton, it is very clearly imbricated.

\section{FAMILY II. HELIASTERIDE.}

This family contains, for the moment, only the genus Heliaster that Gray formed in 1840 at the expense of Asterias.

The very great coalescence of the arms, which are separated by a true interbrachial mesh, their very considerable number, and particularly the multiplicity of pieces that form the madreporite, and the quite special form of the odontophore seem to justify to me an absolute separation of this genus from all those that we have studied up to here.

GENUS HELIASTER (GRAY)

1840. Heliaster, Gray, Annals and Mag. of Natural History, v. VI.

1875. Heliaster, Perrier, Révision des Stellérides, p. 87.

This genus is represented in the Museum of Paris by four species.

My studies have been done on three of them: Heliaster helianthus, $H$. kubinijii, and $H$. microbranchia. The latter species has furnished most of the figures that I give.

The specimen whose portions are represented in natural size (1) came from Acapulco. It was given by the Museum of Cambridge that Agassiz directs. It has no less than forty arms, as can be confirmed by looking at the mouth.

The arms are fused nearly their entire length, forming thus a disc, thick and convex above, on which one still distinguishes, to a certain extent, the lines separating the arms.

On the dorsal surface of each of the arms two marginal series of
(1) See p1. VI, fig. 4 and 5.
* Italics by Viguier. JL. 
imbricated plates from the end of the arm to the center are seen very clearly. Two series of weaker and yet distinct pieces are obvious within the first, to which they are parallel. Finally, in the most enlarged part of the arm, a barely distinct fifth series takes the median position. Each of the plates that make part of these rows has a spine, while the irregular pieces that grow between them and form, in joining them, a solid reticulum are absolutely smooth. Between the marginal series of two rays, the entire length where they can still be distinguished although united, there is a 1 ine lacking ossicles that clearly separates them and corresponds to the interbrachial wall.

Towards the center of the disc, the reticulation becomes very irregular. The pieces that form it are of a larger size. Finally, beside the anus an are found some pieces, the largest of the skeleton, that can be made homologous to the central disc of Lovén. The ocular plate oc is nearly globular as in Asterias (1).

The ventral surface is nearly formed by the ambulacral series. They have the same arrangement as in the ASTERIADAE, and the angle of the opening of the ambulacral groove scarcely varies from its origin to its extremity.

The adambulacral series of each side lean against those on the contiguous arms. For more than a third of the way from the mouth, they form the only separation between two adjacent ambulacral grooves. Further on, there are added successively two rows of marginal plates that project into the interbrachial angle and form a very narrow angle.

The oral surface of Heliaster is not flat at a17. All of the rays are inflected towards the dorsal face in approaching the mouth, which thus is at the bottom of a kind of funnel. As a result of this arrangement, however convex the disc, the cavity of the rays varies considerably from the mouth to the end.

The buccal circle is fortified by such a development of the skeleton that one can scarcely see the opening of the rays from the mouth (2). A little further from the center, this cavity, always very narrow, is somewhat raised. The two sides of the animal then come together and the rays decrease in thickness while their width increases. Finally, at the part where they become free, they rapidly become narrower and end in an obtuse part.

Figures 6,7 , and 8 ( $p 1$. VI) represent three sections, at three different points, at a magnification of two times.

The interbrachial wall i, thick at first, decreases rapidly in approaching the mouth (figs. 6 and 7 ). It is always composed of a double layer of more or less thin ossicles. This justifies again our manner of viewing the interbrachial partition, in the first subclass, as not forming an independent system but being constituted by a coalescence of the walls of adjacent arms that lean against each other. This is the reason the interbrachial angles are always narrow in our first subclass, and never rounded on top as in the asteroids of the adambulacral type.

This character, so easy to verify, distinguishes at first glance the ASTERIADAE with the form of Asterina from animals that actually belong to this latter genus.

In Heliaster, as in Pycnopodia, the arms are restrained 1 argely because of their very number in approaching the mouth. Also the ambulacral pieces themselves are shorter, and we no longer find at this level only two rows

(1) P1. VI, fig. 5. P1. VI, fig. 9. 
of pores.

Figure 10 ( $\mathrm{pl}$. VI) represents teeth magnified ten times. As can be seen, these teeth $d$ are here greatly elongated compared to their thickness, and thus differ much from those that we have seen in the ASTERIADAE strictly speaking (1).

The first ambulacral piece is also greatly elongated in the longitudinal direction, and forms a rather large projection into the mouth cavity (2).

However, beneath the mouth of the intact animal (fig. 5), the teeth appear to project into the circle. However, this appearance is due to the inclination of the series around the mouth, an inclination that makes the first pieces nearly vertical (3).

The odontophore (fig. 11), magnified eight times and in the same position as those of the ASTERIADAE, has undergone in the Heliaster type a very important modification, in harmony with the sole role that it can play here, that of consolidating the oral circle.

In the specimen represented (fig. 5), there are no less than two hundred and five pieces that form the circle, if one counts the odontophores. It is easy to understand that the odontophores must be very small here, and would have difficulty in maintaining a sufficient rigidity if they were to conserve the ordinary form.

We also see a larger piece fused to them posteriorly. One can consider it as making part of the interbrachial wall in which it is inserted. The coalescence of the two pieces is never very complete because one cannot distinguish clearly on the oral face of the ensemble that which appears properly to be the odontophore. Nevertheless, we see the inclined planes of the latter continuing on all of the inferior face of the piece to which it is fused, as well as the pits that serve for the insertion of the ligament of which we spoke above and which fastens the teeth of the odontophore. However, it is no longer only the teeth, but also the first adambulacral pieces following, that are fixed in the same manner. One sees then how a parallel arrangement increases the resistance of so complicated a system.

This remarkable modification of the odontophore of Heliaster microbrachia occurs in all species of Heliaster. I have represented (4), magnified four times, that of Heliaster helianthus.

This piece, whose larger dimensions make it easier to examine than the odontophore of Helianthus microbrachia, is shorter and proportionally wider than its height. In addition, the laterally inclined planes occupy nearly the entire height of the piece.

As for the odontophore of Heliaster kubiniji, it differs little from that of Heliaster microbrachia.

The general constitution of the skeleton is also so similar in the various Heliaster that I am completely of the opinion of Perrier who placed in doubt the real number of species in the genus. When one thinks, he said, of the extreme variability in Helister, with their very restricted distribution between the Galapagos Islands, the Juan-Fernandez Islands, and the west coast of South America, with the slight differences that have been invoked in order to distinguish several species, one wonders if these distinctions are quite valid and if in reality these species are not simple varieties.

(1) PI. V, fig. 10, 11, and 13. (2) P7. VI, fig. 9 and 10. (3) PI. VI, fig. 9, d. (4) P1. VI, fig. 12. 
Heliaster microbrachiata, whose skeleton we just described in detail, is the form that shows most clearly the relative width of its disc and the small free part of the arms.

In Heliaster kubiniji and especially in Heliaster helianthus, the arms are free over a great distance. These two species are closely related. As for Heliaster canopus of Valenciennes, this is perhaps, according to Perrier, only a juvenile Heliaster helianthus.

In $a 11$ of these animals, the number of arms varies between about thirty and forty. The madreporite plate, always single in the specimens I have examined, was always composed of a variable number of pieces, sometimes six or seven, of very different size and form.

The various pieces are very exactly juxtaposed, and constitute an irregular assemblage with an embossed surface, but usually slightly convex as a whole (1). They are grooved, and their cavities communicate among themselves and with the hydropore canal by orifices situated below towards their angle of contact. The grooves of their upper face greatly resemble those seen in the ASTERIADAE. They converge a little towards the center of the ensemble but without regularity.

The madreporite is always situated exactly on the extension of the line that separates two arms. The hydropore canal, which has a very large size here, descends to the pair of corresponding teeth, taking the same relation as in all of the other asteroids (2).

I have already cited above this example of a single hydropore canal leaving from a plate composed of six or seven pieces, in regard to the fact reported by Giard, where two distinct canals leave from a plate formed of two parts. Now I do not have to return to this subject.

Considering the various characters that differentiate Heliaster from all of the other genera of the family ASTERIADAE: 1, the very 7 arge number of arms, many more than in Pycnopodia; 2, their extensive coalescence; 3 , their separation by very strong, veritable ramparts; 4 , the situation of the mouth at the bottom of a sort of funne1; 5 , the fragmentation of the madreporite plate; 6, finally and especially the particular and so remarkable form of the odontophore, I hope that one recognizes with me the incorrectness of this proposition of Lütken (3): "Leptasterias and Coscinasterias of Verrill, Stichaster of Müller and Troschel, Uniophora, Margaraster, and Heliaster of Gray should rather be regarded as sections of the genus Asterias than as separate genera. Pycnopodia of Stimpson is most distinct."

Pycnopodia scarcely varies, as we have seen, in the constitution of the mouth from other ASTERIADAE. Its odontophore is exactly the same type, and a) though it has enough other peculiarities to form a distinct genus, it should evidently stay in the same family.

Is it the same with Heliaster? I do not believe so, and I think that the motifs shown above will determine the adoption of a new family that naturally takes the name HELIASTERIDAE.

\section{FAMILY III. BRISINGIDAE.}

As this family is not represented in the Museum of Paris, and as G.-0. Sars has not even responded to the letter that Perrier has sent him asking

(1) PI. VI, fig. 4, m. (2) PI. VI, fig. 9, ch. (3) Videnskabetige Meddele7ser, 1871 . 
for specimens of the species of the genus Brisinga I have not been able consequently to make any kind of study of these curious animals. I believe it will be good to indicate here the principal features of their skeleton according to the memoir of Sars.

of all of the descriptions I give in the course of this work, this alone is not based on my own research. If I decided to introduce it here, it is to contrast it with that which has just been given and thus make more complete the whole of this work.

It is not at all, moreover, a summary of Sars' work but an evaluation, with the aid of the understanding we have acquired of the mouth of ambulacral asteroids, especially of the HELIASTERIDAE, of the numerous facts in the text and in the plates of the son of the illustrious Norwegian zoologist. We are going to see that, thanks to this understanding, we can account very easily for the bizarre appearance of Brisinga.

\section{GENUS BRISINGA (SARS)}

I shall not emphasize here the calcareous arcs that form the dorsal skeleton of the arms of Brisinga. Sars has shown very well that despite their singular appearance, they belong to the same category of pieces one finds in the skin of the disc. There really is nothing here different from that seen in other asteroids. I shall thus go on to the ambulacral system.

The principal modification consists of a very great development of the pieces of this system in the longitudinal direction of the arms. The great thickness they have acquired permits the ampullae to stretch out freely on their ventral surface. The doubling of the line of ambulacral pores, which was necessary in the other animals of this type in order to permit free play of the tube feet, is no longer necessary in Brisinga. Thus we find the pores disposed only in two rows instead of four.

The adambulacral pieces are cylindrical and elongated in the longitudinal direction of the arm in order to respond to the development of the ambulacral pieces. Each borders, with two of the latter, a large rounded pore. This arrangement, as Sars emphasized, is really nothing special. We usually see, in fact, an ambulacral piece correspond on its lower ridge to the line separating two adambulacral pieces, and connect to both of them by the vertical muscle of which we have spoken. Only the very variable and sometimes very great inclination of the adambulacral pieces often masks this arrangement. The faces of the adambulacral pieces in Brisinga are very oblique, and the space that separates two adjacent pieces in the same series is going to increase from the base of the arm towards its end. This arrangement evidently permits the ventral coiling of the arm and its deviation in a horizontal plane within very narrow limits, especially towards the extremity of the arm. In contrast, the dorsal coiling of the arm should be nearly absent because of the surfaces of the nearly vertical articulation of the ambulacral pieces of two adjacent pairs and their slight spacing.

The buccal ring, which seemed to Sars to have a constitution so peculiar but in which he nevertheless saw rightly only the continuation of the series that form the skeleton of the arm, resembles absolutely that which we have seen in Heliaster.

A simple glance at the plates of Sars is enough to be convinced that the form of the teeth and of the first ambulacral pieces are absolutely that always found in our ambulacral type. 
As for the odontophore, it certainly has undergone a modification similar to that in Heliaster, although the edges of the fused pieces are not seen clearly in the figures of Sars. This is because its form is not that of a simple odontophore. It is no longer the teeth, as in the ASTERIADAE, but also the following adambulacral pairs, as in Heliaster, that are fastened to its inferior face. The buccal ring also forms a solid unit, although it contains no less than ninety distinct pieces in an animal with ten arms. Sars counted one hundred and thirty, himself, but his twenty parietal plates are only parts projecting into the mouth from the first ambulacral pieces.

As for the twenty marginal plates of this author, they really do not make part of the buccal ring. If these plates are considered to rest on the odontophores, they must be considered to correspond to the interbrachial partitions we see in Heliaster.

These interbrachial walls are, as we saw in the latter type, also composed of a double layer of ossicles that connect the dorsal and ventral surfaces of the animal. In Brisinga, the skeleton exists in reality only on the ventral surface. The interbrachial pieces thus no longer need to reach the back, which would offer them only an insignificant support, and their connections are almost exclusively with the adambulacral series. In addition, for the same reason of the extreme separation of the arms, the two plates of this interbrachial partition, or rather the two pieces that represent them, separate immediately, al though being supported meanwhile on the odontophore. It is evident, as sars said, that this remarkable arrangement has as a goal the more solid fastening of the arms to the center of the animal. It is moreover a function that we always see filled by the interbrachial systems.

The madreporite plate is single in Brisinga, and situated as in the other asteroids. The ocular plate has a remarkable development, on which I have nothing at a11 to emphasize here. As for that which Sars has drawn of the mouth musculature, we see that it corresponds exactly to that which we have described in Asterias. It would not have to be different, however, seeing the constitution of the buccal ring.

Thus it is seen, as we have said, that the BRISINGIDAE are near the ASTERIADAE, while the HELIASTERIDAE, in spite of their being so different in appearance from Brisinga, reall1y establish a transition between the two types.

Agassiz who, luckier than the Museum of Paris, has been able to have some specimens of Brisinga, and has devoted to them an article in his last work. He did not give, however, any other information than that of Sars, but considered the type as establishing in a perfect manner the homology of the skeleton of asteroids with that of ophiuroids. As for me, I shall imitate on this point the reserve of Lyman who has studied the ophiuroids, and whose objections I recalled above.

\section{GENERA LABIDIASTER (LUTKEN) AND PEDICELLASTER (SARS).}

These very rare animals have not been examined sufficiently for there to be a complete idea of their skeleton. Unfortunately, I have not been able to establish with certainty their relationship as they are not represented in the Museum of Paris. However, considering that Labidiaster has straight and crossed pedicellariae, which have been encountered only in the animals, Brisinga included, quite evidently part of our first sub-class, and biserial 
tube feet, it is very probable that they should be placed in the family BRISINGIDAE. Their numerous arms, thirty or more according to Lütken, and the characters of their dorsal skeleton will make them perhaps intermediaries between Heliaster and Brisinga. However, they are evidently much closer to the latter because of the biserial arrangement of their tube feet. As for Pedicellaster, their five arms and the absence of straight pedicellariae differentiate them evidently from other types but I can give no other information about them.

\section{SECOND SUB-CLASS}

\section{AMBULACRAL ASTEROIDS}

Our second sub-class corresponds exactly to the second division of Perrier. For us, it currently includes seven families. He recognized only six. This difference comes from our being led to make the genus Archaster the type of a distinct family that has at least as much affinity with GONIASTERIDAE as with the ASTROPECTINIDAE of which it made a part until now.

It has seemed necessary to me, likewise, to establish large sections in the families ECHINASTERIDAE and GONIASTERIDAE. However, as the animals that belong to each of these two families have more in common between them than one family to another, I have limited myself, for the moment, to distinguish tribes that one can, if desired, consider as families as I did myself in a note to the Academy of Sciences (1). I have thus recognized four very distinct tribes in the ECHINASTERIDAE. These are: ECHINASTERINAE, MITHRODINAE, VALVASTERINAE, and GONIASTERINAE.

The first family corresponds here to the limits recognized by Perrier. However, the second includes in addition the genera Fromia, Ferdina, and very probably Metradira that made part of his Linckia. I have included in the ASTERINIDAE the genera Porania, Asteropsis, and Dermasterias that he $1 \mathrm{eft}$ in the GONIASTERIDAE.

The LINCKIADAE are separated from the three genera cited above and increased by the genus Chaetaster that made part of his ASTROPECTINIDAE. It will be necessary without doubt to establish sections in this family. However, I have not, for the moment, enough understanding to do this work in a useful fashion, not even for the ASTERINIDAE.

I have not been able to study the PTERASTERIDAE, which seem to me, however, to be positioned between the ASTERINIDAE and the ASTROPECTINIDAE (type Ctenodiscus). The type ctenodiscus, very distinct from Luidia and Astropecten with which I leave it, should perhaps be separated more al though it has many characteristics in common with them. I have already said that I include Chaestaster in the LINCKIADAE, and that I create for Archaster a family ARCHASTERIDAE.

In summary, the two sub-classes include seven families: ECHINASTERIDAE (four tribes); LINCKIADAE; GONIASTERIDAE (two tribes); ASTERINIDAE; PTERASTERIDAE; ASTROPECTINIDAE; ARCHASTERIDAE.

Throughout the descriptions, as in those that have preceded, the same letters always indicate the same object in all of the figures. However, as the form of the odontophore is more complicated, it has seemed better to me

(1) Comptes rendus, 11 March 1878 . 
to give four views for each. These views are always the same and have the same sign representing the piece seen: from the oral side, with the number alone; from the inferior face, with the sign'; from the superior face with the sign', ; finally, from a lateral view with the inferior face turned to the left and the oral face above, with the sign',". The comparison will be very easy.

\section{FAMILY IV. ECHINASTERIDAE.}

The distinctive characters for the family ECHINASTERIDAE were, for Perrier: 1, skeleton formed of a network of elongated ossicles allowing between them a mesh as large as the ossicles constituting the network. The ossicles also carry more or less elongated spines; 2 , arms ordinarily very elongated in a conical or cylindrical form; 3 , forcipulate pedicellariae, when they exist. A single genus with valvate pedicellariae.

This last genus was created in 1875 by Perrier for Asterias striata of Lamarck, which Müller and Troschel had placed in their genus Asteracanthion.

The name Valvaster, which it bears today, is due to the presence along the length of the edges of the arms of a row of large valvate pedicellariae. These no more exist in the ASTERIADAE than in the other ECHINASTERIDAE. As I have judged it necessary to assure myself of the position of this genus, I have been led to make it the type of tribe in which it is alone for the moment. It certainly will be the first to be separated from the others in order to make a distinct family as far as I can tell from the incomplete study of the single specimen known.

Asterias echinites of Lamarck, which Müller and Troschel counted in 1840 as an Echinaster, received at the same time the same name from Gray. He placed the other Echinaster of Müller and Troschel in various genera: othilia, Rhopia, etc. The sense given to this name of Echinaster has not been accepted. Paul Gervais replaced it in 1841 by that of Acanthaster. Müller and Troschel proposed in 1844 the name of Echinites. However, as Perrier noted, there is no reason to prefer the latter name to the older one given by Germais and which had, moreover, been recognized.

The genus Acanthaster is closely related to the Solaster of Forbes and hereafter will form with it a tribe that takes the name SOLASTERINAE from the oldest named type. The name Solaster in fact dates from 1838.

The form and the dimensions of the teeth and of the odontophore, the arrangement of the interbrachial systems, and finally even the form of the ossicles of the back clearly distinguish this tribe from the three others.

As for Mithrodia clavigata, which was formerly ophidiaster echinulatus of Müller and Troschel, it has indeed, as we see it, a number of characteristics that bring it near ophidiaster. Its affinities are completely with ECHINASTERINAE as Perrier thought. However, I believe that it is still necessary to accentuate the distinction that he made in conserving the genus Mithrodia and creating for this genus the tribe MITHRODINAE, which will be the most closely related to the EHINASTERINAE.

This last tribe includes only two genera: Echinaster and Cribella that are extremely close. However, the difference in arrangement of the dorsal spines justifies completely the separation of the animals of this tribe into two genera.

The general imbrication of their skeleton, and especially the very great simplicity of the odontophore, designates them certainly as the nearest 
relations of the ambulacral asteroids.

Whatever be, however, the simplicity of the odontophore, it belongs certainly to the second type. The articular apophyses do not exist here at a11. However, we demonstrate in all of the various genera 211 states of development of the apophyses, and their absence cannot make an odontophore of the second type an odontophore of the first. The position is, moreover, different. The inferior face of the piece, which is always horizontal in the first class, is always turned obliquely to the side of the mouth in the second.

In addition, the teeth, although rather greatly truncated, are not different from those one sees in the second type, no more than the first ambulacral piece. The plane is exactly the same, only the dimensions are much less. Also, the teeth do not have to have very great movements, and the apophyses of the odontophore are no Tonger necessary here.

one does not find spicules in the tube feet of ECHINASTERIDAE except in Valvaster.

\section{TRIBE 1. ECHINASTERINAE。}

\section{GENUS ECHINASTER (M. AND T.).}

1834. STELLONIA (pars), Nardo, Isis, p. 715.

1835. STELLONIA (pars), Agassiz, Prodrome d'une Monogr. des Rad. (Soc. Neufch.), p. 191.

1840. Echinaster, Müller and Trosche1, Wiegmann's Archiv.

1840. Othilia and Rhopia, Gray, Ann. of Nat. Hist., v. VI, p. 281.

1875. Echinaster, Perrier, Révision, etc.

The Museum has eleven species of Echinaster. The most common of all, Echinaster sepositus, found in very great abundance at Roscoff, has served for this study.

Figure 1 (p1. VII) represents at natural size a well-developed individual. Figure 2 represents an arm of the same, seen from below.

The arms, large at base, are smaller at the top in a fashion being almost conical, scarcely flattened below the level of the ambulacral groove. The entire frame of the back is formed of small imbricated ossicles. Each ossicle carries a single spine that rests on a small hemispherical mamelon at the center of which is the fosette. The ligament that is attached to the spine inserts here. Some of the pieces can be smooth. However, this is quite the exception, and these smooth pieces are not arranged differently than the others. All of these ossicles frame an irregular mesh, large towards the center of the back and on top of the arms, and diminishing gradually in dimensions towards the interbrachial angles, the ventral surface, and especially towards the ends of the arms. Figure 7 (pl. VII) represents part of this network magnified four times. The thickness of the ossicles is very small, and the entire framework of the body of an extreme lightness. There are no marginal plates. However, in approaching the adambulacral series, the small elongated ossicles of the back become very large, close to each other, and finish by forming veritable rows of scales that are imbricated from the tip of the arm to its base. Between the scales are isolated pores.

The small thickness of these ventral plates give only insufficient 
support to the underlying ambulacrals. Thus I was surprised to see them mentioned in Echinaster by Gaudry (1). I have examined this question again attentively. I have assured myself that they really do not exist, no more than in any other genus of the family ECHINASTERIDAE. Gaudry, who moreover has not given a figure on this subject, has without doubt been led into error by the form of the ambulacral pieces.

The scales of the ventral surface carry small spiniferous mamelons, like the pieces of the back. Some even have two. They cover to a rather great extent the adambulacral plates. They are narrow, elongated, regularly rounded below (their form is seen is seen we 17 in figure 7 ad), and rather spread out. The intervals that separate them are nearly equal to the thickness of the plates. In recalling the general notions we have expounded above, it is seen this distribution agrees with the constitution of the dorsal network and the absence of the marginal plates in order to give the arms extreme mobility. Echinaster can in fact twist its arms in all directions.

The ambulacral pieces are tall and strong, and their top reaches nearly to the dorsal surface (fig. 4). These are the ambulacral and adambulacral series that maintain the form of the arms here, the light reticulation of the general skeleton being incapable of filling this role.

The interbrachial system in Echinaster is composed of some very large pieces. They are located near the angle of the junction of the two sides of the animal, but they do not extend to the top of this angle. As this interbrachial partition does not extend very close to the the center of the back and does not rest on the odontophore, the separation of the two sides of the animal can vary considerably.

The mouth is very small in Echinaster. The rays are always nearly closed and the teeth touch when the mouth is nearly closed.

I have not given the lateral view of the teeth of Echinaster. A very exact idea of them can be had from looking at those of Cribella (fig. 14). It is similarly noted that these teeth make a very small projection into the interior of the mouth, and that they are not very thick. As to their form, figure 6, which represents them from below and magnified five times, demonstrates that they are very strongly truncated on the wide of the mouth. However, it is only necessary to go back to the preceding plates to see how this tooth differs from the animals studied up to here.

The odontophore, shown in figure 5 enlarged eight times, is nearly cordiform with a very marked angle. Seen from the dorsal face, it has nearly the form of an isosceles triangle with very rounded angles. The unpaired side would be on the side of the mouth. This dorsal face is smooth, rounded, and almost formed from the two halves that meet on the dorsal line, making a very obtuse angle. The ventral face is elevated, and has two fosettes that recall slightly that found on the odontophore of the ASTERIADAE. animal.

The dimensions of this piece are very small compared to the size of the

The ocular plate is rounded, and has nothing of note. The anus, nearly central, is surrounded by small, rounded ossicles (2). The madreporite plate, small and nearly circular, is located about halfway to the center of the back of an interbrachial angle. This is no longer a large grooved piece, but a simple plate supported by adjacent ossicles. The grooves are irregular, wide, few, and rather isolated.

(1) Loc. cit., p. 29. (2) PI. VII, fig. 1, an. 
There is only one madreporite plate in individuals of five arms that are the vast majority in the genus Echinaster. However, some specimens of Echinaster eridanellal from the Indian Ocean can have six or seven arms and then have two plates.

Agassiz devoted a plate of his memoir to Echinaster sentus from the Caribbean Sea and Florida. As much as can be judged from the figures and the description that accompanies it, this animal does not differ in its constitution of its skeleton from those we have just studied. It is necessary to note, however, that the spines of the back have a stronger aspect, and seem to meet at the junctions of the network instead of being arranged on each of the ossicles that form this reticulation. The interbrachial system seems to have escaped Agassiz.

There are no pedicellariae in Echinaster.

\section{GENUS CRIBRELLA AGASSIZ (PARS)}

1835. Cribella, Agassiz (pars). Prodrome, etc., Soc. Neufchâtel. v. I, p. 191, non synonyme de Linckia, Nardo.

1840. Henricia, Gray, Ann. Nat. Hist., VI, p. 281.

1841. Cribella, Forbes, British Starfishes. p.22.

1842. Echinaster, Müller and Troschel (pars), System der Asteriden,

1862. Cribella, Dujardin and Hupé, Echinodermes, p. 345.

1875. Cribella, Perrier, Révision.

This genus contains only two well-defined species. However, it is probable several others will be distinguished in the future, as the animals of very diverse origins (the coasts of France, Green1and, Sonde Islands) that have been attributed to Cribella oculala do not seem in reality to belong to a single species.

The specimen of Cribella oculata I studied anatomically came from Roscoff. This smal1, bright pink animal occurs there in great abundance. It and the large, deep purple Echinaster sepositus ornament the laboratory aquarium. It is necessary to use the dredge to obtain it as they do not live in the areas uncovered by low tide.

Figures 8 and 9 (p). VII) show the skeleton of a small Cribella oculata magnified two times.

The arms are more cylindrical and less attenuated than in Echinaster. The reticulation of the dorsal skeleton is composed of imbricated ossicles from the tip of the arms to the center. However, here the ossicles are proportionall1y thicker, closer together, and have a very much narrower mesh. Figure 15 shows a frgment of the dorsal network magnified eight times. As can be seen, there are no longer small mamelons for the insertion of mobile, isolated spines. The very small spines covering Cribella are inserted all over the surface of the ossicles of the skeleton.

In approaching the adambulacral series, the ossicles of the back enlarge in scale as indicated in Echinaster. Here, however, the series seems still more clearly indicated. The first after the adambulacral series covers it up a little, and has nearly retangular scales with rounded angles. The second 
series has scales nearly club-shaped (1) with the point turned towards the center of the animal. Between the two series, which are contiguous the entire length of the arm, is intercalated another beginning at the level of the eleventh or twelth ambulacral pair. Beyond the series of club-shaped scales, the rows of scales become less clear and pass insensibly to the dorsal reticulation.

As seen in figure 11, which represents a section of arm magnified four times, the general skeleton of Cribella is proportionally more resistant than that of Echinaster. As the animal has less flexible arms, should we expect to find the ambulacral system much less important? This is indeed the case. The adambulacral plates, which are nearly quadrangular and not regularly rounded above as in Echinaster, are more tightly placed against each other. The shorter ambulacral pieces do not come as close to the dorsal surfce. The depth of the ambulacral groove is always at least half the thickness of the arm.

One sees that these various characters of Cribella differentiate it rather clearly from Echinaster. As for the mouth, it is absolutely the same. If figure 13, which shows the teeth magnified eight times, is compared with figure 6 , which represents the teeth of Echinaster, the similarity (I would nearly say the identity) is certainly striking. It is the same for the odontophore, which figure 12 shows at a magnification of eight times. Except for a relatively larger size, it cannot be differentiated from that of Echinaster (2).

The interbrachial section (3) shows us, as in Echinaster, a support near the angle, but does not reach it. A small row of ossicles follows the ventral surface beyond here, without making very clear connections with the odontophore.

For the anus, the ocular plate, and the madreporite plate, I would only have to repeat that which I said for the preceding genus.

It is thus seen that if Echinaster and Cribella have rather important differences that make them distinct genera, the two genera are very near each other and should be kept in the same tribe of ECHINASTERINAE. The study of other genera of the family is going to show us profound differences.

Plate XVIII of the memoir of Agassiz is attributed to Cribella oculata which he named Cribella sanguinolenta. The figures give a very exact idea of the living animal. However, figure 4, which represents the naked skeleton of the ventral surface, is less clear.

For Agassiz, Cribella approaches more Solaster (endeca, as Agassiz named Crossaster as Solaster papposus). However, this able naturalist recognized that the limits between the ventral and dorsal surfaces are not at al1 marked in Cribella as in Solaster, and that the interbrachial system is arranged completely differently. These are already the important characters, and the comparison of the teeth and of the odontophore have given other good ones as we see further on. I am equally persuaded that Agassiz has exaggerated a little the importance of the interbrachial partition. I have never seen it extended up to the mouth as he said, but instead to be limited in the angle as in Echinaster where the American naturalist has not noted it. This arrangement seems constant to me in the numerous animals of the two

(1) P1. VII, fig. 9. (2) Compare figure 12 and the following ones, p1. VII. (3) Fig. 10. 
types that I have at my disposal.

Pedicellariae are not found in Cribella.

TRIBE 2. MITHRODINAE.

This tribe contains only the genus Mithrodia at this point.

GENUS MITHRODIA (GRAY).

1840. Mithrodia, Gray, Ann. and Mag. of Nat. History, V. VI, p. 288.

1844. Heresaster, Michelin, Revue de Zoologie, p. 173.

1875. Mithrodia, Perrier, Révision, etc.

Only one species Mithrodia clavigera is recognized in this genus that lives in the Pacific Ocean in an area that seems rather extensive.

The specimens of this curious species are not at all numerous at the Museum, and as I have been able to study only one rather greatly damaged specimen, I do not give here as complete a series of figures as for the other types. However, if the state of the subject will not permit me to draw it with the camera lucida, I have been able to satisfy myself perfectly as to the details of its organization.

Figure 16 shows a portion of the dorsal network of an arm at natural size. This arm, cylindrical as in ophidiaster, had a length of 15 centimeters. The disc is very small as can be seen in figure 18. The dorsal surface of this disc was in too bad a condition to be drawn. Morever, its irregular reticulation did not differ from that which is seen in figure 16. It is composed of strong calcareous little rods, cylindrical and rounded at the ends. They overlap each other without very clear imbrication, and border a very irregular mesh. Sometimes, however, this reticulation can take a very regular hexagonal appearance that Perrier (1) compared to that of Pentacerous reticulatus. I have drawn, slightly magnified (3/2) a portion of the individual described by Perrier in figure 17. If this figure is compared with figure 4 ( $p 1$. XI) it is seen that the regularity of this network is still far from that of Pentaceros. It is evident, however, that there is a great difference between figures 16 and 17 . It should without doubt be admitted that young individuals have a regularity that becomes masked by the production of new ossicles.

On the ventral surface, the imbrication seems clearer, especially in the angle of the arms (2). The ossicles that come to cover the plates of the adambutacral series are very frequently bifurcated.

The adambulacral plates have nearly the form one sees in Cribella, and the ambulacral plates have nearly the same relative importance as in the latter genus.

As can be understood easily, seeing their considerable development in relation to the disc, the arms of Mithrodia are very fragile at the base. Moreover, because of the solid nature of their reticulation, they should not be very flexible. They are nearly always found almost rectilinear in all of the preserved specimens.

Although an interbrachial system does not exist, the small dimensions of

(1)) Révision des Stellérides, p. 915. (2) Fig. 18. 
the disc do not permit at all a great variability in the separation of the two sides.

Up to here, we have seen nothing that much resembles ECHINASTERINAE, but the constitution of the mouth is going to show us the relations to this type.

The teeth, represented in figure 24 magnified three times, differ sensibly by their rounded form from the truncated form that occurs in Echinaster and Cribella. However, the odontophore, shown in figure 20 magnified four times, is certainly most related to the ECHINASTERINAE. In no other type do we find such a simple piece. Here, however, beyond a rather noticeable increase in dimensions, this odontophore has already undergone an important modification in its form. A kind of constriction, a short distance from the oral extremity of the piece seems the first indication of the formation of the apophyses. Note that here again, seeing the small dimensions of the mouth and the teeth, the presence of these apophyses is not at all necessary. The dorsal face of the piece is slightly rounded, depressed on the medial line. Seen thus from the back, the odontophore has the form of a retangle with rounded angles whose two large sides would be slightly indented.

The ventral face (20') has a nearly regular crest on the medial 7 ine. This gives the oral face (20) an irregularly pentagonal form.

The lateral view (20"') shows well the depressions of the two sides.

The madreporite plate, irregularly circular, is a little larger than that of the ECHINASTERINAE and its grooves are finer.

If it were possible to discard the absolutely baseless opinion of Gray, who placed Mithrodia in the ASTERIADAE, and if we pass rapidily in review all the characters of this genus, we see by its general aspect, the form and arrangement of the arms, and the absence of an interbrachial system that it approaches the genus ophidiaster.

Another point of resemblance is, as Perrier noted, that each arm has the capacity to reproduce an entire individual when it is broken off. This capacity is proven by numerous examples in ophidiaster. It has not been demonstrated up to here in other ECHINASTERIDAE. The specimen from which figure 17 was made, and which is still in the collection, has the form of a comet due to the regeneration of the animal from a single arm.

Although these characters are not without value, they are not at all conclusive. Lütken, opposing correctly the proposition of von Martens to combine Ophidaster and Scytaster with Linckia, indicated very clearly in 1871 that Mithrodia should form a separate type. Perrier insisted in 1875 on this difference between Mithrodia and ophidiaster, and combined the first genus with the ECHINASTERIDAE but without admitting with von Martens that it was a true Echinaster.

Considering not only the already very clear differences between the constitution of the general skeleton, but the form of the teeth and especially the odontophore (which has such a peculiar form in the ECHINASTERINAE while it is closer to the usual form in Mithrodia) I hope it is understandable why I have believed it necessary to create in a distinct tribe a type that has no very close allies. However, it should be considered nearer the ECHINASTERINAE than to Ophidiaster, as proven by the absence of ambulacral supports that are so well developed in the latter type.

There are no pedicellariae in Mithrodia. 


\section{TRIBE 3. VALVASTERINAE.}

This tribe contains only a single genus that is represented in the Museum by only a single species. A single dried example coming from the Isle of France $\left({ }^{*}\right)$ was donated by Mathieu in 1812 and remains up to the present the sole representative of this species. Lamarck gave it the name of Asterias striata. Perrier reported in 1869 the existence of large valvate pedicellariae. However, he believed he recognized also the presence of straight and crossed pedicellariae and continued to call this animal Astercanthion striatus. A more careful examination convinced him that the straight pedicellariae were in reality forcipulate pedicellariae and that the crossed pedicellariae were simple granulations of the skin. He then reexamined the tube feet and demonstrated that they were arranged in only two rows. It was necessary at that time to remove this animal from the genus Asterias and create for it a new genus, which Perrier gave in his Revision des stellerides the name of Valvaster to recall its most salient characteristic.

He placed this new genus in the family ECHINASTERIDAE because of the constitution of its dorsal skeleton. The examination he was able to make of this singular type could not be very profound because it was necessary to preserve the single specimen. It is the same consideration that has stopped me. Nevertheless, the aspect of Valvaster is so remarkable that I wanted to see if I could not at all find some distinctive new characters in my turn.

If the dried tube feet that still are present on the end of the arm are carefully examined, a small, whitish circle is seen in their sucker, even with the naked eye. It is nothing else than a crown of calcareous spicules as is easily confirmed with a microscope. It is a character that immediately distinguishes Valvaster not only from all the asteroids of the first class but also of all the animals that compose the family ECHINASTERIDAE.

The specimen having its arms split near the mouth, it was easy for me to assure myself of the presence of an interbrachial system bearing directly on the odontophore and just as strong as those of a SOLASTERINAE.

I have denuded with care a pair of teeth that I have represented magnified three times (1). These pointed and tuberose teeth differ absolutely from those of ECHINASTERINAE, which are truncated; from those of MITHRODINAE, which are rounded; and finally from those of SOLASTERINAE, which are equally rounded but much smaller. In dissecting these teeth, I saw that the odontophore (2) had two sma11, very clear apophyses. Its ventral face is a little enlarged; its dorsal face is smooth and flat.

Concern for the specimen did not permit me to go further, and I have not been able to give exact information on the general skeleton, which appears reticulated as those of other ECHINASTERIDAE, or on the supporting ambulacrals that also are very probably missing.

However, beyond the principal differences drawn from the odontophore, the teeth, and the spicular rosettes, we find still other distinctive characters. The general form of the body is not at all that of ECHINASTERINAE, where the disc is small and the arms rounded. Here the arms are large, having a dorsal surface that, in section, would be a flattened arc with a flat ventral surface joined to the dorsal surface by sharp angles.
(1)
P1.IX, fig. 15 .
P1. IX, fig. 14 . 
The disc is large. The interbrachial lines are marked by a depression that corresponds to the interbrachial system. Finally, the spines form on the arms up to ten longitudinal, parallel rows that indicate a regularity that is not ordinarily encounted in the arrangement of the skeleton of the ECHINASTERINAE. The madreporite plate has the form of an armorial shield whose base would be turned towards the center of the star. It seems to be the superior face of a hollow piece, as in Asterias, whose entire surface is covered with very fine, irregularly divergent grooves. The anus is very conspicuous.

If all these characters are combined with the presence of these enormous valvate pedicellariae that form a row the entire length of the upper edge of the arm, one will see that we have to do with a type that remains for the moment absolutely isolated. I have thus made it the type of a tribe whose reticulation of the skeleton places only behind those that we have studied up here, in the ECHINASTERIDAE. However, it would be without doubt the first to be separated from them if it is desired to accentuate the divisions that I have indicated.

\section{TRIBE 4. SOLASTERINAE.}

This tribe, the fourth I recognize in the family ECHINASTERIDAE, differs very clearly from the three: 1 , by the form of the ossicles of the dorsal skeleton; 2, by the number of arms, always rather 1 arge; 3 , by the form of the interbrachial systems; 4 , by the great development of the teeth; 5 , and finally by the form of the odontophore that not only possesses articulating apophyses but has also on the dorsal face a more or less developed extension on which is supported the interbrachial system.

Characters I consider accessory, inferred from the ocular plate that is elongated and narrow, and the madreporite plate or plates differentiate this tribe. The irregular reticulation of the back and the absence of supporting ambulacrals make me keep it provisionally among the ECHINASTERIDAE. There are no spicules in the tube feet.

This tribe is composed of the genera Solaster and Acanthaster.

The former has no pedicellariae, while Acanthaster has well-developed forcipulate pedicellariae.

\section{GENUS SOLASTER (FORBES)}

1833. Solaster, Forbes, Asteridae of Irish Sea. Mem. of Wern. Soc., v. VIII, p.121.

1834. Ste7lonia (pars), Nardo, Isis, p. 715.

1835. Stellonia (pars), Agassiz, Prodrome,etc., Soc. sc. de Neufchate7, v. I, p. 191 . p. 321 . p. 183

1840. Crossaster, Müller and Trosche1, Wiegmann's Archiv, 6th year,

1840. Solaster, Gray (Endeca and Polyaster) Ann. of Nat. History, v. VI,

1842. Solaster, Müller and Trosche1, System der Asteriden, p. 26.

1875. Solaster, Perrier, Révision, etc., p. 94.

1877. Solaster and Crossaster, A. Agassiz, North American Starfishes, p. 98 and 112 . 
This genus is represented by two species in the Museum: Solaster papposus and Solaster endeca. Both inhabit principally the seas of the north. However, one finds the former rather frequently on the coasts of the English Channel, but it is rare at Roscoff where I have been able to collect only one juvenile specimen with the aid of a dredge. Those used for my figures came from Saint Malo.

This animal can inhabit great depths and keeps even there its ordinary coloration. Those Wyville Thompson (1) dredged at 640 fathoms of depth had their bright red-orange color.

Forbes, who created the genus, gave it the following characteristics: "Body stellate, multi-radiate, covered with fasciculated spines; avenues bordered by three sets of spines; suckers biserial." This description is a little vague, and so there remained some doubt until today. We see that $A$. Agassiz placed the two species of this genus in two different genera. Solaster papposus, to which he restored the name Crossaster, did not appear to him to have anything in common with Solaster endeca with many arms. He compared S. endeca to Pycnopodia and Brisinga, which he believed closely related. It is true that Sars, on his side, had compared in the memoir cited above this same Brisinga with Solaster endeca that he found quite close.

At a loss to reconcile the opinions of these two expert naturalists, I took up again the study of these two species of the same genus, totaliy distinct from Pycnopodia and Brisinga, at least as much as a Pentaceros is from an Asterias. Allowing us to decide this question is not the least service that the comparative study of new characters of of classification will have rendered.

We begin by describing Solaster papposus.

Figures 1 and 2 (2) represent, magnified two times, the dorsal and ventral surfaces of a specimen with ten arms. The skeleton of the back is formed, as is seen, of very small imbricated pieces that form an irregular mesh whose form seems derived from the hexagon. At the junction of the slight trabeculae formed by these small imbricated pieces are seen 7 arger ones, elevated and narrowed like an hour-glass in the middle. Their upper part is covered by very fine spines in living individuals. In reality, this is the actual structure that is called paxilla, and which some have wanted to make characteristic of ASTROPECTINIDAE. To be absolutely logical, it would thus be necessary to combine Solaster with this family. It is true that, in them, the paxillae are far from making up the skeleton exclusively. One encounters them only at the nodes of the mesh of the network, and at the center of the mesh where they are rarely seen alone, most often accompanied by two small plates or even by a larger number that then connect them to the network (3).

The mesh of the reticulation is wide on the disc and the middle of the dorsal surface of the arms. It greatly diminishes towards the edges and the arm tip. The latter, as we have said already, is occupied by an elongated ocular plate. As for the borders of the arms, they are garnished with a row of paxillae of a peculiar form. The base of these pieces is elongated in the direction of the length of the arm. The pieces of the same row are imbricated from the arm tip towards the center. The superior part of these paxillae is, in contrast, flat in the transverse direction, forming thus a right angle

(1) The Depths of the Sea, London, 1873, p.118. (2) PI. VIII. (3) PI. VIII, fig. 1 . 
with the basal portion. In the interbrachial angle, this line of ossicles is part of the inferior face, and the flattened tops of the paxillae are disposed according to the fan-shaped radiating lines (1). The extremely reduced ventral face scarcely appears in the interbrachial area. It is made up of slight, calcareous trabeculae composed, as those of the back, by a series of imbricated pieces. Here, however the pieces are more elongated and the trabeculae, instead of anastomosing into a network, are nearly rectilinear and diverge like a fan from the interbrachial angle (2). The length of the arm, one scarcely sees at its base that some analogous pieces are intersposed between the row of flat paxillae and the adambulacral series. For most of their length, these two series are directly in contact.

The adambulacral pieces are wide and rounded on top, but a 1 ittle thickened in the longitudinal direction of the arm and separated by intervals nearly as great as their thickness. The large ambulacral pieces nearly reach to the dorsal face. The angle they form is always rather open (3), so that the ventral face of the arm is principally composed of the ambulacral and adambulacral series.

The first ambulacral piece is very strong, and the wing-shaped apophysis is very developed (4). The two teeth of the same pair spread apart slightly at the middle. They always have their superior faces joined, forming a convex, nearly circular surface or, if one wants, a spherical dome marked by a groove parallel to its border nearly equal distance from this border and the center. The border is like a wafer. The part in the groove has two slight mamelons on each tooth.

It is not at all useless to note, on the subject one can call tooth ornamentation, that the grooves or depressions its surface can have are generally very constant, being linked to the arrangement of the buccal spines. However, there can be some very important variations, and it would not do to rely on these characters in an absolute manner.

The odontophore, shown in figure 5 magnified three times is, as is seen, very large and completely different in form from those of ECHINASTERINAE and VALVASTRINAE. The articulating apophyses clearly are designed to give the piece a $T$ shape. As for the articulating surfaces, they are not very clearly limited and mingle a little with the ventral face. The dorsal face has on the median line a completely special extension, depressed in the middle and with the borders formed like a kind of bourrelet (5). This comes from supporting the interbrachial system, as can be seen in figure 3 . The latter is composed of very thin calcareous scales, arranged in a reversed triangle with one side inserted on the back of the angle and with the summit formed by the odontophore 0 .

The anus an (fig.1) is surrounded by calcareous trabeculae that are more closed and that leave a very small mesh between them.

The madreporite $p l a t e m$ rests on a kind of very massive framework, from which radiate lines of ossicles in 211 directions.

This plate, always single in Solaster, whatever be the number of arms, is very thick, convex, and with very fine rays of grooves that converge towards the center.

From the general arrangement of the skeleton, it is evident that Solaster papposus is a very flexible animal. The spacing of the adambulacral pieces, the large size of the ambulacral pieces, the extreme lightness of the
(1)
PI. VIII, fig. 2 .
(2) Fig. 2 .
(3) Fig. 4.
(4)
Fig. 6 .
(5) See fig. 5', 
dorsal skeleton, and finally the flexibility of the interbrachial system, makes very extensive movements possible.

All this can be repeated nearly completely for solaster endeca. The only difference is that the adambulacral plates of the same series are a

little more separated from each other than in Solaster papposus.

However, the general aspect differs a little. This is due principally to the mesh of the dorsal network being much finer, particularly on the arms where the trabeculae that form it have a very regular radiating arrangement. If I admit completely that this was a character of the species, I would have to see there a character of the genus or even the family. The line of large marginal paxillae we have seen in solaster papposus is found again in Solaster endeca. They are much shorter, it is true, but take the same disposition as in the first species: i.e., they are linked the length of the arm with the adambulacral series, and radiate fanwise in the interbrachial angles. It is to be noted, however, that here this line of paxillae is more on the ventral face than in Solaster papposus. As for the ventral skeleton strictly speaking, which we see only in the interbrachial areas, it has exactly the same arrangement as in the type studied before. Only here these interbrachial areas are a little larger, and the adambulacral series of two adjacent rays scarcely lean against each other nearly to the mouth.

The interbrachial systems are exactly the same in the two species. The teeth of Solaster endeca, larger still than those of Solaster papposus, are rounded like them, and the odontophore, illustrated in figure 7 magnified three times, is exactly the same type as that of figure 5 . It suffices to look at the corresponding positions of the two pieces to be immediately assured of it. The sole difference is that the odontophore of solaster endeca is more robust, its articulating surfaces more clearly limited. Finally, the fosette of the dorsal face is large in relation to the slightly greater development of the interbrachial system.

It can be seen these two species are very closely related and that it would be difficult to separate them. As for comparing them to Pycnopodia and Brisinga, it seems that a simple glance at their mouth would have warned of too risky an assimilation.

As the skeleton of Solaster papposus gives a good idea of the general constitution of that of the other species, it seems useless to me to illustrate Solaster endeca. Moreover, it is possible to refer to plates XVII of the memoir of Agassiz for figures of this animal. It is one of the plates of this work where the skeleton of the two sides of the body is the easiest to see. Plate XII, devoted to Solaster papposus, is less satisfactory. However, there is no error there except that the interbrachial systems should be visible in figure 3. But I cannot understand, from the plates of Agassiz, nor even from his descriptions, why he wants to separate the two species.

He tells us, in fact (1): "In Solaster endeca the arrangement and general structure of the ambulacral and interambulacral plates are identical with those of Crossaster... The actinal floor between the arms is composed of sma 11 , somewhat elongated plates, arranged in more or less regularly diverging rows, quite similar to those of crossaster. The interbrachial partitions can hardiy be intended for the support of the abactinal floor, either in this genus or in Crossaster"*. I must make note here that the principal function of the interbrachial systems is not at all that attributed

(1) Loc. cit., p. 112.

*italics by Viguier. JL. 
to them by the American natural scientist, but on the contrary, to prevent too great a spreading of the two sides of the animal.

"The fundamental difference between these genera, crossaster and Solaster," Agassiz says further, "lies in the structure of the abactinal floor." After these various citation, one without doubt will be astonished to read (1): "From an examination of the hard parts, it is evident that Solaster papposus and Solaster endeca should not be included in the same genus, having really nothing in common beyond the great number of arms."* One will forgive me these numerous citations. At the start of my scientific career, and in opposition to the ideas of a scientist possessing such a deserved reputation as that of Alexander Agassiz, I can only cite, to support my studies, the exact text of the illustrious professor whose conclusions I dispute.

As for Gaudry who has referred to Solaster only in regard to the paxillae of the back, he has supported the idea that the spines that cover them are part of the body of the piece. As with Agassiz, I am persuaded these spines are simply implanted on the paxillae, and $I$ have always seen them separate naturally by maceration in caustic potash.

All species of Solaster have numerous arms in variable number. However, Solaster furcifer of Scandinavian seas can have only five. The figures given by Wyville Thompson (2) allow moreover recognizing only this difference between Solaster furcifer and Solaster papposus.

GENUS ACANTHASTER (P. GERVAIS).

1835. Stellonia (pars) Agassiz, Prodrome, etc., p. 25.

1840. Echinaster, Gray, Ann.Nat. Hist., v. VI, p. 241.

1841. Acanthaster, Paul Gervais, Dic. des sciences naturelles, Supplement, v. I, p. 474.

25 .

1842. Echinaster (pars) Müller and Trosche1, System der Asteriden, $p$.

1844. Echinites, Müller and Troschel, Wiegmann's Archiv, p. 180. p. 350 .

1862. Acanthaster, Dujardin and Hupe, Echinodermes, according to Buffon,

1866. Echinaster under the genus Heliaster, von Martens, Ostasiatische Echinodemen, Archiv für Naturges., 32nd year, 1st part, p. 60.

1875. Acanthaster, Perrier, Révision des Stellérides, p.95.

Perrier recognized in 1875 two species of Acanthaster existing in the Museum: Acanthaster echinites and Acanthaster ellisii. I am going to discuss the first.

The specimen I was able to study was very deteriorated. Nevertheless, the entire center and several of the arms were still intact. However, it was necessary to take much care, because of the extreme fragility of the dried animal, to make the preparations that could be drawn with the camera lucida.

This specimen measured $95 \mathrm{~mm}$ in diameter, had fourteen arms as can be verified by looking at the mouth (3), and five madreporite plates as seen in figure 8. These two figures are made at a magnification of $3 / 2$ as are the interbrachial section (10) and the lateral view of the tooth (13).

(1) Loc. cit., p. 98. (2) The Depths of the Sea, p. 110 and 456. (3) P1. VIII, fig. 9. * Italics by Viguier. JL. 
One can distinguish in the dorsal skeleton two parts very different in aspect: the first on the disc and the base of the arms, the other on the entire length of the arms.

This dorsal network is composed, as in Solaster, by lines of imbricated ossicles that limit the mesh of variable forms and sizes. Here, however, the ossicles are larger and the mesh a little less irregular. Finally, at the points where the lines of the ossicles cross, the elevated ossicle that corresponds to that of Solaster is not narrowed in paxillar form, but depressed at the top with a very deep fosette. Into this fosette is inserted a very resistant ligament that fastens a spine of varying and sometimes very great dimensions. The basilar piece, which really is part of the skeleton, seems at first to be only part of the spine and to constitute a sole regular spine narrowed from the base to the point. However, one easily discovers there an articulation placed at a very variable height.

On the center of the disc (1) is one of these large armed pieces from which radiate lines of ossicles. The anus opens beside it. The other pieces situated all around, to the center of the disc, are of varying but very large size. On the border of the disc, outside the circle formed by the madreporite plates as at the base of the arms, the reticulation becomes slighter and the spiniferous pieces much smaller. There is then an abrupt change, and on the remainder of the arm the mesh becomes larger and the connecting pieces stronger. Finally, the spiniferous pieces reach their greatest development. One does not see, as in Solaster, isolated or grouped pieces at the center of the meshes. In addition, although irregular, they take more generally a quadrilateral form.

The ventral surface, although very different from that of Solaster, is really constructed on the same plan. Easily distinguishable on the border (2) is a marginal row of imbricated plates that correspond in position to the row of paxillae, imbricated at their base and flattened at their top, of Solaster papposus.

Within this marginal series, the entire interbrachial area is occupied by imbricated plates from the interbrachial angle to the mouth. Each of these plates carries, in the same way as the marginal plates, a small hemispherical mamelon on which is inserted a spine, and at the center of which one sees the fosette for the insertion of the ligament that fastens this spine. In the greatest width of the arm there is only a series of ventral plates interposed between the marginal row and the adambulacral series. Towards the base of the arm, one sees two of them. Finally, the adambulacral series of two adjacent rays never fasten to each other as in Solaster. The first pieces after the tooth are separated from it by a ventral unpaired plate that just covers the external extremity of the teeth.

The latter, very large as in Solaster, are not rounded as in that type but elongated, and each carries five small mamelons. Four of these are irregularly spaced on the border of the tooth, and one is in the middle (3). These mamelons serve for the insertion of the buccal papillae.

The first ambulacral is very large, as in Solaster, and also has a welldeveloped, wing-shaped apophysis (4). The other ambulacral pieces are tall and large, and reach the dorsal surface of the ray (5). The adambulacral pieces ad disposed the length of the arms are nearly quadrangular, a little less separated from their neighbors of the series than in Solaster. Each of
(1)
Fig. 8
(2) Fig. 9.
(3) Fig. 9.
(4)
Fig. 13. (5)
Fig. 11 .
(6) Fig. 9. 
them has at their edge, beside the ambulacral groove, a small alveolus with a forcipulate pedicellaria (6).

In contrast to that which we see in Solaster, the ambulacral groove in Acanthaster is nearly always closed. This is explained by the greater development of the ventral surface.

The interbrachial system (1), composed of very thin pieces, is in reality, as in Solaster, a triangle with its top below. Here, however, by a still greater rarefaction of the calcareous material, one finds three small rows that just rest separately on the inferior face of the dorsal network, then join into one that just ends also on a dorsal apophysis of the odontophore 0 .

The latter, shown in figure 12 magnified three times, is exactly the same type as that in Solaster. Their forms are only a little more slender. It is proportionally more elongated in the same way, moreover, as the teeth to which it serves as the point of support. Finaliy, the dorsal apophysis, so remarkable in SOLASTERINAE, is here more developed than in Solaster and is deviated a little in the direction of the mouth.

The madreporite plates are, the same as the arms, very variable in number in the various specimens.

The number of arms varies from eleven to twenty; that of the madreporite, from five to sixteen without having any relation to the former. on our specimen, there were fourteen arms and five madreporite plates (2) arranged in a circle around the center of the animal nearly halfway to the center to the top of the interbrachial angles that corresponded to them. of these five plates, four were nearly circular; one was oval with the long axis turned in the direction of the ray. All were thick, very convex, covered with very fine grooves, and very much resembled the plate of Solaster.

Each of them corresponded exactly to an interbrachial partition. One was isolated, separated from the other by an interbrachial interval, then came two in two adjacent angles; two interbrachial spaces repeated without plates; finally, another pair separated by an interbrachial interval. Five interbrachial spaces in a row completely lacked them. A hydropore canal corresponded to each plate and had exactly the usual connections.

Efforts have been made to distinguish the species of Acanthaster based on the number of arms and plates. For Lutken, there were in the literature on the subject, indications of at least three species of this genus. Acanthaster echinites (Ellis) of the East Indies (Batavia, Ternate, Sumatra, Amboine, the Philippines), Acanthaster ellisii (Gray) of western American (southern America, lower California), and Acanthaster solaris (Gray) of the Straits of Magellan. He avowed, however, that a more exact comparison of these species was still to be done (in 1871). Perrier, who occupied himself with this question in 1875, in his Révision des Stellérides, remained on this subject in an uncertainty that I can only approve. The determination of the species does not enter into the framework of this work, and I have not been occupied with it here. Nevertheless I believe I should emphasize it also in order to caution taxonomists against divisions that rely only on characters as variable as the number of arms and plates. Acanthaster ellisij, which Perrier distinguished from Acanthaster echinites, differs from it only by the naked spines and the shorter pedicellariae.

An attentive examination of Solaster and Acanthaster shows us how it is

(1) Fig. 10, i. (2) Fig. 8, m. 
possible, by the complete study of the skeleton, to establish close relations between two animals that appear at first to have in common only the number of arms and the irregular reticulation of their back. In addition, it makes us see how a cylindrical piece covered with five spines, a paxilla in one word, is strictly homologous to a spiny piece carrying a single large spine, and shows us once again that it is not at all necessary to attach an exaggerated importance, in classification, to this special form.

In recalling the arrangement of the interbrachial systems in solaster and Acanthaster and the typical form of their odontophores, in comparing them then to those that we have seen in other ECHINASTERIDAE, I do not doubt that there will be agreement with me on the necessity of separating these two genera, and of making one tribe that takes the name of SOLASTERINAE.

\section{FAMILY V. LINCKIADAE.}

The various authors who have worked with asteroids have been very divided on the extent of this family, of the delimination of the different genera that are coherent in its constitution, and on the names even to give these various genera. Perrier discussed the opinions of his predecessors in his work appearing in 1875. However, as I modify again this family very greatly, I must first recall how it has been comprised before me.

LINCKIADAE corresponds in part to the Linckia of Nardo, the Ophidiaster and Linckia of Agassiz, to Ophidiaster and Scytaster of Muller and Troschel, and finally to chaetaster of some scientists. Muller and Troschel distinguished their two genera Ophidiaster and Scytaster only by the arrangement of the pores, joined in groups in the first and isolated in contrast in the second to which they gave at first the name Linckia. However, their Scytaster variolaris and the Scytaster zodiacal is have pores joined in groups. Many ophidiaster, having isolated pores as juveniles, were then grouped with Scytaster. It is thus we see that Duchassaing and Michel in called scytaster stella, ophidiaster ornithopus of Valenciennes. It is a true Linckia, Linckia guildingii of Gray.

one sees how the distinction between these genera is arbitrary. Therefore it is not necessary to be surprised that Gray again divided this group of asteroids. Only, following his custom, he went a little too far and found no less than nine different genera in the two original ones of Muller and Troschel. These are: Dactylosaster, Linckia, Tamaria, Cistina, Nardoa, Ophidiaster, Narcissia, Gomophia, and Fromia. Some of these genera were aleady known. Others have not seemed sufficiently established, and the ideas of the English author have not been adopted generally. They have even provoked a singular reaction, and we see that von Martens proposed to unite again into a single genus the ophidiaster and Scytaster of Muller and Troschel.

Lutken correctly opposed this proposal. He noted that it was only necessary to look at an Ophidiaster ophidianus, an Ophidiaster miliaris, and a Scytaster variolaris to demonstrate that they were three distinct types.

In looking at the figures I give (1), it can be seen how the opinion of the Danish scientist was founded. He proposed reserving the name ophidiaster for the type to which belongs ophidiaster ophidianus; of calling Linckia all the animals of the type Ophidiaster miliaris; finally, of leaving the name Scytaster to all the related species of Scytaster variolaris. To these three principal groups are added Leiaster of Peters and Lepidaster of Verri11, 
which should perhaps be made only a single species, and Mithrodia or Hereaster, which return to the ECHINASTERIDAE. It is necessary to note, however, that in order to make these distinctions, Lütken used on $1 y$ a very variable character, the different arrangement of the spines of the ambulacral groove.

Perrier, who has shared the ideas of Lütken, relied in part on the disposition of the skeleton in order to confirm the distinctions established by this scientist. According to him, in the ophidiaster type, the ventral surface is nearly absent, the poriferous areas continue almost without interruption up to the second row of the ambulacral paxillae, from which they are separated only by a thin granular band corresponding to a single longitudinal row, continuous up to the arm tip, of small skeletal plates. Linckia should be considered as animals having a rather wide ventral surface, lacking pores, and having at the base of the arm of at least four rows of continuous plates of which the larger external ones can represent marginal plates as in Linckia multiflora and guildingii. The genus sychaster was not left to encumber it although the armature of ambulacral plates came very near, for some species at least, to that seen in several Linckia. He recognized, however, that in Scytaster, no more than in Ophidiaster, there is strictly speaking no ventral surface, at least one with pores, isolated or in groups, so the adambulacral plates are separated from the first row of pores by one or no more than two rows of plates (2).

A thorough study of the skeleton in various types only confirms the opinions of Perrier and justifies him on this point of classification to which I align myself completely. There is still another type where the anatomy of the skeleton comes to prove the correctness of his views: Scytaster milleporellus. For him, the flattened form of this animal, its double row of large marginal plates, its rounded skeletal ossicles, and its isolated tube-feet pores, were characters that separated the true LINCKIDAE from Pentagonaster. He thus kept for it the name of Fromia, proposed by Gray, and wondered if there was any advantage to transfer this genus to the GONIASTERIDAE.

My studies have proven to me, in fact, that Fromia should be separated from the LINCKIDAE and replaced in the PENTAGONASTERINAE. The absence of supporting ambulacrals and the presence of marginal plates, as well as the absence of interbrachial systems and of spicules in the tube feet, separates it from the GONIASTERINAE, which composes with it our VIth family. The genus Ferdina follows the genus Fromia. As for the genus Metrodira, I place it after the preceding two, although it has not been possible for me to assure myself of its exact position. Perrier stated that Dactylosaster and Tamaria of Gray are only Ophidiaster; Gomophia, Narcissia, and Nardoa are only Scytaster. He was not able to obtain from the British Museum any information on Cistina, which without doubt approaches ophidiaster.

In summary, the LINCKIDAE are composed, for Perrier, of the genera Ophidaster Agassiz (pars), Linckia Nardo (pars), Scytaster Muller and Troschel (pars), Ferdina Gray. To these should be added Leiaster Peters and Lepidaster Verrill that did not exist in the Jardin des Plantes. He retained still the genera Fromia and Metrodira of Gray that formed for him the transition between the LINCKIDAE and the GONIASTERIDAE.

(1) PI. IX, fig. 1, 2, 8, and 9; pl. X, fig. 1 and 2. Révision des Stellérides, p.119. 
Our family LINCKIADAE is composed of the same genera as his, except the latter ones that we eliminate completely as well as the genus Fromia, and Chaetaster that we transfer there from the ASTROPECTINIDAE.

Chaetaster has scarcely any claim to be part of the family ASTROPECTINIDAE, and a comparison of the figures I give (1) shows the great resemblance between the ventral surfaces of Chaetaster and Linckia. The details of the organization are given later. However, I should say that it is only because I cannot do better that I place Chaetaster in the LINCKIDAE. This will be, if one wants, a provisional place. When we have studied completely the skeleton of ophidiaster, Scytaster, and Linckia, we see how this latter type is distinct from the first two and how it is difficult to establish good divisions in the family LINCKIDAE.

Perhaps a complete study of the animals that make it up will bring new groupings. However, as I have not been permitted for the moment to do this work, I shall conserve provisionally this family in order not to complicate without absolute necessity the scientific literature.

It would include, in the sense that we give it, the four genera: Linckia Nardo, Chaetaster Müller and Troschel,Ophidiaster Agassiz, and Scytaster Lütken. Undoubtedly it will be necessary to add Leiaster of Peters and Lepidaster of Verri11. However, I have little information to give on these animals that are not represented in the Museum of Paris.

GENUS LINCKIA (NARDO) EMEND.

1834. Linckia, Nardo, Isis.

1864. Linckia, Lütken, Videnskabelige Meddelelser, p. 164 (the sense of the name is modified).

1875. Linckia, Perrier, Révision des Stellérides, p. 135 (in the same sense as Lütken).

I have been able to study two of the nine species of Linckia that are represented at the Jardin des Plantes. I shall begin by a description of Linckia miliaris, a species found over a very wide area: Zanzibar, the Seychelles, Batavia, the Mollucas, the Philippines, New Caledonia, and eastern Australia. Most of the illustrations I publish refer to it. I shall then discuss Linckia diplax that also is found at very widespread points: Bourbon, Madagascar, New Caledonia, and California.

Figures 1 and 2 (2) are natural size and show the two sides of a small Linckia miliaris.

The skeleton of the back is composed entirely of small plates, irregularly rectangular, thick, and slightly convex on top. The dimensions of these plates vary little from the center of the disc to the tips of the arms. On the two sides of each arm are two rows of these plates arranged very regularly forming a marginal series. The upper row extends a 1 ittle into the interbrachial angle, encroaching on the dorsal surface of the disc (3). Al1 of the other pieces of the dorsal skeleton are disposed without apparent order. They leave between themselves, from place to place, poriferous areas irregular in form and size. It can be seen that these poriferous areas never go up to the medial 1ine. The plates there are very close against each other, as at the arm tips. On the disc is always seen a

(1) P1. X, fig. 2 and 9. (2) P1. X. (3) Fig. 1. (4) Fig. 1, an. 
sma11, nearly central opening that is the anus (4).

on the ventral surface, the disposition is completely different and much more regular.

On nearly the entire length of the arm, there are three rows of rectangular plates, forming three longitudinal and straight series parallel to the adambulacral series. The corresponding plates of the three series are arranged on a line exactly perpendicular to the direction of the ambulacral groove (1). There is no poriferous area on any part of this ventral surface. Towards the extremity of the arm, these parallel rows disappear successively, but the marginal series come in contact with the adambulacral pieces only towards the ocular plate. Towards the base of the arms, there is in contrast a fourth series, parallel to the first ones, placed at their extreme side. Still others are added in the interbrachial angle.

At the junction of the ventral series of two adjacent arms, the arrangement becomes a little irregular except for the most internal as can be seen in figure 2. The number of plates in this series is without relation to the number of adambulacral plates, contrary to that which one would have thought. One sees, in contrast, two transverse series of ventral plates the entire length of the arm, ending at a single plate of the inferior marginal series. This arrangement seems constant, as we find it again in Chaetaster. The ambulacral grooves are nearly always entirely closed in Linckia in our collections, as moreover in all the animals of this family. The adambulacral plates are small, embedded in the ambulacral groove, very close against each other. The ambulacral pieces are short and connected by small supporting ambulacrals, not to the second series of ventral plates as in the genera ophidaster and Scytaster, but to the first (2).

The interbrachial systems in this species are formed by small, flat, vertically aligned ossicles. They divide the interbrachial area by forming an incomplete partition that does not reach the top of the round angle formed by the two sides (3). The arrangement, which seems constant for this species, does not occur in the entire genus Linckia as we shall soon see.

The mouth is remarkable for the small teeth, which are slightly truncated and slightly recall at first sight those of ECHINASTERINAE. However, the odontophore, shown in figure 5 magnified five times, differs completely from that which we have seen in this tribe. Its apophyses are very short, but the articulating surfaces that bear them are perfectly marked (5'). The ventral surface is slightly slanted; the dorsal surface, nearly flat. The thickness of the piece is very slight and its volume very reduced. This, given the smallness of the teeth, should make their movement nearly null.

The ocular plate (4) is small and rounded, and has nothing peculiar.

The sma 17, nearly circular madreporite plate m, marked with a few irregular grooves, is situated very eccentrically on the internal margin of the marginal series.

The description just given applies to a young specimen of Linckia miliaris. This specimen has the same squat form that Gray distinguished under the name Linckia crassa. It is necessary to add some remarks on the arrangement of the poriferous areas in more developed individuals. These areas then are generally very much larger than the adjacent plate, of oval shape, and clearly circumscribed.

(1) Fig. 2. (2) Fig. 4, s. (3) Fig. 3. (4) Fig. 1, oc. 
One always observes, as on our subject, a more or less wide continuous plate on the medial line of the arm, formed by plates pressed close against each other and often smaller than the plates of adjacent regions. This plate, irregularly bordered on the sides, never has poriferous areas. The areas situated immediately within the marginal series are in general smaller than the others and form a rather regular line nearly parallel to this series. This arrangement is very difficult to find again in the following series, of which three can be distinguished, more and more irregular, towards the medial line.

When the poriferous area becomes smaller and invades nearly completely the medial side, it becomes very difficult to distinguish this species from Linckia nicobarica other than by the difference in the disposition of the ambulacral spines and the ventral granulation.

Linckia miliaris nearly always has five arms. However, one of the specimens of the Museum has only four.

In Linckia diplax the number of arms is more variable, although normally five also. Of forty-two specimens in the Museum, two have four arms, thirteen have six, two have seven, and the rest have five. I have not, moreover, illustrated here the odontophore as its differences from the type described above are easy to understand by a simple description.

The arms are more slender and narrower in Linckia diplax. The extremely irregular poriferous areas are larger than the ossicles that form the dorsal skeleton and are disposed without order throughout the area of the dorsal side of the arm as they completely invade it. In place of two distinct marginal series, as in Linckia miliaris, there are here three or four distinct parallel ones that leave regular series of poriferous areas between them.

The ventral surface is formed of four contiguous rows of rectangular plates, disposed as we have seen in Linckia miliaris.

The interbrachial systems are variable in this species. In one of the angles of our specimen, there is nearly the same arrangement as in figure 3 (p1. X). In two others, there are scarcely any isolated small plates. Finally, in three others an interbrachial system does not exist. It is thus not necessary to attach too great an importance to this character in the genus Linckia.

The mouth of Linckia diplax resembles absolutely that of Linckia miliaris. I have illustrated only the odontophore (1) magnified five times. Thus it is possible to note the great resemblance, nearly identical, of that of figure 5 .

The most important character of Linckia diplax is certainly the presence of two madreporite plates, both on individuals that have only four or five arms as on those that have six or seven. There is even an individual with four arms that has three plates, with one composed of three very distinct fragments.

The two plates, each with a corresponding hydropore that has the usual relations, are nearly always located in two adjacent angles. In the comet forms, so frequent in this species, they are generally found on each side of the large arm.

It seems that the faculty of arm regeneration is in general more developed in animals that have several madreporite plates. The rational

(1) Fig. 7 . 
explanation of this fact remains to be found. Whatever it is, this arm regeneration is rarely very regular and species with several plates generally have a variable number of arms.

Agassiz illustrated in his memoir the Linckia guildingii of Gray that has, as in Linckia diplax, a variable number of arms and two madreporite plates. Agassiz's speciemen had six arms. The figure that represents the naked ventral surface is very good; that for the dorsal surface leaves something to be desired and it is impossible to find the madreporite plates there. One of them is well drawn and at a very great magnification. According to the text of Agassiz, a rudimentary interbrachial system exists in this species. We have seen that the disposition of this system is variable in Linckia. The rest of the description gives nothing in particular.

All of the Linckia have a crown of spicules in the sucker of their tube feet. This crown is shown (fig. 8, pi. XVI) at a magnification of twenty times. Figure 10 shows a fragment of this same crown at a magnification of 120 diameters; $b$ is the external side and $c$, the central side of the crown. It is composed of a single row of flat, areolar spicules. There are no spicules in the tube or the ampullae of the tube feet.

Linckia has no pedicellariae.

\section{GENUS CHAETASTER (MULLER AND TROSCHEL)}

1840. Chaetaster. Müller and Troschel, Ueber die Gattungen der Asteriden, Wiegmann's Archiv für. Naturgeschichte, 6th year, v. 1, p.321. 287.

1840. Nepanthia, Gray, Annals and Magazine of Natural History, v. VI, $p$.

1875. Chaetaster, Perrier, Révision des Stellérides, p.329.

Except for a single specimen of Chaetaster nodosus from Guadeloupe, which Perrier described in creating this species, all of the Chaetaster in the Museum are of Chaetaster logipes and come from the Mediterranean Sea. Figures 8-13 of plate $X$ are devoted to this type.

Figures 8 and 9 , of natural size, allow one to have an exact idea of the two sides of the animal.

The dorsal surface is entirely composed of elevated ossicles in the form of hexagonal prisms with rounded angles that are aligned on one of their bases. These ossicles are arranged in longitudinal series. Each is connected to the two contiguous ossicles, which are part of each of the series on either side of it, by four sma11, very fine calcareous ossicles arranged crosswise to its inferior surface. These nearly meet at the center of this surface. There are no small pieces of this kind between two adjacent ossicles of the same longitudinal series. The two figures that Gaudry gave on this subject in his work are inexact. Moreover, in his transverse section of the arm, he has not drawn the supporting ambulacrals.

As $p l a t e ~ X$ is very complete, and as this arrangement of connective pieces is very easy to understand, it has seemed useless to me to give a figure. One sees the cut end in the sections (1).

The rows of the dorsal paxillae, since this name can really be given to them, continue very regularly the entire length of the arm. The spines that

(1) PI. X, figs. 10 and 11 . 
cover them are not at all close enough to mask this arrangement. The medial row is a little distinct from the others, and alone reaches the ocular plate. On the disc, the paxillae become smaller, irregular, have no apparent order, and have spines that hide them completely on the intact individual.

A double row of marginal plates can be seen on each side of the arms. The upper rows border the area occupied by the paxillae. They are composed of small, thin, tightly packed, rectangular, and slightly vertical plates the entire length of the arm. Towards the arm tip, in contrast, these marginal plates elongate transversally in encroaching on the dorsal side, and end by joining the medial row of paxillae with which they alone reach the ocular plate (1).

The ventral marginal series are in contrast composed of very small and nearly always rectangular plates the entire length of the arm. The relation between the number of plates in the two marginal series on the same side is not absolutely constant.

Within the inferior marginal plates, the ventral surface is formed of rectilinear series of very small, rectangular, tightly-packed plates. The number of longitudinal series, three or four at the base of the arms, decreases progressively towards its end. The plates of adjacent series are, as in Linckia, disposed on the line perpendicular to the direction of the ambulacral groove. Likewise, as in Linckia, two of the transverse rows correspond to each marginal plate nearly the entire length of the arm. The arrangement of ventral plates is less regular towards the interbrachial angle. The line bisecting the angle is occupied by slightly larger pieces elongated in the direction of the line (2).

The interbrachial systems are composed of very sma11, thin pieces arranged vertically in a fashion to form a sort of partition that closes the angle formed by the two sides (3) and goes about half the distance from the border of the disc to the mouth.

The adambulacral pieces are very sma71, pressed against each other, and their number seems nearly always to correspond to that of the plates of the ventral series. However, this relation is not absolutely constant.

The adambulacral pieces are proportionally shorter than in Linckia, and connected by very thin supports to the first, and sometimes, but rarely, to the second series of ventral plates (4).

The section of the arm, magnified three times in figure 11 , is of a deformed arm. Ordinarily, the upper part of the arm is rounded.

It is difficult to recognize the mouth of Chaetaster as that of a Linckia, at least at first glance. In both genera, the teeth are a little truncated and very small, and the mouth is reduced to a very narrow opening.

The odontophore, magnified five times in figure 12 , has a great similarity with that of Linckia. The apophyses and the articulating surfaces are arranged nearly the same in both genera. The only obvious difference is that the piece in Chaetaster is not compressed laterally at its external end as seen in Linckia.

There are no pedicellariae in this genus. There is not, as in the preceding genus, the corona of spicules in the sucker of the tube feet.

The ocular plate (oc, fig. 8) is rather large compared to the size of the animal. However, it does not have the great development that we see in ASTROPECTINIDAE. The madreporite plate $m$ is small, ordinarily hidden under
(1)
Fig. 8. (2)
(2) Fig. 9.
(3) Fig. 10, i. (4)
Fig. $11, s$. 
the spines and paxillae of the disc, and situated nearly at the center. It is marked by fine, radiating grooves.

The genus Chaetaster has made part of the ASTROPECTINIDAE until now for the sole reason that the dorsal surface is composed of paxillae.

Independently of its form, so different from that seen in the ASTROPECTINIDAE, the presence of well-developed suckers at the ends of its tube feet must already differentiate this family. The presence of interbrachial systems that never exist in the ASTROPECTINIDAE, the extreme reduction of the teeth that are triangular, slightly truncated, and nearly flat on top instead of being tall, convex, large, and separated, and, finally, the form of the odontophore justify its separation from the family of which it was a part until now and its rejoining Linckia.

It is not necessary, however, to consider Chaetaster as closely allied to Linckia. The very peculiar constitution of its dorsal surface separates it from all the types that I have studied until now. Finally, the marginal plates are very different from those that we see in Linckia. The other differences are less important. The arrangement of the interbrachial system, which moreover does not differ much, does not mean much in a family where these systems are also variable. As to the absence of spicules in the tube feet, we see that scytaster also has them in spite of its affinities with ophidiaster which has them. One should no longer attach a very great importance to them.

\section{GENUS OPHIDIASTER (AGASSIZ) EMEND.}

1834. Ophidiaster, Agassiz, Prodrome d'une Mon. des Rad., Mém. Soc. sc. Neufchâte7.

1834. Linckia (pars) Nardo, Isis.

1840. Dactylosaster, Tamaria, Cistina, Ophidiaster, Gray, Ann. of Nat. Hist., v. VI, p. 283. - 1865, Synopsis of the Asteriadae of British Museum, p. 13 .

28.

1842. Ophidiaster (pars), Müller and Trosche1, System der Asteriden, $p$.

1865. Linckia (pars), von Martens, Ostasiatische Echinodermen, Archiv für Naturges. Year XXXI, v. 1, p. 351.

1864. Ophidiaster Lütken, Videnskabelige Meddelser, p. 163, and 1871 , Vid. Medd., p.265.

1875. Ophidiaster, Perrier, Révision des Stellérides, p. 120.

There exist about a dozen species of Ophidiaster in the Museum of Paris. I have been able to examine Ophidiaster ophidanus of the Mediterranean Sea and ophidiaster pyramidatus. It is the latter that corresponds to the description and figures that I have published. The individual that I studied came from Acapuico and was given by the Museum of Comparative Zoology of Cambridge (Massachusetts). It measures $198 \mathrm{~mm}$ from the end of one arm to that of the alternate arm.

As the disposition of the skeleton is remarkably uniform the entire length of the arm, it seems useless to me to draw it entirely. The figures (1), which are slightly magnified, and the description will suffice to give a good idea of the constitution of this animal.

(1) P1. IX, fig. 1 and 2 . 
The arms are irregularly rounded on top, a little flattened below (1), and decrease very little from the base to the top that is large and rounded. Seven principal rows of imbricated plates are disposed the entire arm length, covering it from the point of the arm to its base. Their form is seen very well in figure 1. These series do not touch laterally, but are connected to each other by narrow but very thick pieces located below them, and which unite the corresponding plates of the two adjacent series at the point where these plates are the largest (2). The dorsal skeleton is thus composed of a series of arcs, each composed of seven large plates and six connective pieces. As I have said, the plates cover those of the adjacent arc from the side of the disc. However, the connective pieces, because of their narrowness, have a relation only with the plates of the arc where they are found. As a consequence, there are six rows of openings, each bordered by six pieces or two connective pieces and four plates.

The medial series of an arm ends at the level of the disc in an enlarged, irregularly rectangular plate. These five plates form the top of a regular pentagon. They are connected to each other by V-shaped plates in pairs. Inside the pentagon the arrangement of plates is less regular. Towards the center is seen a large irregular piece beside which is the anus. The medial series of the arm, which is a little stronger than the others, is not continuous for long. One already sees in figure 1 how it begins to break up very near the disc on the upper arm, particularly on the left. This arrangement is only accentuated further on. On nearly the entire length of the arm this medial series, instead of being single, is composed of a large number of pieces irregularly pressed against each other. The connective pieces leave regularly from this complicated system in order to reach to the two adjacent series. The latter remains single for a long $t i m e$. Nevertheless, towards the middle of the arm they commence to undergo the same modification as the medial series. Their pieces multiply so that they end by encroaching on the two medial lines of poriferous areas that disappear about two centimeters before the arm tip. The three medial series of plates are then united and form a solid pavement in which a transverse section will meet sometimes more than ten pieces. As for the lateral dorsal series of each side, they are always single and the rows of poriferous areas they border continue until the end of the arm.

The ventral surface is composed, towards the center of the arm, of three series of plates. The most external of these rows leaves from the most lateral series of the dorsal surface (3), and can be considered as formed of connective pieces. Each of these pieces that compose this series covers interiorally a plate that is larger and enlarged at its internal end. We thus have there a second series of which the number of plates is still rigorously equal to that of the dorsal system. However, between this second series and the row of adambulacral pieces, we see a row of small rounded plates, very closely pressed against the others. Two of these small plates correspond to each piece of the second series. There is no regular relation between their number and that of the adambulacral pieces (4).

The plates of this series are nearly all pitted by one, sometimes two alveoli for pedicellariae and form an uninterrupted row from the tooth to the end of the arm. The other series of the ventral side are less constant.

In approaching the mouth, the external series breaks up in a fashion so

(1) Fig. 4. (2) Fig. 1 and 4. (3) Fig. 4. (4) Fig. 2. 
that it can form the interbrachial area. We can count, in the angle formed by two arms, up to six pieces arranged in a single row corresponding to each of the pieces of the dorso-1ateral series. In the section (1), very nearly at the base of the arm, are two of them. However, already in figure 2 is seen the disposition described above. In approaching the end of the arm, the pieces of this series, afterwards alone, first become smaller and then end by disappearing. The pieces of the dorso-lateral rows come to rest on this series of enlarged pieces, nearly at the level of the last third of the arm.

This series of enlarged pieces, which exists nearly the entire length of the arm, ends by disappearing a little before its end. The pieces of the most extreme dorso-lateral rows then rest directly on the series of small pieces with pedicellariae that are absolutely constant as we have already said. The poriferous areas of the ventral surface, at first very elongated transversely, decrease in size gradually and end by disappearing before the end of the arm.

The adambulacral pieces are small and very tightly packed against each other. The ambulacral pieces are remarkably short, especially towards the ends of the arms. They are propped by a series of supporting ambulacrals (2) that go from their end to the row of enlarged pieces, jumping the row of pieces with pedicellariae.

By the compact arrangement of their skeleton, and especially by the brevity of their ambulacrl pieces and the existence of elongated supports, the arms of Ophidiaster pyramidatus should be very rigid. Thus we find the arm nearly always straight in collections.

The interbrachial section (3) shows an interbrachial system does not exist in this type. With the rigidity of the body being nearly absolute, the necessity of one would not be understandable.

Although the height of the ambulacral pieces increases in approaching themouth, the first piece of this series is small compared to the dimensions of the animal. Nevertheless, the winglike apophysis is very well developed (4). The teeth are short and rounded, and marked on top with grooves corresponding to the insertion of the papillae.

The odontophore, shown in figure 5 magnified four times, has a very peculiar form. The apophyses are very developed, and situated completely in a straight line with the oral face of the ossicle. The dorsal face is very convex and marked with a small hole (5). The lateral faces are very indented. Finally, the ventral face is extended in a very narrow spur.

The ocular plate is rounded, small compared to the size of the animal, and has nothing pecutiar.

The madreporite plate (6) offers a remarkable but variable development. It can attain twice the size shown in the figure. It is slightly concave, sometimes smooth and whole as shown in our figure, sometimes cut up with a broken more or less jagged and irregular surface. The vermiculations that cover this surface are very fine and the plate has a granular appearance.

To this great development of the plate corresponds a very peculiar form of the hydropore canal. Figure 7 shows this canal, magnified two times, and the indication of the trace of pieces on which is applied the plate that constitutes the madreporite.

As can be seen, this canal has basically the usual size and appearance.
(1)
Fig. 4
(2) Fig. 4, s.
(3) Fig. 3 .
(4) Fig. 6 .
(5) Fig. 5',
(6) Fig. 1, $m$. 
However, on top it is widened considerably to encompass the entire inferior face of the plate. Although one can see up to the top the longitudinal groove which is always observed on the oral side of the hydropore canal, it loses its tracheal appearance at the point where the dilation begins. In place of calcareous arcs one sees only branches irregularly intersecting and taking the vertical position. I have already reported this remarkable arrangement in speaking of the hydropore canal in general.

I have described Ophidiaster pyrimidatus in detail because it is the first species I studied, and because the differences presented by ophidiaster ophidianus have not all seemed sufficient to require a second set of figures. However, these differences merit being reported. Moreover, after the preceding description, it is very easy to get a very exact idea.

In this species, the seven longitudinal series of dorsal plates are perfectly regular and simple. One can follow them up to the ocular plate, which is nearly twice the size that it has in Ophidiaster pyramidatus. Thus there is on the entire length of the arm six rows of perfectly regular dorsal poriferous areas.

The ventral poriferous areas can also be followed on the entire length of the arm. The disposition described for the middle of the arm of ophidiaster pyramidatus is found here for the entire length. The aspect of ophidiaster ophidianus thus is much more regular than that of the other species.

It is still necessary to report on the ambulacral pieces that are shorter still than in Ophidiaster pyramidatus and reach nearly a third of the distance between the two sides of the body. As for the madreporite plate, it is equally granular, but of normal size and recalls nothing of the enormous development we examined above.

Most Ophidiaster have five arms. Nevertheless one encounters some that have four, and others that have six or seven according to Doctor Lutken. In the latter case, they also have two madreporite plates.

All animals of this genus have a very great faculty of reproduction from broken parts. A broken arm is so often found reproducing a whole animal that some scientists have wondered if this would not be the normal development in this type.

Ophidiaster lives especially in warm seas. Its limit to the north seems to be the Mediterranean Sea.

Animals of this genus have a crown of spicules in the sucker of the tube feet. An impression of them can be obtained by looking at those of Linckia miliaris (1). There are no spicules in the tube feet, but the ampullae have sma11, irregularly dispersed ones.

The pedicellariae of Ophidiaster were not reported by Perrier when he made his important memoir on these so unusual organs. However, in his work titled Revision des Stellerides du Museum, he gave detailed descriptions of the pedicellariae that are encountered in the various species of ophidiaster. As this latter work has no plates, I have drawn at his request (2) one of the most characteristic types, the pedicellaria of ophidiaster germani.

The space that I used permitted me to give only three views. I hope they will suffice to give a comprehension of its constitution. All three were made at a uniform magnification of twenty diameters. The first (fig. 12) represents a pedicellaria completely open, seen from above and surrounded

(1) P1. XVI, fig. 8 and 10. (2) P1. XVI, fig. 12, 13, and 14. 
by granulations of the skin. The second (fig. 13), another pedicellaria with closed jaws also seen from above. Finally, figure 14 shows a half-open pedicellaria from the side. All of these figures were drawn with a camera Tucida.

The basal piece $b$, which is about 1 millimeter long in this species, is much smaller and has a thickness nearly equal to its width. It is pitted with two cavities that reduce it to a simple she11, and that are separated by a vertical transverse partition in the middle of the piece. There is thus the remarkble appearance that Perrier justly compared to a salt cellar. The opening of these cavities has a singular form: narrow towards the median partition, it becomes wider towards the extremity of the piece. The extremity rises, as we see in figure 14, and ends in long, slender teeth, bent back towards the interior of the cavity. It is to be noted, as can be seen well in figures 12 and 13 , that the teeth of one end of the basal piece correspond at intervals to the teeth of the other end. We are going to see the reason for this soon. From each side of the partition $c$, the cavity of the pieces does not immediately reach its full depth. There is a little shoulder at the level a little below that of the top of the partition $c$. It is on this little shoulder that rests the basal extremity of the corresponding valve $v$. Smal1 muscles, inserting from one part to the sides of the partition $c$, from the other to the narrow portion of the valves $v$, raise the valves, and close the pedicellaria. Other muscular or perhaps simply elastic fibers insert from one part to the base of the cavities, and from the other to the base of the valves to oppose the first muscles. They open the pedicellariae whose valves then are hidden in the cavities. The magnification at which I had to prepare my figures does not allow me to show these muscles. Their position and function are easy to understand.

The valves are very complex and widened at the upper part. One valve ends in five teeth; the other, in four. These teeth interdigitate exactly, as can be seen in figure 13, when the valves are closed. When the valves fall back, the teeth interdigitate exactly with those of the basal piece. It is for this that the teeth situated at the end of the basal piece are exactly arranged as those of the valve of the opposite side.

The valves, like the basal piece, are very compact. The small holes that pierce them are so fine that, in our figures, they scarcely appear as a simple dot. subjects.

The valves are very fragile and are most often missing in dried

For the modifications these pedicellariae are subject to in the various species of Ophidiaster, I shall refer to the memoir of Perrier.

GENUS SCYTASTER (LUTKEN).

1840. Nardoa, Gomophia, Narcissia, Gray, Ann. and Mag. of Nat. History, p. 286 .

1842. Scytaster (pars) and Ophidiaster (pars), Müller and Trosche1, System der Asteriden.

1864. Scytaster, Lütken, Vidensk. Meddele7ser.

1875. Scytaster, Perrier, Révision des Stellérides, p. 156. 
Perrier recognized seven species in this genus at the Museum of Paris. Scytaster novaecaledonia, whose name indicates its origin serves as my subject.

The figures (1) that represent part of the two sides of the animal, at natural size, do not require my giving the dimensions.

The difference in aspect of this animal and an Ophidiaster is quite remarkable. However, the skeleton has numerous points of similarity.

The irregularly rounded arms taper to a point towards their ends. Their dorsal side is in the form of large plates, slightiy convex and irregularly circular or elliptical. Their arrangement in series is scarcely visible towards the base of the arm. These plates, which decrease little by little in size in approaching the tip of the arm press against each other in such a manner as to form a kind of irregular pavement. They are less packed on the disc and at the arm base and leave spaces between them that are true poriferous areas. Moreover, the smaller plates are nearly everywhere interposed beween them and further increase the irregularity of the group. As we have seen in the section of the arm magnified two times (2), the upper pieces, analogous to the connective pieces of ophidiaster but naturally not having the same regularity, arise between the large dorsal plates. One sees very clearly in the interbrachial angles, especially in the left of figure 8 , series of small, very regularly arranged plates.

The arrangement of plates on the ventral surface is much more regular. Immediately in connection with the adambulacral plates is a series of small pieces that recall completely those that we have seen in ophidiaster (3).

The pieces of this series, with a nearly constant size the length of the arm, become however much larger in approaching the mouth. Moreover, no more than in ophidiaster, their number is in constant relation with that of the adambulacral pieces as Perrier believed. It is easy to be convinced of this by counting them in the figures. The figures, drawn with the camera lucida, reproduce exactly the disposition of the plates. As we have seen, those that occupy the top of the interbrachial angle and make contact with the teeth have a relatively very great development. Outside this series are other large, round, slightly convex, and imbricated pieces. Sometimes one of these plates corresponds to two of the first series. However, this relationship, indicated by Perrier, was quite exceptional in our samples, and it is not possible to trace the constant relation between the number of plates in the two series. Finally, on the border of the arm, is seen a third row. Its plates are of the same form and number as those of the second series. The plates of these three rows leave between them, the entire length of the arm, very limited poriferous areas. In the interbrachial angle, these poriferous areas disappear completely. This is due to the presence of plates interposed between the first and second series as seen in figure 9 .

The adambulacral pieces are very large as in ophidiaster. The adambulacral plates are also proportionaliy taller.

As in the preceding genus, a series of supporting ambulacrals go from the ambulacral pieces to the first series of large ventral pieces, jumping over the series of small plates (4).

I have very frequently encountered, in this type, the support formed of two pieces instead of one. Sometimes there are even three of them, solidiy

(1) P1. IX, fig. 8 and 9. (2) Fig. 11. (3) Compare figs. 2 and 9. (4) Fig. $11, s$. 
united and appearing at first glance as being only one. This arrangement has already been cited above.

The mouth of Scytaster is easy to distinguish from that of Ophidiaster. The teeth are, in fact, long and pointed instead of being round, and nearly meet at the center of the mouth (1). Their inferior face is marked, like the adambulacral pieces, with two grooves parallel to their border and correspond to theambulacral and buccal spines.

The first ambulacral piece is naturally a little larger than in Ophidiaster and in proportion to the size of the tooth (2).

The wing-like apophysis is well developed.

Figure 10, magnified two times, shows us that, no more than in Ophidiaster, an interbrachial system does not exist.

The odontophore, although of the same types in the preceding genus, has some very remarkable differences however.

In examining figure 12, which magnifies it four times, it is seen that the apophyses, well developed also, are no longer exactly in a straight 1 ine with the oral face of this ossicle. The dorsal face, equally marked here with a small fossette, is nearly flat. The spur of the ventral face has disappeared, although this same ventral face has a rather considerable projection towards its oral extremity. The similarities in the ventral faces and especially the dorsal faces (figs. 5 and 12) are striking. The differences in this characteristic piece in the two genera Ophidiaster and Scytaster are immediately apparent in a lateral view (figs. 1' and 12' ').

The ocular plate (3) is small as in Ophidiaster. As for the madreporite plate, it is finely striated with grooves radiating from the center. It is rather small, encased in the large ossicles of the back, and sometimes is very difficult to discover. It is nearly circular, and located about half the distance between the center and the edge of the disc.

Pedicellariae do not exist in animals of this genus. I have not found in them the rosette of spicules in the suckers of tube feet. Sometimes, as the tube feet were in a very bad state in the speciments that I had between my hands, I could not give the absence of spicules as an absolutely certain fact, but only extremely probable as it is ordinarily very easy to demonstrate the presence of rosettes even in very deteriorated subjects.

Now that I have described in detail the principal types that constitute the family LINCKIDAE, perhaps it will not be useless for me to recall that which I said at the beginning: there is no question that a division should be made in this family.

In the first division would be placed ophidiaster and scytaster that possess everything: poriferous areas on the ventral surface; never an interbrachial system; very developed teeth; very marked apophyses on the odontophore; and finally the supporting ambulacrals constantly supported on the second ventral row that leaves from the adambulacral series.

In the second division would be placed Linckia and Chaetaster with common characters: ventral surface formed of very tightly packed plates and without poriferous areas; interbrachial systems, not always it is true; very reduced teeth; very short apophyses on the odontophore. Finally the underlying ambulacrals nearly always supported on the first ventral row.

I have given above the reasons for which $I$ believe it inopportune to make of this family two distinct families, and I shall not review them here.

(1) Fig. 9. (2) Fig. 13. (2) Fig. 8, oc. 


\section{FAMILY VI. GONIASTERIDAE.}

I have indicated above the modifications I have introduced in the family that Perrier named, and why it seems useful to me to set out again in two tribes the genera that I leave there. I shall finish by explaining the bases that made me do this as I discuss the genera in each of the two tribes: PENTAGONASTERINAE and GONIASTERINAE.

\section{TRIBE 1. PENTAGONASTERINAE。}

In the general discussion of the family LINCKIDAE, I explained why it seemed necessary to me to separate Fromia from this famity. The presence of a double row of very distinct marginal plates, the form of their odontophore, and the absence of supporting ambulacrals is clearly different.

The genera of Metrodira and Ferdina should follow the fortune of Fromia.

To these various genera I add Pentagonaster of Linck which, being the oldest named will give its name to the tribe, and Hippasteria of Gray, which was at another time Astrogonium phrygianum of Muller and Troschel.

There is a very varied opinion on the position and relations of the genus Pentagonaster.

In his classification, Perrier made with Goniodiscus (M. and T., emended), Gymnasteria (Gray), Asteropsis (M. and T.) or Petricia (Gray), Porania (Gray), and Dermasterias (E. Perrier) the first section of the family GONIASTERIDAE.

Except for Goniodiscus, on the position of which I remain uncertain, this section should disappear. Gymnasteria is reported beside Pentaceros. As for Asteropsis, Porania, and Dermasterias, they should re-enter the family ASTERINIDAE as we shall see further on.

Pentagonaster, by the slightly more slender form of their teeth, the absence of apophyses developed on their odontophore, the absence of interbrachial systems, and of spicules in their tube feet deviate from the true GONIASTERIDAE and quite approach Fromia.

The general form of the body, to speak truly, is very different in the two types I show. However, looking at Pentagonaster dilatatus and Pentagonaster pulchellus instead of Pentagonaster astrologorum, it will be seen that the arm is very clearly accentuated. Finally, the slender, elongated arms of Pentagonaster longimanus are no longer formed only by the marginal plates and the ambulacral systems. It is thus not necessary to attach great importance to the general form of the body, and to consider especially the characters furnished by the same structure of the skeleton.

Perhaps it will be necessary to add to this tribe the genera Goniodiscus and Nectria, which I leave provisionally in the GONIASTERINAE.

I have been unable to examine Nectria sufficientiy. As for Goniodiscus, the Goniodiscus plyadella, which is the only one for which I have been able to ascertain the characters, may only be a young Pentaceros according to Perrier.

The tribe of PENTAGONASTERINAE thus contains the genera Fromia Gray, Metrodira Gray, Ferdina Gray, Pentagonaster Linck, and Hippasteria Gray. 
GENUS FROMIA (GRAY).

1846. Fromia, Gray, Ann. and Magazine of Natural History, v. VI, p. 286. 1842. Scytaster, Mül 1er and Trosche1, System der Asteriden, p. 35.

22.

1845. Scytaster, Michelin, Faune de l'ile Maurice, Mag. de Zoologie, p.

1862. Scytaster, Dujardin and Hupé, after Buffon, Echinodermes, p. 367.

1865. Fromia, Gray, Synopsis, p. 14.

1866. Linckia, von Martens, Ostasiatische Echinodermen, Troschel's Archiv für. Naturgeschichte, 32nd y, vol. I, p. 69.

1869. Linckia, von Martens, C1. v. d. Decken's Reise, Seesterne und Seeigel, p. 130.

1869. Scytaster, Perrier, Pédicellaires, p. 62.

1875. Fromia, Perrier, Révision des Stellérides, p. 172.

of the four species of Fromia at the Jardin des Plantes, I have been able to study only the most common, Fromia milleporella, a pretty little species from the Red Sea, Ile Bourbon, and the Indian Ocean.

With Fromia indica, it constituted for a very long time the entire genus. It is only recently that Fromia monilis was distinguished definitively and Perrier described a new species Fromia balansae.

Figures 15-20 (1) refer to Fromia milleporella.

Figures 15 and 16, magnified two times, show how the skeleton is constituted on the two sides of the animal.

The dorsal surface is formed of polygonal plates with rectilinear sides. The face of these plates is slightly convex. As to their form, although it is very variable, it can be recognized that it derives in general from the hexagon. Some plates have this hexagonal form very well defined as can be seen, for example, on the medial line of the arms. There it is possible to follow a line, very irregular it is true, of these plates. It is impossible to describe the disposition of the other plates of the dorsal surface that have no regularity in their arrangement. They become smaller on the sides of the arms and towards their ends, and wider, in contrast, toward the medial line and on the disc. However, there are very small plates, mixed with the large, up to the middle of the disc. Nearly at the center is seen a large hexagonal plate that borders with two others, the anus an. This is found, as always, situated a little to the left of the line that would run from the madreporite plate to the tip of the opposite arm, supposing the madreporite plate behind it.

Between all of the plates of the dorsal surface, at their point of meeting, are isolated pores that give it the singular appearance seen in figure 15 that has given its name to the animal. This dorsal surface is nearly flat, slightly convex.

On each side of the arms appear two series of well-defined but irregular marginal plates. The dorsal marginal plates, nearly straight as seen in figure 18, do not encroach much on the dorsal surface except in the interbrachial angles where they are a little more developed. The ventral marginal series, also arranged nearly vertically, are in contrast not very apparent in the interbrachial angles and come to rest on the adambulacral series after a certain distance to the end of the arm (2).

(1) PI. X. (2) P1. X, fig. 16 . 
Nearer the mouth, the ventral surface is formed of longitudinal series, with the number of plates varying with each row. Those of this series, which are related to the adambulacral series, end beside the mouth with an unpaired plate connected with the teeth and exactly interbrachial. Behind it, the two plates of the rows of two adjacent arms meet on the interbrachial line. We rediscover exactly this arrangement in Pentagonaster (1).

Two other longitudinal series are interposed between this first ventral row and the inferior marginal series towards the base of the arm. However, they disappear successively near the first and second levels of its free part. Entirely at the top of the interbrachial angle, two or three more small pieces are placed between the third ventral series and the inferior marginal series.

As on the dorsal surface, there is a pore at the junction points of the ventral plates, except however on the interbrachial line which lacks them.

The adambulacral pieces are rectangular, rather thick and tightly packed against each other. The ray is nearly completely closed (2). The ambulacral pieces are short and are not, as in the LINCKIADAE, supported by supporting ambulacrals. The interbrachial section (fig. 17) shows, beyond the considerable thickness of the skeleton, that the interbrachial system does not exist here. However, in one of the angles of our specimen, there are two or three excessively small pieces in the fold of the peritoneal membrane. The triangular, pointed teeth differ entirely from those seen in the LINCKIADAE and their size is relatively great. From these two points of view they approach those of Scytaster, a1 though they are proportionally greater. However, the form of the odontophore completely differentiates Fromia from scytaster. This odontophore, magnified eight times in figure 19, has no apophyses developed as those in scytaster. In addition, the articulating surfaces are elliptical and not circular. Their large axis is situated in a direction oblique to the medial line of the piece. The axes of two articulating surfaces of the very same piece form between them an open angle beside the mouth (3). This remarkable arrangement is found exaggerated more in Pentagonaster (4). The piece is very flat.

The ocular plate (5) is round and very large. The madreporite plate is oval, and rather smal1. It rests on five dorsal plates and has radiating grooves that are sinuous and not close together. six.

The number of arms is five in this species. In Fromia indica there are

There are no pedicellariae.

\section{GENUS METRODIA (GRAY).}

1840. Metrodia, Gray, Ann. and Mag. of Natural History. vol. VI, p. 182.

1842. Scytaster, Mül ler and Troschel, System der Asteriden, p. 12.

1862. Scytaster, Dujardin and Hupé, After Buffon, Echinodermes, p.368.

1866. Metrodia, Gray, Synopsis, p, 12.

1869. Scytaster, Perrier, Pédicellaires, p. 62.

1875. Metrodia, Perrier, Révision des Steliêrlides, p. 180.

(1) P1. X, fig. 16 and 22. (2) Fig. 18. (3) Fig. 19', (4) Fig. 25'. Fig.15, oc. 
The sole specimen of this genus that the Museum has, Metrodira subulata, has only one intact arm. The center has a hole and the two surfaces of the animal have been polished. Thus it is hardly fit to study.

The slender and elongated arms are flattened below, and must have been slightly convex above as those in Fromia. The dorsal plates form three irregular rows on the arms. The bad state of the subject does not permit me to be certain of their disposition on the disc. On the ventral surface is a single row of rectangular, elongated plates, which seem to alternate regularly with those of the inferior marginal series. Between this ventral row and the marginal series are intercalated six small plates in the interbrachial angles. The inferior marginal series are formed of small trapezoid plates that alternate their wide and narrow ends. The superior marginal series are in contrast formed of rectangular plates. They seem to reach alone, with the dorsal row, up to the ocular plate which is rather large.

The madreporite plate is small and slightly projecting. As for the test, it is impossible to see them without a preparation that would result in the destruction of the subject. It thus is impossible for me to say with certainty on the place of this type that I leave between the genera Fromia and Ferdina.

It is necessary to read, in the memoir of Perrier (1), the description of the types of Gray he was able to examine in the British Museum and that differ sensibly from this one.

\section{GENUS FERDINA (GRAY).}

1840. Ferdina, Gray, Annals and Magazine of Natural History, vol. VI.

1875. Ferdina, Perrier, Révision des Stellérides, p. 183.

I have been able to make an examination of Ferdina flavescens of Mauritius. However, I have judged it useless to give here a series of figures. Plate $X$ was already composed when $I$ had the specimen at my disposition.

The general aspect recalls a little Scytaster variolatus that would have very short arms.

The adambulacral plates are small and rectangular. After them comes an irregular row, sometimes interrupted, of small and equally rectangular plates. There are then two irregular rows of larger plates of variable form and dimensions. The external row nearly reaches the middle of the arm. This ventral surface greatly resembles, as is seen, that of Fromia. However, there are no pores that would bring this type near to Pentagonaster. The marginal plates are indistinct, and the dorsal surface is composed of complex round and irregular plates between which are completely isolated pores. This last characteristic also belongs to Fromia. However, for the rest, Ferdina approaches scytaster. There are not found, in a section of the arm, supporting ambulacrals as well developed in this latter genus. The form of the odontophore, nearly identical to that of Fromia, finally fixes the plate of Ferdina for us. The teeth are the same as in this type. There are not, certainly, interbrachial systems or spicules in the tube feet. The madreporite plate is nearly rectangular, but disposed, moreover, nearly as in

(1) Loc. cit., p. 82 
Fromia. The animals of this genus are small. The specimen examined was 6 centimeters in diameter.

GENUS PENTAGONASTER (LINCK).

1733. Pentagonaster, Linck, De stellis marinis, p. 20.

1836. Goniaster (pars), L. Agassiz, Prodrome, etc., Mém. Soc. sc. Neufchâtel, vol. 1.

1840. Goniaster (pars), Müller and Trosche1, Wiegmann's Archiv, 6th y., lst vol., p. 322 .

1842. Astrogonium, Stellaster and Goniodiscus (pars), Müller and Trosche1, System der Asteriden, p. 52-62.

1840. Stellaster, Hosea (pars), Calliaster, Astrogonium, Pentagonaster, Tosia, Gray, Annals and Mag. of Nat. History, vol. VI.

1847. The same, plus Calliderma, Gray, Proceed. of Zool. Society.

1866. The same, plus Dorigona, Gray, Synopsis.

1866. Goniaster (pars), von Martens, Ostasiatische Echinodermen, Archiv für Naturgesch., 32nd y., vol. 1.

1871. Goniaster (pars), Lütken, Videnskabelige Meddels7ser.

1875. Pentagonaster, Perrier, Révision des Stellérides, p. 190.

A very profound discussion of the various species that should be replaced in this genus has been given by Perrier in great detail. In order to have the right to modify it anew or to confirm definitively the results he reached would have necessitated my study of each of the very different types that, for him, should be placed under the same name. Unfortunately, these animals are still rather rare in the collection of the Museum, and I shall be able to give here only the study of a single species Pentagonaster astrologorum. It represents very certainly the type of the genus and has the same name in Gray's classification.

There is no doubt that Pentagonaster does not belong to a type different from that we see in GONIASTERINAE. The entirely different form of the odontophore, the absence of the interbrachial system and of spicules in the tube feet, which I always encounter in GONIASTERINAE, evidently brings this Pentagonaster from the genera that we just studied.

Is it the same with Calliaster, Astrogonium, Calliderma, Dorigona, and Stellaster of Gray? I would not know what to say at the moment. Thus I leave intact the genus Pentagonaster of Perrier, making however the observation that all of the animals in which one would find odontophores with well-developed apophyses, interbrachial systems, and coronas of spicules in the tube feet should immediately pass into the tribe GONIASTERINAE. Likewise, it would be necessary to move Nectria and Goniodiscus into the PENTAGONASTERINAE. The relations of all of these types are very difficult to determine in fact, outside of these characters that I reported.

For Perrier, the name of Pentagonaster should be applied "to a genus characterized: by a skeleton entirely formed of circular, polygonal, or slightly wavy ossicles; by a more or less flat body edged by a double row of general rectangular marginal plates". Species whose dorsal ossicles are star-shaped should take the name of Goniodiscus. A difficulty occurs here. We are going to see that the dorsal ossicles of Pentagonaster are truly starshaped, only the projections do not go up to the top of the piece. The aspect is different, it is true, but is it a difference that can characterize 
absolutely a genus? I doubt it for my part.

In summary, I have demonstrated the necessity of separating the PENTAGONASTERINAE from the GONIASTERINAE. As to the Timits of these two tribes, they are still in part to be established. Because of the impossibility of my studying it, I have had to leave in the genus Pentagonaster all of the elements that Perrier included in it, i.e. Calliaster, Tosia, Goniaster (pars), Astrogonium, Calliderma, Dorigona, and, finally, Stellaster of Gray, the latter making a link to Goniodiscus. If Goniodiscus is really in the GONIASTERINAE, as I have not been able to completely assure myself, what is Stellaster? Should it also make part of this latter tribe? These questions will be able to be answered only by the complete examination of the anatomical characters unfortunately impossible today. However, it is now possible to affirm that all these animals should be united into a single genus as von Martens and, to a lesser degree, Doctor Lütken wanted.

Nearly a11 the Pentagonaster astrologorum of the Museum come from New Holland where they were collected in 1829 by Quoy and Gainard. The figures (1) that represent the two surfaces of the animal have been magnified $3 / 2$. The dorsal surface is composed of more or less convex plates with irregularly star-shaped borders. It is, moreover, only the bottom of the piece that is extended as a star as can be seen in the sections (2). The inferior surface of these dorsal plates is flat. Each of the small star-shaped extensions that garnish their base abuts end to end against its homologue of the adjacent piece to which it is simply juxtaposed without any kind of imbrication. The number of these extensions is ordinarily six per plate but it varies, according to the size and irregularity of the pieces, from three to eight and even more. The small poriferous areas thus are limited ordinarily between three adjacent plates, sometimes four. The dimensions of the ossicles vary a lot. In the middle of the arm there is a nearly regular line of hexagonal plates. These plates are of average size, uniform, and have two sides perpendicular to the direction of the arm. The interbrachial angles are very little marked, the asteroid being nearly pentagonal. There is exactly in the middle of the interbrachial angle a plate, elongated in the direction of the interbrachial, that leaves the superior marginal series. There is in the interbrachial angle a very large plate that immediately follows two paired plates of a still larger size. A fifth large plate, forming a losenge with these last three, occupies an exactly interbrachial position like the two first ones. This plate, with its four homologues of the other arms, forms a regular pentagon. In the interior of the pentagon is another composed of smaller pieces that alternate with the larger ones in surrounding a dorsal-central plate. The madreporite plate (3) is situated in the center of the losenge of large pieces, but rests only on the most internal, especially the two lateral. These pieces are indented in the form of a kidney to leave space for the hydropore canal. Imagining the madreporite plate behind, it is on the left side of the dorsal-central plate, between it and the two that form the left inferior side of the internal pentagon where the anus an opens. The smallest dorsal pieces occur along the marginal plates and at the top of the arms.

The marginal plates form two rows. The upper row has six pieces from the top of one arm to that of the adjacent arm, while the lower row has fourteen.

(1) P1. X, figs. 21 and 22. (2) Id. figs. 23 and 24.(3). Fig. 21, m. 
On each side of the interbrachial line are two plates, nearly the same size, in each of the two ventral and dorsal series. These four plates correspond exactly. They are rectangular and have a convexity that is more marked in the dorsal than in the ventral. The end of the ventral marginal series is composed of five plates that decrease rapidly in size towards the end of the arm. The last is very small as can be seen in figure 21 at the end of the left arm. To these five ventral plates corresponds a single, large dorsal plate. It is by far the largest of all in the skeleton and can attain, in Pentagonaster pulchellus for example, an enormous development. The two plates that form the end of the dorsal marginal series of the same arm first connect to each other on the medial line, then separate a little to leave space for the ocular plate oc that is nearly circular and flat. The end of the arm is always a little raised. This permits the last dorsal marginal plate to correspond to the last five ventral ones, although it is really shorter than all of these five plates.

The ventral surface is composed of flat ossicles of irregularly quadrangular form. They are tightly pressed against each other their entire length and form a sort of pavement. Their surface is nearly flat. At the very top of the interbrachial angle and in contact with the teeth is an unpaired plate from which leave two series of plates. These are the adambulacral series. The first two plates connect on the interbrachial line behind the unpaired plate.

The other series, whose dimensions decrease, are in direct connection with the adambulacral series. This arrangement is found again the entire length of the well-developed arms of Pentagonaster longimanus where the ventral plates strictly speaking exist only on the disc. In this animal, moreover, it is the same with the dorsal ossicles. There are the marginal dorsal plates that, uniting along the medial line like the last pair of Pentagonaster astrologrum, complete the arm skeleton.

The adambulacral pieces are nearly quadrangular, thin, and tightiy pressed against each other. Their inner edge is marked by a double groove parallel to this border that is continued on the teeth.

The ambulacral pieces are slender and short. However, because of the thinness of the animal, their upper extremity nearly reaches the dorsal surface. There are no supporting ambulacrals nor interbrachial systems. The interbrachial area is only divided by a vertical fold of the peritoneal membrane.

The teeth are triangular and pointed as we have seen in Fromia and as we shall find, moreover, in all the rest of the GONIASTERINAE. Onty here it seems they are much more limited in function because of the form of the odontophore, as we find it more elongated and much less massive. The odontophore is exactly of the same type as that of Fromia. It is very flat, with the apophyses 1ittle developed, with large articulating, elliptical facets (1) whose major axes form an open angle at the side of the mouth. It differs absolutely from the so remarkable type that we see in the GONIASTERINAE.

The madreporite plate is rather large, triangular, with a very round top and the base turned towards the center of the disc. It is slightly concave and marked with sinuous and radiating grooves.

There are no pedicellariae in our specimen, no more than in any of those

(1) P1. X, fig. 25'. 
of the same origin. There are in contrast very small valvate pedicellariae in two individuals originating from the collection of Michelin. Perrier, who has given a detailed description of them, hesitated to separate them as distinct species. Moreover, these small organs occur in Pentagonaster pulchellus. They were described by Perrier in 1869 in his memoir on pedicellariae.

GENUS HIPPASTERIA (GRAY).

1733. Pentaceros (pars), Linck, De stellis marinis. 278. 1840. Hippasteria, Gray, Annals and Magazine of Natural History, $p$.

1844. Astrogonium (pars), Müller and Troschel.

1865. Goniaster (pars), von Martens.

1871. Goniaster (pars), Lütken.

1875. Hippasteria, Perrier, Révision des Stellérides, p. 270.

For Perrier, the genus Hippasterias is distinguished from the genus Pentagonaster by the extraordinary development of the valvate pedicellariae of the two surfaces of the animal. When pedicellariae are encountered in Pentagonaster, they are always very reduced. I understand that the comparison of the ventral surfaces of Hippasteria and Anthena have led to a combining of the two types. However, a closer examination shows us great differences between them.

The disposition of the ossicles is little apparent on the surface, and I cannot give exact information on the exterior skeleton. However, I have removed a pair of teeth from one of the specimens and I thus have been able to ascertain that there is no interbrachial system. The teeth are strong, but the odontophore, although it begins to have a little better marked apophyses, quite recalls the very characteristic form we have seen in Pentagonaster. There are no spicules in the tube feet. A11 of these characters clearly distinguish this genus from the two genera Goniaster and Anthenea. The peculiar aspect of the ventral surface of Hippasteria had led to its classification to these two genera that are in the GONIASTERINAE as we shall see later. asteroid.

The space at my disposal does not permit me to give figures of this

Hippasterias plana, the only species known, inhabits the northern seas.

TRIBE 2. GONIASTERINAE.

For Perrier, the family GONIASTERIDAE, with very disparate forms, corresponded to the genera Pentagonaster and Pentaceros of Linck; Goniaster and Culcita of Agassiz; and Astrogonium, Goniodiscus, Stellaster, Asteropsis, Oreaster, and Culcita of Müller and Troschel. Gray combined all these types, as well as those that constitute the families of ECHINASTERIDAE and LINCKIDAE of Perrier, into a large family to which he gave the name of PENTACEROTIDAE.

The distinction that Müller and Troschel established between their Astrogonium and their Goniodiscus is quite insufficient. They differentiated them, in fact, only on the disposition of the granules that surround only the marginal plates of the first and completely cover those of the second. There are all transitions between these two states. Accordingly Lütkin and later 
von Martens proposed uniting Astrogonium, Goniodiscus, and Stellaster of Müller and Troschel into a single genus Gonioaster. Perrier did not adopt this point of view, although he recognized the genus Goniodiscus ( $M$. and $T$. ) to be completely artificial. He united to the true Astrogonium, i.e., Pentagonaster, Goniodiscus singularis and mammillatus (M. and T.), which differ from it only by the granulations of their plates. Of these, no more than of stellaster, we shall not speak now as we have placed them in our tribe PENTAGONASTERINAE.

The species that have their skeletal ossicles variously notched to leave space for the tube feet, and whose anus is surrounded by four plates, form the genus Goniodiscus of Perrier. Of the six species he recognized in this genus, the Museum has only three. One only, Goniodiscus pleyadella, of which a deteriorated specimen has allowed me to ascertain the characters, is reattached confidentiy by me to the GONIASTERINAE. However, as Perrier raised the possibility that it is only a juvenile pentacerous, I remain undecided about the definitive position of this genus.

The Goniodiscus pentagonulus of Müller and Troschel, to which Perrier correctly restored the name Anthenea that Gray had given it, is perfectly distinct because of the articulation of its back, the pedicellaria of its ventral surface, and the singular development of its interbrachial systems.

Finally, the Goniodiscus ocelliferous (Müller and Troschel), which should keep the name Nectria (Gray), al so stays perfectly distinct. However, the state of the two specimens of the Museum do not permit me to determine confidently the place of this genus.

To the type Anthenea it is necessary to unite the Asterias obtusangula of Lamarck that Müller and Troschel had counted as Oreaster and whose ventral surface quite resembles that of Anthenea. This is the type to which Perrier applied the name Goniaster.

These two genera seem to make a perfectly natural section of the tribe GONIASTERINAE.

In a third section, we find the genera Astrodiscus (Gray), Culcita (Agassiz), and oreaster ( $M$. and T.) to which Perrier restored with justice the name of Pentaceros which it held from Linck. The genus Randasia (Gray) is only a young Culcita.

Beside Culcita is still placed Nidorellia (Gray) and Choriater (Lutken). From Pentaceros, a genus that may need to be divided as we see later, should be dropped Gymnastria ofGray. This leaves only the genus Asteropsis of Müller and Troschel.

These Asteropsis have as a common character only the immersion of the skeletal ossicles in a thick naked skin without spines or grannules.

Perrier, who corectiy distinguished Gymnasteria, which he believed a1lied to Pentagonaster, was very undecided on the place of other Asteropsis should occupy. He did not think that they should be, as Gray did, united with the ASTERINIDAE, and left them in the family GONNIASTERIDAE. It will be seen later why I separate them from this family whose 7 arge and rounded teeth suffice, moreoever, to distinguish them immediately.

In summary, our tribe GONIASTERINAE is divided into three sections. The second should perhaps disappear, either by joining with the third or by uniting with the tribe PENTAGONASTERINAE.

The constant characters of the tribe GONIASTERINAE are well-developed and pointed teeth, odontophores with well-developed apophyses, interbrachial systems of various but constant forms, and finally a corona of spicules in 
the rosette of the tube feet.

The three sections of this tribe are: A, the genera: Anthenea (Gray; Goniaster Agassiz (in the sense the Perrier has given this name). -, the genera: Goniodiscus Müller and Trosche1; - Nectria Gray. - C , the genera: Asterodiscus Gray; - Culcita Agassiz; - Choriaster Lutken; - Nidorellia Gray; - Pentaceros Linck; Gymnastria Gray.

GENUS ANTHENEA (GRAY).

1840. Anthenea, Gray, Annals and Mag. of Nat. Hist., p. 279.

1835. Goniaster (pars); Agassiz, Prodrome d'une Monogr. des Radiaires, Mém. Soc. sc. Neufchâtel.

1842. Goniodiscus (pars), Mül1er and Troschel, System der Asteriden.

1865. Goniaster (pars), von Martens, Ostasiatische Echinodermen, Archiv für. Naturgeschichte, 31 st year.

1875. Anthenea, Perrier, Révision des Stellérides, p. 271.

It is Anthenia articulata, species of the Seychelles Islands, that has furnished the figures of plates XI and XII. Unfortunately the specimen was a little damanged. It was not possible for me to draw the madreporite plate.

Figures 1 and 2 ( $p$ late XI) are of natural size and show the disposition of the skeleton on the two surfaces of the animal.

The dorsal surface is completely composed of an admirably regular articulation. However, it is little apparent in a minute preparation as the ossicles are drowned in a very thick skin.

The principal ossicles of the back are very convex, nearly hemispherical, and have six small projections in a star shape. Smooth, cylindrical connective pieces, rounded at the end, support the two projections of two adjacent ossicles to which they are fastened. Each principal ossicle is thus connected to six adjacent ossicles. The whole of the reticulation forms a triangular mesh. The dimensions of the ossicles and the mesh they form decrease towards the arm tips.

The medial row is formed of pieces of a special form. They are indeed elongated transversely. However, their medial part alone is swollen like the ossicles of the lateral series and has two small projections resembling those of these ossicles. The lateral parts, in contrast, are a little flat and serve to support the two connective pieces. As a result, the mesh of each side of the medial line has a pentagonal form with the base turned towards this 1 ine (1). This arrangement, which exists the entire length of the arm, disappears towards the center where the ossicles take the ordinary form.

The end of the arm has, in the angle formed by the dorsal marginal series, some large quadrangular pieces, slightly convex and in general arranged transversely. The presence of these pieces is troublesome for the theory that the growth of the animal occurs by the addition of new pieces behind the ocular plate. What indeed becomes of these plates during this growth? They are obviously too large for one to be able to see in them future dorsal ossicles. As for considering them as marginal plates in the process of formation, their singular situation and the fact that they are already larger than the marginal plates situated immediately behind the ocular plate makes this opinion as little probable as the first. This is

(1) P1. XI, fig. 1 . 
certainly an interesting problem to resolve, but I cannot now propose a solution.

The medial series and the two adjacent lateral series reach only to these large pieces that complete the end of the arm. On each side, another series comes equally close to this level. Further on, there is another that stops nearly halfway. Finally, a last series is composed only of two or three pieces. There is no transition between the marginal plates and the dorsal articulation that stops abruptly at their level.

Towards the center of the animal, the reticulation loses its regularity. Sometimes there are two dorsal ossicles juxtaposed, without interposition of connective pieces. There is then imbrication between the small extensions of these ossicles. At the center, a little to the left, is the anus an surrounded by irregular plates.

The interbrachial 7 ine is remarkable for the projections made by a double row of rather irregular ossicles, some of which are very large. They belong to the interbrachial system as can be seen in figure 2 (pl. XII), and we shall speak of it later. They never have alveoli with pedicellariae, as we see with some of the adjacent ossicles. At their level, the reticulation becomes very irregular and has no direct relation with them.

A double row of marginal plates encircles the animal. These plates correspond exactly in the two rows except at the very end of the arm. Leaving the top of the interbrachial angles, or rather the interbrachial line, as here the body is a little less pentagonal, on our specimen are ten pairs of exactly corresponding plates. Leaving from there are no more than three dorsal plates up to the ocular plate, while there are four ventral ones. The number of marginal plates from the tip of one arm to that of an adjacent arm is therefore twenty six for the dorsal series and twenty eight for the ventral series. The end of the arm, being slightly raised, permits the agreement although the plates are still of corresponding dimensions in the two series.

A11 the marginal plates are rectangular with rounded ends. They are a little more elongated in the dorsal series and always positioned transversely. The plates of the ventral series are pierced with a large number of alveoli on which are lodged pedicellariae of 7 arge size. These pedicellariae are more numerous on the plates adjacent to the arm tip. The plates of the dorsal series carry as well some alveoli with pedicellariae towards their external border. However, these alveoli are much smaller and in much fewer numbers (1).

The ventral surface is composed of pieces in the form of oblique boxes that overlap each other from the marginal series towards the ambulacral groove and whose upper end narrows to a point. The lower base, in the form of an irregular losenge with one side parallel to the ambulacral groove, has an alveolus with a pedicellaria in the major diagonal of the losange, occupying the entire surface of the piece. These singular ossicles, which give the animal lits characteristic physiognomy, are not tightly pressed against each other and are arranged in series with the adambulacral series. There are up to six of them, and the dimensions of the plates and their number diminish progressively. The eleventh ventral marginal plate and those beyond are in direct connection with the adambulacral series.

In addition to the arrangement of the ventral ossicles in longitudinal

(1) PI. XII, fig. 1 and 2 . 
series, they also clearly form transverse series, oblique and diverging to the ambulacral groove like the barbs of a feather. Towards the interbrachial line, the arrangement becomes very irregular, especially at the top of the interbrachial angle. There, large pieces (1) belonging to the interbrachial system force their way to the surfade and separate the ventral ossicles.

The adambulacral pieces are quadrangular, thick, and tightly pressed against each other. Each of them has, near the middle slightly towards the border of the mouth, a small alveolus with a pedicellaria. The alveolus is not elongated like the others, but circular. It has a forcipulate pedicellaria while all the others are valvate pedicellariae.

The ambulacral pieces are very robust, and occupy the entire thickness of the body. On the dried specimen, they push back even the dorsal surface that, concave everywhere else, has five longitudinal ridges at the site of the five grooves (2).

The first ambulacral piece is very strong and has a well-developed wingshaped apophysis. This arrangement is in harmony with the size of the tooth $d$ (3) that is quite remarkable, as it is moreover in all the GONIASTERINAE. These long and pointed teeth are marked with a series of projections where the buccal spines are inserted.

The odontophore (4) is, as in all this tribe, one piece thick and possesses two projecting apophyses. The dorsal surface is composed of two inclined planes. The principal differences that can be ascertained in the form of this piece in the different genera of the tribe pertains to the point where these two planes stop. They stop very near the oral surface in Anthenea, nearly at the middle in Pentaceros, and in contrast very near the other extremity in Culcita. The other differences consist principally in the relative divergence of the apophyses. They nearly form a right angle in Anthenea (fig. 3) and are not very open as in Pentaceros (fig. 6).

The interbrachial system in Anthenea reaches the greatest development that one finds in asteroids. Not only, indeed, do they nearly completely seal the interbrachial area, but the tall and powerful pieces that constitute them project from both surfaces of the animals as we have seen above (5).

There is especially one piece bi, particularly remarkable, that is named the interbrachial basal. This long and arched piece, which projects from the dorsal surface and is really one of the dorsal pieces, abuts against the other pieces of the interbrachial system.

When the dorsal surface is looked at from below, these five pieces form a regular star with five branches around the center. The one corresponding to the madreporite plate is hollowed by a groove to hold the hydropore canal. unusual.

The ocular plate oc is small, as in ail this tribe, and shows nothing

The madreporite plate, which the state of my subject does not allow me to illustrate, is in this species nearly a third of the distance from the center to the edge of the disc. It is elliptical and furrowed with grooves that diverge and divide in leaving the center.

This species has been described well, at least for that which one can see without dissection, by Perrier, at first under the name Goniodiscus articulatus or Astrogonium articulatum in his Recherches sur les pédicellaires, then under its present name in his Révision des Stellérides.

(1) P1. XI, fig. 2, i. (2) PI. XI, fig. 1, and p1. XII, fig. 1. (3) PI. XII, fig. 2. (4) PI. XI, fig. 3. (5) PI. XII, fig. 2, and pI. XI, fig. 1 and 2 . 


\section{GENUS GONTODISCUS (MULLER AND TROSCHEL).}

1842. Goniodiscus (pars), Müller and Troschel. System der Asterides.

1865. Hosea (pars), Gray, Synopsis.

1866. Goniodiscus (pars), von Martens, Ostasiatische Echinodermen, Archiv für. Naturg., 32nd year, lst vol.

1875. Goniodiscus, Perrier, Révision des Stellérides.

For Perrier this genus coreresponded to one part of the genus of Mülier and Trosche1. Al1 the genera that composed it entered the genus Hosea of Gray.

Goniodiscus has, as Pentagonaster, the arms and disc bordered with a double series of large marginal plates, very different from the other plates of the skeleton. "It is the form of the dorsal pieces", said Perrier, "that distinguishes our Goniodiscus. While the skeleton of the dorsal disc is formed by contiguous rounded or polygonal plates in Pentagonaster and Hippasteria and by a network of calcareous ossicles in Anthenea, here they are formed by polygonal plates with notched sides. Each plate touches its neighbor only by projecting parts that separate the notches. Thus there are empty spaces between the plates filled by tube feet."

In referring to the study we made above of Pentaceros astrologorum, it is seen that there also the plates are polygonal with notched sides and touch only by projecting parts. Nevertheless, it is a true Pentagonaster. This arrangement, which exists without doubt in all the genera, loses nearly all its value as a characteristic. Whether the projections occupy, in fact, the entire height of the piece or only the base will affect the aspect, without doubt, but the pieces are morphologically identical.

Another difference is that the anus in Goniodiscus is located between four dorsal plates arranged in the form of a cross around it, instead of being surrounded by three plates as we have seen in Pentangonaster. However, in Ferdina, which certainly belongs to the PENTAGONASTERINAE, the anus is surrounded by three plates.

The Goniodiscus cuspidatus the Museum possess has beeen described in detail by Müller and Troschel. As Dujardin and Hupé have given a translation, I do not believe it useful to repeat this description.

Goniodiscus sebrae, of which the Museum also possesses only a single example of unknown origin, having given rise to some doubts, was redescirbed by Perrier. It has seemed useful to me to complete this description.

The animal has five very marked rays, pointed at their end. There are eighty marginal plates in each of the dorsal and ventral series from the tip of one arm to that of the adjacent one. The last six ventral marginal plates are in direct connection with the adambulacral series. The last dorsal marginal is very small, and the three following, although noticeably larger than it, are much smaller than all the others. The teeth are much stronger than in Pentagonaster. They are truly the teeth of Pentaceros. The plates of the back are tightly juxtaposed as in Fromia, but they are much less convex. There is distinguished very clearly a medial series of the arm, and two series nearly exactly symmetrical on each side of the interbrachial 1 ine. In the interval left free by the indentation of the plates is an alveolus with a pedicellaria. The madreporite plate is large, elliptical, and nearly at the center from the border of the disc. The ventral plates are arranged nearly as in our type of Pentagonaster. They have, as well as some margina? 
plates, three or four small irregularly placedpedicellariae. There is an additional pedicellaria at the angle of each adambulacral plate.

Goniodiscus pleyadella has been described in detail by Müller and Troschel. However Perrier attributed it to the genus Goniodiscus only with misgivings. The keeled form of the arms, the five large tubercles situated on the disc and forming a pentagon whose top corresponds to the medial line of the arms, strongly recalls Pentaceros, of which it could very well be the juvenile. Moreover, the form and disposition of the dorsal plates recall more that we see in Pentaceros muricatus and $P$. turritus than that one finds in other Goniodiscus. There exist in the Museum only two specimens of this species. They were brought here by Peron and Lesueur in 1803. One is intact. The other has an arm broken at the base which has permitted me to ascertain the existence of an interbrachial system like that of pentaceros cited above and of culcita. In addition, the tube feet have rosettes of calcareous spicules arranged in a single row. Thus I have no doubt that this species belangs to the tribe GONIASTERINAE. Whether it is the same for the other Goniodiscus, the state of the two dried specimens of the Museum does not allow me to decide.

\section{GENUS NECTRIA (GARY).}

1840. Nectria, Gray, Annls and Magazine of Natural History, p. 287. 60.

1842. Goniodiscus (pars), Müller and Trosche1, System der Asteriden, $p$.

1862. Nectria, Dujardin and Hupé, after Buffon, Echinodermes, p. 406.

1869. Nectria, Perrier, Pédicellaires, p. 91.

1875. Nectria, Perrier, Révision des Stellérides, p. 185.

Nectria, which Müller and Troschel placed in their Goniodiscus, seems to me, with even more justification than these latter ones, to have to be a part of the tribe GONIASTERINAE although it has been impossible for me to completely assure myself of it. The teeth are, it is true, a little slender and resemble more those of Pentagonaster than those of Pentaceros. However, the back shows us an arrangement found only in the GONIASTERINAE. Each dorsal ossicle is in fact isolated by itself from its neighbors to which it is connected only by six small connected pieces fixed to its base by ligaments. It is true we have seen something analogous in chaetaster. However, in this type there were only four connective pieces, and the ossicles of the same longitudinal series were not at all directly connected with each other. In Nectria, in contrast, the connective pieces form a star with six branches and limit a very narrow poriferous area. The form of the large dorsal ossicles is quite remarkable. They are in fact cylindrical or in the form of an inverse cone with the superior surface clearly sectioned and nearly flat. The quite special appearance it gives the animal justifies completely its separation as a genus. The ventral surface is composed of sma17, polygonal, slightly convex plates that appear a little imbricated.

The dorsal and ventral marginal plates are equal in number. Those towards the end of the arms are often very small. All are rectangular.

The small and convex madreporite plate is situated at a level less elevated than the top of adjacent ossicles. There are no pedicellariae.

The two specimens of the Museum, which Perrier believed had to differ specifically and described in detail in his work, were both taken from 
104

southern seas by Peron and Leseur. One is dried; the other is in alcohol. Their state of preservation is very defective.

I believe I have ascertained the existence of interbrachial systems on the specimen in alcohol. However, the care necessary to take of the specimen has not at all permitted me to elucidate this manner in a definitive manner. In addition, no tube feet remain. As a consequence, I am not able to know if there are rosettes of spicules. As yet, the position of this genus, al though very probably that I have given it, is not fixed definitively.

There are no pedicellariae.

\section{GENUS ASTERODISCUS (GRAY).}

1847. Asterodiscus, Gray, Proceedings of the Zoological Society, p. 78.

1875. Asterodiscus, Perrier, Révision des Stellérides, p.256.

There is only a single species, Asterodiscus elegans, represented in the Museum by a single specimen in alcohol without indication of origin. The type of the British Museum came from China.

The specimen I have been able to examine, and only in a very insufficient manner, quite resembles culcita except for the two large marginal plates. These recall a little those of Pengagonaster pulchellus. The ocular plate is between them. The ornamentation of the skin and its thickness hides all the rest of the skeleton. The madreporite plate is very small, nearly circular, convex, and marked with very fine grooves.

This genus is without doubt allied very close to the following.

GENUS CULCITA (AGASSIZ).

1834. Les Oreillers de Blainville, Manuel d'Actinologie.

1835. Culcita, L. Agassiz. Prodrome d'une monogr. de Radiaires, Soc. SC. de Neufchâtẹt.

1875. Culcita, Perrier, Révision des Stellérides, p. 257.

The species of which I have published a detailed description is Culcita schmideliana that lives off the coast of east Africa, Madagascar, Bourbon, etc.

The animal that served as my subject was very deformed, which gave to the dorsal reticulation a very irregular aspect far from that of other specimens.

I have preferred however to make the exact reproduction with the camera lucida instead of giving a corrected figure that still would have been more or less theoretical. I have, moreover, always conformed to this rule.

Figures 5 and 6 (p). XII) represent the two surfaces of the animal at natural size.

The dorsal surface of the animal is composed, as in Anthenea, of large rounded ossicles in the form of batonettes. It is very difficult to bare, without disturbing their position, all these pieces that are entirely embedded in a very thick skin.

The principal ossicles are here much larger than in Anthenea. The number of connective pieces is not fixed and can go up to eight for each ossicle. The anus an is large and edged by a variable number of irregular pieces. Around them, towards the middle of the disc, are the largest 
ossicles after, however, those that support the madreporite plate $m$. This is large, nearly circular, marked with radiating and winding grooves, and rests on five pieces that are the largest of the entire dorsal skeleton. It is nearly half the distance from the center of the disc to the border of the marginal series.

The marginal plates are very irregular in this animal. The pieces of the superior row are nearly vertical, while the inferior marginal plates are in large part covered by the ventral pieces. Their number seems to correspond in the two series towards the middle of the sides, but this agreement ceases towards the top of the angles. There are on our specimen sixteen dorsal plates and twenty-two ventral plates from one tip to the other. The dorsal plates have their upper part visibly inclined towards the top of the corresponding angle on each side of the interbrachial line (1). The ocular plate oc is very small as in all this family.

The ventral surface is composed of thick ossicles, normally with a hexagonal surface except at the border of the ambulacral groove where it is pentagonal, and towards the margin of the disc where it becomes irregular. These ossicles, as can be seen in the sections (2), recall what we saw in Anthenea, and can be compared to the oblique prisms slightly inclined towards the adambulacral series. Their surface is nearly flat and smooth in this species, although in others it is pitted with small alveoli with pedicellariae.

They are arranged in regular series, parallel to the border of the ambulacral groove. However they become without apparent order towards the border of the disc where they are much thinner and cover the inferior marginal plates. The group forms a veritable pavement.

The adambulacral pieces are rectangular, with 7 arge sides disposed vertically, very thick and very tightly packed against each other. The ambulacral pieces are tall and strong and, in the dried animal, they come in contact with the internal surface of the back.

The first ambulacral piece is here very developed, and its wing-like apophyses very projecting.

The strong and pointed teeth are however smaller proportionally than in the animals of the same tribe. They are situated at a level notably different from that of the ventral pieces. The most advanced ventral piece in the interbrachial angle projects from beneath them (3).

The odontophore (4) has the same typical form as in all the GONIASTERIDAE. The very open angle the apophyses make betyween them can be noted here. In addition, it is seen that the thickest portion of the piece occurs at its excentric end and that it becomes thinner nearly regularly in the direction of the mouth.

The interbrachial systems have here a disposition we have not yet encountered. It appears most frequently in this family as in the ASTERINIDAE.

A Tine of ossicles (5) goes from the odontophore to the internal surface of the back of the animal, in describing a concavity turned from the side of the mouth. The arc thus formed is not at all rigid but can to the contrary be completely bent as is found in the dried animal, or to the contrary extend itself nearly in a straight line in the animal full of ingested material. The

(1) PI.XII, fig. 5. (2) PI. XIII, fig. 1 and 2. (3) PI. XIII, fig. 2. (4) PI. XII, fig. 7. (5) PI. XIII, fig. 2, i. 
length this line of ossicles can attain in its state of complete extension can be noted in our figure. It is understandable how Gray was able to write, without any doubt correctly, that this animal we find so flat in our collections is ordinarily nearly globular in its living state. As should be expected there, the dorsal-ventral muscles, whose disposition I described in the general discussion on the mouth of adambulacral asteroids, are very well developed here as, moreover, in all the animals that have this form of interbrachial system.

The elasticity of the skin could not suffice in fact to establish the form of the animal distended so greatly without the aid of a direct muscular action, and powerful by the mode of muscular insertion itself.

The tube feet of this culcite are very powerful, and their rosettes of spicules are large, thick, and composed of a large number of tubular and alreolar spicules and others of a simpler form. This arrangement, which we find in all the species of this genus, is the most complicated that one encounters in the asteroids. Accordingly, I have chosen it as the type. An entire rosette at a magnification of 120 times: $b$ is the border; $c$ is the central side.

There is a line of very small forcipulate pedicellariae on each side of the ambulacral groove, and numerous pedicellariae on the back. These latter have a form intermediate between the valvate type and the forcipulate type.

Culcita schmideliana was described in 1871 by Schmidel, who was especially struck by the arrngement of the poriferous areas. These areas, so remarkable in most of the culcites, are not so obvious in Culcita coriacea where the disc is uniformly granular. seas.

The six species of culcites now represented in the Museum inhabit warm

The Randasia of Gray is a young calcite.

\section{GENUS CHORIASTER (LUTKEN).}

1869. Choriaster, Lütken, 4e catalogue du Musée Godefroy (Hamburg), p. 35, and 1871, Videnskabe7ige Meddele7ser, p. 243.

1875. Choriaster, Perrier, Révision des Stéllérides, p. 256.

A single species of this genus, Choriaster granulatus, was described by Dr. Lutken. It came from Fiji and is not represented in the Museum of Paris. The form of its body makes it an intermediate between Culcita and Pentaceros. The prominent character of its physiogomy is the absolute smooth aspect of the animal, which is covered above and below by a tough skin. The description of Lutken teaches us nothing about the constitution of the skeleton, which should be, as in the culcites, nearly impossible to see without preparation.

one does not encounter pedicellariae.

\section{GENUS NIDORELLIA (GRAY).}

1840. Pentaceros, sub-genus Nidorellia, Gray, Annals and Magazine of Natural History, p. 277.

1840. Paulia, Gray, same work, pl 278.

1842. Goniodiscus (pars), Müller and Trosche1, System der Asteriden, $p$. 57.

1875. Nidorel7ia, Perrier, Révision des Stellérides, p. 251. 
Nidorellia is an animal that inhabits the west coast of the two Americas.

The form of its body differentiates it from Pentaceros, to which one would have wanted to unite it at first, and makes it resemble culcita, or rather Anthenea because its body is less thick than Culcita and the form less exactly pentagonal. The sides are slightly concave as in Asthenea articulata.

The dorsal skeleton is little apparent across the skin. However, it is probable from the arrangement of the very extensive poriferous areas that it has a constitution analogous to that we have seen in Anthenea and Culcita.

As near as can be judged, the ventral surface seems a little like that of the culcites. However, the marginal plates differ from that we have seen in the two types of this family we described above. Indeed, instead of decreasing while approaching the arm tip, the dorsal marginals increase in size. The terminals are very large and bulging. The ocular plate, very small in comparison, is in the groove that separates them. There is here an arrangement that recalls that seen in Pentagonaster pulchellus, or yet in Asterodiscus elegans, where the terminal marginal plates alone are apparent. glance.

This single character suffices to distinguish Nidorellia at first

I shall not emphasize here the remarkable arrangement of the spines. That goes into the description of the species found in full of the memoir of Perrier.

The madreporite plate in the specimen of Nidorellia armata of which I have been able to make a superficial examionation was large, irregular, and finely and irregularly striated.

\section{GENUS PENTACEROS (LINCK).}

1733. Pentaceros Linck, De stellis marinis.

1833. Goniaster (pars), Agassiz, Prodrome, Soc. sc. de Neufchâtel.

1840. Pentaceros, Gray, Ann. and Mag. of Natural History, p. 276.

1842. Oreaster, Müller and Troschel, System der Asteriden, p. 44.

1862. Oreaster, Dujardin and Hupé, After Buffon, Echinodermes, p. 379.

1864 and 1871. Oreaster, Lütken, Videnskabelige Meddelelser.

1866. Oreaster, von Martens, Ostasiatische Echinodermen.

1867 and 1871. Oreaster, Verri1, Transactions of Connecticut Academy.

1869. Oreaster, Perrier, Pédicellaires.

1869 and 1877. Pentaceros, Al. Agassiz, Bulletins and Memoirs of the Museum of Comparative Zoology.. -- Cambridge (Massachusetts).

1875. Pentaceros, Perrier, Révision des Stel7érides.

of the thirteen species of Pentaceros found described in the memoir of Perrier, only nine are represented in the Museum of Paris.

One distinguishes in this genus two types so different that it would perhaps be advantageous to separate them into two distinct genera. I shall do nothing about it however, wanting to restrict myself in the present work to the familial arrangement of the genera already recognized. Moreover, it would be necessary to study each of the species of Pentaceros in order to be able to decide on thier place.

If Pentaceros reticulatus and Pentaceros muricatus are considered, the 
differences they have are striking. I have believed it necessary to give a detailed description of each of the two species.

If it were desired to make two distinct genera of the types, it would be necessary to put in the first, as much as an external examination allows judging, Pentaceros mamillatus, $P$. regulus, and $P$. dorsatus, while Pentaceros turritus and $P$. hiulcus would be placed in the second, Pentaceros alveolatus perhaps being intermediate.

The arms are clearly accentuated in all the Pentaceros, as the name Linck gave them expresses, except however in the Pentaceros granulosus of Gary. This species, which lives in Australia, has rather the form of a Goniodiscus. As it is not at all represented in the Museum of Paris, I have not been able to assure myself that it is a true Pentaceros.

Let us pass on to the description of our two types:

Pentaceros reticulatus, a species of the Antilles and the southern Atlantic, has been known for a long time, and is found reported by Rondelet in his book de Piscibus marinis (1554) under the name of Stella reticulata seu cancellata. Aldrovandi, Mathoeus, Gessner, Johnston, Margrau, Rochefort, 07 earius, Sloane, and Brown have spoken of it after him, nearly always under the same name. Finally, since Linck himself imposed its present name, the synonymy of this species has varied considerably. I can only refer on this subject to the memoir of Perrier.

Figures 4 and 5 of plate XI show, at natural size, the skeleton of the two surfaces of the animal.

The dorsal surface is composed of a nearly flat, elevated disc to which are attached the inclined surfaces of the strongly keeled arms. Figures 3 and 4 (p1. XII) allows judging the thickness of the animal.

In the middle of the central disc is found a large, elongated ossicle, slightly indented on the left in the form of a kidney. The anus an is found on this side. The edge of this disc is bordered by a series of ossicles of the same form as those seen in Anthenea. Five of them, larger than the others, mark the beginning of the medial series of the arms. The others, slightly smaller, are disposed between them by pairs corresponding to the interbrachial lines. The madreporite plate $m$ is supported on two of these pieces that are modified in their much larger size and form. The madreporite plate is very small compared to the size of the animal. It has the form of a triangle with rounded angles, with the base turned towards the center of the animal. It is marked by fine grooves, divergent and sinuous. Beneath it, the supporting pieces are indented to allow passage of the hydropore canal.

on the interior of the central disc, the reticulation is very irregular and often incomplete. It is no longer the same on the arms, where we find again a reticulation with triangular meshes of the type of those of Anthenea but without the same regularity.

A medial line of large ossicles marks the ridge of the arm. There are two others on each side of it formed by smaller ossicles that all converge towards the arm tip. Each of these ossicles is generally connected to an adjacent ossicle of the same longitudinal series by a single connective piece. However, the calcareous trabeculae that connect the pieces in the lateral direction are nearly always composed of two or three pieces, at least towards the middle of the arm. This results in the meshes being 7 arger and less regular than in Anthenea, although the medial ossicles do not have here a form different from the others.

The network becomes much tighter in the interbrachial spaces, but it 
continues regularly on each side of the interbrachial line without being interrupted at its level by the projections of the internal pieces. Likewise, the mesh of the network becomes smaller towards the arm tip. It is filled with an accumulation of large, juxtaposed ossicles to which can be caplied the considerations made on the subject for their homologues in Anthenea.

The marginal-dorsal plates here are elongated and nearly cylindrical, slightly swollen in the middle. Each has three flat surfaces. The horizontal one is in connection with the corresponding inferior marginal plate. The other two vertical ones are in connection with their neighbors of the same series. Their size varies little, except towards the arm tips where they become very small and abut the very slight ocular plate (1).

The ventral marginal plates have a form that is little different except at the top of the very rounded interbrachial angle where they become much wider.

The ventral and dorsal marginal plates correspond almost exactly nearly the entire length of the arm.

The ventral surface is composed of large, very clearly imbricated ossicles (2).

The largest of these ossicles are arranged in a row the length of the adambulacral series. The edge turned towards this series is slightly indented. The rest of the contour of the piece is rounded and its surface very strongly convex. Each of these large ossicles is the point of departure of a series of pieces whose size greatly decreases as they approach the corresponding medial series. They are arranged in lines perpendicular to the ambulacral groove, except towards the base of the arm where they form concave arcs turned towards the arm tip. Approximately one and a half centimeters before this point there are no more ventral plates strictly speaking, and the inferior marginal plates come to border the adambulacral series.

Towards the middle of the interbrachial triangle, the nearly losengeshaped space between the adambulacral series and the two ventral series that leave from the top of the interbrachial angle is filled with irregular pieces that are no more contiguous than are the neighboring ventral plates of the inferior marginal series.

The aspect of our specimen thus differs greatly from that Alexander Agassiz has drawn under the same name in his last memoir (3). The general form is moreover very different and one can wonder if it is even a question of the same species. However, the reticulation of the back, very visible although not denuded in his figure 1 , and the form of the interbrachial system, at least as far as one can judge by his figure 7 , shows us that it is at least a species of the same type and the difference in the ventral surfaces is quite singular. It is necessary however to note that the figure of Agassiz recalls more than ours the ordinary general aspect of this family.

The ambulacral pieces are tall and strong, but usually do not quite reach to the top of the dorsal skeleton. The first is very developed. The teeth here reach their maximal development. Strong and pointed, they nearly reach the center of the mouth (4).

The very large odontophore (5) has the typical form already seen. Its apophyses are extremely developed, and the thickest portion is near the

(1) P1. XI, fig. 4, oc. (2) PI. XI, fig. 5, and pl. XII, fig. 3. (3) North American Starfishes, p1.XVI, fig. 4. (4) PI. XI, fig. 5, d. (5) Fig. 6. 
middle of the piece as moreover in Pentaceros muricatus.

The interbrachial system is composed of a veritable barrier of ossicles dividing completely the interbrachial area. It is composed of very small pieces.

The dorsal surface has small pedicellariae, scattered among the granulations of the integument. The ventral surface also has a large number of valvate pedicellariae that have nearly the size of the granulations and do not leave an impression on the skeleton. There are no forcipulate pedicellariae on the adambulacral pieces whose surface is smooth.

These are the secondary characters that help differentiate the type we just described along with Pentaceros muricatus.

This latter species, which lives off the eastern coast of Africa, differs at first glance from Pentaceros reticulatus. Here, in fact, the spines are not simply implanted on the skeletal pieces and fragile, but are the dorsal ossicles themselves that are developed enormously and give the animal its peculiar physiognomy.

Figure 8 (pl. XVII) was prepared in a way to show clearly the dimensions of these dorsal spines. Figure 10 represents the center of the disc whose profile only is seen in figure 8 . Finally, figure 9 shows the ventral surface of an arm. All three are of natural size.

The strongly keeled arms have on the medial line a series of hexagonal and slightly convex pieces elongated in the transverse direction. The pieces $1,7,11,14$, and 16 in leaving the arm are extended as 7 arge, rounded spines nearly one centimeter tall. All the pieces of this medial series are nearly exactly contiguous. After the fifth spine are two nearly cuboidal ossicles, then a last one, very elongated in the 1ongitudinal direction, that abuts with one of the five large apical pieces of the disc.

From each side of this medial series is another one also composed of hexagonal plates towards the arm tips where they are exactly contiguous with the medial series. Nearly at the center of the arm, they separate from this series that they touch only by an extension from their inner side, limiting thus a quadrangular area. Their outer border has become narrow at this point. Finally, leaving the fifth spine, they lose all connection with the medial series and end in a large, elongated stone that also abuts with the apical spine in limiting a very elongated poriferous area.

We thus have, the entire length of the arm, three longitudinal series of ossicles, of which the two lateral are always composed of nearly flat pieces. Towards the middle of the arms, some irregular pieces are interposed between the external series and the superior marginal plates. Finally, the interbrachial space is filled with irregular pieces whose form seems to derive from the hexagon. There is always a pair of them on either side of the interbrachial line immediately outside the disc. On one of these pairs is found the madreporite plate $m$ (fig. 10). It has nearly the same form and characters as in Pentaceros reticulatus. Here equally, the two supporting pieces are indented in the form of a kidney on the contiguous surfaces to allow passage of the hydropore canal.

The five large apical pieces of which we have spoken form a nearly regular pentagon on the center of the dorsal surface. Their form, which is very difficult to describe, is seen very well in figures 8 and 10 (pl. XII).

From the base of each of the spines leave six pieces. Three, as we have already seen, are the beginning of the longitudinal series of the arms. Two go to the adjacent apical spines. Finally, the sixth goes to the center of 
the pentagon. It is there, a little to the left of the medial line, imagining the madreporite plate to the rear, that the anus is found (1), surrounded by very small plates as in the other type of Pentaceros.

The sides of the pentagon are formed by large arched pieces going from one spine to another. From the middle of the sides of this pentagon, opposite the pair of plates described above, an irregularly forked piece also goes toward the center. The poriferous areas thus are very irregular on the disc as well as in the interbrachial spaces.

The dorsal madreporite plates also differ very noticeably from that we have seen in the other Pentaceros. Here, in fact, instead of being elongated in the direction of the arm, they are, in the angle formed by two arms, very elongated in the direction of the interbrachial 1 ine. Their width is more than a third of their length. Moreover, they are not contiguous in the angle of the arms and take a radiating dispostion.

In diverging from the medial line, the marginal plates shorten very quickly at the same time that they enlarge a little and press against each other. They never have very intimate connections with the lateral-dorsal series to which they are connected only by small pieces irregular in form and disposition and often missing. They decrease in size very regularly up to the ocular plate oc that here is very reduced. The fifth or sixth marginal plate before the ocular plate is raised as a large rounded spine similar to those of the medial series of the arm. Above it is an ordinary plate, then another transformed, spined plate of a still considerably greater size.

There are thus, at the end of each arm, four marginal spines, two on each side, of nearly corresponding heights. The rest of the marginal plates have a smooth, slightly convex surface.

The plates of the marginal-ventrai series have their largest dimensions towards the middle of the arm. From there they decrease regularly, on one hand towards the interbrachial line, on the other towards the arm tip. They correspond, moreover, exactly to the marginal-dorsal plates except at the very tip of the arm where three ventral plates correspond to two dorsals. The elevation of the arm tip, which permits this agreement, lets us see this arrangement in figure 8 . The free surface of these marginal-ventral plates is nearly circular, very slightly convex, and sometimes marked with very small alveoli with pedicellariae. As is seen in figure 9 , a very small number have them. However, there is on the left side of the figure a plate that has a dozen by itself. It was thus wrong for Perrier to say that valvate pedicellariae never exist on the marginal plates in this species.

The internal border of the ventral marginal plates is covered by the ventral ossicles. These are very variable in form and size and tightly pressed against each other. They form a sort of mosaic where it is impossible to recognize the regular rows except right in contact with the adambulacral series. Yet this row, composed of rather 1 arge and distinct pieces the entire length of the arm, itself becomes rather difficult to follow near the mouth because of the irregularity of the ossicles that compose it. All of the pieces of this row have at least one, and most often several alveoli with very small valvate pedicellariae.

In the interbrachial angle, where the ventral plates are very small and extend nearly to the teeth, each plate has at least one alveolus with a pedicellaria as Perrier saw very well. They nearly always lack them along

(1) Fig. 10, an. 
the length of the arm.

All the ventrai plates have a very slightly convex surface that gives the bottom surface of the animal a pavement-like appearance. They are rather thin.

The adambulacral plates are nearly cuboidal, a little less pressed against each other than in Pentaceros reticulatus. Each of them has, the length of the ambulacral groove, a very fine alveolus with a forcipulate pedicellaria turned from the side of the mouth. These small alveoli disappear toward the end of the arm. There is nothing particular to say about the ambulacral pieces that resemble those of the other Pentaceros although they are a little less strong. As can be seen (1), there is nothing extraordinary in their disposition. The section of the arm of this species that Gaudry gave, which he named Oreaster Linckii, was undoubtedly done with a very deformed specimen as it is absolutely unrecognizable. It would be very difficult to distinguish in this figure a marginal plate of a dorsal, ventral, or even ambulacral piece other than by their location.

The mouth of Pentaceros turritus, which is quite like that of Pentaceros muricatus, has served us as the type for our general description and figure $A$ (p. 70). We shall only have to refer there for a detailed description. Figure 11 ( 1 1. XII) shows the odontophore. The great similarity with that of Pentaceros reticulatus can be noted.

The interbrachial system (2) recalls completely what we have seen in the culcites, and differs completely from the rampart of ossicles of the other type of Pentaceros. In referring to figure $A$ it is possible to see the disposition of the dorsal-ventral msucles.

In recalling the differences that separate the two types we have just studied, we are first of all struck by the difference in the constitution of the dorsal skeleton. We have said that, in the Pentaceros of the first type, the principal ossicles were developed first, and that they had then an appearance like that of the second type. It is later that the connective pieces, developing in their turn, alter this arrangement that persists throughout $\mathrm{l}$ ife in the second type. As to the formation of the enormous elevated ossicles, we have explained it by the confluence, the intimate fusion of a spine with the dorsal piece that supports it. Whatever happens to these theories, of which nothing up to now indicates the correctness, the difference between our two types is no less pronounced. The disposition of the interbrachial system and the constitution of the ventral surfaces are the other equally important characters that also contribute to differentiate them. It is necessary to attach less importance to the absence of the forcipulate pedicellariae in the ambulacral groove of Pentaceros reticulatus as they are encountered in Pentaceros mamillatus obviously belongs to the same type.

Pentaceros obtusatus merits a specific study, as Perrier has already remarked. It does not recall either of the two types we just studied. The dorsal ossicles have very irregular forms and very different dimensions without an areolar disposition or a very distinct medial row. The marginaldorsal plates are very sma11, irregularly circular, and are distinguished from the other dorsal ossicles by the regularity of the line they form. On the ventral surface, which moreover has the characters of Pentaceros muricatus, is a row of small pieces separating each of the inferior marginal

(1) PI. XIII, fig. 3. (2) P1. XIII, fig. $4 i$. 
plates from its neighbor in the series. All these particulars, joined to the flatness of the arms and disc, makes it at least doubtful that it is a true Pentaceros. I shall limit myself to these thoughts, however, not having been able to make a complete study of these animals.

\section{GENUS GYMNASTERIA (GRAY).} p. 278

1840. Gymnasteria, Gray, Annals and Magazine of Natural History, V. VI, 62.

1842. Asteropsis (pars), Müller and Trosche1, System der Asteriden, p.

1866. Gymnasterias, von Martens, Ostasiatische Echinodermen, Archiv für Naturges, y. XXXIII, p. 74.

1869. Asteropsis, Perrier, Pédicellaires, p. 93.

1869. Gymnasteria, Verri11, Addit. observations on Echinod. fauna of California. - - Transactions of Connecticut Academy, v. I, part 2, p. 574 and 593.

1875. Gymnasteria, Perrier, Révision des Ste77érides du Museum.

Gymnasteria is the onty animal of the former genus Asteropsis of Müller and Troschel that we keep in the family GYMNASTERIA. We are going to see by the study of Gymnasteria carinifera that they come very close to Pentaceros, while Porania, which we shall study later, differs absolutely from it.

Gymnasteria carinifera Tives in localities very far from each other: the Red Sea, Ile de France, the Fiji Islands, the Hawaijan Islands, Panama, etc., but has, however, remarkable uniformity.

The entire skeleton is composed of thin plates embedded in a very thick skin that almost completely masks them in specimens preserved in alcohol. In dired specimens, in contrast, the arrangement of the plates shows very distinctly. The arms are very marked as is seen in figure 5, p1. XIII, and strongly keeled as shown in figure 8 . The medial line of the arm is filled with a row of ossicles, irregularly circular towards the arm tips, that extends a little in a point towards its base. These ossicles are very regularly imbricated and have, on every other one, a small, perforated tubercle for the insertion of a spine. However, all of this is subject to very great variation.

From each of the pieces of the median series leave lines of ossicles nearly perpendicular to the direction of the arm. These ossicles are elliptical and slightly depressed in their center. They form, on the side of the medial line, three parallel series that extend to the arm tip. There, a11 the series are confused in an accumulation of ossicles without arrangement or regular imbrication. The most internal lateral series is connected to the medial series by smal1, very short connective pieces (1).

our specimen being very deformed, the arrangement of these dorsal series have in our figure a very great irregularity. Their imbrication in the lateral direction is shown well in figure 8 . In the interbrachial angles, which are very rounded, are supplementary series of imbricated ossicles with a nearly circular free surface. They fill up the space left free between the dorsal series.

At the center of the back is a pentagon. Its tops are formed by the

(1) PI. XIII, figs. 5 and 8. 
first piece of the medial series of the arm. The ossicles in its interior do not have enough regularity to lend themselves to a description (1).

It is at the edge of the central pentagon that is found the madreporite plate $m$, which is small, oval, very thick, and marked with divergent, extremely fine grooves. In the middle of the pentagon, a little to the left of center, is the anus an.

The dorsal marginal plates are very regularly imbricated but in the inverse direction of the ossicles of the medial series of the arm. There is, in fact, at the top of the interbrachial angle an unpaired plate that covers lateral1y its two neighbors. From them, the imbrication continues in this direction, each plate covering its neighbor from the side of the arm tip. However, this arrangement becomes irregular towards the end. At this level, the marginal plates become very small, no longer differentiated from the other dorsal pieces and end at an ocular plate of very small dimensions.

The inferior marginal plates, which are always bordered by the superior, are very irregularly circular with a wavy contour. They are very exactly juxtaposed, without apparent imbrication, and in the same number as the marginal dorsal plates.

Right at the end of the arm, they come in contact with the adambulacral series. However, nearly the entire length of the arm there is interposed between them a line of small, irregularly circular plates with very variable imbrication. Near the base of the arms and in the interbrachial angles are intercalated still others with a little larger diameter so that the entire triangle made between the two adambulacral series and the marginal series is nearly completely filled by imbricated pieces from the base towards the top of the triangle (2).

The adambulacral pieces are sma11, quadrangular, and not tightly pressed against each other. The ambulacral pieces are very ta11, but do not at all rech the dorsal skeleton (3). The first (4) has a very developed wing-shaped apophysis, and the tooth it supports is strong and pointed as in all the GONIASTERINAE. The odontophore (5) has, here again, the form typical of the tribe and its apophyses are very well developed.

The interbrachial system is composed of two 1 ines of ossicles and form in consequence an arc more resistent than in Pentaceros muricatus or culcita. However, the disposition is quite evidently the same.

If these characters taken from the constitution of the mouth and the presence of spicules in the tube feet are combined, it can be seen that this type should be placed in the GONIASTERINAE. However, beyond the other peculiarities the study of the skeleton showed us, it is necessary to say the disposition of the spicules in the tube feet is rather singular. They seem rather to garnish the end of the tube than to form a coronal plate at the suckers. In addition, the pedicellariae have a quite remarkable arrangement, being here composed of three pieces as in the ambulacral asteroids. It is necessary to read the detailed description of the pedicellariae in the memoir of Perrier.

Gymnasterias thus has singular peculiarities. However, their place should certainly be here. We are going to see, in studying Porania, what differences separate these two genera joined under the same name at another time.

(1) Fig. 5. (2) Fig. 6. (3) Fig. 8. (4) Fig. 10. (5) Fig. 9. 


\section{FAMILY VII . ASTERINIDAE.}

This family corresponded exactly, for Perrier, to the genus Asteriscus of Müller and Troschel who united the species of the genera Palmipes and Asterina. The extreme thinness of Palmipes made Perrier preserve it as a distinct genus, and we see there are in this genus two very different types.

Asterina forms a genus very homogeneous in appearance to which Nepanthia would have to be joined. The imbrication of the arms of Nepanthia closely approaches Asterina, while their slender form recalls Chaetaster to which Gray had united them under the same name.

Patiria, with all the dermal ornamentation of Asterina, does not have their dorsal ossicles imbricated, no more than Diasterina, in which the dorsal skeleton is only composed of thin and rounded calcareous plates that are completely disjointed.

This arrangement is found again, as well as the imbrication of the ventral surface, in the genera Asteropsis and Dermasterias of Perrier. He nevertheless preserved them among the GONIASTERINAE, because the rounded ossicles of the dorsal skeleton are united by often up to six elongated radiating trabecular that thus form a hexagonal network as in Anthenea or the first type of Pentaceros.

That is not at all a character sufficient to determine the position of the genera. In Disasterina and Patiria very small ossicles are intercalated between the large ones. Thus this would be the only fact of their arrangement that would serve to characterize the family. However, if we would envisage Porania, whose appearance is so close to those of Asteropsis and Dermasterias that it is nearly impossible to separate them, and as Perrier continued to $\mathrm{place}$ them side by side, it is very easy to see that one is concerned with ASTERINIDAE. The ossicles are disjoined on the back and mixed with smaller spicules. However, instead of a network arrangement, it is possible to distinguish even here an imbrication. It is less marked, it is true, but it becomes very apparent on the arm tips.

These three genera: Asteropsis, Dermasterias, and Porania seem so closely allied and differ so greatly on the other hand to Gymnasterias. They were recently reunited again. This should take place here as we shall show by the attentive examination of the skeleton of porania. It is true there are distinct marginal plates, but must this peculiarity make them distinguished absolutely? We believe it just as little as for the Ganeria of Gray. Perrier placed Ganeria in his family of ASTERINIDAE. He did this as he had been able to see these animals in the British Museum showing very developed marginal plates and greatly resembling Porania by their dorsal skeleton according to the description he gave.

It is thus necessary, according to us, to add to the ASTERINIDAE of Perrier the three genera Asteropsis, Dermasterias, and Porania which made part of the GONIASTERIDAE. They have the general characters of ASTERINIDAE: large teeth, rounded at the side of the mouth, very convex, a ittle separated; massive odontophore, without apophyses, clearly developed; and no spicules in the tube feet. These are as much the characters that clearly distinguish the two families.

Our family of ASTERINIDAE includes thus the genera: Patiria Gray; Asterina Nardo; Palmipes Linck; Disasterina Perrier; Asteropsis Müller and Trosche1; Dermasterias Perrier; Porania Gray; and Ganneria Gray. 
1840. Patiria, Gray, Annals and Mag. of Nat. History, v. VI, p. 290.

1847. Patiria, Gray, Proceeding of the Zoological Soc. of London, p. 82. 1875. Patiria, Perrier, Révision des Stellérides, p. 323.

The limits of the genus Patiria, such as admitted by Perrier, differ greatly from those for Gray. He gave the name only to animals with rounded ossicles, complex, complete, and simply juxtaposed, while the covering of the spines is identical to that of Asterina. All the other Patiria of Gray were replaced in Asterina. The true Patiria has wide arms, short and semicylindrical.

The Museum of Paris contains none of these animals. I can only refer to the description made by Perrier who examined the specimens of the British Museum.

\section{GENUS ASTERINA (NARDO).}

1834. Asterina, Nardo, Oken's isis, p. 716.

1835. Asterina, Agassiz, Prodrome., Mém. Soc. sc. de Neufchâte7, v. I.

1840. Asterina, Gray, Ann. and Mag. of Nat. History, p. 286, v. VI.

39.

1842. Asteriscus (pars), Müller and Troschel, System der Aseriden, p.

1862. Asteriscus, Dujardin and Hupé, After Buffon, Echinodermes, p. 374.

1865. Asterina, Gray, Synopsis, p. 16.

1875. Asterina, Perrier, Révision des Stellérides, p. 294.

Perrier explained in his work why the name Asterina of Nardo should be restored and that of Asteriscus, which moreover was applied indifferently by Muller and Troschel to Asterina and Palmipes, rejected. Two species of the genus Nepanthia of Gray (we know the other Nepanthia are Chaetaster), should it seems reenter the genus Asterina from which they differ only by their thin and elongated arms. These species, which Perrier examined in the British Museum, do not exist in Paris. However, Asterina cephea, A. stellifera, and especially $A$. setacea show already this very strongly marked disposition.

I shall take Asterina gibbosa as the type. It is encountered in abundance at Roscoff on a 11 the rocks uncovered at low tide. I shall then say some words on Asterina calcar, a pretty Australian species.

Figures 8 and 9 ( $p 1$. XIV) represent, magnified three times, the two surfaces of Asterina gibbosa. As can be seen in these two figures, the arms are short and obtuse, and the interbrachial angles very rounded. The sections (1), which are magnified only two times, show the great thickness of the body, which has given the animal its specific name.

The dorsal surface is composed of small scales, very small towards the margin of the body and increasing in size towards the center. They are tightly imbricated from outside to inside. The smallest have a rounded contour, but their free border is more and more indented as they increase in size. At the same time, the scales, flat at first, overlap as the tiles on a roof.

The nearly vertical position affected by the lateral parts of the body of Asterina gibbosa, because of the great thickness of the animal, prevents

(1) P1. XIV, fig. 10 and 11 
recognizing the serial arrangement of the dorsal scales. However, if we examine Asterina calcar, whose body is much thinner, we find a very great regularity. Each scale belongs to two rows, one parallel to the medial 1 ine of the arm, the other perpendicular to this same direction. As these rows are not at all straight lines, but curved, the parallels in one arm, which are really slightly divergent, are perpendicular to the adjacent arm.

It is the same arrangement we see on the two surfaces of Palmipes and that is very evident on the ventral surface of Asterina gibbosa (1). However, on the dorsal surface, in the position of our specimen, the nearly vertical direction of the scales makes that which is seen very shortened and masks their serial arrangement. The entire border of the interbrachial spaces, where the scales are rounded and tightly pressed against each other, do not have poriferous areas. It is no longer the same in the middle of the arm and the center of the star.

Here, in fact, the scales are much less pressed against each other. Their position, nearly normal to the surface of the body, permits the appearance of poriferous areas. They are very small and not numerous towards the arm tip, but increase rapidly in number and size towards the center. Nearly two-thirds of the distance from the border to the center, the interbrachial spaces themselves become poriferous. The scales, more and more loose and large, end in a very sma71, unpaired one on the interbrachial 7 ine. These five interbrachial scales alternate regularly with five larger apical scales and constitute thus, in the center of the star, a circle where there is no longer any regularity, no more than on the first third of the arms beyond the apical scale. Immediately beyond each interbrachial scale is a pair of large scales arranged on each side of the interbrachial line and supported on the adjacent apical scales. Beyond is still another pair of scales, smaller but more distinct. These two pairs and the corresponding interbrachial scale enclose the madreporite plate $m(2)$. This plate, with an irregularly pentagonal form with its base turned towards the center of the star, is marked with irregular and sinuous grooves that do not at a 71 appear to converge towards the center.

Al1 the large scales, of which we have just spoken and which form the central circle and the top of the interbrachial spaces, are visible even on the living animal because of the greatest development of the spines that they have. The interior of the circle is filled with irregularly arranged rounded pieces. The anus an is in its center, always a little to the left of the medial line if one imagines the madreporite plate is in back.

The first third of the arms is equally filled with irregular pieces without apparent order. Very small pieces are interposed among them. These very small rounded pieces are seen again intercalated between the most separated scales, but it is impossible to find a definite order there.

The border of the arm is filled by a double row of very small but very distinct marginal plates, expecially in Asterina calcar. They are seen very well in our figures.

In spite of their smallness, these plates are very well distinguished from the adjacent scales, which are even smaller than they are. In addition, their arrangement in two parallel lines, situated completely on the edge of the body, is so much different from that seen, as much on the dorsal surface as on the ventral surface, that it is impossible to mistake them.

(1) Fig. 9. (2) Fig. 8. 
The dorsal marginal plates are clearly imbricated and cover the top of the arms towards the middle of the interbrachial angle. The ventral plates are less imbricated, nearly juxtaposed. The four plates, two dorsal and two ventral, which meet each other exactly on the interbrachial line, are arranged into a cross. I.e. the dorsals are separated from each other at their upper part and the ventrals, at their lower part. This inclination, which continues nearly to the end of the arm, masks nearly entirely at first glance the actual imbrication of the plates.

In the dorsal and ventral series, the plates are always exactly the same number and abut the ocular plate oc that is small, round, and less elongated than in Palmipes.

The ventral surface is flat and formed of scales whose arrangement has been described above. It is very easy to see in figure 9 .

These scales are tridentate and the median portion, which connects to the middle tooth, is thicker than the rest of the scale. The rows that border the adambulacral series have scales with a little different form. The two teeth of the side of the ambulacral groove are no longer separated and form a nearly rectilinear border. No more than in Palmipes is there a large unpaired one ending these two series behind the teeth (1). The first unpaired one marks the top of the angle formed by the second row.

The adambulacral pieces are nearly cuboidal, slightly separated at the border, and very tightly pressed against each other. Thus ait the movements of these arms are those of elevation. Movements in the lateral direction are very limited. Bending of the arms ventrally seems to be nearly nil.

The ambulacral pieces are very short, as seen in figure 11 and show nothing unusual. There are no supporting ambulacrals.

The interbrachial system (2) is composed of a single large piece, from which one or two smaller pieces strengthen the connections on one hand to the dorsal surace, and on the other to the odontophore. This latter, magnified five times in figure 12 , is very massive. Its ventral surface, beyond its apophyses, is smooth and composed of two planes slightly inclined between them. It does not have the small bourrelet at the external border. This character is in constant throughout the family of ASTERINIDAE. The apophyses are never very detached in this family. The dorsal surface fits to the ventrl surface by a more or less narrow angle. In Asterina gibbosa the articulating surfaces are not marked. Moreover, the teeth in a11 these types have only very limited movements. They are large, round, and slightly separated in the same pair. The mouth is always very slightly open (3).

Asterina calcar differs from Asterina gibbosa by being much less thick and by its eight more pointed arms, which give it the form of a soft spur, from which its specific name. I have spoken above of the disposition of the marginal and dorsal scales. I shall not return to it. The center is constituted exactly as we have seen except, certainly, that there are sixteen pieces in the circle instead of ten. The ventral surface is a 1 ittle different due to the form of its scales and recalls that seen in Acanthaster (4). Each scale has only one spine. It has a small tubercle with a depression for the spine ligament. The adambulacral pieces are not as thick as in Asterina gibbosa. The teeth are similar. The odontophore, magnified three times in figure 13 ( $\mathrm{pl}$. XIV), differs little from that of our Asterina

(1) Figure 2, p1. XIV, is inexact in this point due to the artist's error. (2) P1. XIV, fig. 10, i. (3) Fig. 9. (4) PI. VIII, fig. 9. 
except by the articulating surfaces that are better defined.

The interbrachial systems show no differences.

There are no spicules in the tube feet of Asterina. Small pedicellariae are encountered only on the back of Asterina gibbosa. However, they are not connected to the pieces of the skeleton.

The ventral surface has none, not even the adambulacral pieces. They have not been reported in Asterina calcar.

In his last memoir, Alexander Agassiz gave a short..description of Asterina minuta of Gray, under the name Asterina folium of Lutken. All the characters indicated by Agassiz agree perfectly with those we have seen above. Unfortunately his figures will not serve for the study of the skeleton.

Fig. 9. P1. VIII, fig. 9.

GENUS PALMIPES (LINCK).

1733. Palmipes, Linck, De ste7lis marinis, p. 29.

I.

1835. Palmipes, Agassiz, Prodrome, Mémoires Sos. sc. de Neufchâte7, v.

1839. Palmipes, Forbes, On the Asteridae of the Irish Sea, Mem. of Wernerian Society, v. VIII, p. 114.

1840. Pa7mipes, Gray, Ann. of Nat. History, p. 288. 39.

1842. Asteriscus (pars), Müller and Troschel, System der Asteriden, p.

1862. Palmipes, Dujardin and Hupé, After Buffon, Echinodermes, p. 372.

1875. Palmipes, Perrier, Révision des Stellérides, p. 200.

There exist in the Museum of Paris only three species of Palmipes. One, Palmipes rosaceus, is represented only by a single specimen of large size and fifteen arms. It was not possible for me to examine it. I shall give further on some details on Palmipes inflatus, of which a nice series originating from the Straits of Cook were brought by Filhol in 1875 . However, it is Palmipes membranaceus, very common on our coasts, that I have been able to examine in most detail and that I shall describe here. This singular and beautiful asteroid is encountered frequently at Roscoff. However, it is necessary to use the dredge as it is never found in areas uncovered by low tide.

The figures I publish here, like those of Asterina gibbosa, were done at Roscoff in 1876 .

Palmipes membranaceus rarely has six arms. Most ordinarily there are only five, or rather five angles, because the form of this asteroid is completely pentagonal. It enjoys a great faculty for regeneration and it is very rare to find a perfectly regular individual.

The skeleton is composed of thin scales, imbricated and in immense numbers. They differ in form on the ventral surface where they are al1 very much alike and the dorsal surface where they have two very distinct types: one in the center of the back and the arms, the other in the intervals of the arms. Figures 1 and 2 ( $p l$. XI) give a good idea of the general skeleton. They are magnified two times, as are the sections (figs. 3 and 4 ).

The upper surface of the animal is constituted, in the intervals of the arms, by very thin scales, imbricated from the margin of the body towards the central disc and arranged in divergent series from each side of the 
interbrachial line. Towards the tip of the arm, the series curves in an arc with the concave side turned towards the ocular plate. In addition, the scales in these series are arranged in rows in the form of longitudinal lines parallel to the axis of the arm. Figure 1 will give, moreover, a better idea of this very complicated arrangement as we cannot give a long description. A11 the scales have a similar form. They are oval, with the central portion a little thickened, which makes it appear dull, while the very thin border is absolutely transparent. The end turned towards the border of the animal is extended, in all these scales, in a thin and elongated point. It makes a very open angle with the plane of the scale and is sunk into the interior of the body. Each of these small extensions, which can be seen well in figures 3 and 4 , extends to one of the similar extensions of the scales of the bottom surface of the body. The ensemble of these small broken arches, which are found in immense numbers, maintain the separation of the two surfaces.

In approaching the top of the interbrachial angles, the scales increase. However, instead of the thick, dull portion of the center of the scale developing proportionally with the margin of the scale, new points of thickness develop. At first isolated, they end by uniting with the central point, giving the scale a trifoliated appearance although the transparent margin is always rounded. These trifoliated scales form two rows on our specimen, one of five and the other of three scales. Beyond them are three or four rows of scales where the points of lateral thickness are not yet united with the central portion.

Finally, right at the end of the angle and exactly on the interbrachial line, are three scales, larger and larger as they near the center of the disc. Their transparent margin is still simple. However, by the development of new points of thickening, always in pairs, they present, one five, the next seven, and the innermost nine digitations arranged in a fantail.

At the interior of the pentagon whose tops are marked by large interbrachial scales, it is very difficult to discover a regular arrangement. The scales, which have irregular thickened points, are thus very diverse in form, very strongly indented, and right in the center, transformed into narrow plates. They abut a kind of circle formed of a variable number of pieces at the middle of which is found the anus surrounded by very small irregular plates. All these scales, contracted and indented, thus limit toward the center of the disc a certain number of poriferous areas arranged without marked order around the anus. A 1ittle inside one of the large interbrachial scales is the madreporite. It is small, oval, and marked with divergent, relatively very large grooves. The striated portion of the plate is the superior surface of a pitted piece reduced to a simple, very thin shell. Its delicate extensions connect below to the adjacent scales. The internal wall of this shelf is perforated at the level of the opening of the hydropore canal. This disposition of the shell-like, pitted madreporite plate is the only example I known in the asteroids of the second subclass. It is probably due to the lack of resistance of the skeletal scales that have not been able to furnish a sufficient point of support to the madreporite.

From the raised central disc, whose constitution we are going to see, leave five grooved lines that correspond to the furrows of the ventral surface. Here the scales no longer are of very regular form. There is one, however, exactly on the medial line of the arm that has five digitations but is nearly a straight line instead of being arranged in a fantail. These five 
apical scales alternate regularly with the five interbrachial scales between which they are placed.

Behind the apical scale is yet a median one, then the arrangement becomes more irregular. The scales, of diverse form, have a variable number of irregularly placed thickenings. They are generally arranged in rows crossing obliquely the direction of the arm and connecting the interbrachial series between them. A double line of irregular poriferous areas follows the direction of the arm up to the ocular plate. The latter is very smal1, elongated, and narrow.

In al1 the scales, only the thick portions are spiniferous. This is the reason why the arrangement of the spines, so regular in the interbrachial spaces, becomes confused on the arms and disc to the point that it is impossible to describe the arrangement. These are the same part that, in vivo, are a brilliant purple while the palmures, if one wants to say it thus, are whitish-yellow as is the ventral surface.

The latter is absolutely flat and very easy to describe. All the scales are in fact of the same form. Only the dimensions vary. Each scale is part of two rows. One is nearly parallel to the ambulacral groove. The other is transverse. However, as the longitudinal lines converge towards the tip of the arm and transversals, towards the middle of the side of the animal, a11 these lines are curves that intertwine like the lines engraved on the face of a watch (1). The regularity is nearly absolute. At times, some of these lines bifurcate, but this is incidental and does not enter into the general plan.

All the scales of the ventral surface lack the small internal projections of which I spoke above. They are very thin and entirely transparent except for their free border that is a little thicker and spiny.

Right at the border edging the body are two rows of very small plates that are nothing other than very reduced marginal plates. They are difficult to distinguish from the others on the ventral surface where they correspond exactly to the rows of ventral scales. However, on the dorsal surface, they are much easier to see because they correspond to the interstices of the series of scales and their ornamentation is slightly different. However, it is only at the arm tip that they are easy to distinguish as can be seen in our figure (2).

The adambulacral pieces are nearly cubical and very tightly pressed against each other. The arm movements must not be very extensive here. The adambulacral pieces are very short and do not reach the dorsal skeleton, as seen in Fig. 4. The irregular dorsal plates that correspond to the grooves do not have internal projections that would in fact be useless here.

As for the large interbrachial plates, they show in this type veritable 1 amellae of extreme thinness, as seen in figure 3 . However, they are not intimately united with them. These lamellae, with others that rest on the ventral surface, and the odontophore constitute an incomplete interbrachial partition that extends, moreover, only in the enlarged portion of the body.

The teeth are large, convex, a little separated from each other, and rounded on the side of the mouth. The mouth is always rather wide open. The ambulacral grooves are never completely closed. The odontophore has a quite singular form. I have shown it magnified five times in figure 5 . The apophyses, rather marked, are poorly separated from the body of the piece,

(1) P1. XIV, fig. 2. (2) Fig. 1. 
nearly indented at their end, and do not have well-defined articulating surfaces. The body of the piece is very thin. Its dorsal surface is extended in a long, laterally compressed apophysis that goes obliquely in the directly of the mouth. It is a very strange type, without a very direct relation with any other form. However, it can certainly be considered an alternation of the type seen in Asterina.

The type of odontophore found in Palmipes inflatus quite approaches that found in Asterina (1). The interbrachial system of this Palmipes equally well recalls that of Asterina (2). However the teeth (3), and al1 the rest of the skeleton as far as can be judged without dissection, resembles that of Palmipes membranaceus. There are some differences to note however. The body is not absolutely pentgonal. Its sides are slightly indented to form short, obtuse arms. The thickness of the body is much greater, but the animal takes its name from its usual posture rather than its form. The center of the disc, in fact, rarely touches the bottom and the animal uses only the arm tips to move.

The most important differences are found in the arrangement of the poriferous areas. They no longer form on each side of the ray only a single line as in Palmipes membranaceus but four. Only the two inner ones reach the ocular plate. The other two stop respectively at the first and second third of the arm length. The disc is equally covered with poriferous areas that seem to have the same arrangement as in our

Palmipes. The madreporite plate, very like that seen above, is a little larger here.

The ventral scales have spines like those of our type. However the dorsal scales of the interbrachial plates are not spiny at all. They are covered with a uniformly granular integument that prevents seeing their exact disposition. However they seem to correspond to those seen above.

These two species are very different. However Perrier was correct in removing Palmipes inflatus from the genus Pteraster where Captain Hutton had placed it. He was led into error by the fact that the ambulacral spines are united by the integument. Palmipes.

There are no supporting ambulacrals or pedicellariae of any sort in

\section{GENUS DISASTERINA (E. PERRIER).}

1875. Disasterina, Perrier, Révision des Stellérides, p. 289.

A single species Disasterina abnormalis is represented in the Museum by three specimens.

The dorsal skeleton is composed of scales irregularly imbricated on the borders of the animal but without connections between each other on the disc. These scales are surrounded and intermingled with smaller ones. The largest ones fill the top of the interbrachial spaces as in Asterina. The madreporite plate seems arranged as in Asterina. As for the scales of the ventral surface, they are of the same type as those of Asterina calcar.

I have not been able to examine this species whose specimens, all from New Caledonia, are still too few in our collections.
(1) See fig. 7.
(2) Fig. 10 .
(3)Fig. 6 . 
GENUS ASTEROPSIS (MULLER AND TROSCHEL, in the sense of PERRIER).

1842. Asteropsis, Müller and Trosche1, System der Asteriden, p. 62.

1847. Petricia, Gray, Proc. of the Zool. Society, p. 80.

1875. Asteropsis, Perrier, Révision des Stellérides, p. 281.

The removal of Porania goes along with that of Asteropsis. The genus corresponded for Perrier to the genus Petricia of Gray who included it with Porania and Gymnasteria in the Asteropsis of Müller and Troschel.

Asteropsis is distinguished from Porania by its skeleton formed of rounded ossicles, distinct from each other and united by elongated, radiating ossicles. These are generally six in number and thus form a hexagonal network as in Anthenea and certain Pentasceros. It is this appearance of the dorsal network that has led to error until now and caused this animal to be placed in the GONIASTERIDAE. In fact, except for the form of the principal ossicles of the back and the radiating arrangement of the small pieces, there is nothing here that differs from Porania that was always thought to be very related to this genus.

The two dried specimens from the vayage of Peron and Lesueur are the only representatives in the Museum of Asteropsis vernicina, the single species of this genus. The state of the specimens nearly completely masks the arrangement of the ossicles. It is easy to see, however, that the teeth are large, rounded, and a little separated as in Porania. This character immediately separates it from Anthenea and Pentagonaster, to which Perrier believed it to be related. The marginal plates, as well as the ventral plates, seem to approach what we are going to see in Dermasterias. However, there is a character that immediately makes this species recognizable: it is the presence of a large valvate pedicellaria at the base of each arm, on the back, or two in each interbrachial angle. On the ventral surface is a similar pedicellaria, isolated in each of the angles formed between the adambulacral series.

I have not been able to examine the tube feet. They without doubt lack spicules as I have shown in Porania and Dermasterias.

\section{GENUS DERMASTERIAS (PERRIER).}

1875. Dermasterias, Perrier, Révision des Stellérides du Museum, p. 282.

1877. Asteropsis, A1. Agassiz, North American Starfishes, Memoirs of the Musum of Comp. Zoo7., Cambridge, Mass., p. 106.

In his memoir, Perrier described the single specimen for which he created this genus. It was given to the Museum of Paris by that of Cambridge, directed by Agassiz.

In his last work, the American scientist devoted to this anima1, under the name Asteropsis imbricata given it by Grube in 1857, a short description and a plate that is certainly the best of this beautiful work, at least from the point of view of the study of the skeleton.

The specimen given by Agassiz being still the only one in Paris, I have not been able to make a figure, which the illustration of Agassiz moreover makes superfluous in large part. I have, however, examined this specimen with much attention and I shall complete on certain points the descriptions I just cited, while briefly summarizing them. 
The dorsal surface is composed of very thin ossicles. The star-shaped form, less regular than in Asteropsis, can be regarded as an intermediate between that one and that in Porania.

The ventral plates are contiguous and not imbricated according to Perrier. Agassiz simply said that they form a regular pavement, diverging from the interbrachial angle in a direction parallel to the axes of the arm.

In the specimen I have examined, as in the figure given by Agassiz, there seems to be a sijight imbrication. The marginal plates, large as in Porania, reproduce exactly the arrangement in Asterina, and diverge to go to the top of the interbrachial angle.

The madreporite plate is large, as in this genus, and situated nearly the same. However, the figure does not allow me to see very distinctly its mode of emplacement that is masked by the skin of the specimen. The ocular plate seems very small as in Porania.

As in this animal, the teeth are 7 arge, round, and separated, even more in the specimen I have than in the illustration of Agassiz. Moreover, Agassiz and Perrier did not speak of it in their descriptions.

The interbrachial systems resemble absolutely, according to the figure and text of Agassiz, that in Asterina and Palmipes inflatus and differ from that in Porania where their disposition had not escaped Agassiz.

I have not been able, understandably, to examine them myse1f, nor the odontophore that is still to be described. I have assured myself that there are no spicules in the tube feet. As for pedicellariae, they would be represented, according to Perrier, by small granules grouped in threes or twos on the poriferous areas.

This genus is, as is seen, closely related to the two preceding ones, and Perrier was completely correct to say (1): "This species forms a distinct genus that should be placed between Asteropsis and Porania, but has nothing at all to do with Gymansteria."* I am surprised that Agassiz still said in his work (2): "In Gymnasteria, otherwise closely related to Asteropsis, there is no special difference between the plate of the actinal and abactinal systems..."*

I think that henceforth one would consider as the only character that Gymnasteria has with the three species that formed the genus Asteropsis for Agassiz is the fact that the skeletal ossicles are embedded in the thick skin that masks their arrangement.

\section{GENUS PORANIA (GRAY).}

1840. Porania, Gray, Ann. and Mag. of Nat. History, v. VI, p. 288. 62.

1842. Asteropsis (pars), Müller and Troschel, System der Asteriden, $p$.

1875. Porania, Perrier, Révision des Stellérides, p. 280.

Figures 1 and 2 show at natural size the two surfaces of Porania pulvillus, sole species of this genus.

The body is nearly flat, above and below. The entire thickness is made by the marginal plates. These always correspond exact1y in the ventral and dorsal series. Towards the end of the arm, where they are very sma11, they take a vertical position in both series as in Ganeria. They increase rapidly
(1) Révision, p. 283.
(2) Loc. cit., p. 107
*Italics by Viguier. JL. 
in size in leaving the ocular plate oc, which is very small, and advancing towards the interbrachial angle, which is very rounded. They are developed differently.

The dorsals grow in fact principally in the middle of of their borders, which are turned towards the interbrachial angle. This extension covers the adjacent plate. Moreover, the plates of the marginal-dorsal series always keep a position nearly straight or at least very little inclined. The inferior marginal plates are juxtaposed. It is principally their external border that is developed and ends by giving them the very unequal rectangular form seen in figure 12 and the nearly horizontal position shown in figure 13 . There is nothing unusual in the arrangement of the ventral plates in the middle of the interbrachial arac. However, the superior marginal plates show very clearly the disposition already seen in Asterina. They are simply justaposed on the interbrachial line and separated at their upper ends (1).

The dorsal skeleton is composed of ossicles with very apparent imbrication, but which are a little pressed together only at the arm tip. On the entire surface of the body they are very thin, flat, and with round tops and indented sides already reported above. Very small pieces 1 ie between them. Even there the imbrication is very distinct. A11 of this moreover is very irregular.

Four large plates border the anus an. The madreporite plate, large and marked with fine grooves, is encased in six pieces that are the 1argest of al1 the dorsal skeleton. There is no difficulty in recognizing the same mode of encasement as in Asterina except here two pieces placed end to end correspond to the piece that forms the base of the pentagon. It is without doubt a fragmentation of this kind that should be seen in the madreporite plate of Ganeria surrounded by six to eight pieces of this nature.

The ventral surface of Porania, as that of Ganeria, is composed of thick pieces, nearly rectangular, without obvious imbrication, and having a tendency to form rows transverse and parallel to the marginal series as seen in figure 12. However in Porania, the lateral borders of the ventral plates do not touch and form series that diverge as they leave the interbrachial angle. The arrangement is not very regular. For a third of the arm's length, the inferior marginal plates border directly the adambulacral series and there are no longer ventral plates.

The adambulacral pieces are rounded on top and not very thick relative to their size. The ambulacral pieces are long, and nearly reach the under surface of the back. These dispositions, joined with the structure of the dorsal skeleton, should permit very extensive movements in this animal that is, in fact, the most often deformed in the collections.

The interbrachial systems, without doubt for the same reason as in Palmipes membranaceus, i.e., because of the lack of resistance of the dorsal surface, is composed here of a series of flat pieces placed on their edge that close the interbrachial space and are apparent on the dorsal surface.

The teeth here are large and rounded as in all the ASTERINIDAE, and the mouth is always rather largely open. If this mouth is compared to that of Gymnasteria, which is illustrated on the same plate, it is difficult to understand the necessity of uniting these two animals in the same genus. Figure 15 gives a lateral view of this tooth to show the projection that the teeth make on the ventral surface in all the ASTERINIDAE.

P1. XIII, fig. 11 . 
The odontophore, magnified two times in figure 14 , has a very peculiar form, but approaches that of Palmipes inflatus. The principal difference is in the obliqueness of the articulating surfaces.

There are no spicules in the tube feet and no pedicellariae of any kind in Porania. Moreover, all the skeletal ossicles are covered by a very thick skin that absolutely prevents distinguishing their disposition without a very careful preparation. It is difficult to distinguish, across this skin, the projections of the marginal plates and a depression at the level of the interbrachial systems. It is, without doubt, because of these conditions so unfavorable to a superficial examination, that the true position of this genus was unrecognized for so long.

The form of the teeth and the odontophore, and the absence of spicules in the tube feet separate it from the GONIASTERIDAE and connect it to the ASTERINIDAE. Ganeria fills in large part the space, seemingly very large, that separates this type from Asterina.

Porania pulvillus is a species of northern seas, and is found below 100 fathoms depth, according to Wyville Thomson (1).

\section{GENUS GANERIA (GRAY).}

1847. Ganeria (Gray), Proceedings of the Zoo1. Soc. of London, p. 83.

1867. Ganeria Verri11, Geogr. distr. of Echinoderms, Trans. of Connecticut Academy, v. I, p.336.

1875. Ganeria, Perrier, Révision des Stellérides, p. 327.

This genus is not represented in the Museum of Paris. Perrier, who saw Ganeria falklandica in the British Museum, gave the following characteristics of it:

The pentagonal body has five rather distinct arms with nearly rectilinear sides, joined by rather short interbrachial arches. It is rather thick, flattened below, a little convex above, bordered on each side by a double series of marginal plates very much larger than the dorsal or ventral plates, and corresponding exactly to each other. These plates are nearly vertical. The dorsal ossicles are rectangles in form with rounded tops and indented sides as is most often the case in Asterina. They are imbricated as in this genus. There are very small ossicles in the indentations of the large ones. The madreporite plate is large and surrounded by six to eight plates. The ventral plates are thick, nearly square, a little indented on the sides, and touch only by a certain extension of the sides. They are not imbricated and have a tendency to group themselves in transverse rows as seen also in the various species of Asterina.

It seemed useless to me to give a summary of the principal characters of this genus that establishes a good transition to the preceding genus.

Our family of ASTERINIDAE has these common characters: teeth $j$ arge and a little separated, projecting on the ventral surface; mouth always rather largely open; odontophore massive, without very detached articulating apophyses; interbrachial systems constant, but varying in their disposition. Neither the supporting ambulacrals nor the spicules in the tube feet can distinguish the two groups. In one group the marginal plates attain a great development. They are very reduced, but never absent, in the second. The

(1) Depths of the Sea. 
four first genera form the first group; the last two, the second.

FAMILY VIII. PTERASTERIDAE.

This family is still very imperfectly known, and I cannot, to my great regret, give very complete information on these animals.

There are, in fact, only two specimens of Pteraster cribrosus in the Museum of Paris. One is dry; the other, in alcohol. The other species are among the asteroids sent by A. Agassiz, a small new species Pteraster caribaeus E. Perrier. One of these specimens, greatly damaged, has permitted me to look into some interior details.

There is rather general agreement on the affiities of PTERASTERIDAE and ASTERINIDAE. The general form of the body and the imbrication of the skeletal ossicles in fact bring together these two families. In the damaged specimen of Pteraster caribaeus referred to above, I have been able to ascertain the presence of an interbrachial system analogous to that of Asterina. I have even been able to perceive the odontophore. Its form seems to me to approach singularly that I have illustrated in Palmipes inflatus. The care of a specimen that does not even belong to our museum does not at a11 permit me more extensive investigations.

The genus Hymenaster has a regular pentagonal body, as that in Palmipes, covered with a membrane supported by short paxillae. It should without doubt be placed after the genus Pteraster from which it scarcely differs, according to the description I have read of it, except by the disposition of the membrane of the ventral surface of the arms.

Must Corethraster or Korethraster (there are both spellings), with its double row of conical ambulacrals and its dorsal surface covered by long, free paxillae also belong to this family or must it be regarded as an intermediate type between it and Ctenodiscus? Finally, must it be arranged right beside the others that occupy a distinct place in the ASTROPECTINIDAE? These questions still wait new investigations in order to receive a satisfactory solution. These animals are so rare today that it is given only to some privileged ones to contemplate. It is regrettable that the figures that Wyville Thomson (1) devoted to them do not permit forming a satisfactory idea.

The specimens of the English scientist were collected in the dredging expedition and soundnding enterprises by the ships Lightning, Porcupine, and Challenger.

These species have been missing from our collections for so long that one believes that our navy has renounced using for the service of science the immense means of research at their disposal.

The initiative of the officers filled, in certain cases, the absence of official expeditions. It is thus that the lieutenant of the vessel Heurtel and Admiral Serres have enriched the Museum of Paris with types both rare and interesting. Unfortunately, lacking special equipment, the efforts of these officer-scientists have not been able to go beyond shallow water.

\section{FAMILY IX. ASTROPECTINIDAE。}

This family included, for Perrier, the genera Chaetaster Müller and (1) Loc. cit. 
Troschel; Luidia Forbes, Astropecten Linck; Archaster Müller and Troschel; and Ctenodiscus Müller and Troschel. Gray also placed Solaster Forbes there. Perrier, very correctly ranked them in the ECHINASTERIDAE. I have been led, as seen above, to make solaster the type of one tribe of this family.

Chaetaster has been moved to the family LINCKIDAE, being allied nearer to Linckia than to any other genera. I thus have nothing to say about it here.

Luidia and Astropecten are related to each other, although entirely distinct. However, ctenodiscus is greatly separated from them. The imbrication of its dorsal surface and the reduction of its marginal plates make it a very difficult type that will doubtlessly require 1 ater the formation of another group that will include perhaps some of the new and poorly known types of which I have spoken above.

It is necessary, however, for the moment to leave ctenodiscus in the ASTROPECTINIDAE that we will characterize by: the existence of supporting ambulacrals, well-developed in general; the constant absence of interbrachial systems; large teeth, elevated, rounded on the side of the mouth, and separated in each pair; very large ocular plates; the absence of an anus; and, finally, conical tube feet.

There is not one of these characters that does not distinguish this family from Archaster, which others have left here and which I separate absolutely. The reasons for this are in my description of this type.

There remains, thus, in our family of ASTROPECTINIDAE the genera: Ctenodiscus MüTler and Troschel; Luidia Forbes; and Astropecten Linck.

\section{GENUS CTENODISCUS (MULLER AND TROSCHEL).}

1842. Ctenodiscus, Müller and Trosche1, System der Asteriden, p. 76.

1875. Ctenodiscus, Perrier, Révision des Stellérides, p. 380.

There are only two species in this genus: Ctenodiscus australis, described in 1871 by Lütken, which the museum does not have; and Ctenodiscus corniculatus, which Linck had already described in plate XXXVI of his work under the name Astropecten corniculatus.

It is easy to understand (1) how Linck took Ctenodiscus for an Astropecten. The back is made, in fact, in these two types in so similar a fashion that all that I shall say about the form and arrangement of paxillae in Astropecten applies to Ctenodiscus. I think it is useless to speak of them now. However, there are other important differences.

The marginal plates are reduced here to a simple lamella positioned vertically with a projecting crest in the middle. This can be considered an exaggeration of that seen in Astropecten and Luidia, as can be realized by comparing the sections of these three genera in plate XV. The ventral surface has a very great difference. Here, in fact, because of the form of the body, the marginal plates are only connected to the adambulacral series right at the arm tip. All of the triangular space left betyween the inferior marginal series and the two adambulacral series is filled with very thin 1 ame $11 \mathrm{ae}$, imbricated from the periphery to the center. These lamellae form radiating series from the top of the interbrachial angle and are without regular relation in number with the marginal plates or the adambulacral

(1) Compare figures 1 and $14, \mathrm{pl} . \mathrm{XV}$. 
pieces (1). These adambulacral pieces are singularly flat (2).

As for the ambulacral pieces, they resemble those in Luidia. However, they are relatively much larger and their orientation is nearly horizontal (3).

The supporting ambulacrals $s$, much smaller than in the following types, are perfectly distinct however.

The mouth of Ctenodiscus is largely open, and bordered with large teeth, projecting, and a little separated in the same pair. They approach all the characters given later, but great differences are stili soon seen. The teeth are not as thin as in Astropecten or Luidia, but wide and thick. They also project much farther towards the center of the mouth. This is due to a peculiar arrangement, already mentioned above, and of which I know only this single example. It is easy to ascertain in figure 19 that the first ambulacral piece is made by the coalescence of three pices, while the tooth corresponds to only two adambulacral pieces. The very reduced ambulacral pore, seen right in front, can leave no doubt about this. The winglike apophysis is extremely reduced.

A singular odontophore, also with a great modification of the mouth, should be expected. In fact, it does not recall any of the type we have seen up to here, as can be confirmed by looking at figure 18. The articulating apophyses are extremely small in order to correspond to the smaller ambulacral pores. The piece itself is large in order to maintain the teeth of the same pair in place.

This singular modification of the mouth has seemed constant to me in ctenodiscus. However, I have been able to assure myself only with my specimen. Perhaps it is not neccessary to generalize this fact that will always be, at least, very interesting from the point of view of the constitution of the mouth.

The madreporite plate, situated nearly at the edge of the disc as in the two following genera, is large, oval, convex, and marked with longitudinal and sinuous grooves.

The ocular plate, likewise very large, has a very singular form. It is marked near the free border with two small fosettes separated by a median crest. Behind these fosettes, the piece is strongly convex, nearly globular. There is no interbrachial system, no more than in the following genera. There has been no report of pedicellariae in Ctenodiscus, which seems to 1 ack them completely as in Astropecten.

Ctendiscus corniculatus is an animal of northern seas.

\section{GENUS LUIDIA (FORBES).}

1839. Luidia, Forbes, Memoirs of Wernerian Society, v. VIII, p. 123. VI.

1840. Hemicnemis, Mụ̈ler and Trosche1, Archiv für. Naturgeschichte, v. v. VI, p. 183 .

1840. Luidia and Petalaster, Gray, Annals and Magazine of Nat. History.

1842. Luidia, Müller and Trosche1, System der Asteriden, p. 77.

1875. Luidia, Perrier, Révision des Stellérides, p. 331.

The Petalaster of Gray are, according to Perrier, really Luidia. The (1) Pl. XV, fig. 15. (2) Fig. 19. (3) Fig. 17. 
English author believed they corresponded to the Chaetaster of Müller and Troschel. Actually, one of his Nepanthia is the type of the genus Chaetaster. The others should be placed in the genus Asterina.

Luidia clathrata, of the Antilles and the east coast of America, serves as my subject. Since this study was done, the description of the same subject has appeared accompanied by one plate in the memoir of A. Agassiz. I have not published my drawings, which are far from duplicating his. My description will complete his on several interesting points.

The ventral surface of Luidia greatly resembles that of Astropecten. In both genera, it is formed on $7 y$ of marginal plates and the adambulacral series. It is only towards the buccal corners that some pieces are intercalated between these two series. These pieces in Luidia are much smaller and much more numerous than in Astropecten (1). They seem to form from a fragmentation of the marginal plates located closest to the top of the interbrachial angle. However, the most prominent character, which immediately separates the ventral surface of Luidia from that of Astropecten, is the small width of the marginal plates that are in exactly the same number as the corresponding adambulacral pieces. There is no constancy in their relation in Astropecten.

The dorsal surface is still more different. In fact, there are no superior marginal plates, but three or four rows of ossicles of a quite peculiar form. The base of these ossicles is in the form of a cross. The two transverse arms are relatively rather elongated while the two longitudinal arms are very short. The longitudinal arms are imbricated from the tip of the arm to its base. The ossicle nearest the top covers the one immediately adjacent from the center. As for the imbrication in the transverse direction, it is rather peculiar. The first lateral row is covered by the border of the marginal plates, and covers the second row. The latter in its turn covers the third. But the third is covered at the same time by both the second and the fourth. After that, all of the series of smaller and irregular ossicles that fill the median line of the arms have an imbrication exactly in the inverse direction of that of the regular lateral rows. The number of ossicles in these rows is exactly equal to that of the marginal plates of the lower surface.

All the dorsal ossicles have only small cross-shaped extensions that garnish their base that is imbricated in that way. The middle of the ossicle is elevated, rarely constricted in an hourglass shape, and ends in a slightly rounded surface marked with very fine depressions for the insertion of granules. The free surface of the ossicle is generally rectangular with the long sides directed transversely for the regular lateral series. The others do not have a constant form or disposition. The upper surface of a denuded Luidia shows thus a series of very deep grooves intersecting in all directions. (2) At the base of these grooves are isolated pores. Each of these in included between the small apophyses of four adjacent ossicles. Some of them are found between a 71 the ossicles except between the first lateral row and the marginal series. The very small madreporite plate is located very near the border of the disc in one of the interbrachial angles, is irregularly digitated, and hidden in living individuals by the covering of paxillae. These have escaped the attention of investigators for a rather long time. Only the two first lateral rows reach the ocular plate, which is

(1) Compare figures 2 and 8, pl XV. (2) Fig. 7. 
large as in Astropecten but regularly rounded.

The adambulacral pieces are rounded below and tightly pressed against each other. The ambulacral pieces, maintained by the strong supporting ones that reach their maximal development in this genus, have an even more marked disposition than in Astropecten. The superior longitudinal muscles are scarcely visible as simple vertical lines. Their action is evidently nearly nul. However, Luidia has another modification. The superior transverse muscles, very developed in Astropecten, are considerably reduced here. Thus, not only are the arms nearly immobile, but the movements of even the ambulacral grooves have lost most of their importance.

The exact agreement of the lateral rows with the ambulacral and marginal plates, joined to the lack of flexibility of the arm, contributes to give this genus a great fragility that is possessed to the highest degree by Luidia savignyi, to which Forbes gave the name fragilissima. This singular species is, according to Robertson (1), still more fragile in summer than in the spring. Thus it is rare to find a specimen of Luidia in which there is not at least one arm in a state of disintegration.

The mouth of Luidia greatly resembles that of Astropecten (2). The odontophore merits special mention. At first glance it seems to be very separate from that of Astropecten. However, a more attentive examination shows the same lateral compression of the piece that develops into a vertical lamella that we shall find only in the following type (3). The principal difference here, beyond the more marked development of the articulating apophyses, is the presence of a bourrelet on each side of the border edging the piece. This greatly changes the physiognomy. However, the odontophores of Astropecten and Luidia are really very related to each other. No other form comes so close to them.

As in Astropecten, there is no interbrachial system here. There is nothing special to say about the species with numerous arms such as Luidia senegalensis which has ten. The mouth is only a little more widely open.

The pedicellariae of Luidia have a disposition quite singular in asteroids. The pinchers are formed of three valves, as in echinoids, except in Luidia savignyi where there are only two.

\section{GENUS ASTROPECTEN (LINCK).}

1733. Astropecten, Linck, De stel7is marinis 7iber singularis.

1834. Stellaria, Nardo, Isis.

1835. Asterias, Agassiz, Prodrome, Mém. de la Soc. de Neufchâtel, v. I.

1840. Asterias, Müller and Troschel, Gattung der Asteriden, Wiegman's Archiv, VIth year, p. 333 .

1842. Astropecten, Müller and Trosche], System der Asteriden, p. 67.

1850. Crenaster, d'Orbigny, Prodrome de Paléontologie, v. I, p. 240.

1859. Asterias, Forbes, Mem. of Werner. Society, v. VIII, fig. 118.

1875. Astropecten, Perrier, Révision des Stellérides, p. 349.

It is Astropecten aurantiacus, so common on the coasts of Europe and already the subject of many studies, that I have taken as the type of this genus. Although few things in this description are new, I believe it will be

(1) P.N.H. Soc. Glasgow, I, p. 36 XV.. (3) Compare fig. 5 and 12 .

(2) Compare fig. 2, 8, 6, and 13, p1. 
useful to have it here. First of all as it is according to the same principles as all the others covered in this work. Then as it will serve to establish comparisons with other types, notably Acanthaster, so completely ignored until now.

I have represented (1) the disc and one entire arm, seen from above, after removing the spines of the paxillae, at natural size. Figure 2 shows the mouth and the beginning of an arm, also at natural size.

The first striking thing about Astropecten is the development of the marginal series. They constitute the skeleton in large part, and it is necessary to start its description with them.

The superior marginal plates are remarkable for their regularity. They become however much smaller at the top of the interbrachial angles and take a more vertical orientation. They then enlarge gradually in a transverse direction to the middle of the arms, then decrease regularly to the ocular plate oc that has a quite remarkable development.

This plate is completely folded on itself so as to form a gutter on its inferior surface. It is likewise marked on top by a shallower and wider longitudinal groove that narrows towards the free end of the plate.

The inferior marginal plates, which correspond with the superior ones, increase regularly in size from the tip of the arm to its base. However, the six plates at the top of the interbrachial angle, three on each side, are nearly vertical and shortened to leave room for supplementary plates intercalated between them and the adambularal series.

The ventral marginal plates surpass the dorsal ones nearly the entire length of the arm. They are intimately connected to them on al1 their corresponding surfaces except that a free passage is always included between the four adjacent plates, two dorsal and two ventral. The plates of a single series are not at a11 interconnected for a11 their corresponding surfaces. The relative size of the surface in contact and the portion that remains free can be seen in figures 3 and 4 . As a result, the marginal plates appear separated by deep grooves when the spines are removed from the animal.

The entire dorsal surface is constituted of a resistant membrane inserted on the superior marginal plates. On certain dried Astropecten, the paxillae can be successively removed, leaving this transparent membrane completely intact. The paxillae are sma11, cylindrical, or hour-glass shaped ossicles. The rounded superior surface is circular or oval. The inferior end widens abuptly to a circular or ellipitical lame1la. Its entire surface is applied to the dorsal membrane and imbricates sometimes more or less irregularly with the adjacent ones.

The 1argest paxillae occur in the middle of the base of the arms. They diminish regularly on the sides of the disc and the arms, towards the ends of the arms, as well as towards a point located near the middle of the disc where they become extremely smal1. They radiate more or less irregularly around this central point or, rather, of this small line. They appear arranged on the border of the arms following lines nearly perpendicular to this border.

On the internal surface of the back, on the medial line of each arm, is a band where the plates for the insertion of the paxillae do not leave passages for the pores. On the sides, the small paxillae leave passages between them for the pores arranged between their series.

(1) P1. XV, fig. 1 . 
The ventral surface really is constituted only by the inferior marginal plates and the small complementary pieces intercalated in the buccal corners. These pieces are very small. The two at the top of the angle alone are a little larger.

The adambulacral pieces are rounded on top, wide, and pressed against each other. They decrease suddenly in size towards the mouth and their direction changes in such a way that the tooth seems to be in reality only a slightly modified one. It is this arrangement, already described by Mecke1, that is the cause for error for various zoologists. However, if the teeth are looked at from the lateral view (1), it is apparent that nothing has changed from that which we have seen up to here, and that the tooth is certainly formed from the coalescence of two pieces. It is nevertheless necessary to note this special form. The teeth thus are not narrowed, separated from each other on the interbrachial line, and projecting from the ventral surface as in Astropecten and Luidia.

There is nothing very special to say about the ambulacral pieces except the peculiarity we noted at the beginning of this memoir, and their considerable size. The supporting ambulacrals are very developed here. As for the odontophore, it has so special a form that it is necessary to look at figure 5 to get a good idea of it. The lateral compression of the distal end of the piece, which ends suddenly as a lamella, is particularly notable.

There are no traces of the interbrachial system. The madreporite plate is, as I have said in the general comments on this piece, rather variable in form of Astropecten. In the type represented, there are kinds of digitations between which occur paxillae.

Agassiz has given in his last memoir a description of the skeleton of Astropecten articulatus. This description is accompanied by a plate to which applies the remarks already made several times.

There are no pedicellariae in Astropecten.

The various forms that the odontophore has in the family ASTROPECTINIDAE cannot be an argument against their use as a means of classification. We have, in fact, remarked above that the odontophores of Astropecten and Luidia differ more in appearance than reality. As for that of ctenodiscus, the exceptional constitution of the mouth prevents making any general conclusion.

Moreover, Ctenodiscus is far from being intimately connected to the other two genera. The imbrication of its ventral surface, the completely peculiar form of its marginal plates, and even the form of its body, differentiate it greatly without speaking of the mouth. I hardly think, however, that it can be considered as a transition type with the ASTERINIDAE. The absence of interbrachial systems, the presence of supporting ambulacrals, the constitution of the back, the absence of an anus, and the conical tubefeet clearly separate this family and place it in the ASTROPECTINIDAE where it nevertheless forms a very distinct type.

I suppose that Corethraster, with its conical tube-feet, its back covered with free paxillae, and its short, thick arms must be related to this type.

As for the Platasterias of Gray, which he says is allied to Astropecten, but very much flatter and more like a greatly divided Palmipes, and without marginal plates, it is impossible for me to say what it could be. The figure

(1) Fig. 6. 
no more than the description that Gray has given does not permit me to assign it a probable place.

\section{FAMILY X. ARCHASTERIDAE.}

This family is composed, for the moment, only of the sole genus Archaster, which I separate from the ASTROPECTINIDAE. Great differences exist between this genus and Astropecten with which it has been grouped because the back in both genera is composed of paxillae.

Paxillae are really a very poorly defined form. The name is applied to all ossicles taller than they are wide. However, how many differences are not found in the different genera? In Astropecten and Ctenodiscus, the paxillae are hour-glass shaped, the top is rounded, the base dilated in a flat circular or oval plane that is inserted on the ordinary dorsal membrane without obvious imbrication with adjacent ones. In Luidia, the paxilla is a robust piece, rarely hour-glass shaped, but ordinarily comparable to a truncated quadrangular pyramid. The top is rounded and four cross-shaped extensions leave the base and imbricate with their analogues on adjacent paxillae. In Archaster, the piece is likewise provided with cross-shaped extensions but is never hour-glass shaped, no more than in Chaetaster. In the latter, the paxilla is a hexagonal prism with a rounded top and standing on one of its bases. The superior surface is rounded and connective pieces interconnect the paxillae at the bottom. This arrangement is still much more accentuated in Nectria where the paxillae have an enormous development and are square on top. Finally, in Solaster, the paxillae form no more than a very small part of the skeleton. The connective pieces have taken preponderance. In addition, in this type the paxillae on the border of the arm have a very singular flat form.

Thus what does the term paxilla mean? Is it a particular form? Evidently not. Everything varies in them, their form as well as their importance in the dorsal skeleton, which they can form alone or take a very insignificant part. Would it be their covering? If most usually they have fine spines, they can be crowned with flat granules or finally support a single spine since the homology of the spiniferous pieces of Acanthaster with the paxillae of Solaster can scarcely be denied. Here again it is impossible to find a constant character.

I believe thus that one should not use this word in characteristics because it is necessary to give a definition each time.

In any case, all animals that have elevated ossicles cannot be regarded as related without being concerned whether the other characters correspond or not.

It is for not having done this that the group of Chaetaster, Astropecten, and Archaster has been abandoned.

of the three absolutely distinct types, the first belongs in the LINCKIADAE, the latter must form the type of a new family as its general body form approaches, it is true, the ASTROPECTINIDAE but as all its other characters tend to approach the GONIASTERIDAE. 


\section{GENUS ARCHASTER (MULLER AND TROSCHEL).}

1840. Archaster, Mü11er and Trosche1, Monastsbericht der Acad. der Wiss. zu Berlin and Wiegmann's Archiv, 6th year, vol. II, p. 323. p. 181 .

1840. Astropecten (pars), Gray, Ann. and Mag. of Natura7 History, V. VI.

1875. Archaster, Perrier, Révision des Stellérides, p. 343.

Up to this day, Archaster has been considered very closely related to Astropecten. Perrier sti11 said in 1875, "The presence of an anus alone distinguishes Archaster from Astropecten." Another very distinçtive character is the form of the tube feet, which have suckers. However, Lütken refused to accord great importance to this character as, he said, there are intermediate forms. Gray had quite simply proposed uniting Archaster and Astropecten into a single genus. Perrier wondered if it would not be necessary to return to this radical means, in the difficulty of ascertaining the absence or the presence of an anus in an animal still covered with spines.

Although the method of Müller and Trosche1, which separated the asteroids into two large sub-classes distinguished by the absence or presence of an anus, is subject to this criticism, it is necessary at least to recognize that these authors were perfectly right in not wanting to unite in the same genus animals that had such an important difference. Without speaking, moreover, of the internal anatomical details that had not been investigated until now, other external features to distinguish the two families are not lacking. The arrangement of the superior marginal plates, the disposition of the madreporite plate, the form of the ocular plate, and finally the form of the teeth and the presence of pedicellariae already reported by Perrier, are also very clear characteristics without speaking of the disposition of the dorsal ossicles that are most often visible even when the spines are still in place.

Archaster typicus, of the south Pacific 0cean, has served for most of my figures. I also give the odontophore of Archaster angulatus, a large species that lives off Ile de France and even in Australia.

Figures 1 and 2 ( $p 1$. XVI) show the two surfaces of Archaster typicus.

There is a double row of marginal plates on the border of the arms that gives this animal a certain external resemblance to Astropecten. However, it can then be noted that, if the inferior marginal plates are arranged as in this latter species, the superior marginal plates are in contact for the entire extent of their corresponding surfaces with the adjacent plates of the series, and that it is not only the ventral surface that has grooves separating the surfaces of two adjacent plates.

The superior marginal plates attain their greatest dimensions precisely in the interbrachial angle where the two at the top are cut at an angle. They then diminish regularly to the ocular plate that is very far from having here the size it has in Astropecten. It is in contrast very smal1, slightly enlarged at its free end, and cut at an angle at the other end. At each side of this angle correspond several small marginal plates. There are up to four in Archaster angularis and no longer one alone as in Astropecten. The truncated top of the corner is connected with the last plate of the median row alone reaches up to this level with the two first lateral rows. 
This median row, which is very clearly distinguished the entire length of the arms and whose ossicles enlarge from the end of the arm to its base, is composed of hexagonal plates whose two sides are transverse in the direction of the arm. From each side of this series is another of smaller plates, regularly joined with the first, but whose form already begins to be reduced a little. Finally, from each of these plates leave lines of other plates, smaller and of irregular diamond-shaped form. They run parallel to each other toward the marginal plates, leaving the median line like barbs of a feather. At the top of the interbrachial angles these series become radiating in passing regularly from one arm to the other. In addition, in these transverse series, the small plates are disposed in a way to form longitudinal lines parallel to the median which join the circular arcs of one arm to another.

All of these small plates are imbricated by small extensions at their base. Each of them covers that which is immediately outside up to the median series that covers the two lateral ones.

on the disc the pieces become very much larger and their contours rounded. A large plate is very easily distinguished at the center. The anus is to the left of it, supposing the madreporite plate is behind. The latter rests on dorsal ossicles that are notched below it for the hydropore canal just as in the GONIASTERIDAE. Nothing there recalls Astropecten. This plate is thick, convex, rounded, and marked with very straight ridges that converge at the center.

The ventral surface is constituted, as in Astropecten and Luidia, only of inferior marginal plates and the ambulacral series. As in these two genera, there are some complementary pieces in the buccal corners. These are larger here and ordinarily number only two pairs, with the most internal being the larger. There are only two marginal plates at the top of the angle, which is shortened.

The adambulacral plates have a rather singular form. Their surface, which is nearly flat instead of being rounded as in Astropecten, has the form of an irregular pentagon with notched sides and a rounded top projecting into the ambulacral groove (1).

The ambulacral pieces have a form different from that of Astropecten and approaches that of the GONIASTERIDAE. There are no supporting ambulacrals. Finally, there are very powerful interbrachial systems (2) composed of two large, vertical pieces connected to the odontophore.

The large ossicles of the back are pitted with fosettes to receive the superior piece, and form a sort of bourrelet al1 around its insertion.

The mouth differs absolutely from that in Astropecten. The teeth, large, triangular, and contiguous on the interbrachial line do not project to the ventral surface, and advance up to the middle of the mouth, which they nearly completely close. The first ambulacral piece has a very developed winglike apophysis (3).

The odontophore has a very peculiar form. It is magnified five times in figure 4. It has two very detached articulating facets like apophyses. Its ventral face is not narrowed like a triangle as in Astropecten. This ventral face can be considered the base of a quadrangular pyramid of which two ridges are short. The thickness of the piece is considerble.

The odontophore of Archaster angulatus is magnified three times in
(1)
Figs. 2, 3, and 7 .
(2)
Fig. 6, i.
(3) Fig. 3 
figure 5. The type of piece is much the same. However, its distinctive features are less exagerated, if it can be said, and approaches more the odontophore of the other families, particularly the GONIASTERIDAE, while remaining perfectly distinct.

Moreover, there are no important differences to note in this animal except the absolutely vertical direction of the superior marginal plates that change its physiognomy a little.

We are far from the ASTROPECTINIDAE. In reality, these forms have in common only the constitution of their ventral surfaces and, there again, the different appearance of the teeth can be considered a hint.

As for the dorsal surface, it is constituted of elevated ossicles crowned with spines, paxillae in a word. However, except for this character, these two genera have absolutely nothing in common. Chaetaster, Astropecten, and Arachaster, were united before us for the sole reason that their back is formed of paxil1ae, it is seen how it is not very necessary to attch importance to this character.

The teeth, the odontophore, the interbrachial systems, the absence of supporting ambulacrals, the form of the ocular plate, and the disposition of the madreporite plate all differ profoundly from the ASTROPECTINIDAE.

It is the same with the tube feet that have a well-developed sucker but no calcareous spicules.

Forcipulate pedicellariae occur in these two species of Archaster towards the ambulacral groove. They are also on the back of Archaster angulosus.

A question arises here: Are all of the species of Archaster part of the ARCHASTERIDAE? In a word, should all the animals that now carry the name, keep it?

I have been able to ascertain, on the single specimen of Archaster parelii possessed by the Museum, that it is certainly a true Archaster. The state of decay of the specimen has permitted me to verify that supporting ambulacrals do not exist. In addition, the character of the teeth and of the ocular plate permit me to place this species confidently with the two preceding, although the central paxillae are much smaller and the general aspect, at first view, rather approaches that of an Astropecten. However, it is beyond doubt that a certain number of Astropecten wrongly carry the name of Archaster.

Archaster vexillifer, illustrated in the work of Wyville Thomson (1), is assuredly only an Astropecten if the figure is exact. As for his Archaster bifrons (2), it certainly seems to be an Archaster. I am not sure, in contrast, that his Astropecten tenuispina that has, he says, "...paxillae arranged on the dorsal surface of the disk in the form of a rosette, or the petaloid ambulacra of a Clypeaster", should be an Archaster at a11. The fact is even very probable as the paxillae of Astropecten would not have this disposition.

Individuals of Archaster are, in general, rare animals, living at great depths, and one would scarcely be astonished that no one dreams of destroying precious specimens for anatomical studies that are believed without doubt to be useless. Unfortunately, however, it is necessary to consult the figures that I have reported above in order to place with certainty the new species in such or such genera.
(1)
Depths
of
the Sea, p. 150 .
(2) Id., p. 122 and
455 . 
The proposition of $\mathrm{Dr}$. Lütken (1), "To the degree that one can show an anus in such or such a species of Astropecten, it should be classed as an Archaster.", is without doubt correct as it is probable that the anus is constant in this genus. But I think that this character, important as it is, should be subordinated on occassion to those I have indicated.

As for the pedicellariae, they are not yet reported in Archaster typicus and Archaster angulatus, and it is impossible to say what values should be attached to this character in this genus.

\section{SUMMARY}

Now that I have explained in detail my personal research, I am going to present a quick summary, in order to bring out the conclusions of this work.

The study of the asteroid skeleton, neglected until now and which many naturalists believed incapable of furnishing characters of classification, to the contrary gives us the only rational means of separating the various genera of this class into natural groups.

The mouth of asteroids is normally composed, whatever the type, of a number of ossicles equal to the number of arms multiplied by five.

The mouth is bordered by a number of pieces equal to the number of arms multiplied by four. These pieces are disposed in pairs: the ones forming the ends of the ambulacral grooves, the ambulacral pairs; the others are disposed between the first, the adambulacral pairs.

Above each adambulacral pair is an unpaired piece, exactly interbracial: the odontophore. The mouth, thus constituted, has two very distinct types:

In one, the adambulacral pairs project into the interior of the mouth and limit its contour; the adambularal pairs being more separated from the center.

The ambulacral type characterizes our first subclass. The ambulacral pairs here are horizontal. The adambulacral pairs are always absolutely truncated, and the odontophore is a massive piece that does not permit extensive movements to them and never has apophyses.

In the other, the adambulacral pairs project into the mouth while the ambulacral pairs, more separated from the center and reduced, have a vertical position.

The adambulacral type characterizes our second subclass. The odontophore is nearly always provided with more or less projecting apophyses, permitting movements of the adambulacral pairs that are never completely truncted.

I have given the name tooth, whatever be their form, to adambulacral pairs that enter into the constitution of the mouth.

This division into two sub-classes is superimposable on that which considers the pedicellariae. Division by the pedicellaria however is less precise as they are often lacking, while the pieces of the mouth are necessarily present.

Thus far, in our first sub-class, the pedicellariae, straight or crossed, are constant. However, they are often lacking in the adambulacral asteroids.

In this second sub-class, the pedicellariaae of the genera ophidiaster and Pentagonaster seem to indicate that it is a matter of organs in the

(1) Videnskabelige Meddelelser, 1871. 
process of disappearing. There are all kinds of intermediates between the well-developed pedicellariae of Ophhidiaster germaine or Hippasteria and the absolutely rudimentary forms as those of ophidiaster pyramidatus or Pentagonaster pulchellus in which the jaws are absolutely incapable of grasping anything.

There is a special musculature for the mouth without analog along the arm and which has not been described until now. This musculature is easy to homologize in the two types.

The pieces of the mouth, teeth and odontophores, have forms that vary with each genus, even with each species, but which agree evidently with a series of distinct types which can characterize a family.

The supporting ambulacrals are a very good character of classification. The interbrachial systems are more variable, but nevertheless give good information. The rosette of spicules in the tube feet are more variable indicators and are more often lacking. Finally, the ocular plate and the madreporite plate give much less certain characters. However, it is not necessary to neglect them as they are generally easy to ascertain on the intact anima1.

By the reasoned use of these various characters, the table of classification found on page 41 is reached.

only those genera that I have examined in detail can be considered as definitively fixed. Those marked with an asterisk must perhaps change place as a result of future studies.

The means of classification that I have indicated has never been employed until now, except the pedicellariae and the exterior skeleton that can be seen without preparation.

The spicules of the tube feet, the interbrachial systems, the supporting ambulacrals, and the constitution of the mouth are only imperfectly known and have never been employed in the characterization of families and genera.

I have demonstrated that the odontophores of asteroids cannot be homologous to the pieces that Muller named peristomial bony plates in the euryalids and to the homologues in ophiurids and ophiocomids.

I have likewise observed that the only piece in the echinoids that occupies a position exactly corresponding to that of the odontophore of asteroids is the tooth plume of regular urchins.

Finally, relative to the relation of echinoderms to annelids, I have two objections: the irregular segmentation of the body, and the lack of concordance between the segments of the ambulacral apparatus and the divisions of the radial caeca.

Regarding my plates, most of the types have never been illustrated. I am the first to give a regular series of interbrachial and transverse sections of the arms. Finally, except for three imperfect views of the odontophore of a Brisinga in the memoir of Sars, this piece has never been illustrated alone. I have given a series of views in thirty-four species belonging to twenty-seven genera.

The coronal spicules of the tube feet had never been illustrated.

There remain without doubt great holes in this work, but they are those that can be filled only to the degree that types now too rare in our collections can be studied.

I am aware that this further study could lead to modificationsin the classifications that I propose. I have even indicated several of the most probable changes. However, I nevertheless think the major landmarks are 
established, and that it is in practicing the method I have followed that a rational classification of all the animals in the class of Stelleroidea can be reached.

At the moment I received the last proofs of this work, I read a memoir of Hubert Ludwig (Beiträge zur Anatomie der Ophiuren, Zeitschrift für Wissenschaft7. Zoo7., 11 November 1878.

This memoir, too large for me to give here even a simple analysis, is pertinent to my study only in one regard: the comparison of the ophiuroid type and the asteroid type.

Ludwig reached conclusions very different from those of Lyman. However, I do not at all return here to that which $I$ said in the course of my present work. I cannot however prevent myself from citing his homologies of the mouth in the two types.

In the figures, absolutely theoretical, that make up plate XXV and suppose the animal seen in the same position as in our figures on pages 25 , 29, and 35., one can see that he considered the tooth of the asteroid to be formed of a single adambulacral piece, while the support of the tooth would be formed by the confluence of the two first ambulacral pieces.

For the buccal pieces of the ophiuroid, each of the branches of $V$ would be formed by the confluence of the two first adambulacral pieces and the ambulacral, the latter alone having the two first pores of the tube feet.

The group of peristomial plates, which I have always seen composed of three small plates in Ophioderma and Ophiocoma, would be formed only of two small symetrical plates. Each of them belonging to the adjacent ray, they would be the first ambulacral piece.

It seems strange that Ludwig, who admitted that the discs are the homologues of the ambulacral pieces, saw in these thin elongated scales the first pieces of a series from which they differ so greatly. I do not think, morever, that he would have proposed a similar homology if he had looked at the mouth of Astrophyton.

Whatever it is, this author has not perceived the odontophore of asteroids, and, in the angle between two adjacent adambulacral series, he indicated only, in each of the two types (asteroids and ophiuroids), the contour of one large plate. He called this, which is evidently only a ventral plate, the first intermediary interambulacral plate.

It scarcely needs to be said that my opinions on the subject would not be changed. I believe, moreover, the comparison of figures made after nature with the camera lucida will be more useful than diagramatic figures that are sometimes incomplete, as is the case here, and always greatly artificial.

\section{PLATE LEGENDS}

All of the figures that I publish were done by myself from sketches prepared with a camera lucida. One can thus depend absolutely on their correctness. As for the artistic aspects of the plates, my original designs permitted me to hope for much better. Unfortunately, the more I retouched the stones, the more the prints were defective. I have had to content myself there for fear of reaching still worse results. 
The legends that give the names of the animals represented do not mean to say at a11 that the species were created by the authors cited (that would not always be true), but only that the authors were the first to give the animal at the time the genus and species names that I conserve. I have done this to avoid complete confusion.

On all the plates: a indicates ambulacral piece; ad, adambulacral piece; $o$, odontophore $d$, tooth; $m$, madreporite plate; oc, ocular plate; an, anus' $i$, interbrachial system; $s$, supporting ambulacral; $m . s$, superior marginal plate; $m$. $i$, inferior marginal plate; $c$. $h$, hydropore canal.

For the odontophores of the first two plates: a, lateral surface; $c$, oral surface of the inverted piece; $b$, inferior surface.

\section{PLATE V.}

Fig. 1. Young Asterias glacialis, seen from above. Enlarged 2X.

2. The same, seen from below. Enlarged $2 X$.

3. Interbrachial section. Enlarged $2 X$.

4. Section of the arm. Enlarged $2 X$.

10. Mouth of a larger specimen, seen from below. Enlarged $2 X$.

5. Odontophore of the same. Enlarged $4 X$.

6. Teeth grouped on the odonotophore. Enlarged $4 X$.

7. First ambulacral piece seen from below. Enlarged $4 X$.

8. Tooth seen from below. Enlarged $4 X$.

9. The same, seen from the side of the ambulacral groove and inverted. Enlarged $4 X$.

11. Portion of the mouth of Pycnopodia helianthoides. Enlarged $3 X$.

12. Odontophore of the same. Enlarged $3 X$.

13. Portion of the mouth of Stichaster aurantiacus. Enlarged 5X.

14. Odontophore of the same. Enlarged 5X.

PLATE VI.

Fig. 1. Stichaster aurantiacus, seen from above. Enlarged 3/2X.

2. The same, seen from below. Enlarged $3 / 2 X$.

3. Section of a arm. Enlarged 3/2X.

4. Heliaster microbrachia, seen from above. Natural size.

5. The same, seen from below. Natural size.

6 . Transverse section near the mouth. Enlarged $2 X$.

7. Transverse section of the enlarged portion of the arm. Enlarged $2 X$.

8. Transverse section of the free portion. Enlarged $2 X$.

9. Relations of the hydrophore canal. Enlarged $3 X$.

10. Portion of the mouth. Enlarged 10X.

11. Odontophore. Enlarged 8X.

12. Odontophore of Heliaster helianthus. Enlarged $4 X$.

For the odontophores of the last ten plates: the number alone, oral surface of the inverted piece; the number ('), ventral surface; the number ("), dorsal surface; the number (") lateral surface, the ventral surface being to the left and the oral surface above.

For comparisons of one type to the other: the number alone, in the second, corresponds exactly to the position $c$ in the first; the number (') at 
the position $b$, inverted the top of the figure below; finally, for the number (", '), the top of the figure corresponds to the left side of the position a. It is the necessity of showing well the forms of these pieces that we were led to adopt the different positions.

\section{PLATE VII.}

Fig. 1. Echinaster sepositus, seen from above. Natural size.

2. The same, seen from below. Natural size.

3. Interbrachial section of a smaller specimen. Enlarged $2 X$.

4. Section of an arm of the same. Enlarged $2 X$.

5. Odontophore of the first specimen. Enlarged $8 X$.

6. Superior surface of the teeth. Enlarged 5X.

7. Fragment of the mesh of the dorsal surface. Enlarged $4 X$.

8. Cribella oculata, seen from above. Enlarged $2 X$.

9. The same, seen from below. Enlarged $2 X$.

10. Interbrachial system. Enlarged $4 X$.

11. Section of the arm. En 1arged $4 X$.

12. Odontophore. Enlarged $8 X$.

13. Superior surface of the teeth. Enlarged $8 x$.

14. Lateral face of the end of the ambulacral groove. Enlarged $4 X$.

15. Fragment of the dorsal mesh. Enlarged $8 X$.

16. Portion of the arm of Mithrodia clavigera, above. Natural size.

17. Portion of the arm of a small individual in the form of a comet. En1 arged $3 / 2 x$.

18. Inferior surface of the first specimen. Natural size.

19. Section of the arm. Natural size.

20. Odontophore. Enlarged $4 X$.

21. Superior surface of the teeth. Enlarged $3 X$.

PLATE VIII.

Fig. 1. Solaster papposus, seen from above. Enlarged $2 X$.

2. The same, seen from below. Enlarged $2 X$.

3. Interbrachial section. Enlarged $2 X$.

4. Section of the arm. Enlarged $2 X$.

5. Odontophore. Enlarged 3X.

6. Lateral surface of the end of the ambulacral groove. Enlarged $2 X$.

7. Odontophore of Solaster endeca. Enlarged 3X.

8. Acanthaster echinites, seen from above. Enlarged $3 / 2 X$.

9. The same, seen from below. Enlarged $3 / 2 x$.

10. Interbrachial section. Enlarged $3 / 2 X$.

11. Section of the arm. Enlarged $2 X$.

12. Odontophore. Enlarged $3 X$.

13. Lateral surface of the end of the ambulacral groove. Enlarged $3 / 2 X$.

PLATE IX.

Fig. 1. Ophidiaster pyramidatus, seen from above. Natural size.

2. The same, seen from below. Natural size.

3. Interbrachial section. Natural size.

4. Section of the arm. Natural size. 
5. Odontophore. Enlarged $4 X$.

6 . Lateral surface of the end of the ambulacral groove. Natural size.

7. Hydrophore canal. Enlarged 2X.

8. Scytaster novae-caledoniae, seen from above. Natural size.

9. The same, seen from below. Natural size.

10. Interbrachial section. Enlarged $2 X$.

11. Section of the arm. Enlarged 2X.

12. Odontophore. Enlarged $4 X$.

13. Lateral surface of the end of the ambulacral groove. Enlarged 2X.

14. Odontophore of Valvaster striatus. Enlarged $3 X$.

15. Superior surface of the teeth of the same. Enlarged $3 X$.

\section{PLATE $X$.}

Fig. 1. Linckia miliaris, above. Natural size.

2. The same, below. Natural size.

3. Interbrachial section. Enlarged $2 X$.

4. Section of the arm. Enlarged $2 X$.

5. Odontophore. Enlarged 2X.

6. End of the ambulacral groove. Enlarged $3 X$.

7. Odontophore of Linckia diplax. Enlarged 5X.

8. Chaetaster longipes, above. Natural size.

9. The same, below. Natural size.

10. Interbrachial section. Enlarged $3 X$.

11. Section of the arm. Enlarged $3 X$.

12. Odontophore. Enlarged 5X.

13. End of the ambulacral groove. En1arged 5X.

14. Fromia milleporella, above. Enlarged $2 X$.

15. The same, below. Enlarged $2 X$.

16. Interbrachial section. Enlarged $3 X$.

17. Section of the arm. Enlarged $3 X$.

18. Odontophore. Enlarged 8X.

19. End of the ambulacral groove. Enlarged $3 X$.

20. Pentagonaster astrologorum, above. Natural size.

21. The same, below. Natural size.

22. Interbrachial section. Natural size.

23. Section of an angle. Natural size.

24. Odontophore. Eniarged $4 X$.

25. End of the ambulacral groove. Natural size.

\section{PLATE XI.}

Fig. 1. Anthenea articulata, above. Natural size.

2. The same, below. Natural size.

3. Odontophore. En1arged 3/2X.

4. Pentaceros reticulatus, above. Natural size.

5. The same, below. Natural size.

6. Odontophore. En1arged 3/2X. 
Fig. 1. Section of an angle of Anthenea articulata. Natural size.

2. Interbrachial section of the same (bi, interbrachial basilar piece). Natural size.

3. Section of an arm of Pentaceros reticulatus. Natural size.

4. Interbrachial section of the same. Natural size.

5. Culcita schmideliana, above. Natural size.

6. The same, below. Natural size.

7. Odontophore. Enlarged 3X.

8. Pentaceros muricatus, seen from above. Natural size.

9. The same, below. Natural size.

10. The same. Centre of the back seen from above. Natural size.

11. Odontophore. En1arged 3X.

\section{PLATE XIII.}

Fig. 1. Section of an angle of Culcita schmideliana. Natural size.

2. Interbrachial section (the animal swollen). Natural size.

3. Section of an arm of Pentacerosmuricatus. Natural size.

4. Interbrachial section of the same. Natural size.

5. Gymnasteria carinifera, above. natural size.

6. The same, below. Natural size.

7. Interbrachial section. Enlarged $2 X$.

8. Section of an arm. Enlarged $2 X$.

9. Odontophore. Enlarged $4 X$.

10. End of the ambulacral groove. Enlarged $2 X$.

11. Porania pulvillus, above. Natural size.

12. The same, below. Natural science.

13. Section of an arm. Enlarged 3/2X.

14. Odontophore. Enlarged $2 X$.

15. End of the ambulacral groove. Enlarged $3 / 2 X$.

PLATE XIV.

Fig. 1. Palmipes membranaceus, above. Enlarged 2X.

2. The same, below. Enlarged $2 X$.

3. Interbrachial section. Enlarged $2 X$.

4. Section of an angle. Enlarged $2 X$.

5. Odontophore. Enlarged 5X.

6. Teeth of Palmipes inflatus. Enlarged 2X.

7. Odontophore of the same. Enlarged $3 X$.

8. Asterina gibbosa above. Enlarged $3 X$.

9. The same, below. Enlarged 3X.

10. Interbrachial section. Enlarged $2 X$.

11. Section of an arm. Enlarged 2X.

12. Odontophore. Enlarged 5X.

13. Odontophore of Asterina calcar. Enlarged 3X. 
PLATE XV。

Fig. 1. Astropecten aurantiacus, above. Natural size.

2. The same, below. Natural size.

3. Interbrachial section. Natural size.

4. Section of the arm. Natural size.

5. Odontophore. Enlarged 2X.

6 . End of the ambulacral groove. Natural size.

7. Luidia clathrata, above. Natural size.

8. The same, below. Natural size.

9. End of an arm. Enlarged 2X.

10. Interbrachial section. Enlarged $3 / 2 x$.

11. Section of an arm. Enlaged $3 / 2 X$.

12. Odontophore. Enlarged $4 X$.

13. End of the ambulacral groove. Enlarged $3 / 2 X$.

14. Ctenodiscus corniculatus, above. Enlarged $2 X$.

15. The same, below. Enlarged 2X.

16. Interbrachial section. Enlarged $2 X$.

17. Section of an arm. Enlarged $2 X$.

18. Odontophore. Enlarged $3 X$.

19. End of the ambulacral groove. Enlarged 2X.

\section{PLATE XVI。}

Fig. 1. Archaster typicus, above. Enlarged 3/2X.

2. The same, below. Enlarged 3/2X.

3. End of the ambulacral groove. Enlarged $2 X$.

4. Odontophore. Enlarged 5X.

5. Odontophore of Archaster angulatus. Enlarged 3X.

6. Interbrachial section of Archaster typicus. Enlarged $2 X$.

7. Section of an arm of the same. Enlarged $2 X$.

8. Coronal spicule of the tube foot of Linckia miliaris. Enlarged 20X.

9. Coronal spicule of the tube foot of Culcita schmideliana. Enlarged $5 X$.

10. Fragment of the corona of Linckia. Enlarged 120X.

11. Fragment of the corona of Culcita. Enlarged 120X. (b, edge of the corona. - $c$, central side).

12. Embedded pedicellaria of Ophidiaster germani, seen from above, surrounded by dermal grandulations: the valves are open. Enlarged $20 x$.

13. The same. The valves are closed. Enlarged 20X.

14. The same. Lateral view. Enlarged 20X. (b, basilar piece. - $c$, partition. -- $v$, valves).

\section{ERRATA}

Page 49, line 11, instead of VI, VII, and XI, read IX, X, and XV.

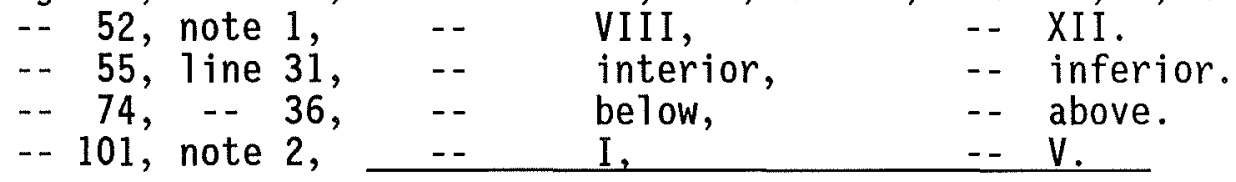



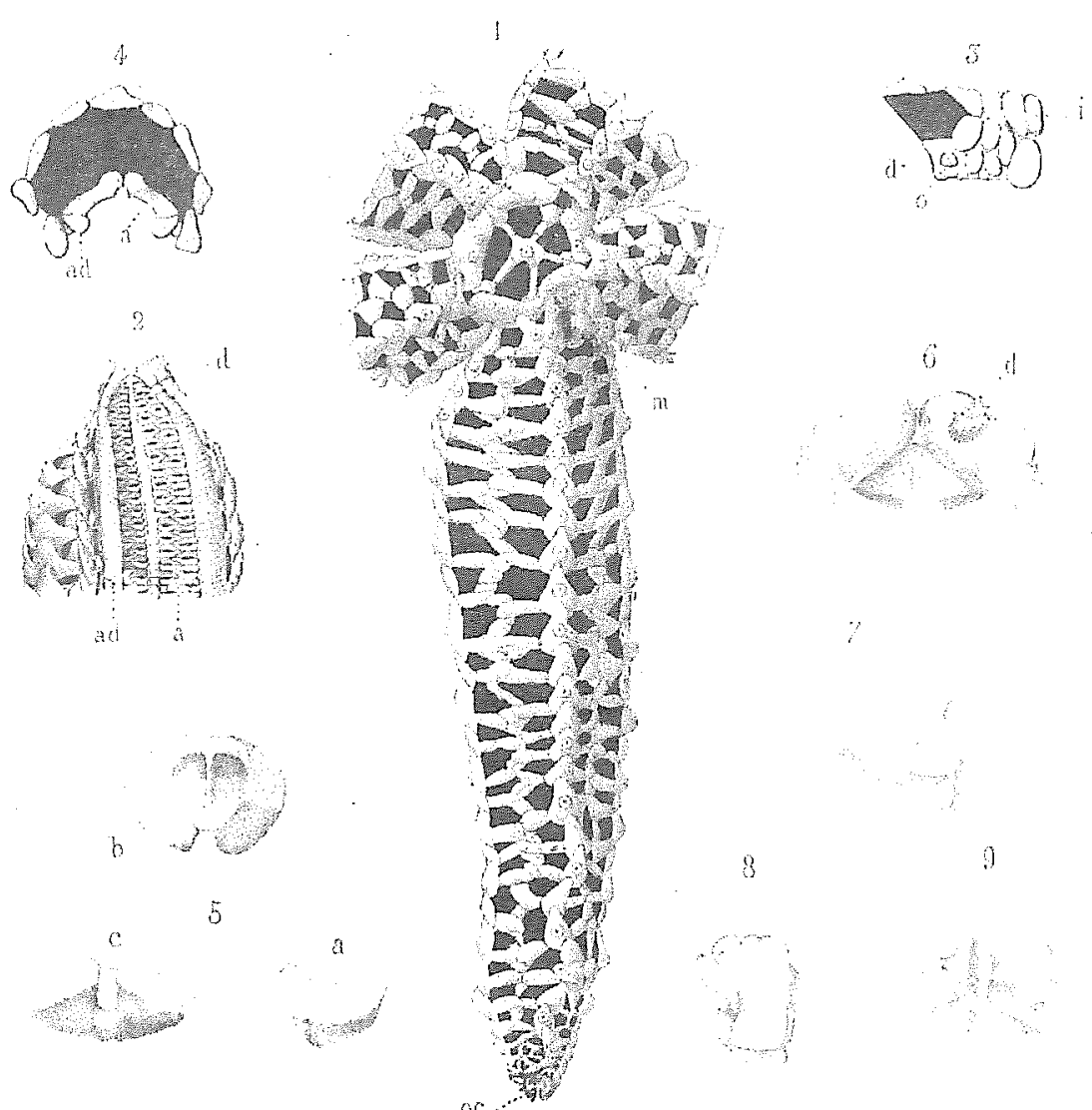

0
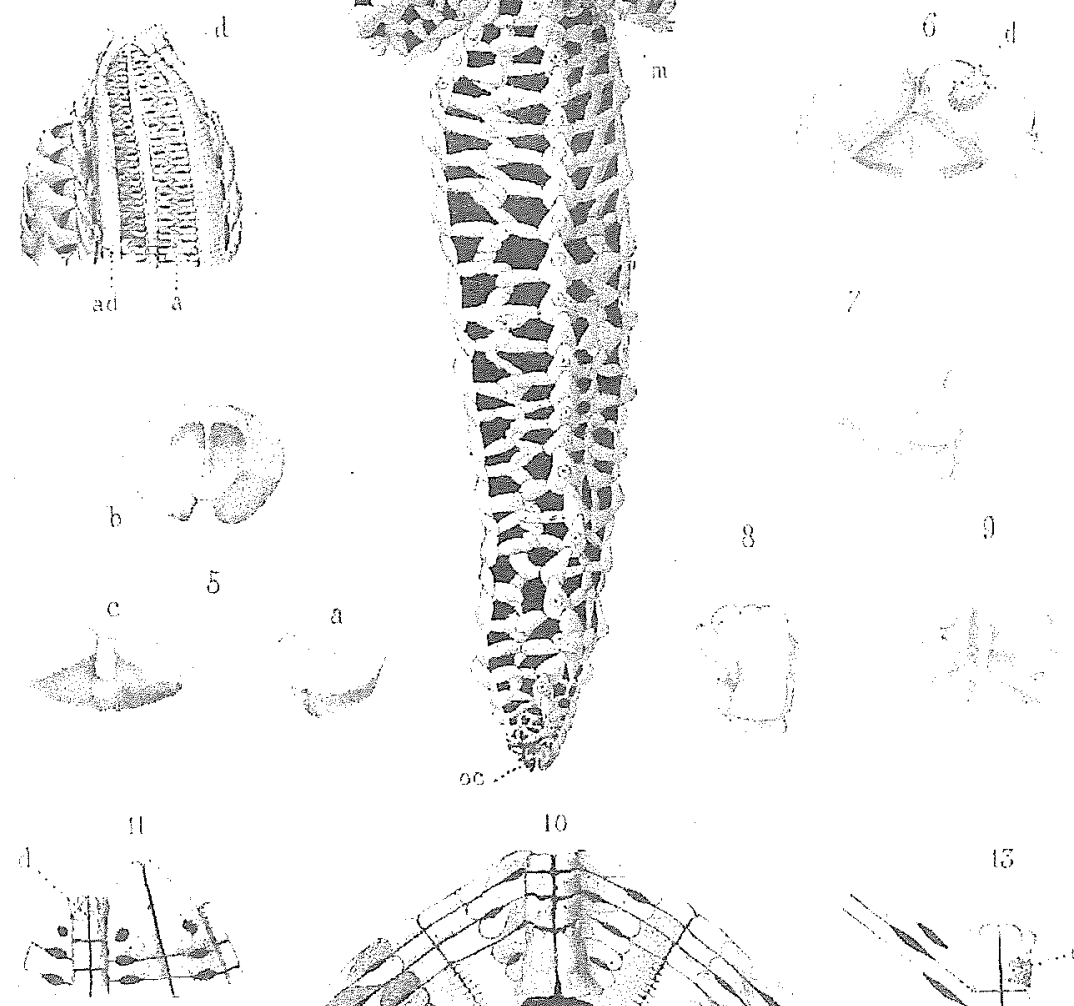

$\because$

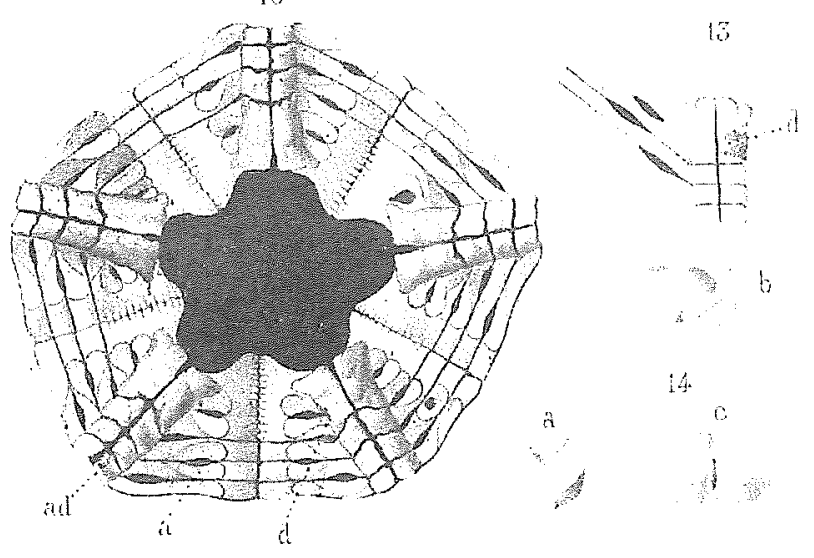

CViguer ad naidel.

Imp. Becurut.

Karmanski lith.

1.10. Asterias glaciatis (O.F.M.) _- it, 12. Pyeropodia holianthoides rstum.) 13.14. Stichaster ar cantiacus (F.P.) 
Ardete Fot Fine con

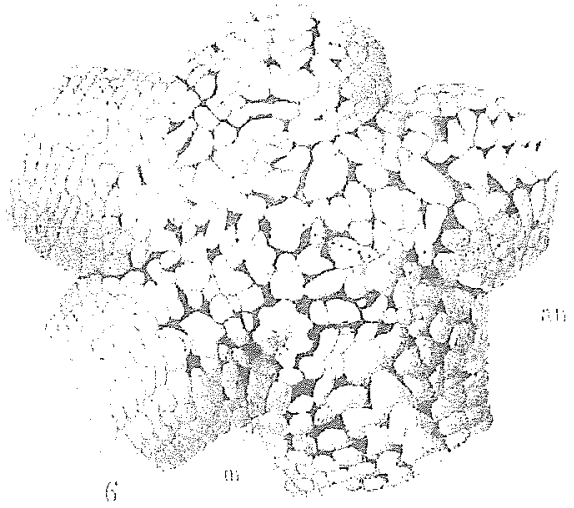

Vol. VII.H. Vl.

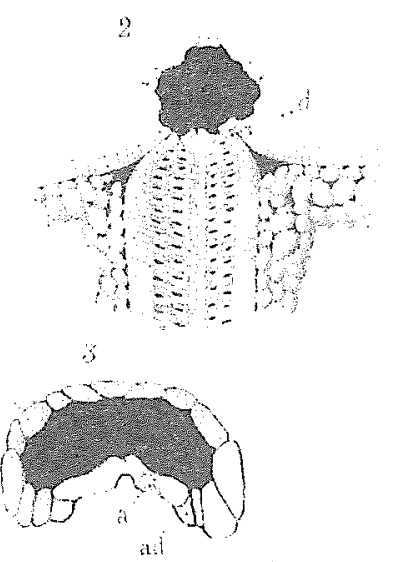

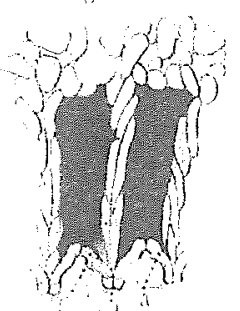
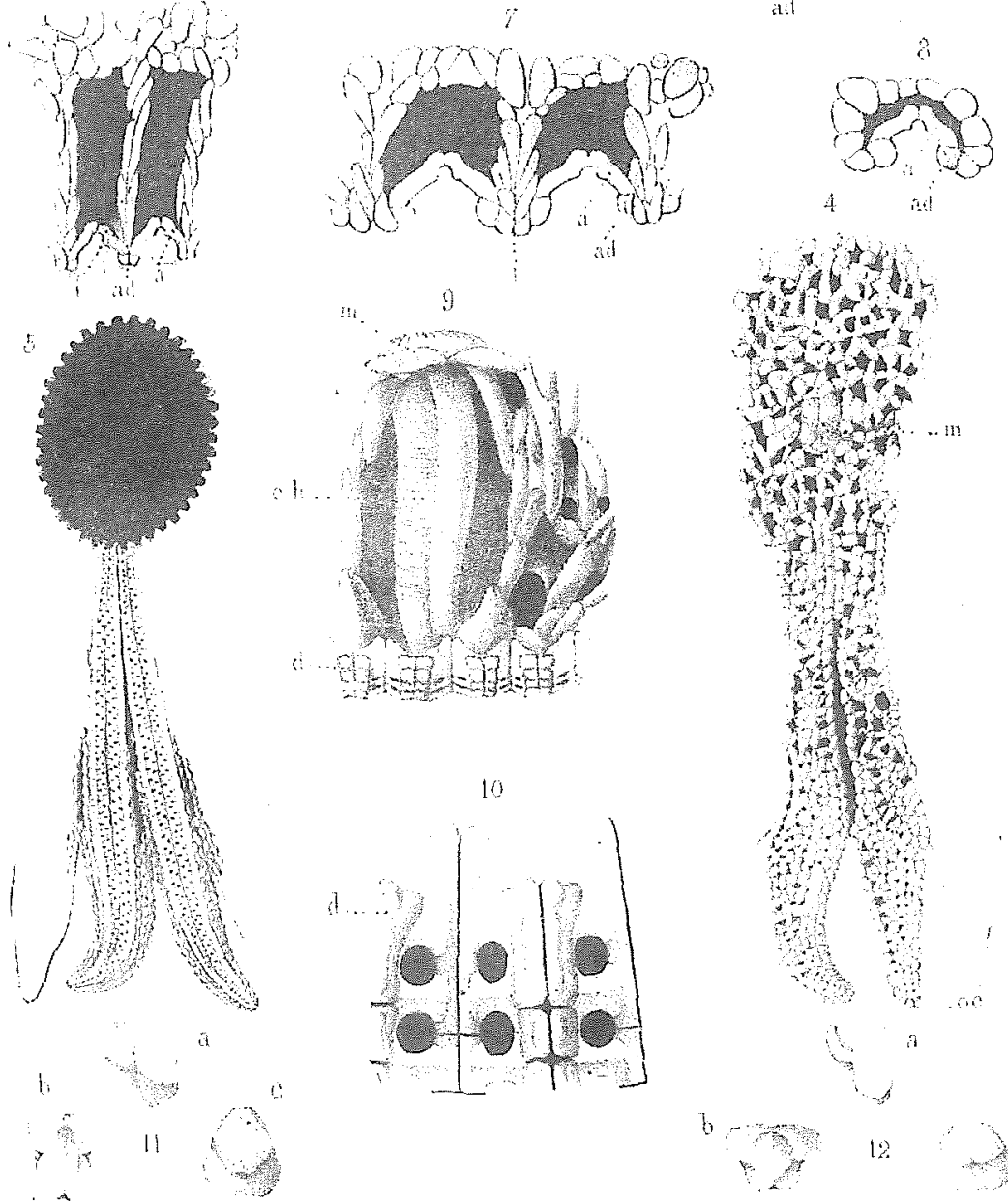

10
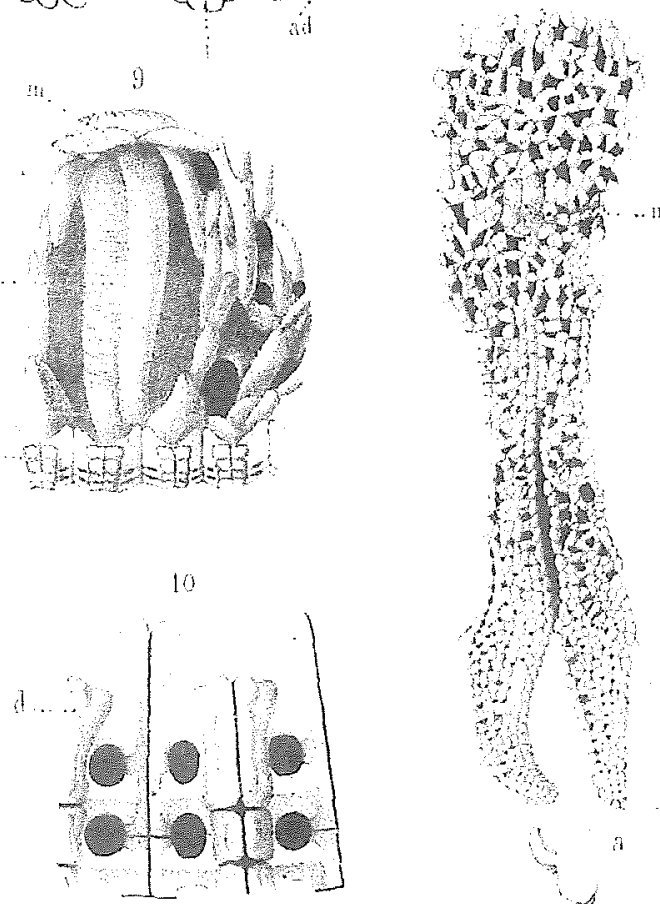

C. Viguim and nat.

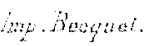
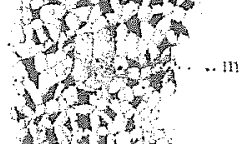

inis.

trined

(1)

का

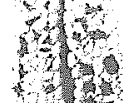

, 15 .

, the?

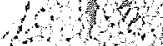

wh

8
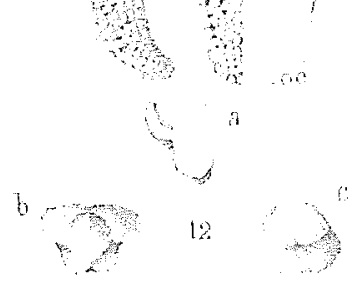

1. B. Slichastor a rantiacus (E.P. 4-11. Holiastor miomotrachia (Xublus.) -12. H helianthus (Gray.) 


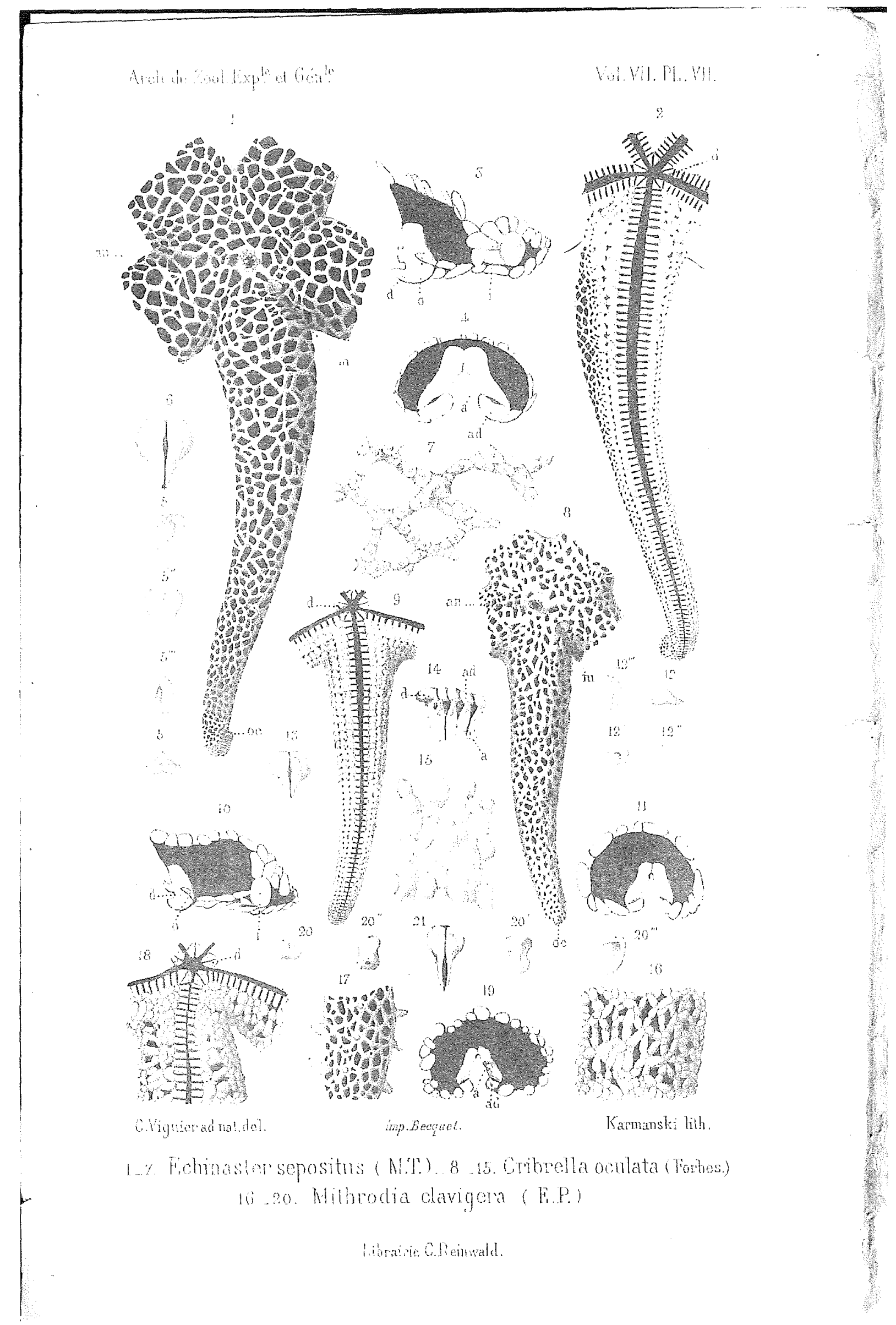



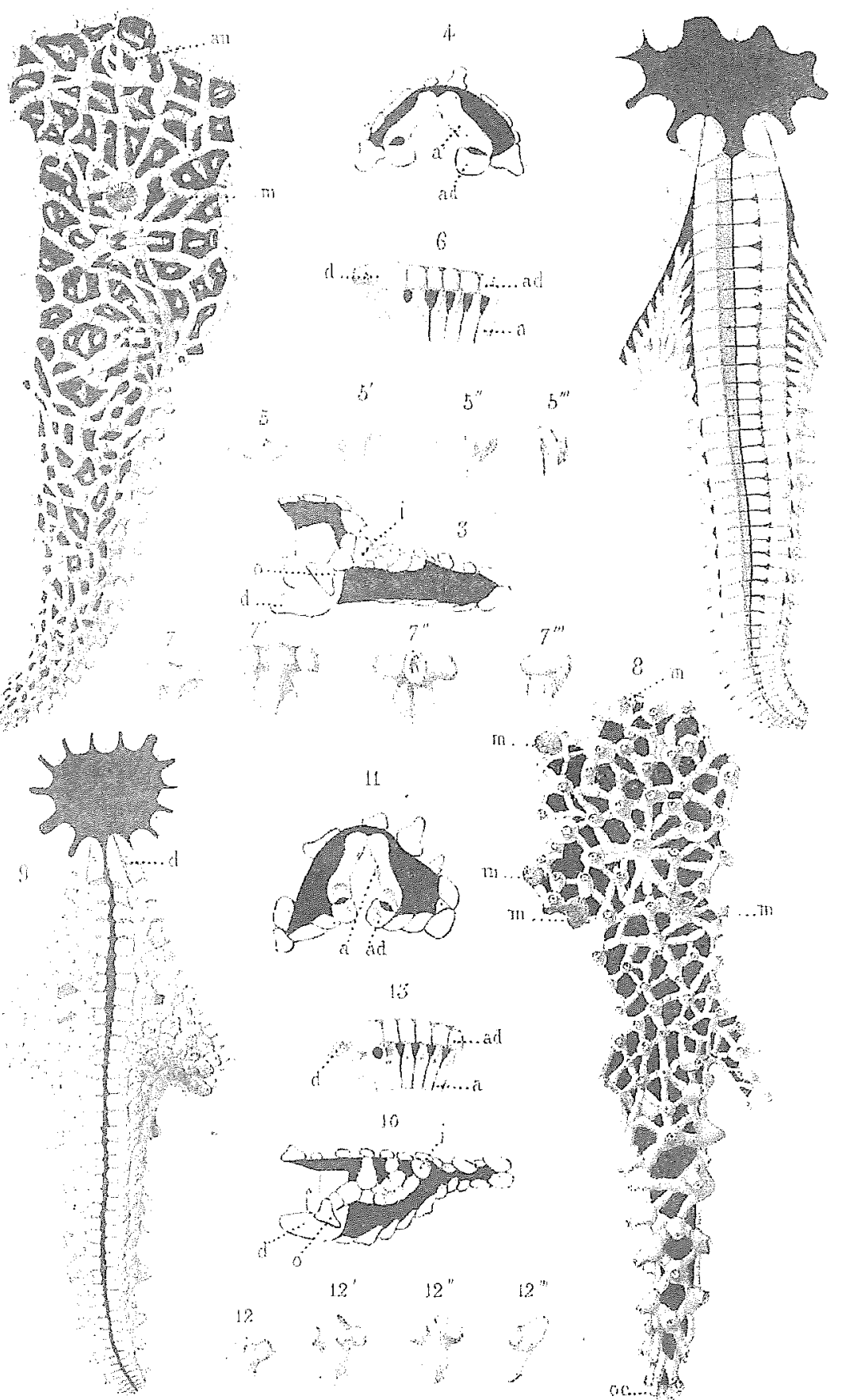

\section{i.}
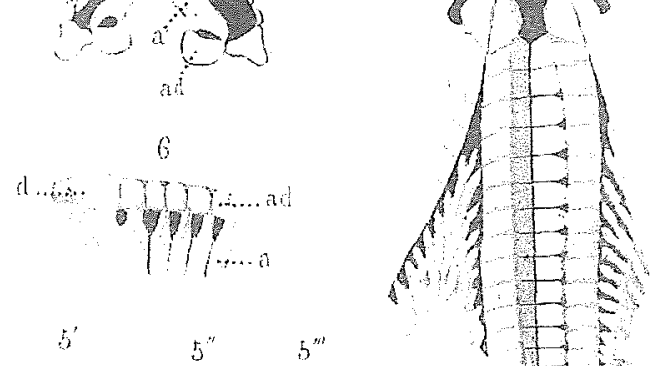

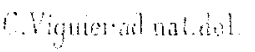
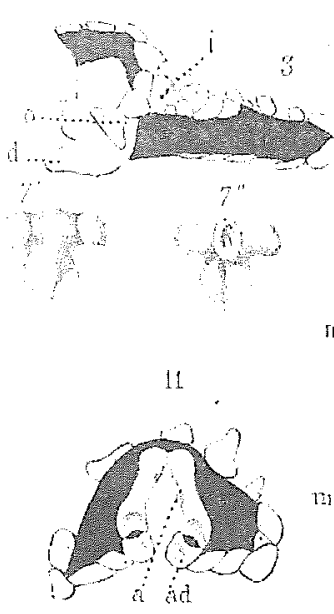

in

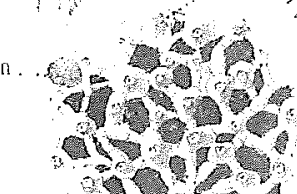

12

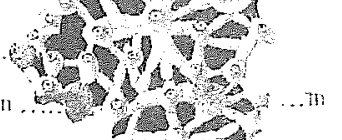

13

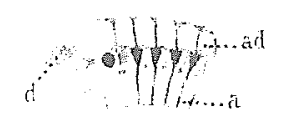

10

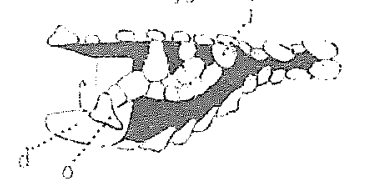

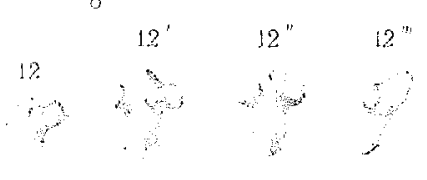

ingl . Becgutet.

Karmanski lith.

I f. Solaster papposus (Forbs. ..7. S. cludoca (Forbes.)

8 12. Acarhaster echinites (li.P.) 

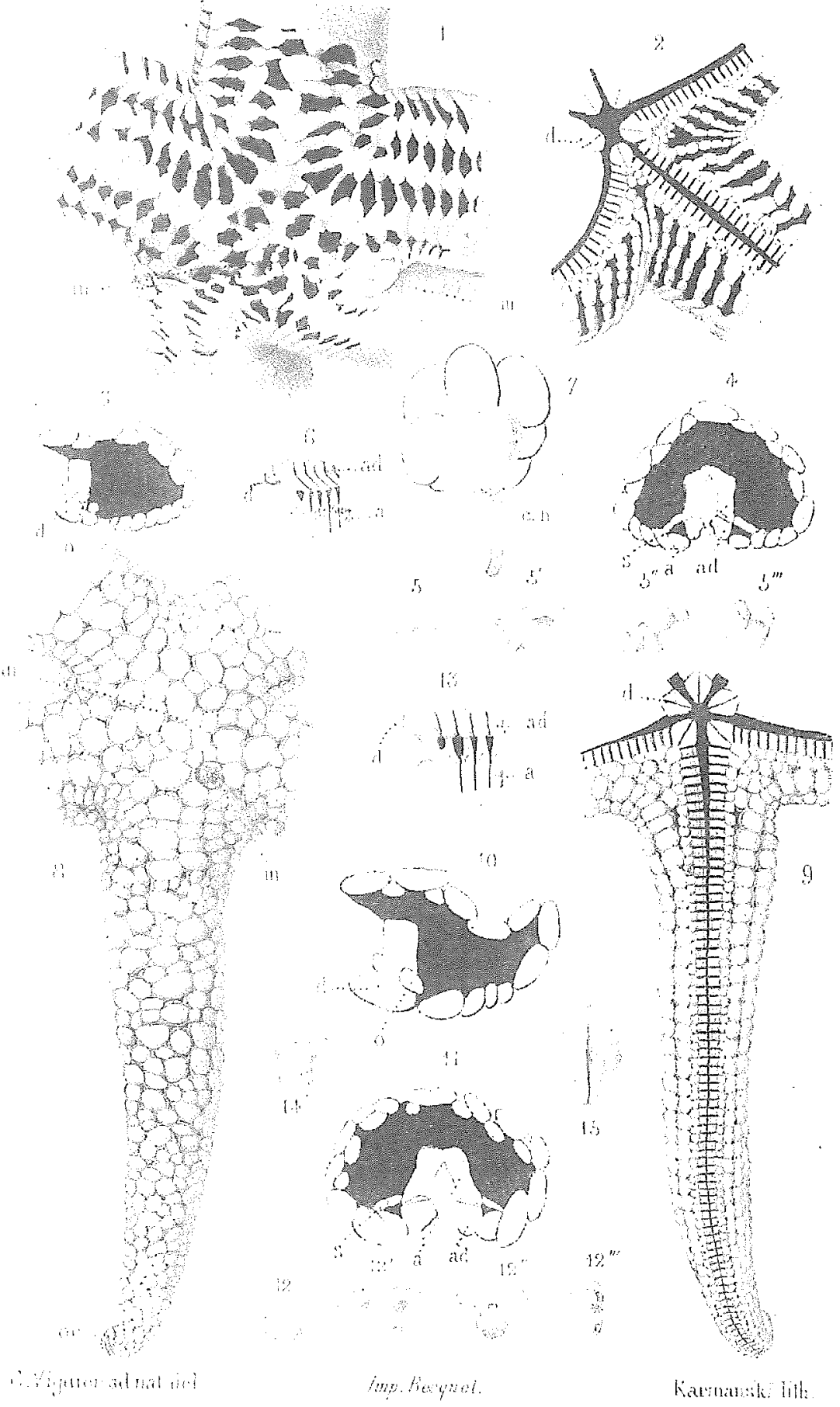

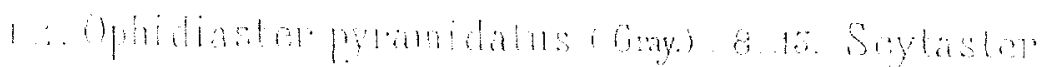

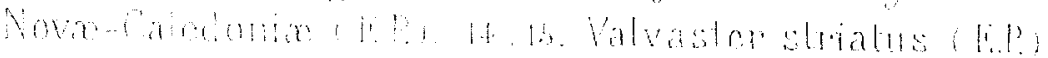




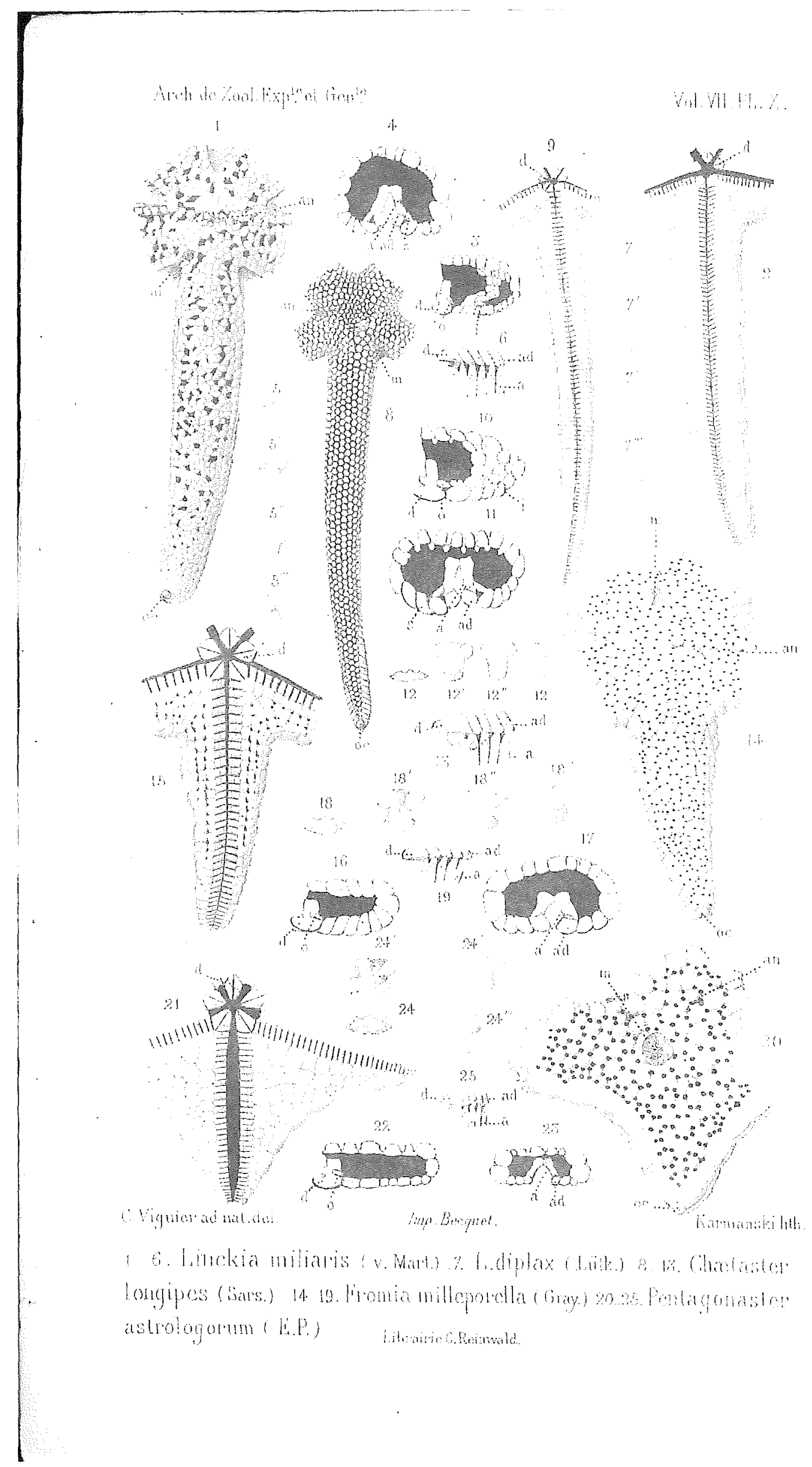




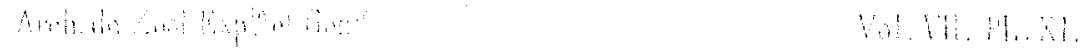
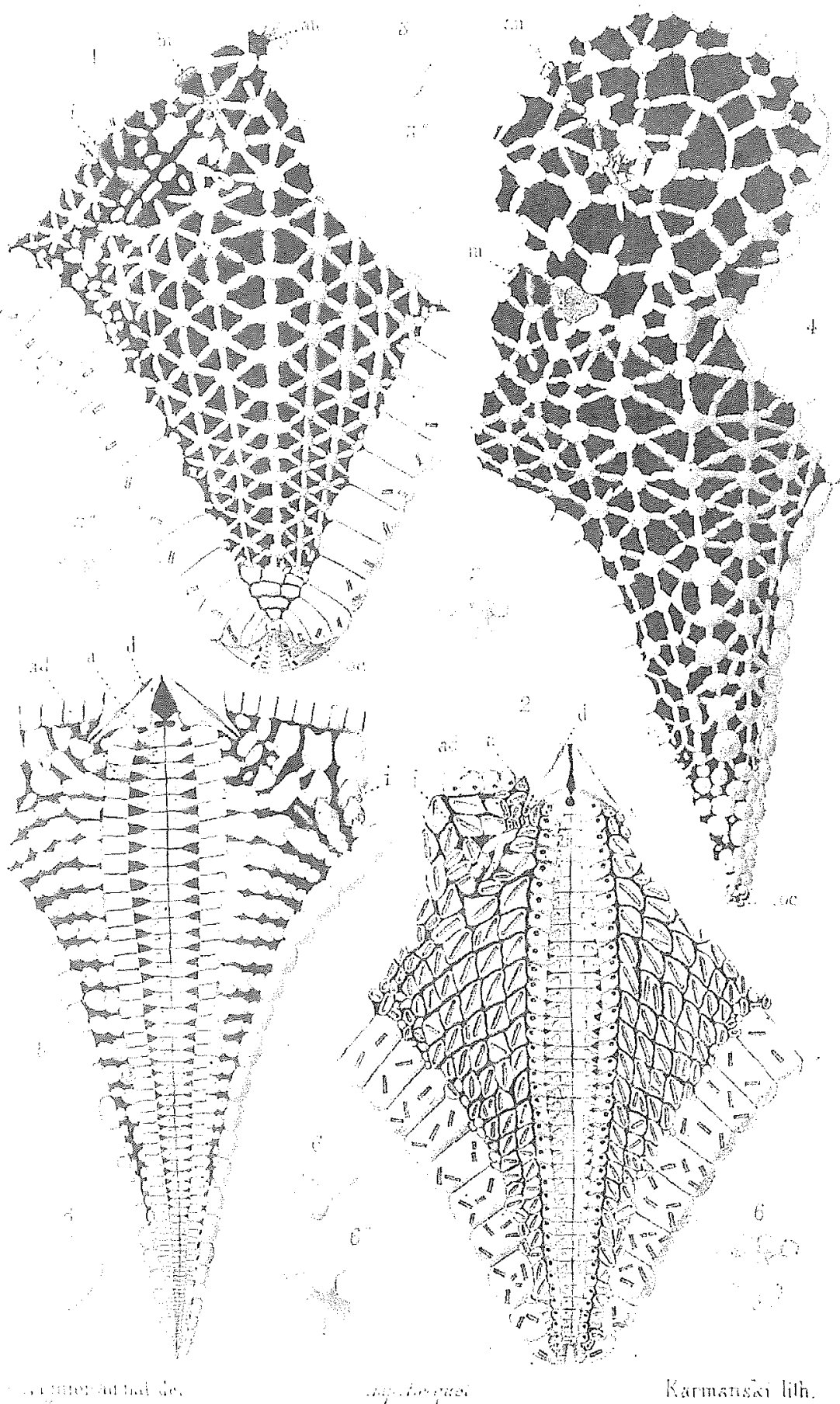

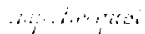

Ratmonsing lith.

:3. Anthomén arlionlata F.P. 4. Gentaceros ietict tatus lines 


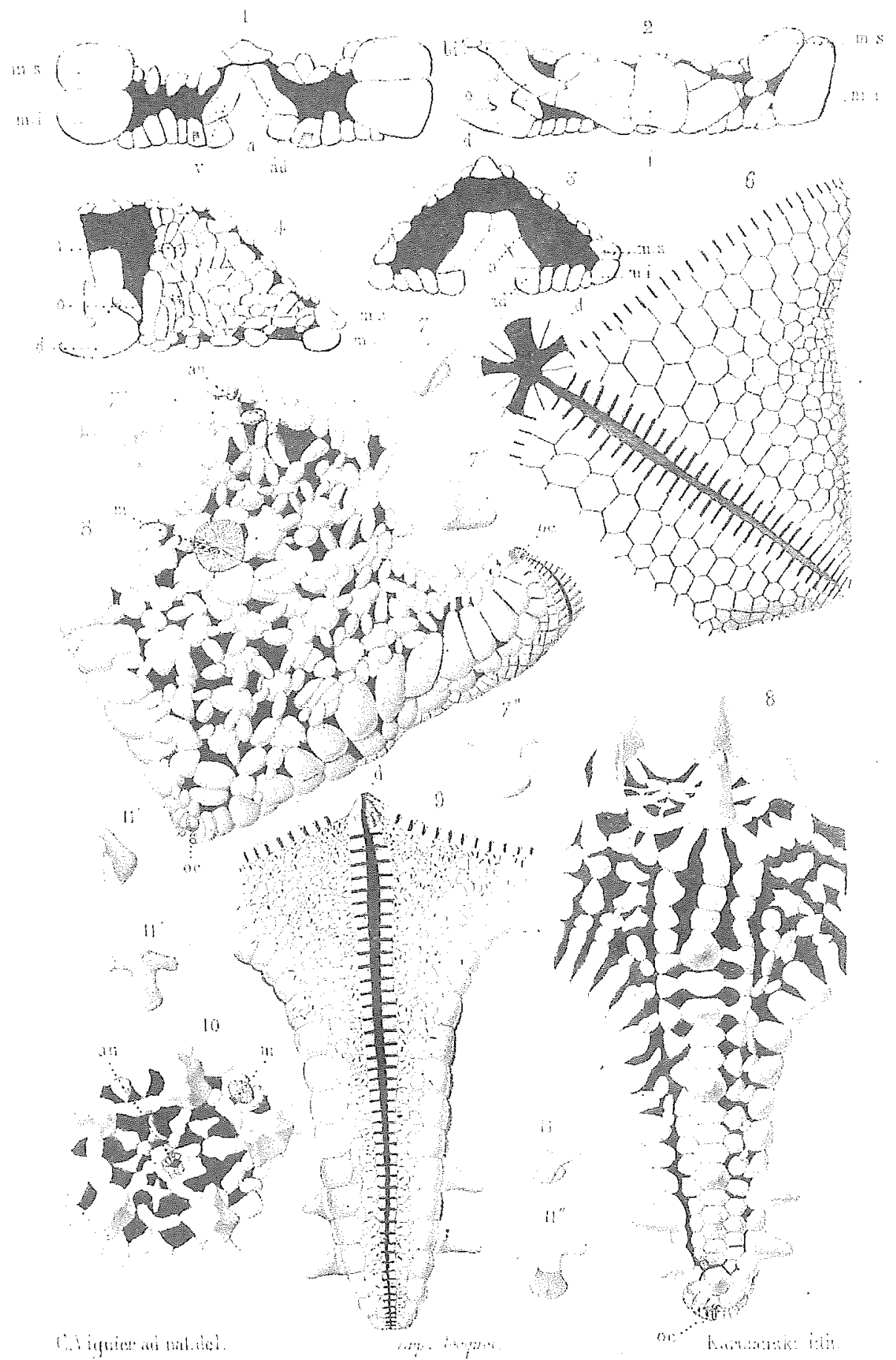

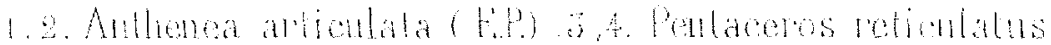

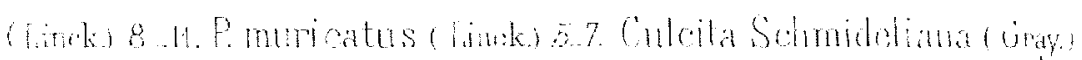




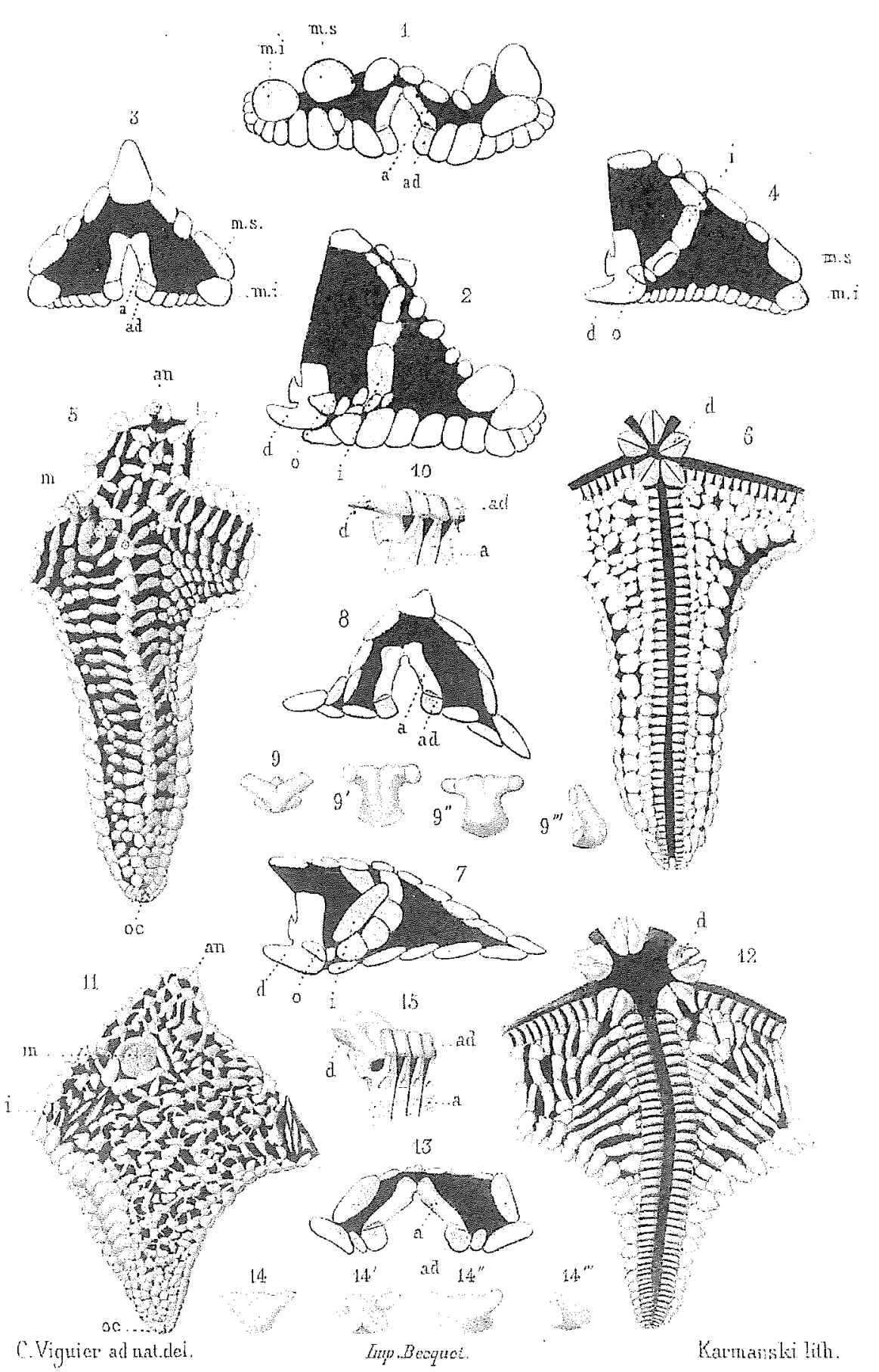

1,2. Culcita Schroideliana (Gray.) - 3,4. Pentaceros muricatus (Linck.) 5.10. Gymnasteria carinifera (v.Mart.) -11_15. Porania pulvillus (Nom.) Librarie C. Reinwald. 


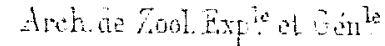
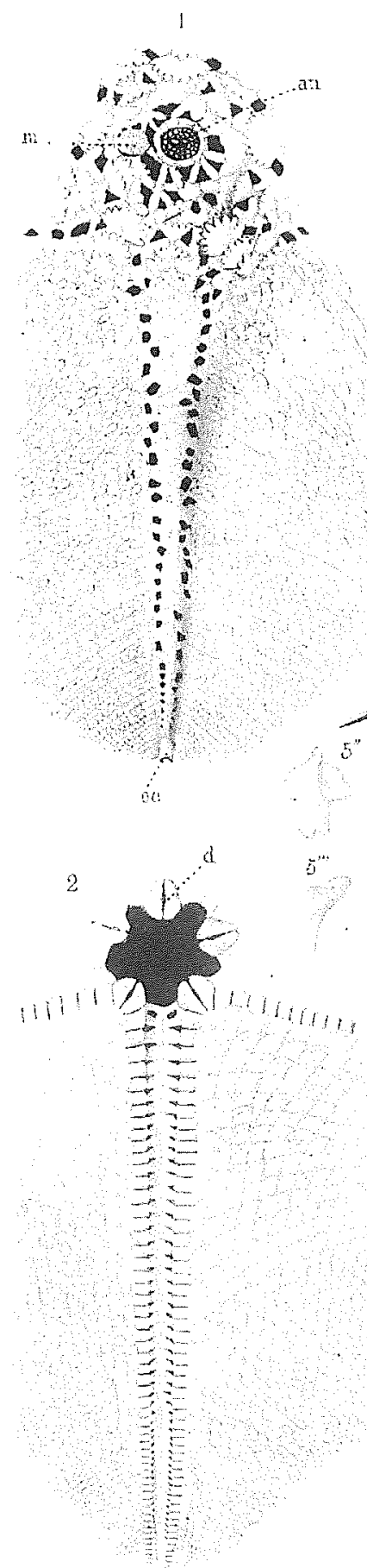

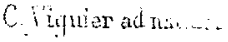

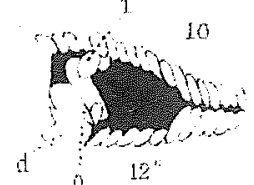

12
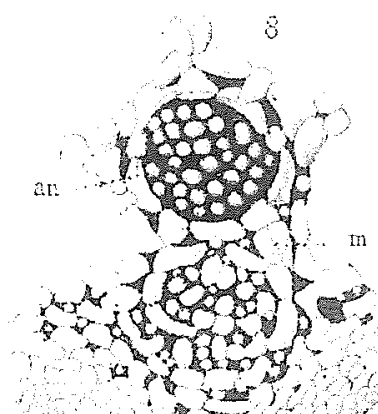

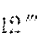

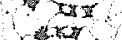

$x+4$

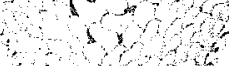

?

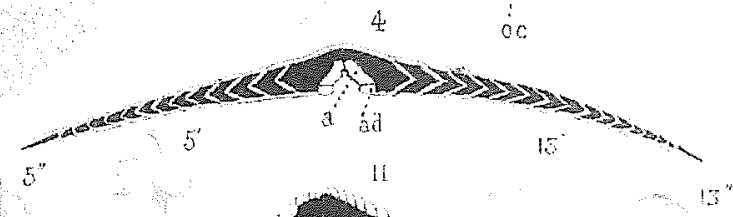

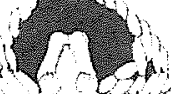

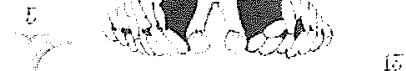

15

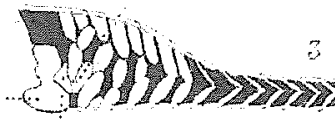

3
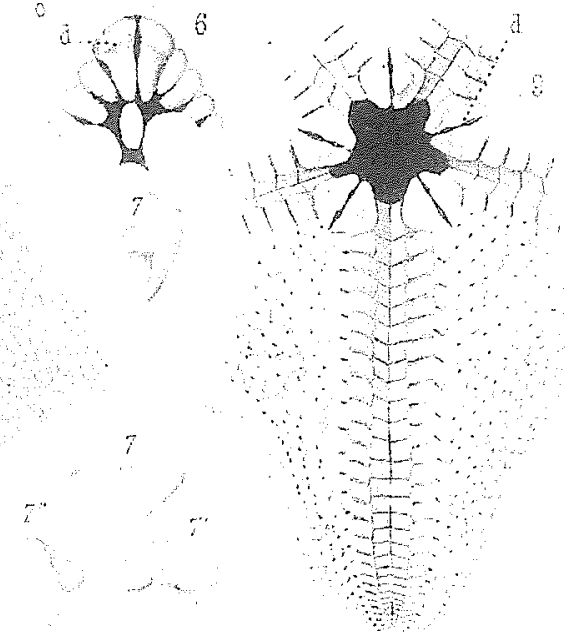

Ans singuet

Ciamenclitith.

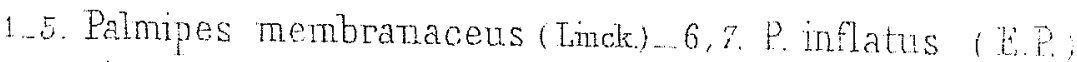

8.12. Asterima gibbosa (Forbes.) - 13. A. calcat (Gray.)

Lbraime C Reinwati. 


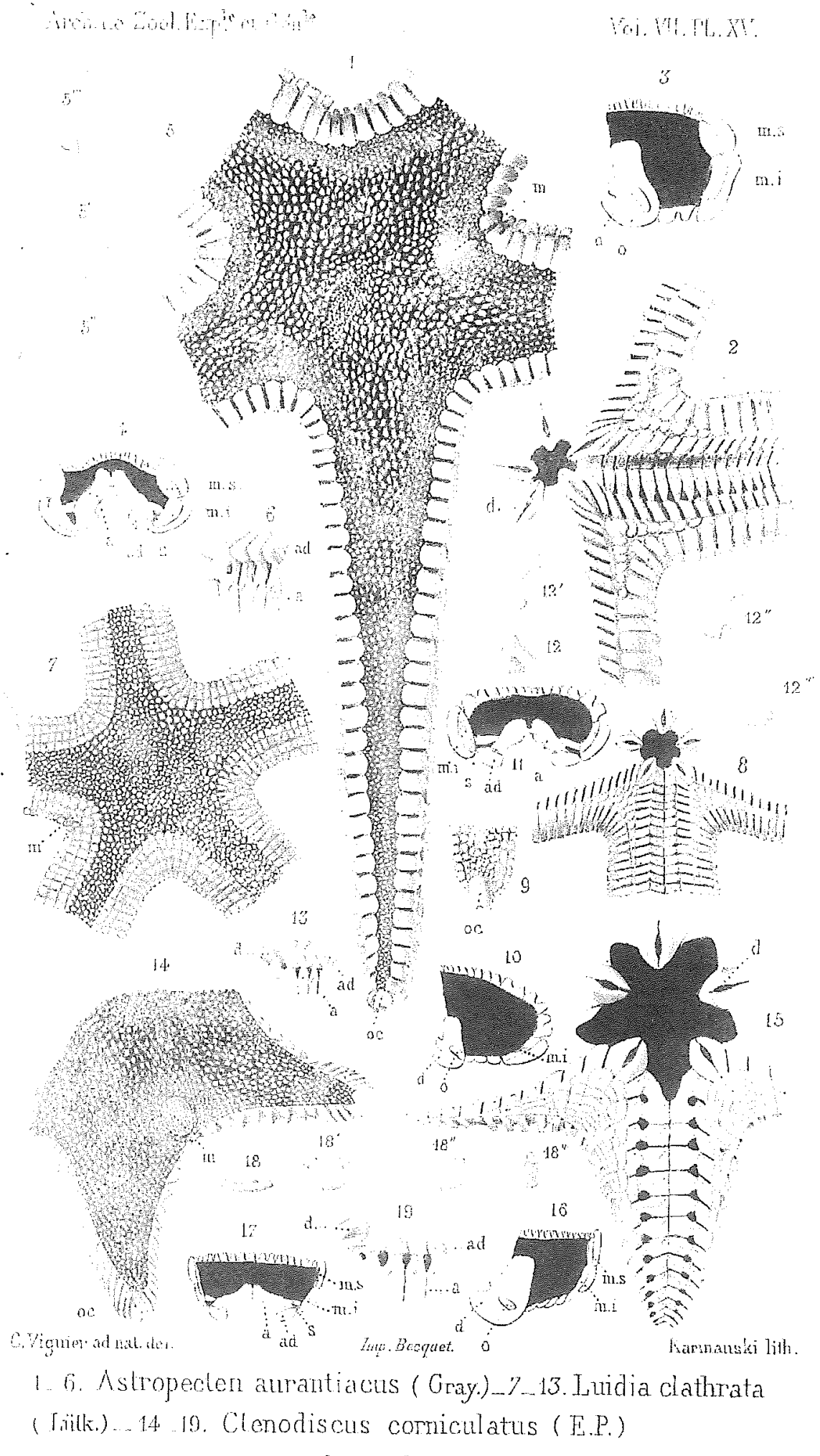

Jibrairic C.Reinwald. 


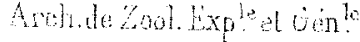

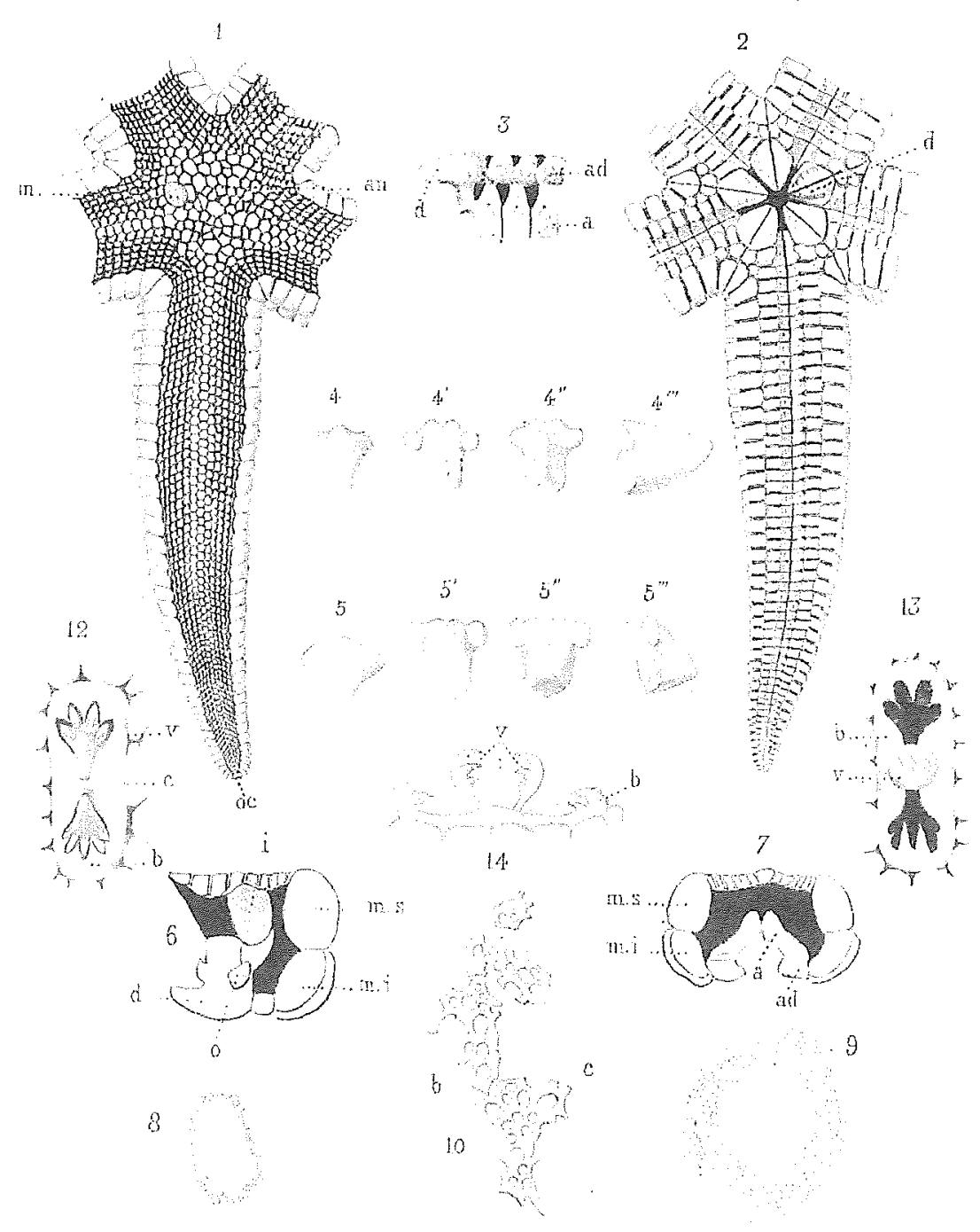

11
Vol. YII PT XVI 